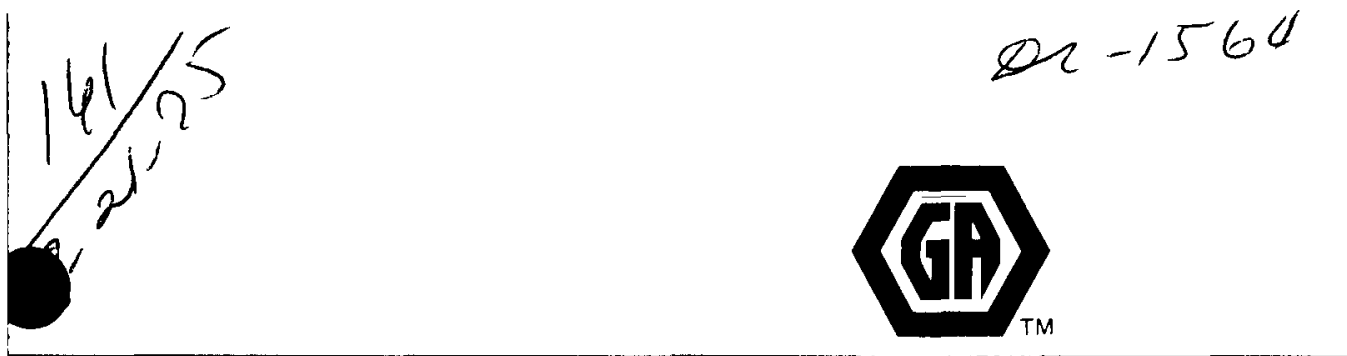

GA-A 13135

UC-77

\title{
PNEUMATIC CLASSIFICATION OF FORT ST. VRAIN FUEL PARTICLES
}

\author{
by \\ DAVID deLESDERNIER
}

\author{
Prepared under \\ Contract AT(04-3)-167 \\ Project Agreement No. 53 \\ for the \\ San Francisco Operations Office \\ U. S. Energy Research and \\ Development Administration
}

Date Published - June 30, 1975 


\section{DISCLAIMER}

This report was prepared as an account of work sponsored by an agency of the United States Government. Neither the United States Government nor any agency Thereof, nor any of their employees, makes any warranty, express or implied, or assumes any legal liability or responsibility for the accuracy, completeness, or usefulness of any information, apparatus, product, or process disclosed, or represents that its use would not infringe privately owned rights. Reference herein to any specific commercial product, process, or service by trade name, trademark, manufacturer, or otherwise does not necessarily constitute or imply its endorsement, recommendation, or favoring by the United States Government or any agency thereof. The views and opinions of authors expressed herein do not necessarily state or reflect those of the United States Government or any agency thereof. 


\section{DISCLAIMER}

Portions of this document may be illegible in electronic image products. Images are produced from the best available original document. 
This report was prepared as an account of work sponsored by the United States Government Nether the Unted States nor the United States Eneigy Research and Development Adminıstıation, nor any of their emplovees, nor any of their contractors, subcontractors, or their employees, makes any warranty, express or imphed, or assumes any legal liability or responsibility tor the accuracy. completeness or usefulness of any information, apparatus, product or piocess disclosed, or represents that its use would not intringe privately owned rights

Printed in the United States of America Available from

National Technical. Information Service

U.S. Department of Commerce 5285 Port Royal Road

Springfield, Virginia 22161

Price: Printed Copy $\$ 7.60$; Microfiche $\$ 2.25$ 
GA-A 13135

UC-77

\title{
PNEUMATIC CLASSIFICATION OF FORT ST. VRAIN FUEL PARTICLES
}

\author{
by \\ DAVID de LESDERNIER \\ Prepared under \\ Contract AT(04-3)-167 \\ Project Agreement No. 53 \\ for the \\ San Francisco Operations Office \\ U. S. Energy Research and \\ Development Administration
}

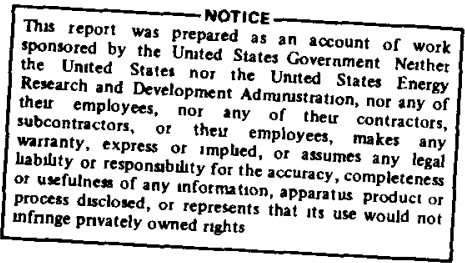

1952

General Atomic Project 3225

Date Published

(Formerly Project 0852) June 30, 1975 
01 


\begin{abstract}
Closure of the High-Temperature Gas-Cooled Reactor (HTGR) fuel cycle necessarily involves the reprocessing of fuel. During the reprocessing sequence, it is necessary to separate the bred, 100\% enriched (U-233) fertile fuel stream from the contaminated (U-235) fissile fuel stream which contains U-238 and the neutron poison U-236. Cross mixing of these fuel streams results in a proportionate cost penalty. For this reason separation of the fuel into its respective components was studied. The various methods of effecting a fertile-fissile fuel particle separation were considered and the method of pneumatic classification was selected for further experimentation. This report discusses a parametric study of pneumatic classification in which a commercial pneumatic classifier and an experimental pneumatic classifier were evaluated to determine the effect of height and feed composition on the efficiency of separation.
\end{abstract}

A model is proposed that can predict crossover of TRISO/TRISO fuel over a wide range of operating conditions once feed composition is known. The model offers potential for further economic evaluation of the fuel cycle. Recommendations are made for prototypical pneumatic classification equipment. 
-

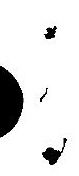

$\gamma$

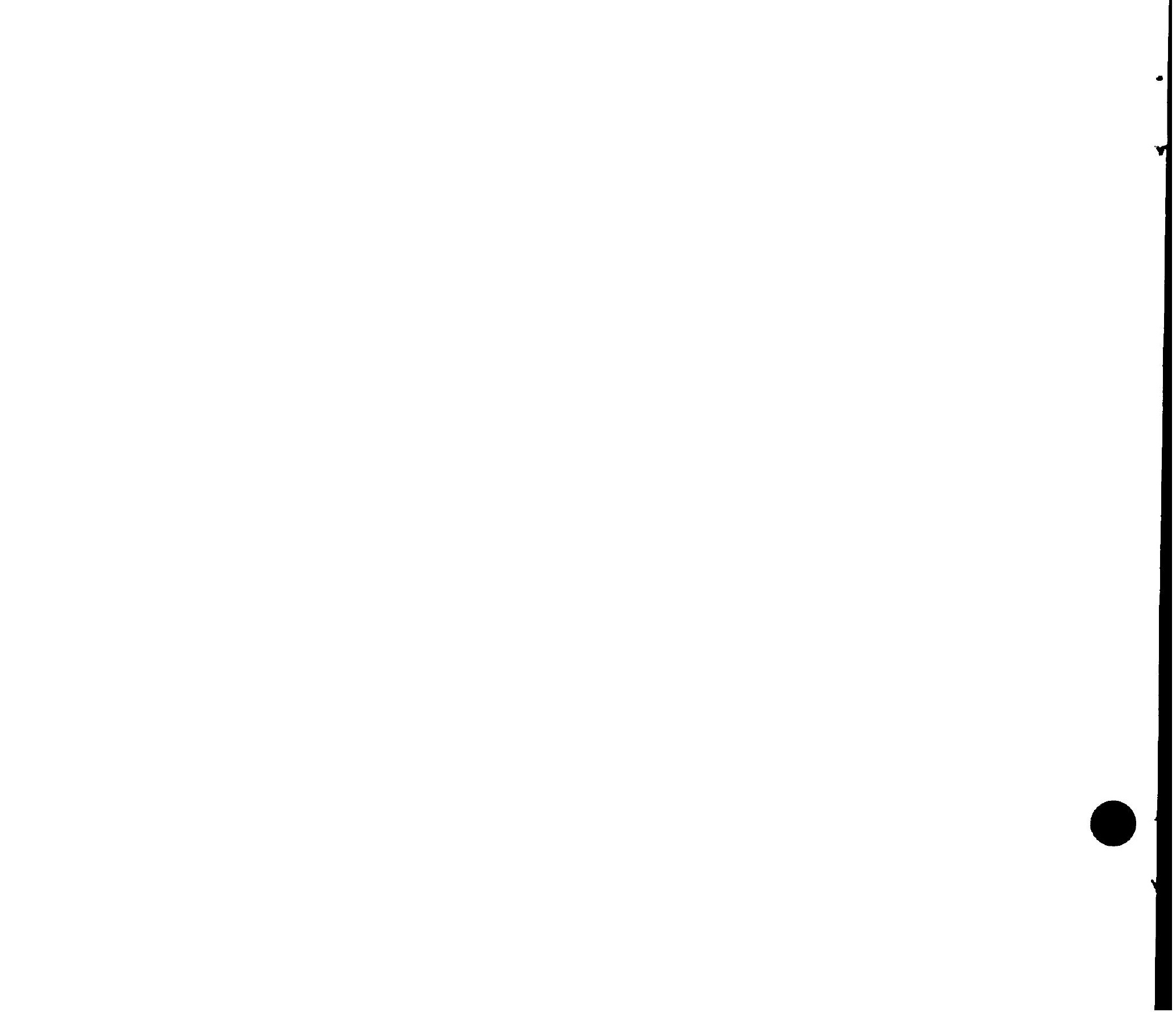


CONTENTS

ABSTRACT . . . . . . . . . . . . . . . . . . . . $i i i$

1. INTRODUCTION. . . . . . . . . . . . . . . . . . 1-1

2. FINANCIAL BACKGROUND. . . . . . . . . . . . . . . . . 2-1

3. THEORY. . . . . . . . . . . . . . . . . . . . 3-1

4. EXPERIMENTAL: DEVELOPMENT AND ANALYSIS OF PNEUMATIC

CLASSIFICATION TECHNIQUE. . . . . . . . . . . . . . . . 4-1

4.1. Description and General Operating Procedure with the
Alpine Multiplex Zigzag Pneumatic Classifier. . . . . 4-1

4.2. Simulated Feed. . . . . . . . . . . . 4-5

4.2.1. Effect of Solids Feed Rate and Gas Flow Rate on Separation Efficiency........ . 4-5

4.2.2. Separation of SiC Hulls from Fertile Kernels. . 4-22

4.2.3. Additional Findings . . . . . . . . . . . 4-23

4.2.4. Effect of the Addition of Graphite. . . . . . 4-25

4.3. Initial Tests with FSV Fuel . . . . . . . . . . . 4-28

4.3.1. Description of FSV Fue1 . . . . . . . . 4-28

4.3.2. Prediction of the Separation. . . . . . . 4-35

4.3.3. Prediction of the Crossover... . . . . 4-39

4.3.4. Density and Its Effect on Separation. . . . . 4-40

4.4. Scrap Rod Program ............... . . 4-46

4.4.1. The Feed. . ............... 4-46

4.4.2. Estimation of the Products. . . . . . . . . 4-48

4.4.3. Prediction of Crossover . . . . . . . . 4-53

4.4.4. Evaluation. ............. . 4-54

4.5. Feeding Performance . . . . . . . . . . . 4-55

4.5.1. Vibratory Feeder. . . . . . . . . . . 4-55

4.5.2. Rotary Feeder . . . . . . . . . . . 4-59

5. MODULAR PNEUMATIC ClAASSIFIER. . . . . . . . . . . . 5-1

5.1. Feed. . . . . . . . . . . . . . . . 5-1

5.2. Results................... 5-5

5.2.1. Effect of Height. . . . . . . . . . 5-5 
5.2.2. Effect of Feed Position........... 5-9

5.3. General ................ . . 5-9

○. SIEVING . . . . . . . . . . . . . . . . . . . 6-1

6.1. Description of Experimental Procedure . . . . . . . 6-1

6.2. Blinding Rate.................. . 6-2

6.3. Throughput. . . . . . . . . . . . . 6-2

6.4. Efficiency of Separation. . . . . . . . . . 6-6

6.5. Comparison of Sieving with Pneumatic Classification . . 6-20

7. DATA REDUCTION AND ANALYSIS ............... . . 7-1

7.1. Particle Size Distribution. . . . . . . . . . . 7-1

7.2. Crossover Analysis. . . . . . . . . . . . 7-2

7.2.1. Wet Chemical Method ............ 7-2

7.2.2. Particle Size Analysis Method . . . . . . 7-4

8. SUMMARY . . . . . . . . . . . . . . . . 8-1

9. RECOMMENDATIONS . . . . . . . . . . . . . . . . 9-1

10. REFERENCES. . . . . . . . . . . . . . . . . . . 10-1

11. ACKNOWLEDGMENTS . . . . . . . . . . . . . . . . . 11-1

APPENDIX A: ROD PROPERTIES. . . . . . . . . . . . . . . . . A-1

APPENDIX B: PARTICLE SIZE DISTRIBUTIONS OF PRODUCTS FROM SCRAP ROD

PROGRAM . . . . . . . . . . . . . . . . . . B-1

APPENDIX C: PREDICTIONS OF SEPARATIONS FOR SCRAP ROD RUNS . . . • . C-1

APPENDIX D: DESCRIPTION AND OPERATION OF THE COATED PARTICLE

ANALYSER. . . . . . . . . . . . . . . . . D-1

APPENDIX E: COMPUTER PROGRAMS USED FOR DATA REDUCTION . • • • • . E-1

APPENDIX F: DRAWINGS FOR MODULAR CLASSIFIER . . • • . • • . . . . F-1

APPENDIX G: ABBREVIATIONS FOR SECTION $3 . \cdot$. . . . . . . . . G-1

FIGURES

2-1. Fuel cost penalty resulting from crossover of bred fuel into

retired stream ................. 2-2

2-2. Fuel cost penalty resulting from crossover of residual makeup uranium into recycle stream. . . . . . . . . . . 2-3

3-1. Free body force diagram. . . . . . . . . . . . . . 3-2

3-2. Friction factor for spheres in relative motion to a fluid. . . 3-4

3-3. Separation efficiency. . . . . . . . . . . . . . 3-6

4-1. Alpine pneumatic classifier. . . . . . . . . . . . . 4-2 
FIGURES (continued)

4-2. Alpine Multiplex Zigzag Pneumatic Classifier. ...... . 4-3

4-3. Rotary feeder ............... . . . 4-4

4-4. Particle size distribution of TRISO/TRISO fuel particles. . 4-6

4-5. Particle size distribution of FSV fuel particles, Fissile A - Fertile B. . . . . . . . . . . . . . . 4 4-7

4-6. Particle size distribution of FSV fuel particles, Fissile B - Fertile A . . . . . . . . . . . . . . 4-8

4-7. Separation efficiency versus feed rate and diameter at constant air velocity of $3.15 \mathrm{~m} / \mathrm{sec}$. . . . . . . . 4 4-14

4-8. Separation efficiency versus feed rate and diameter at constant air velocity of $3.70 \mathrm{~m} / \mathrm{sec}$. . . . . . . . . 4-15

4-9. Separation efficiency versus feed rate and diameter at constant air velocity of $4.25 \mathrm{~m} / \mathrm{sec}$. . . . . . . . . 4-16

4-10. Separation efficiency versus feed rate and diameter at constant air velocity of $4.80 \mathrm{~m} / \mathrm{sec}$. . . . . . . . . 4-17

4-11. Separation efficiency versus air velocity and diameter at constant feed rate of $100 \mathrm{~g} / \mathrm{min}$........... . 4-19

4-12. Separation efficiency versus air velocity and diameter at constant feed rate of $300 \mathrm{~g} / \mathrm{min}$. . . . . . . . . . . 4-20

4-13. Separation efficiency versus air velocity and diameter at constant feed rate of $500 \mathrm{~g} / \mathrm{min}$. . . . . . . . . . . 4-21

4-14. Density versus particle size for simulated feed . . . . . 4-26

4-15. Separation efficiency versus diameter at constant feed rate of $300 \mathrm{~g} / \mathrm{min}$ and air velocity of $3.70 \mathrm{~m} / \mathrm{sec}$. . . . . . 4-27

4-16. Comparison of separation of simulated feed at $3.70 \mathrm{~m} / \mathrm{sec}$ air velocity with additional $5 \mathrm{wt} \%$ graphite and with no graphite. . . . . . . . . . . . . . . . . . .

4-17. Comparison of separation of simulated feed at $3.70 \mathrm{~m} / \mathrm{sec}$ air velocity with additional 10 wt \% graphite and with no graphite. . . . . . . . . . . . . . . 4-30

4-18. Comparison of separation of simulated feed at $3.70 \mathrm{~m} / \mathrm{sec}$ air velocity with additional 10 wt $\%$ graphite (lower portion of size distribution) and with no graphite......... 4-31

4-19. Comparison of separation of simulated feed at $3.70 \mathrm{~m} / \mathrm{sec}$ air velocity with additional 10 wt \% graphite (upper portion of size distribution) and with no graphite. . . . . . . . 4-32

4-20. Size distribution for tertiary crusher product. . . . . . . 4-34

4-21. Uncorrected model for separation efficiency versus air velocity and diameter at constant feed rate of $200 \mathrm{~g} / \mathrm{min}$. . 4-37 
FIGURES (continued)

4-22. Model corrected for the effect of density; separation efficiency versus air velocity and diameter at constant feed rate

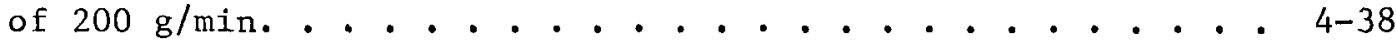

4-23. Theoretical density versus cumulative weight percent of

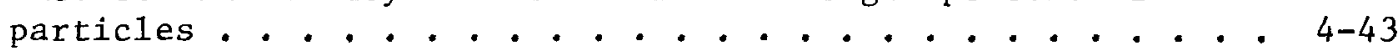

4-24. Weight percent mean diameter versus density at SiC coating for ESV type fuel............... 4-45

4-25. Particle size distribution for Scrap Rod Run No. 1; Fissile A - Fertile A - Fertile B . . . . . . . . . . . 4-47

4-26. Effect of relative size of modes upon separation efficiency . 4-51

4-27. Vibratory feeder. . . . . . . . . . . . . . 4-56

4-28. Instantaneous feed rate of vibratory feeder . . . . . . . 4-57

4-29. Relationship of feed rate of vibratory feeder to material in hopper. . . . . . . . . . . . . . . . . 4-58

4-30. Relationship between feed rate of vibratory feeder and air velocity rate (vacuum)................ 4-60

4-31. Relationship between feed rate of rotary feeder and its rpm . 4-62

4-32. Comparison of rotary feeder performance and vibratory feeder

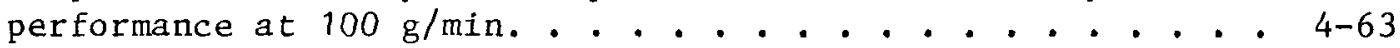

4-33. Comparison of rotary feeder performance and vibratory feeder

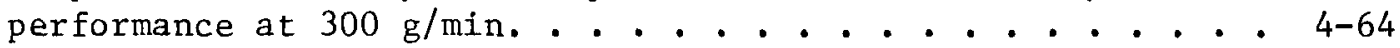

5-1. Modular pneumatic classifier. . . . . . . . . . 5-2

5-2. Schematic of modular pneumatic classifier . . . . . . . 5-3

5-3. Height and feed position configurations of modular classifier investigated. . . . . . . . . . . . . . . . . .

5-4. Comparison with respect to height of separation efficiency of modular classifier configurations with that of Alpine classifier at a constant solids feed rate of $100 \mathrm{~g} / \mathrm{min}$. . . 5-6

5-5. Comparison with respect to height of separation efficiency of modular classifier configurations with that of Alpine classifier at a constant solids feed rate of $300 \mathrm{~g} / \mathrm{min}$. . . . 5-7

5-6. Comparison with respect to height of separation efficiency of modular classifier configurations with that of Alpine classifier at a constant solids feed rate of $500 \mathrm{~g} / \mathrm{min}$. . . 5-8

5-7. Comparison with respect to feed position of separation efficiency of modular classifier configurations with that of Alpine classifier at a constant solids feed rate of 100

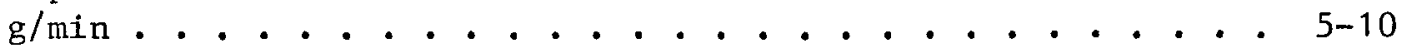


FIGURES (continued)

5-8. Comparison with respect to feed position of separation efficiency of modular classifier configurations with that of Alpine classifier at a constant solids feed rate of 300

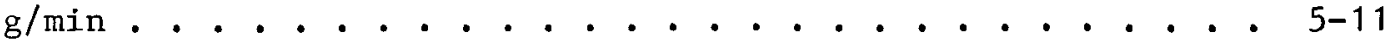

5-9. Comparison with respect to feed position of separation efficiency of modular classifier configurations with that of Alpine classifier at a constant solids feed rate of 500

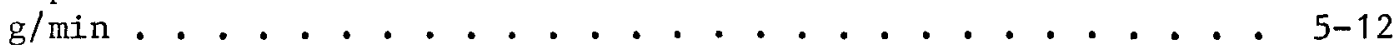

6-1. Blinding rate of simulated feed ............ . 6-3

6-2. Blinding rate of Fissile B - Fertile A FSV fuel . . . . . . 6-4

6-3. Blinding rate of Fissile A - Fertile B FSV fuel . . . . . . 6-5

6-4. Throughput of simulated feed, 200 gm charge . . . . . . 6-7

6-5. Throughput of simulated feed, $400 \mathrm{gm}$ charge . . . . . . . 6-8

6-6. Throughput of simulated feed, 800 gm charge . . . . . . 6-9

6-7. Throughput of Fissile B - Fertile A FSV fuel, 200 gm charge . 6-10

6-8. Throughput of Fissile B - Fertile A FSV fuel, 400 gm charge . 6-11

6-9. Throughput of Fissile A - Fertile B FSV fue1, 800 gm charge . 6-12

6-10. Separation efficiency of simulated feed with 200 gm charge. . 6-14

6-11. Separation efficiency of simulated feed with 400 gm charge. . 6-15

6-12. Separation efficiency of simulated feed with $800 \mathrm{gm}$ charge. . 6-16

6-13. Separation efficiency of Fissile B - Fertile A FSV fuel with $400 \mathrm{gm}$ charge . . . . . . . . . . . . . . 6-17

6-14. Separation efficiency of Fissile B - Fertile A FSV fuel with 200 gm charge . . . . . . . . . . . . . . 6-18

6-15. Separation efficiency of Fissile A - Fertile B FSV fuel with 800 gn charge................... 6- . . . . . . . . .

6-16. Size distribution of particles plugging a 500 micron sieve. . 6-21

TABLES

3-1. Parameters for an example of matrix modeling. . . . . . 3-8

4-1. Separation efficiency versus feed rate and diameter at constant air velocity rate of $3.15 \mathrm{~m} / \mathrm{sec}$. . . . . . . . 4-10

4-2. Separation efficiency versus feed rate and diameter at

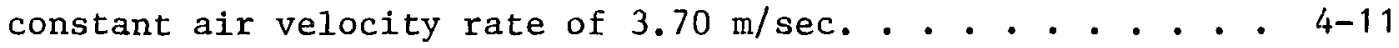


4-3. Separation efficiency versus feed rate and diameter at constant air velocity rate of $4.25 \mathrm{~m} / \mathrm{sec}$. . . . . . . . . 4-12

4-4. Separation efficiency versus feed rate and diameter at constant air velocity rate of $4.80 \mathrm{~m} / \mathrm{sec}$. . . . . . . . . 4-13

4-5. Constants $A$ and $B$ of Equation $\phi=$ feedrate $/ A+B$. feed rate versus air velocity and diameter. . . . . . . . . . 4-18

4-6. Separation of $\mathrm{SiC}$ hulls and carbon coatings from $\mathrm{ThC}_{2}$ kernels .. . . . . . . . . . . . . . . . 4-24

4-7. Effect of graphite on separation of the simulated feed. . . 4-33 4-8. QA fuel specifications. . . . . . . . . . . . . . . 4-41 4-9. Theoretical particle density vs particle diameter . . . . . 4-44 4-10. Feed and product composition. . . . . . . . . . . . 4-49 6-1. Throughput of various feeds............... . 6-13 


\section{INTRODUCTION}

Closure of the High-Temperature Gas-Cooled Reactor (HTGR) fuel cycle is essential for successful introduction of the HTGR. General Atomic Company is currently funded under the Thorium Utilization Program of the U.S. Energy and Development Administration (ERDA) to develop the technology necessary for reprocessing spent HTGR fuel in a facility using unirradiated fuel materials. The reference process consists of the reduction of fullsize HTGR fuel elements to $<3 / 16$ in. particles, which are then fluidized and burned to remove fuel element and matrix graphite from the fuel particles. After these two process steps, the fissile and fertile fuel particles are separated and continue throughout the remaining process steps as separate streams. As fuel cycle economic success depends in part on separation of the bred U-233 in the fertile particles from the U-236contaminated U-235 in the fissile particles, it is important to achieve separation of the fertile from the fissile fuel particles as completely as is economically feasible in the Head-End Reprocessing System. This report describes a comprehensive year-long study of pneumatic classification of fuel particles.

Pneumatic separation was investigated in detail using an Alpine Multiplex Zigzag Air Classifier and a modular pneumatic classifier designed especially for this study. Effects of the following variables were determined:

1. Solids feed rate

2. Air velocity

3. Column height

4. Feed position

5. Particle size distribution

6. Ratio of fuel and graphite 
For a comparison of separation methods, the fuel was also classified using a standard sieve and sieve shaker technique. In this analysis, the separation efficiency was related to charge size on the screen, rate of blinding of the screen opening, and screen throughput.

The pneumatic separation efficiency was applied to actual fuel particle size distributions to give the crossover of the fissile and fertile streams. (Crossover is defined as the percent loss of fissile heavy metal to the fertile stream and the percent loss of fertile heavy metal to the fissile stream.) Since the crossover of these two streams constitutes a cost penalty in the Thorium Fuel Cycle (Ref. 1), this mixing must be kept to a minimum. A model was developed that would predict the separation and crossover of the fissile and fertile streams. Using this model, the final crossover can be calculated for any size distribution of Fort St. Vrain (FSV) type TRISO/TRISO fuel. With this information, cost analyses and design decisions can now be made with greater accuracy and confidence. 


\section{FINANCIAL BACKGROUND}

The cost penalty associated with the crossover of the fissile and fertile streams has been a major consideration in this research. The fissile stream is recycled once, then is disposed of because of the depletion of fissionable U-235 and the build-up of the neutron poison U-236. Loss of fertile material to the fissile stream results in either disposal of the bred U-233 or at best a minor improvement of the reactivity of the recycled fissile fuel. Loss of fissile material to the fertile stream contaminates the pure U-233 with other isotopes of uranium, one of which is a neutron poison - U-236. In the past, this cost penalty has been either ignored, assumed to be zero, or only treated generally for establishing the costs of the fuel cycle (Ref, 2). The main reason for this was that until Ref. 3 was published, no data were available on the crossover of the two streams. However, after that report led the way toward understanding the separation of TRISO/TRISO fuel, further information was obtained (Ref. 4) on the results of the Scrap Rod Program (Ref. 5), and this is now followed by the present detailed account of pneumatic classification. An accurate picture of the cost penalties resulting from crossover may now be drawn through the comparison of the results from these studies on separation with those from economic studies.

One study (Ref. 6) determined the cost penalties associated with the crossover of the HTGR fuel particles for a wide range of possible net crossover values ( 0 to 50\%) and for various economic situations. The information from this broad range of data is summarized in this report in Figs. 2-1 and 2-2. These two figures (one for fissile, the other for fertile crossover) give the cost penalty as a function of crossover for two cases: (1) an average for 31 years of recycle operation; (2) a near equilibrium concentration of U-236 in the fertile particles. For both cases, three curves are given, each representing a different resale value associated with the residual makeup uranium. These figures permit the assignment of 


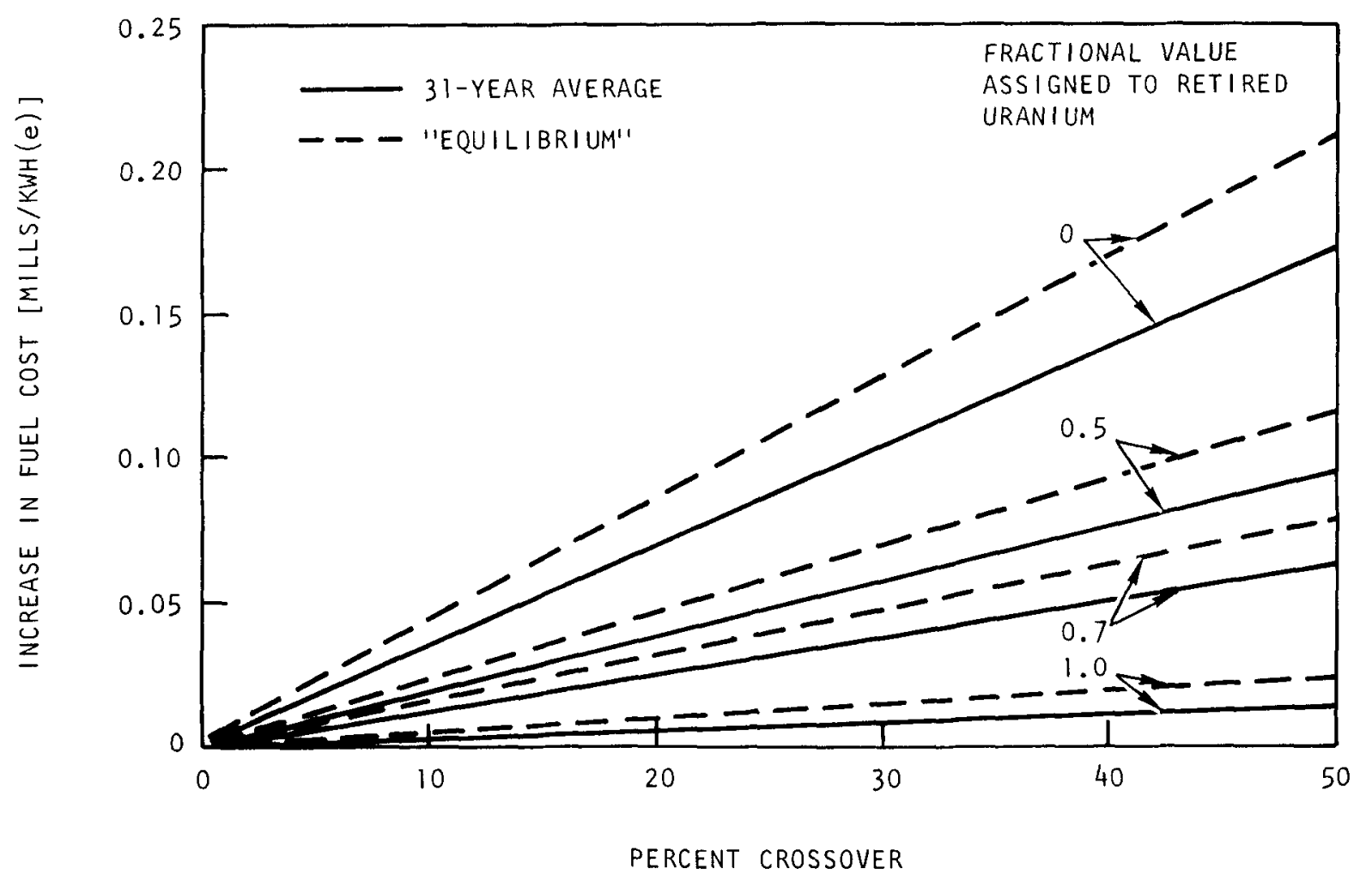

Fig. 2-1. Fuel cost penalty resulting from crossover of bred fuel into retired stream 


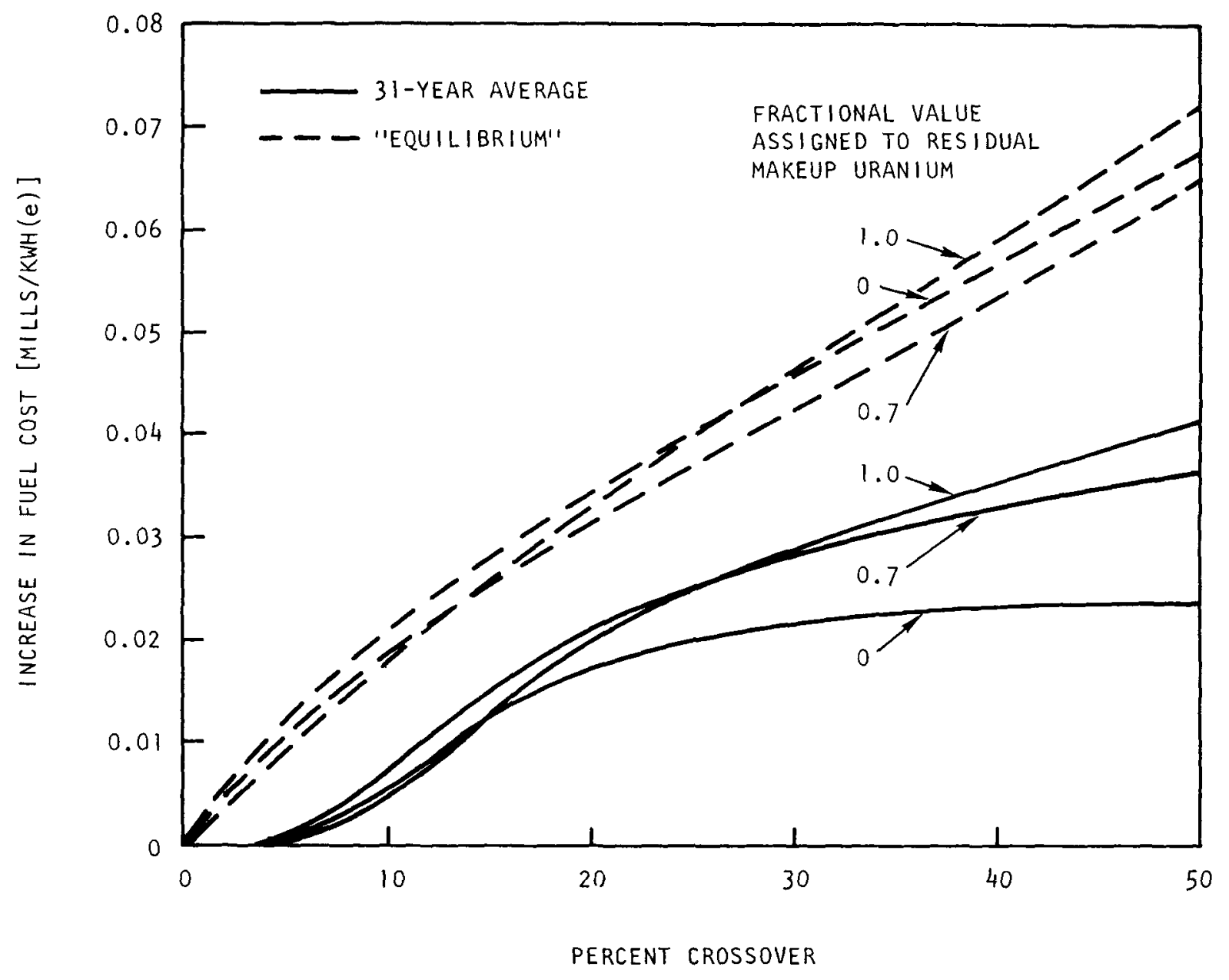

Fig. 2-2. Fuel cost penalty resulting from crossover of residual makeup uranium into recycle stream 
cost penalties to known crossover values which can then aid in the design, economic, and process decisions governing HTGR fuel reprocessing. Using the average parameters of the second Scrap Rod Run, a fissile crossover of 13.3 wt $\%$ and a fertile crossover of 4.0 wt \% are predicted using the model. These crossovers lead to a combined cost penalty of $0.044 \mathrm{mils} / \mathrm{kWhr}$ assuming the upper curves in Figs. 2-1 and 2-2 apply to this situation.

In the following sections, the results of various experiments on separation of the fissile and fertile streams are reported. In addition, a model that will permit the estimation of fissile and fertile crossover for a variety of process conditions and fuel compositions is proposed and refined. By coupling the model developed in the course of this investigation with Figs. $2-1$ and $2-2$, it is now possible to assess the cost penalties associated with the separation of TRISO/TRISO fuel in the headend reprocessing. 


\section{THEORY}

Pneumatic classification is based on a hydrodynamic force balance between the moving gas phase and the solid phase. In this force balance, the differences in size, in density, or in a combination of the two is used to separate the particles. The starting point for the theoretical consideration surrounding the pneumatic classification or separation of two particulate systems begins with the classic solution of the Navier-Stokes Equation (Ref. 7) for an incompressible fluid:

$$
\frac{\partial V}{\partial t}+V \nabla \cdot V=\frac{2}{R e} \nabla^{2} V-1 / 2 \Delta P
$$

(For definition of symbols see Appendix G.) For steady state flow the first term is zero, and from the equation of continuity

$$
\nabla \cdot \mathrm{V}=0
$$

The resulting equation of motion is nonlinear and as a result only approximate solutions can be found. The first solution to this equation was given by G. Stokes in 1851 (Ref. 8) when he assumed the inertial terms to be negligible. This solution gave

$$
\bar{F}=3 \pi \mu d V
$$

which is valid for Reynolds numbers less than 0.5 . In the situation where a spherical particle is in a rising gas stream, the gravitational force is balanced by the viscous force (Eq. 3-3) and the buoyant force (see Fig. 3-1), giving the following equation:

$$
v_{f}-v_{p}=v_{t}=\frac{g}{18} \frac{d^{2}}{\mu}\left(\rho_{P}-\rho_{F}\right)
$$




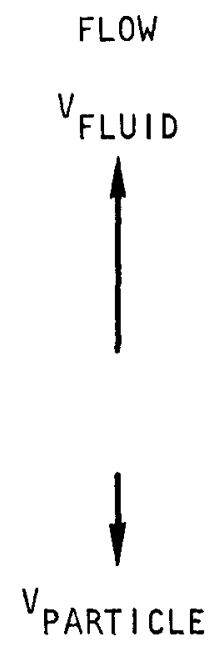

FORCES
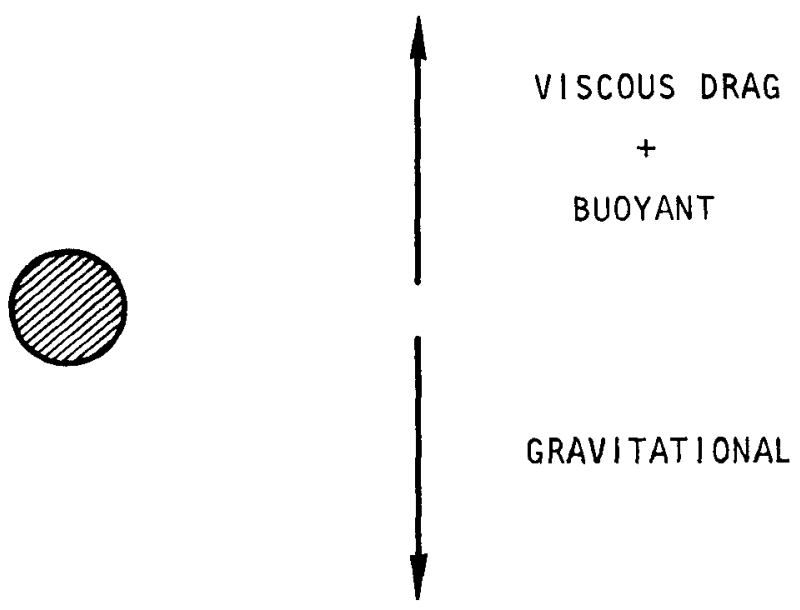

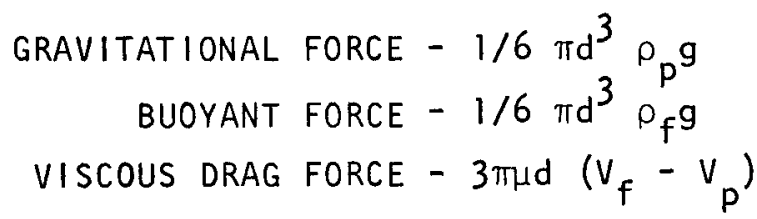

Fig. 3-1. Free body force diagram 
When the gas flow is such that the particle is suspended motionless, this velocity is equal to the terminal velocity of the particle falling in a stagnant gas. This force balance is useful in specifying an effective (Stokes) diameter for a nonspherical particle. This diameter is calculated from the experimentally determined terminal velocity and Eq. 3-4 and is useful in describing the interaction of a nonspherlcal particle and a fluid.

Other methods (Ref. 9) for solution to Eq. 3-1 have extended the applicable range of Reynolds number. In addition to these methods a friction factor chart (Fig. 3-2, Ref. 10) gives the relationship between a sphere and fluid over a wide range of Reynolds numbers. However, all of these solutions are only valid for low concentrations of particles in the fluid (Refs. 11-13). When the concentrations exceed 0.05 volume percent, the error exceeds 20\%. Because normal operation of a pneumatic classifier has a concentration many times this value, these solutions cannot be used to describe the operation.

A pneumatic classifier is used to separate a mixture of particles into two fractions based upon the difference in size and/or density. In the ideal case of very low solids concentration, all of the larger and/or more dense particles will fall in the rising gas stream while all of the smaller and/or less dense particles will rise with the gas. This can be predicted via the above solutions to the Navier-Stokes equation if the solids concentration is $10 \mathrm{w}$.

However, as the solids concentration increases, there are more and more particle to particle interactions which cause some of the large and/or more dense particles to be entrained with the rising less dense particles. The opposite also occurs. This results in contamination of the two fractions. For a binary system this leads to a percent purity of each stream. For a system which consists of particles having a spread of sizes and/or densities, the term separation efficiency is used and designated as 


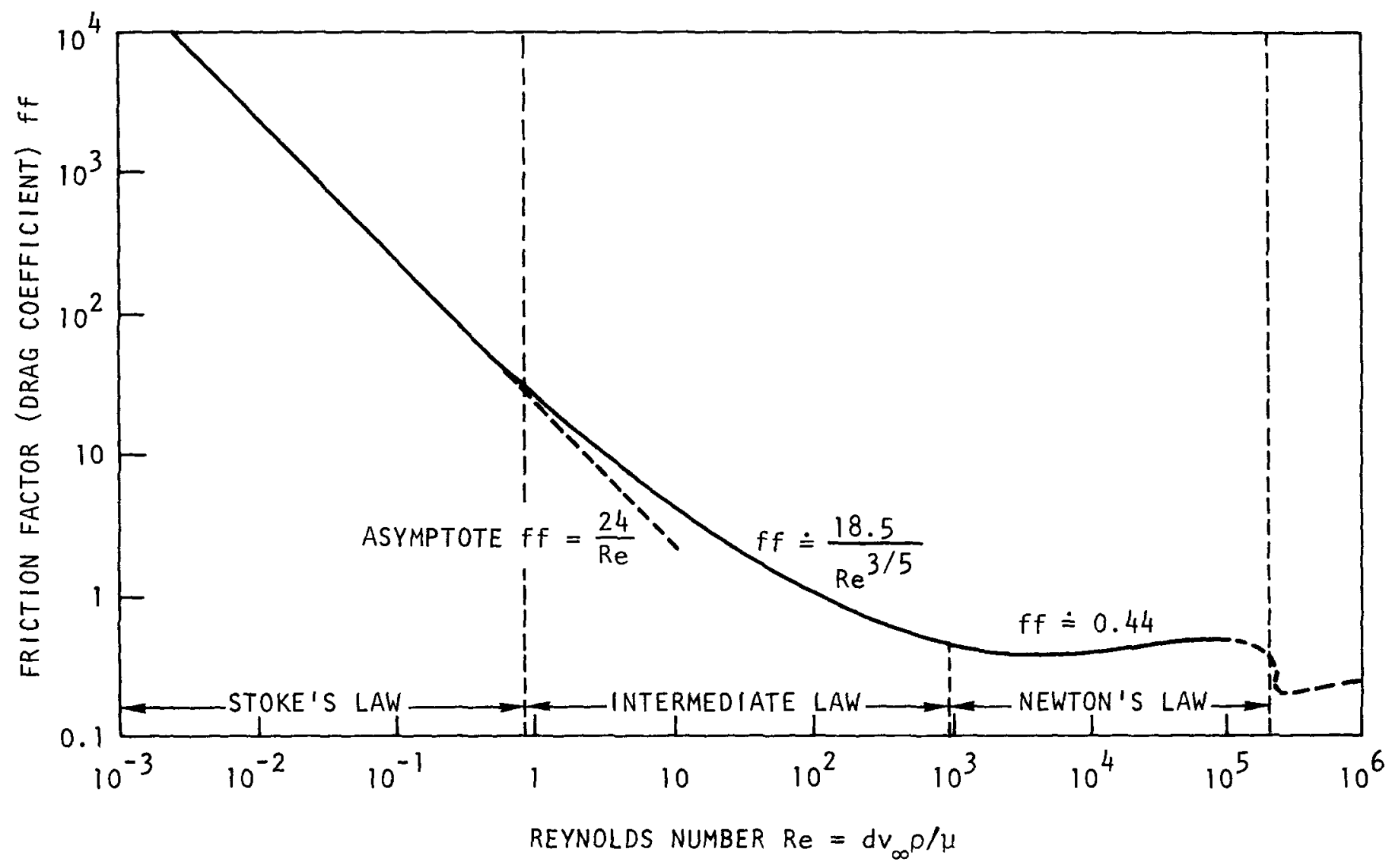

Fig. 3-2. Friction factor for spheres in relative motion to a fluid 
\$. The separation efficiency is defined as the weight fraction of feed that is present in the coarse fraction for a certain size interval. Curve A in Fig. 3-3 represents the ideal case for separation. References 13 and 14 state this ideal separation can only be approached in classification since there will always be some degree of overlapping of distributions or entrainment. As the slope of the separation efficiency curve decreases from ${ }^{\infty}$, the separation departs further and further from the theoretical maximum. For a measure of this departure from the ideal situation, the diameter with a $75 \%$ probability of falling into the coarse fraction is divided by that diameter with a $25 \%$ chance or

$$
\phi_{25}^{75}=\frac{d_{25}}{d_{75}}
$$

As this value approaches unity, the separation approaches theoretical efficiency.

The relationship of $\phi$ to diameter describes the separation process for a given set of conditions. Establishing the relationship between $\phi$ and $d$ as a function of such variables as air velocity, solids feed rate, particle size distribution, and powder system components characterizes the separation process. With the process characterized with a mathematical model, the separation under any desired set of conditions may be determined. For manipulation of this model, it is convenient to use matrices (Ref. 15).

The particle size distribution of the feed is divided into consecutive equal size increments. The weight fractions of particles for each size increment comprise the elements of a column matrix which may be denoted as $Y_{i}$. As $i$ increases the average dlameter of the size increment increases. Also, the sum of $\mathrm{Y}_{i}$ for all $i$ is equal to unity. To describe the process of classification, the elements of a diagonal matrix, $Y_{i i}$, are set equal to the fraction of feed in size increment $i$ that goes to the coarse product 


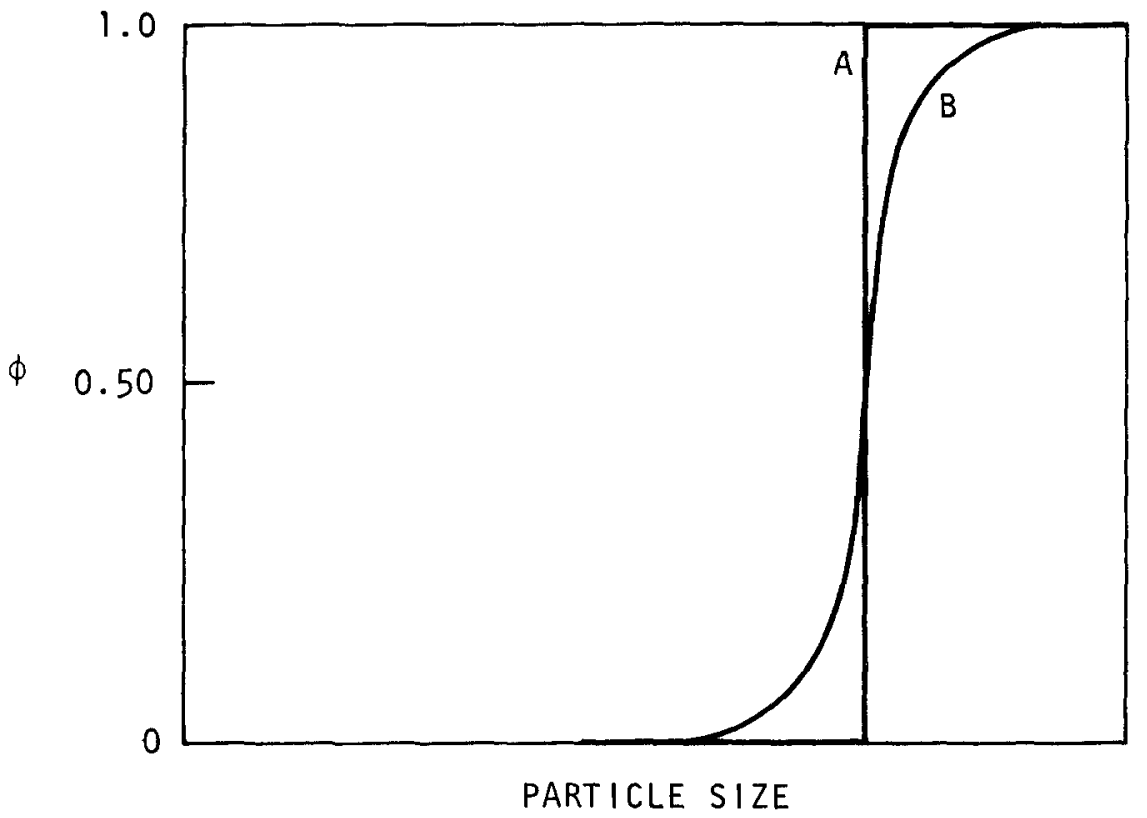

Fig. 3-3. Separation efficiency 
$\left(Y_{i i}=\phi_{i}\right)$. Now with both the feed size distribution and the separation process described by matrices, the size distribution of the product may be found by simple matrix arithmetic or

$$
\begin{aligned}
& \mathrm{o}=\mathrm{f} \cdot \mathrm{C} \\
& \mathrm{u}=\mathrm{f}-\mathrm{o}
\end{aligned}
$$

For example, suppose a feed had a size analysis as given in Table $3-1$ and was separated by a classifier whose $\phi$ varied with size as given in Table 3-1. Then to find the size distribution of the products one needs only to substitute the above information into Eqs. 3-6 and 3-7 to obtain

$$
\begin{aligned}
0 & =\left|\begin{array}{l}
0.10 \\
0.30 \\
0.35 \\
0.20 \\
0.05
\end{array}\right| \times\left|\begin{array}{lllll}
1.00 & 0 & 0 & 0 & 0 \\
0 & 0.80 & 0 & 0 & 0 \\
0 & 0 & 0.50 & 0 & 0 \\
0 & 0 & 0 & 0.25 & 0 \\
0 & 0 & 0 & 0 & 0
\end{array}\right|=\left|\begin{array}{l}
0.10 \\
0.24 \\
0.18 \\
0.04 \\
0
\end{array}\right| \\
u & =\left|\begin{array}{l}
0.10 \\
0.30 \\
0.35 \\
0.20 \\
0.05
\end{array}\right|-\left|\begin{array}{l}
0.10 \\
0.24 \\
0.18 \\
0.04 \\
0
\end{array}\right|=\left|\begin{array}{l}
0 \\
0.06 \\
0.17 \\
0.16 \\
0.05
\end{array}\right|
\end{aligned}
$$

By having the elements of the diagonal matrix responsive to the operating parameters of the classifier, one may determine the products for a given set of operating conditions and for a given feed composition. 
TABLE 3-1

PARAMETERS FOR AN EXAMPLE OF MATRIX MODELING

\begin{tabular}{c|c|c}
\hline $\begin{array}{c}\text { Size Range } \\
\text { (microns) }\end{array}$ & $\begin{array}{c}\text { Feed } \\
\text { (Weight Fraction) }\end{array}$ & $\begin{array}{c}\text { Separation } \\
\text { Efficiency }\end{array}$ \\
\hline+2000 & 0.10 & 1.00 \\
$+1000-2000$ & 0.30 & 0.80 \\
$+500-1000$ & 0.35 & 0.50 \\
$+250-500$ & 0.20 & 0.25 \\
-250 & 0.05 & 0.00 \\
\hline
\end{tabular}




\title{
4. EXPERTMENTAL: DEVELOPMENT AND ANALYSIS \\ OF PNEUMATIC CLASSIFICATION TECHNIQUE
}

\begin{abstract}
4.1. DESCRIPTION AND GENERAL OPERATING PROCEDURE WITH THE ALPINE MULTIPLEX ZIGZAG PNEUMATIC CLASSIFIER
\end{abstract}

The majority of these data on pneumatic classification was obtained using an Alpine Multiplex Zigzag Pneunatic Classifier (Figs. 4-1 and 4-2) consisting of a feeder, a zigzag colum, a cyclone, fine and coarse product receivers, and a vacuum source. A positive displacement vacuum pump with a bag and a sintered metal filter for removing dust carried over from the cyclone was used for the experiments. In addition to the vibratory feeder used in a majority of the experiments, a rotary valve feeder was tested (Fig. 4-3). Section 4.5 compares the performance of these feeders.

A typical run followed these steps: $\sim 1.5 \mathrm{kgm}$ of feed was loaded into the feed hopper with an adjustment of the air flow to the desired value. A few hundred grams of particles were then fed and removed from the product receivers to fill the vibrating channel to the normal run depth. Next the feeder control was adjusted and the unit turned on. After a measured length of time (usually 1-2 min) the feeder was stopped and the particles in the colum were allowed to classify. After all of the particles had either been elutriated or gravity discharged from the column, the operator shut off the air flow and removed the product receivers. To obtain an accurate feed rate, the operator divided the total feed rate by the time run. After the fine and coarse products were weighed, a riffle split sample from each was sent out for size analysis. Using this method several runs could be made from one loading, provided $\sim 1 / 2 \mathrm{kgm}$ was left in the feeder (see Section 4.5).

The fine and coarse samples were sent to the Fuel Test Techniques Branch for a size distribution analysis using the coated particle analyzer 


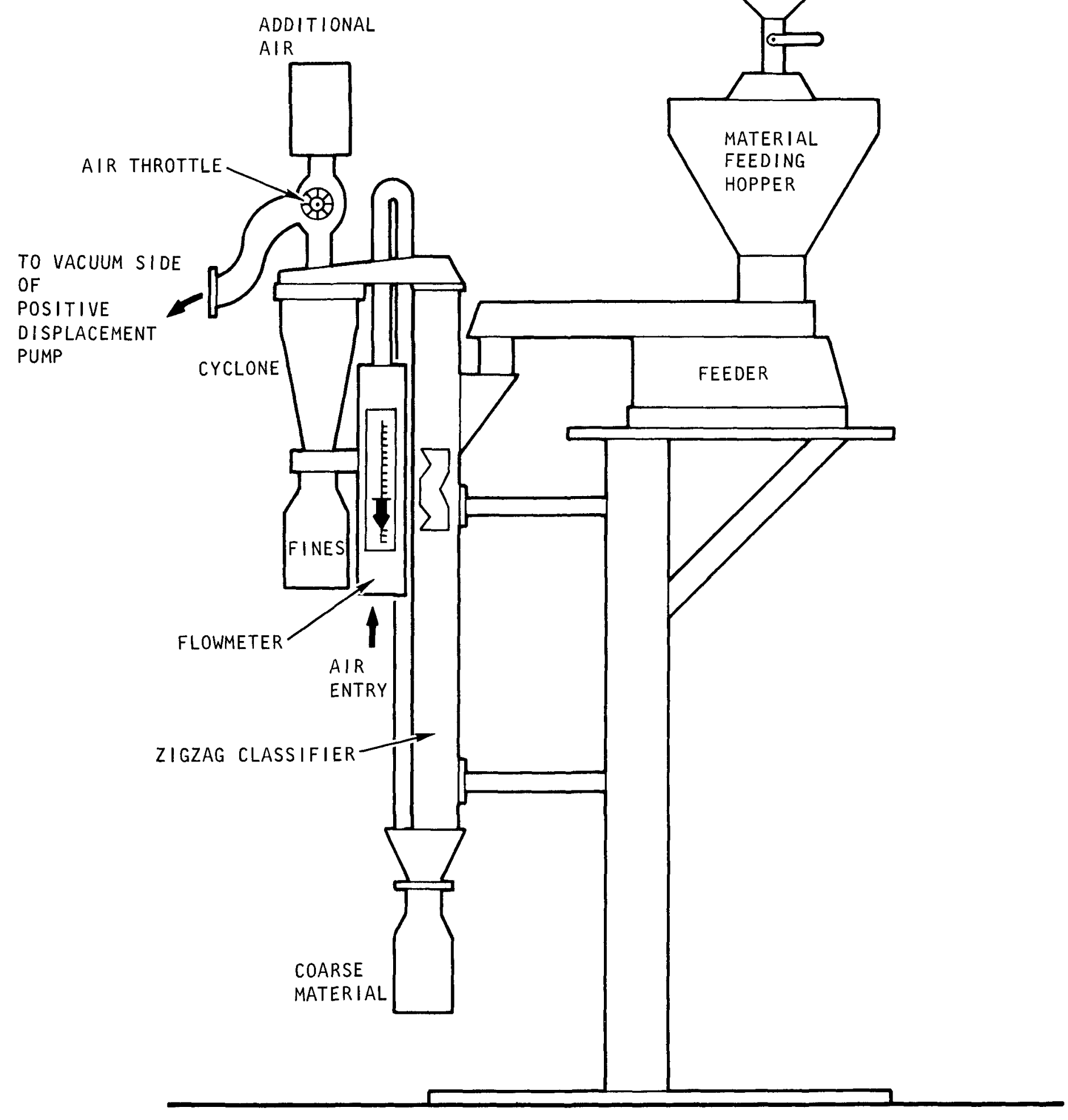

Fig. 4-1. Alpine pneumatic classifier

$$
\text { 4-2 }
$$




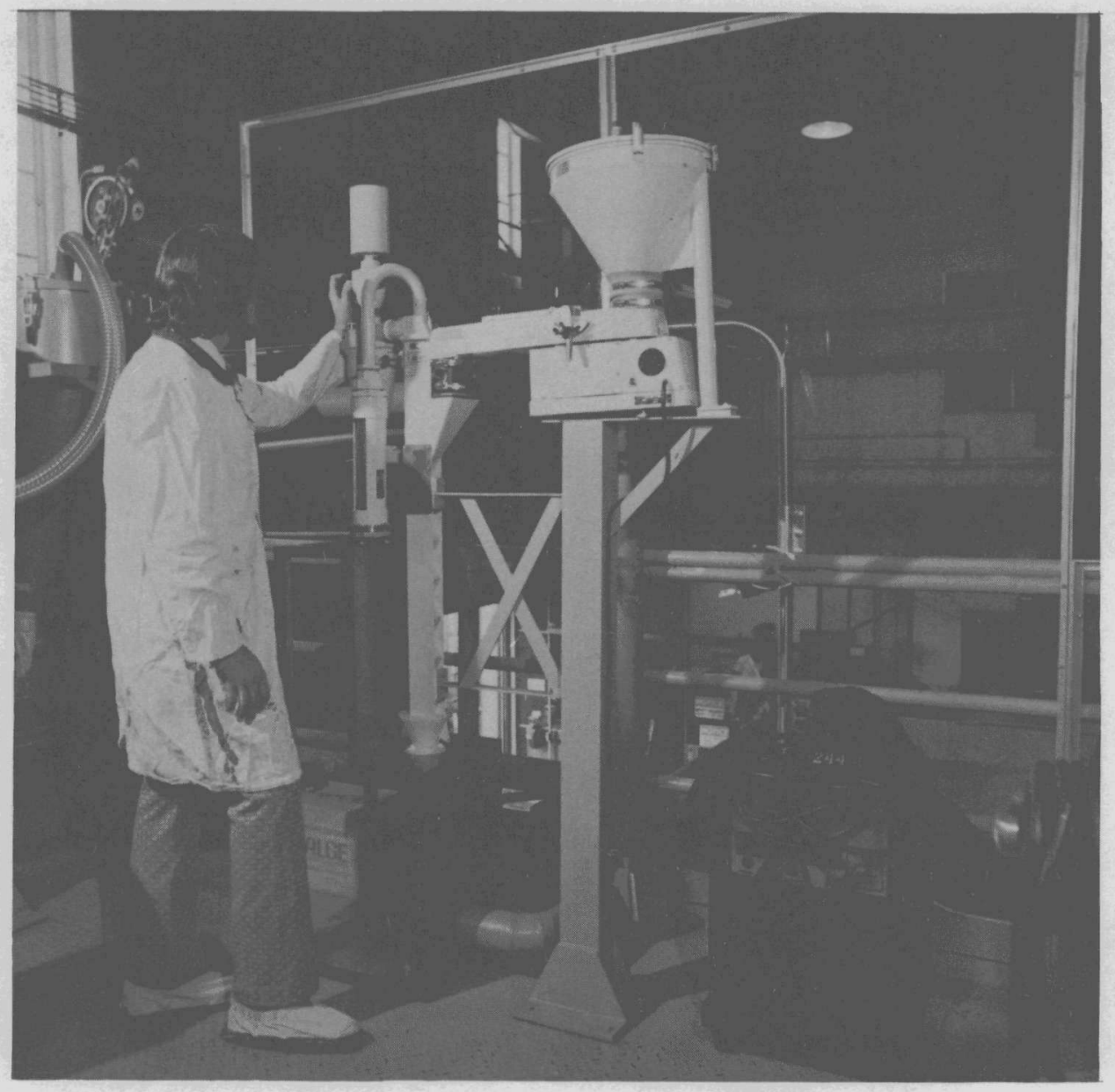

Fig. 4-2. Alpine Multiplex Zigzag Pneumatic Classifier 


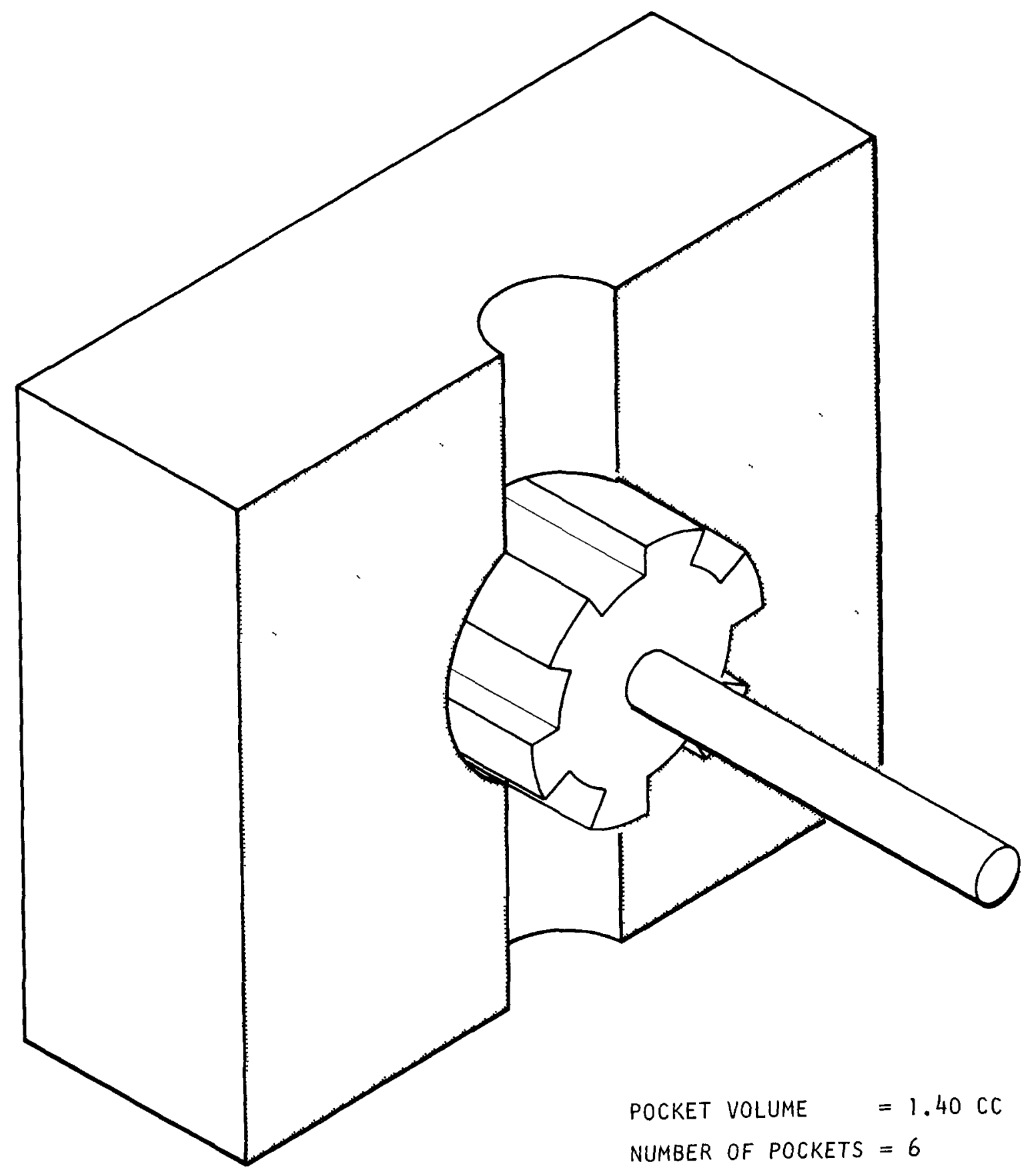

Fig. 4-3. Rotary feeder 
which is described in Appendix D. Briefly, this unit counts and sizes $\sim 20$ particles per second using a collimated light beam, a photodetector, and computer logic. The resulting data give the number of particles in a particular size interval (e.g., 48 particles between $400 \mu$ and $419 \mu$ ), which is then used by a computer program to calculate a number-percent size distribution. From this distribution and the density vs size relationship, the program calculates a weight-percent size distribution. With this weight distribution for the fine and coarse products and their weight ratio, the program then computes the feed and the weight fraction of the feed that becomes the coarse product. Appendix E reproduces the program and a typical output for FSV type fuel. A more detailed description of the data reduction and analysis is given in Section 7.

\subsection{SIMULATED FEED}

The majority of the experiments on classification utilized simulated feed consisting of rejected, depleted fissile particles and rejected fertile particles burned back to their SiC coating. This type of feed was used because rejected FSV fuel was not available until the more recent experiments. Thus, all the initial tests were made with simulated fuel although some of the tests were later duplicated with actual FSV fuel. Figure 4-4 gives the size distribution of simulated feed. By comparing this with the size distributions of FSV fuel given in Figs. 4-5 and 4-6, it can be seen that there is a rough approximation of simulated feed to a combination of the four components of FSV fuel: Fissile A, Fissile B, Fertile A, and Fertile B.

\subsubsection{Effect of Solids Feed Rate and Gas Flow Rate on Separation Efficiency}

The major thrust of this study was to determine the efficiency of separation with respect to gas flow rate and solids feed rate. To establish this relationship, runs were made with the feed rate ranging from 


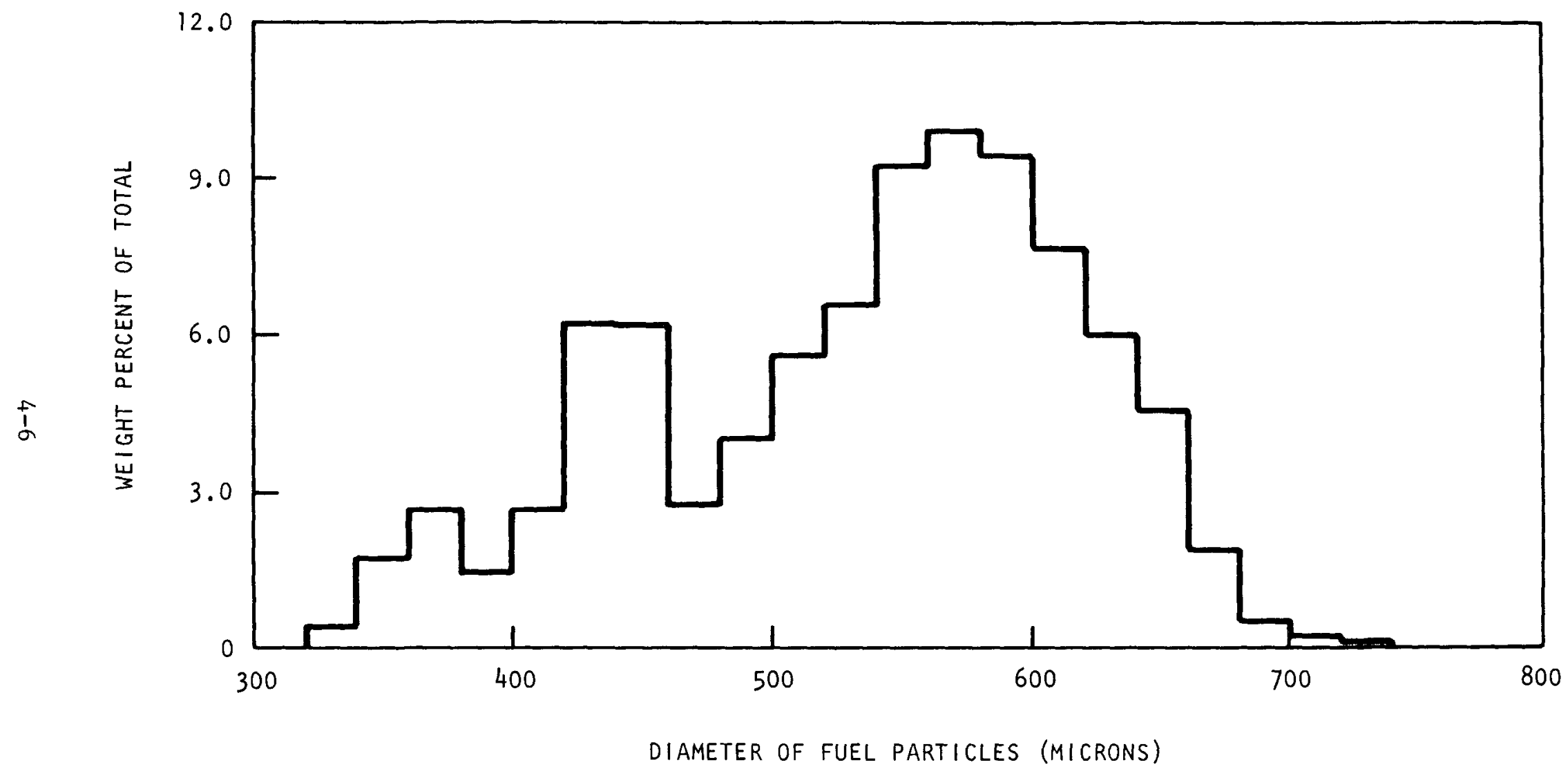

Fig. 4-4. Particle size distribution of TRISO/TRISO fuel particles 


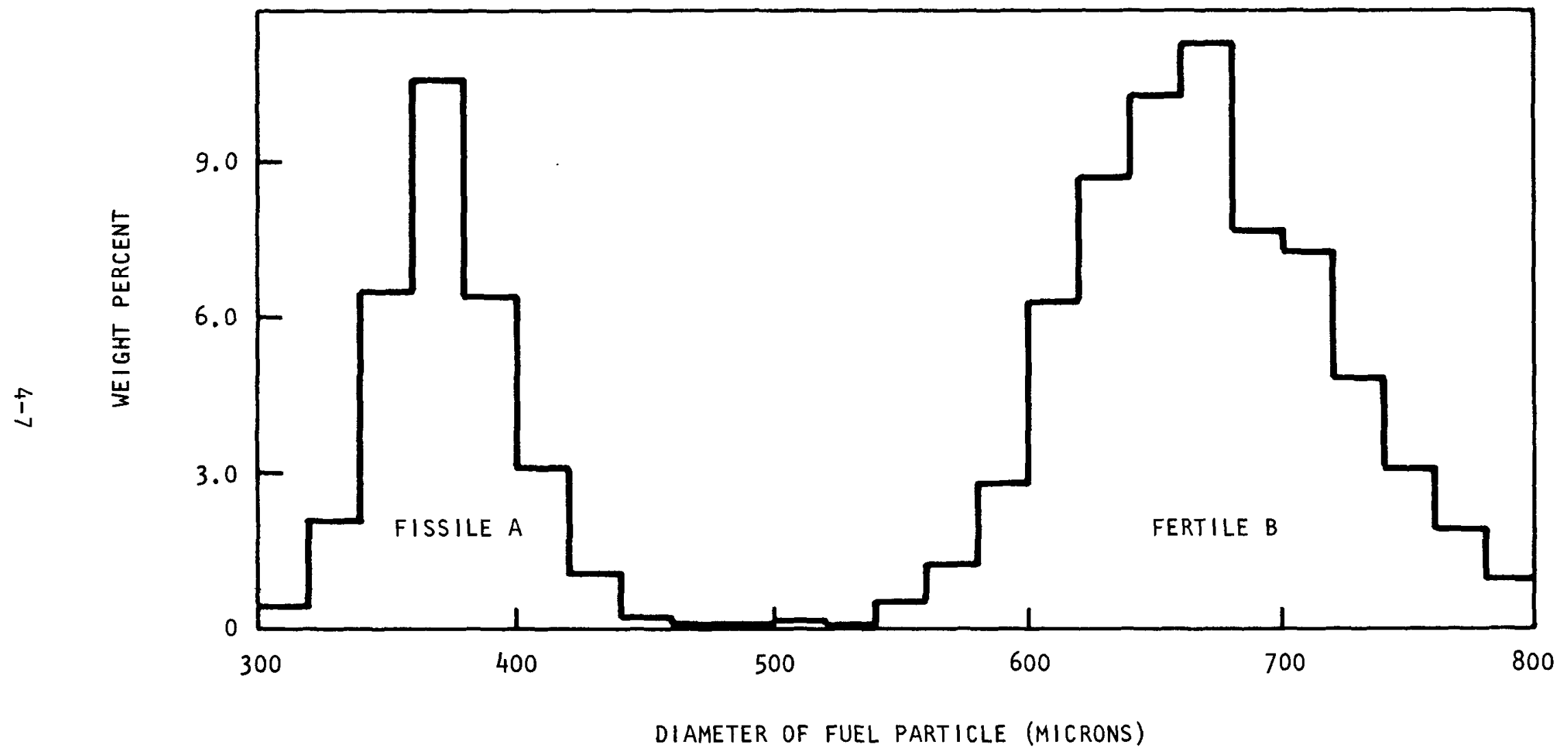

Fig. 4-5. Particle size distribution of FSV fuel particles, Fissile A - Fertile B 


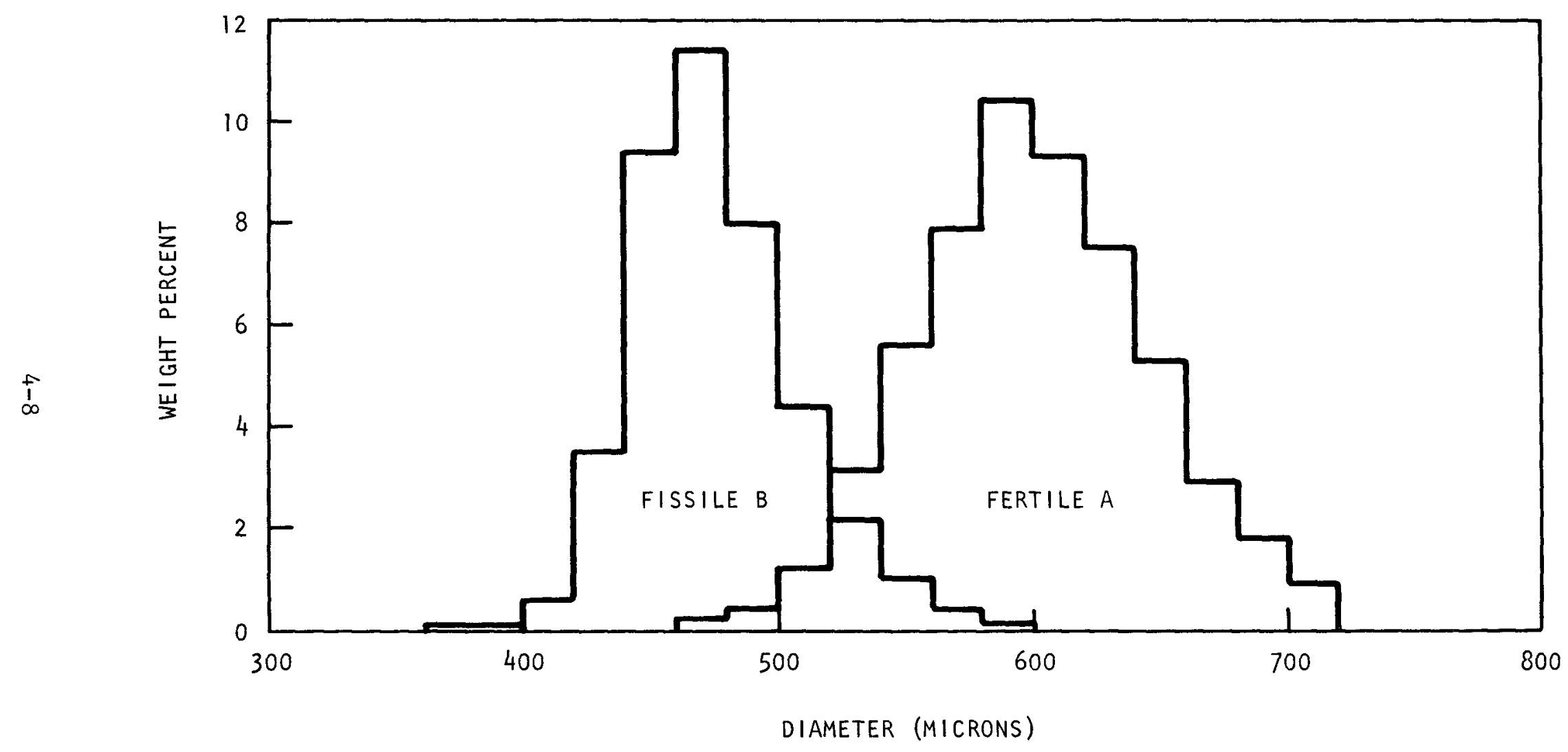

Fig. 4-6. Particle size distribution of FSV fuel particles, Fissile B - Fertile A 
50 to $1000 \mathrm{gm} / \mathrm{min}$ holding the air velocity constant at $3.15 \mathrm{~m} / \mathrm{sec}$. These tests were repeated for air velocities of $3.70,4.25$, and $4.80 \mathrm{~m} / \mathrm{sec}$. By analyzing the size distributions of the fine and coarse products and their weight ratios, the efficiency of separation, $\phi$, was calculated for each $20 \mu$ increment from 300 to $900 \mu$ in the distribution. Tables 4-1 through 44 give the $\phi$ ratio versus particle size and solids feed rate at $3.15,3.70$, 4.25 , and $4.80 \mathrm{~m} / \mathrm{sec}$. These were plotted as $\phi$ versus feed rate with constant diameter lines (Figs. 4-7 through 4-10). Each graph representing a particular air velocity shows that separability depends upon feed rate. In fact, as feed rate increases, the $50 \%$ cut point shifts downward and the sharpness of separation falls (the constant diameter lines come closer together). On obtaining the smooth curves represented in these figures, it was decided to curve fit least squares curves to the data. For this, $\phi$ was found to be a function of the feed rate of the form

$$
\phi=\frac{\text { FEED RATE }}{A+B \cdot \text { FEED RATE }}
$$

where $A$ and $B$ are constants that depend upon particle diameter and air velocity. Table 4-5 gives the values for the constants $A$ and $B$ as $a$ function of diameter and air velocity.

The next step was to find the relationship between separation efficiency and air velocity. To achieve this, efficiency was plotted against air velocity with constant diameter lines for a constant feed rate. (See Figs. 4-11 through 4-13.) Examining these graphs begins to reveal the relationship between efficiency and air velocity: as the gas flow rate increases, the $50 \%$ cut point increases. Further, the spread between the constant diameter lines reaches a maximum at $\phi=50 \%$.

Several unsuccessful attempts were made to curve fit these data. Alternatives to this method would be (1) to find the relationship of $A$ and 
TABLE 4-1

SEPARATION EFFICIENCY VERSUS FEED RATE AND DIAMETER AT CONSTANT AIR VELOCITY RATE OF $3.15 \mathrm{M} / \mathrm{SEC}$

\begin{tabular}{l|l|l|l|l|l|l|l|l}
\hline \multirow{2}{*}{$\begin{array}{l}\text { Diameter } \\
\text { Microns) }\end{array}$} & \multicolumn{1}{|c|}{ Feed Rate } \\
\cline { 2 - 9 } 300 & 0.20 & 0 & 0.14 & 0 & 0.63 & 0.04 & 0.14 & 0.12 \\
320 & 0.10 & 0.09 & 0.19 & 0.16 & 0.48 & 0.45 & 0.41 & 0.49 \\
340 & 0.17 & 0.31 & 0.32 & 0.33 & 0.62 & 0.68 & 0.54 & 0.73 \\
360 & 0.27 & 0.47 & 0.43 & 0.44 & 0.70 & 0.75 & 0.67 & 0.77 \\
380 & 0.23 & 0.38 & 0.34 & 0.30 & 0.60 & 0.68 & 0.65 & 0.74 \\
400 & 0.17 & 0.33 & 0.22 & 0.25 & 0.52 & 0.68 & 0.66 & 0.77 \\
420 & 0.22 & 0.45 & 0.38 & 0.36 & 0.60 & 0.71 & 0.69 & 0.81 \\
440 & 0.27 & 0.47 & 0.43 & 0.45 & 0.67 & 0.73 & 0.74 & 0.85 \\
460 & 0.43 & 0.60 & 0.60 & 0.55 & 0.73 & 0.78 & 0.80 & 0.89 \\
480 & 0.83 & 0.93 & 0.89 & 0.90 & 0.92 & 0.97 & 0.97 & 0.98 \\
500 & 0.89 & 0.97 & 0.95 & 0.92 & 0.96 & 0.97 & 0.98 & 0.99 \\
520 & 0.92 & 0.98 & 0.95 & 0.96 & 0.97 & 0.99 & 0.99 & 0.99 \\
540 & 0.95 & 0.99 & 0.97 & 0.98 & 0.98 & 0.99 & 0.99 & 1.00 \\
560 & 0.96 & 1.00 & 0.98 & 1.00 & 0.99 & 1.00 & 1.00 & 1.00 \\
580 & 0.98 & 1.00 & 1.00 & 1.00 & 1.00 & 1.00 & 1.00 & 1.00 \\
600 & 1.00 & 1.00 & 1.00 & 1.00 & 1.00 & 1.00 & 1.00 & 1.00 \\
\hline
\end{tabular}


TABLE 4-2

SEPARATION EFFICIENCY VERSUS FEED RATE AND DIAMETER AT CONSTANT AIR VELOCITY RATE OF $3.70 \mathrm{M} / \mathrm{SEC}$

\begin{tabular}{l|l|l|l|l|l|l|l|l|l|l}
\hline $\begin{array}{l}\text { Diameter } \\
\text { (Microns) }\end{array}$ & \multicolumn{1}{|c|}{63} & 75.3 & 91.9 & 129.3 & 136 & 168.1 & 178.2 & 239 & 321.5 & 369 \\
\hline 300 & & & & & & & & 0.03 & 0.04 & 0.16 \\
320 & & & & & & 0.01 & & 0.01 & 0.09 & 0.12 \\
340 & & & & & & 0.04 & & 0.05 & 0.18 & 0.27 \\
360 & & & & & & & & & & \\
380 & & & & & & 0.07 & & 0.10 & 0.32 & 0.35 \\
400 & & & 0.03 & & & 0.02 & 0.05 & 0.04 & 0.09 & 0.20 \\
420 & & & 0.01 & & & 0.04 & 0.03 & 0.08 & 0.18 & 0.27 \\
440 & & 0.01 & 0.01 & & 0.02 & 0.06 & 0.04 & 0.08 & 0.27 & 0.35 \\
460 & 0.15 & 0.11 & 0.13 & 0.11 & 0.14 & 0.23 & 0.23 & 0.34 & 0.42 & 0.53 \\
480 & 0.36 & 0.44 & 0.55 & 0.36 & 0.50 & 0.71 & 0.70 & 0.80 & 0.80 & 0.88 \\
500 & 0.47 & 0.52 & 0.64 & 0.49 & 0.55 & 0.79 & 0.80 & 0.84 & 0.90 & 0.89 \\
520 & 0.64 & 0.69 & 0.75 & 0.63 & 0.68 & 0.89 & 0.87 & 0.91 & 0.92 & 0.94 \\
540 & 0.78 & 0.78 & 0.83 & 0.77 & 0.82 & 0.93 & 0.92 & 0.94 & 0.96 & 0.95 \\
560 & 0.76 & 0.86 & 0.91 & 0.83 & 0.88 & 0.96 & 0.95 & 0.97 & 0.96 & 0.97 \\
580 & 0.84 & 0.89 & 0.94 & 0.90 & 0.90 & 1.00 & 0.98 & 0.98 & 0.98 & 0.98 \\
600 & 0.90 & 0.89 & 0.97 & 0.90 & 0.95 & 1.00 & 0.99 & 1.00 & 0.99 & 1.00 \\
620 & 0.95 & 0.94 & 1.00 & 0.95 & 1.00 & 1.00 & 1.00 & 1.00 & 1.00 & 1.00 \\
640 & 1.00 & 0.97 & 1.00 & 1.00 & 1.00 & 1.00 & 1.00 & 1.00 & 1.00 & 1.00 \\
660 & 1.00 & 1.00 & 1.00 & 1.00 & 1.00 & 1.00 & 1.00 & 1.00 & 1.00 & 1.00 \\
\hline
\end{tabular}


TABLE 4-3

SEPARATION EFFICIENCY VERSUS FEED RATE AND DIAMETER AT CONSTANT AIR VELOCITY RATE OF $4.25 \mathrm{M} / \mathrm{SEC}$

\begin{tabular}{|c|c|c|c|c|c|c|c|c|}
\hline \multirow{2}{*}{$\begin{array}{l}\text { Diameter } \\
\text { (Microns) }\end{array}$} & \multicolumn{8}{|c|}{ Feed Rate } \\
\hline & 81.1 & 104.8 & 199.7 & 292.7 & 381.6 & 448.2 & 514.6 & 708.2 \\
\hline 300 & & & & & & & & \\
\hline 320 & & & & & & & & \\
\hline 340 & & & & & & & 0.01 & 0.01 \\
\hline 360 & & & & & & 0.01 & 0.02 & 0.02 \\
\hline 380 & & & & & & 0.01 & 0.01 & 0.02 \\
\hline 400 & & & & & & 0 & 0 & 0.01 \\
\hline 420 & & & & & & 0 & 0 & 0.02 \\
\hline 440 & & 0.01 & & 0.01 & 0.01 & 0.01 & 0.01 & 0.01 \\
\hline 460 & 0.01 & 0.02 & 0.08 & 0.05 & 0.07 & 0.15 & 0.10 & 0.10 \\
\hline 480 & 0.02 & 0.04 & 0.30 & 0.25 & 0.34 & 0.43 & 0.45 & 0.44 \\
\hline 500 & 0.07 & 0.11 & 0.42 & 0.34 & 0.47 & 0.59 & 0.51 & 0.51 \\
\hline 520 & 0.16 & 0.20 & 0.63 & 0.45 & 0.57 & 0.70 & 0.63 & 0.67 \\
\hline 540 & 0.28 & 0.38 & 0.75 & 0.61 & 0.72 & 0.81 & 0.71 & 0.78 \\
\hline 560 & 0.47 & 0.53 & 0.87 & 0.73 & 0.78 & 0.84 & 0.83 & 0.84 \\
\hline 580 & 0.58 & 0.68 & 0.92 & 0.81 & 0.86 & 0.92 & 0.87 & 0.89 \\
\hline 600 & 0.68 & 0.75 & 0.93 & 0.87 & 0.93 & 0.94 & 0.88 & 0.91 \\
\hline 620 & 0.74 & 0.77 & 0.97 & 0.92 & 0.97 & 0.97 & 0.90 & 0.95 \\
\hline 640 & 0.80 & 0.89 & 1.00 & 0.96 & 1.00 & 1.00 & 0.95 & 1.00 \\
\hline 660 & 0.87 & 0.95 & 1.00 & 1.00 & 1.00 & 1.00 & 1.00 & 1.00 \\
\hline 680 & 0.95 & 1.00 & 1.00 & 1.00 & 1.00 & 1.00 & 1.00 & 1.00 \\
\hline 700 & 1.00 & 1.00 & 1.00 & 1.00 & 1.00 & 1.00 & 1.00 & 1.00 \\
\hline
\end{tabular}


TABLE $4-4$

SEPARATION EFFICIENCY VERSUS FEED RATE AND DIAMETER AT CONSTANT

AIR VELOCITY RATE OF $4.80 \mathrm{M} / \mathrm{SEC}$

\begin{tabular}{|c|c|c|c|c|c|c|c|}
\hline \multirow{2}{*}{$\begin{array}{l}\text { Diameter } \\
\text { (Microns) }\end{array}$} & \multicolumn{7}{|c|}{ Feed Rate } \\
\hline & 38.9 & 116.1 & 288.0 & 334.4 & 512.7 & 782.8 & 1002.2 \\
\hline 300 & & & & & & & \\
\hline 320 & & & & & & & 0.03 \\
\hline 340 & & & & & & 0.01 & 0.09 \\
\hline 360 & & & & & & 0.02 & 0.14 \\
\hline 380 & & & & & & 0.02 & 0.11 \\
\hline 400 & & & & & & 0.01 & 0.06 \\
\hline 420 & & & & & & 0.01 & 0.08 \\
\hline 440 & & & & & & 0.02 & 0.09 \\
\hline 460 & & & & 0.01 & 0.02 & 0.11 & 0.20 \\
\hline 480 & & & 0.01 & 0.02 & 0.08 & 0.34 & 0.45 \\
\hline 500 & & & 0.02 & 0.05 & 0.16 & 0.43 & 0.55 \\
\hline 520 & & 0.01 & 0.06 & 0.15 & 0.29 & 0.55 & 0.60 \\
\hline 540 & & 0.02 & 0.12 & 0.26 & 0.46 & 0.65 & 0.70 \\
\hline 560 & 0.01 & 0.08 & 0.25 & 0.39 & 0.60 & 0.74 & 0.80 \\
\hline 580 & 0.02 & 0.18 & 0.38 & 0.50 & 0.69 & 0.83 & 0.83 \\
\hline 600 & 0.04 & 0.29 & 0.48 & 0.62 & 0.77 & 0.83 & 0.85 \\
\hline 620 & 0.08 & 0.44 & 0.68 & 0.75 & 0.85 & 0.88 & 0.93 \\
\hline 640 & 0.15 & 0.61 & 0.79 & 0.78 & 0.89 & 0.94 & 0.97 \\
\hline 660 & 0.32 & 0.65 & 0.82 & 0.83 & 0.94 & 0.97 & 1.00 \\
\hline 680 & 0.36 & 0.80 & 0.90 & 0.92 & 0.97 & 1.00 & 1.00 \\
\hline 700 & 0.65 & 0.88 & 0.95 & 0.96 & 1.00 & 1.00 & 1.00 \\
\hline 720 & 0.80 & 0.93 & 1.00 & 1.00 & 1.00 & 1.00 & 1.00 \\
\hline 740 & 0.89 & 0.97 & 1.00 & 1.00 & 1.00 & 1.00 & 1.00 \\
\hline 760 & & 1.00 & 1.00 & 1.00 & 1.00 & 1.00 & 1.00 \\
\hline
\end{tabular}




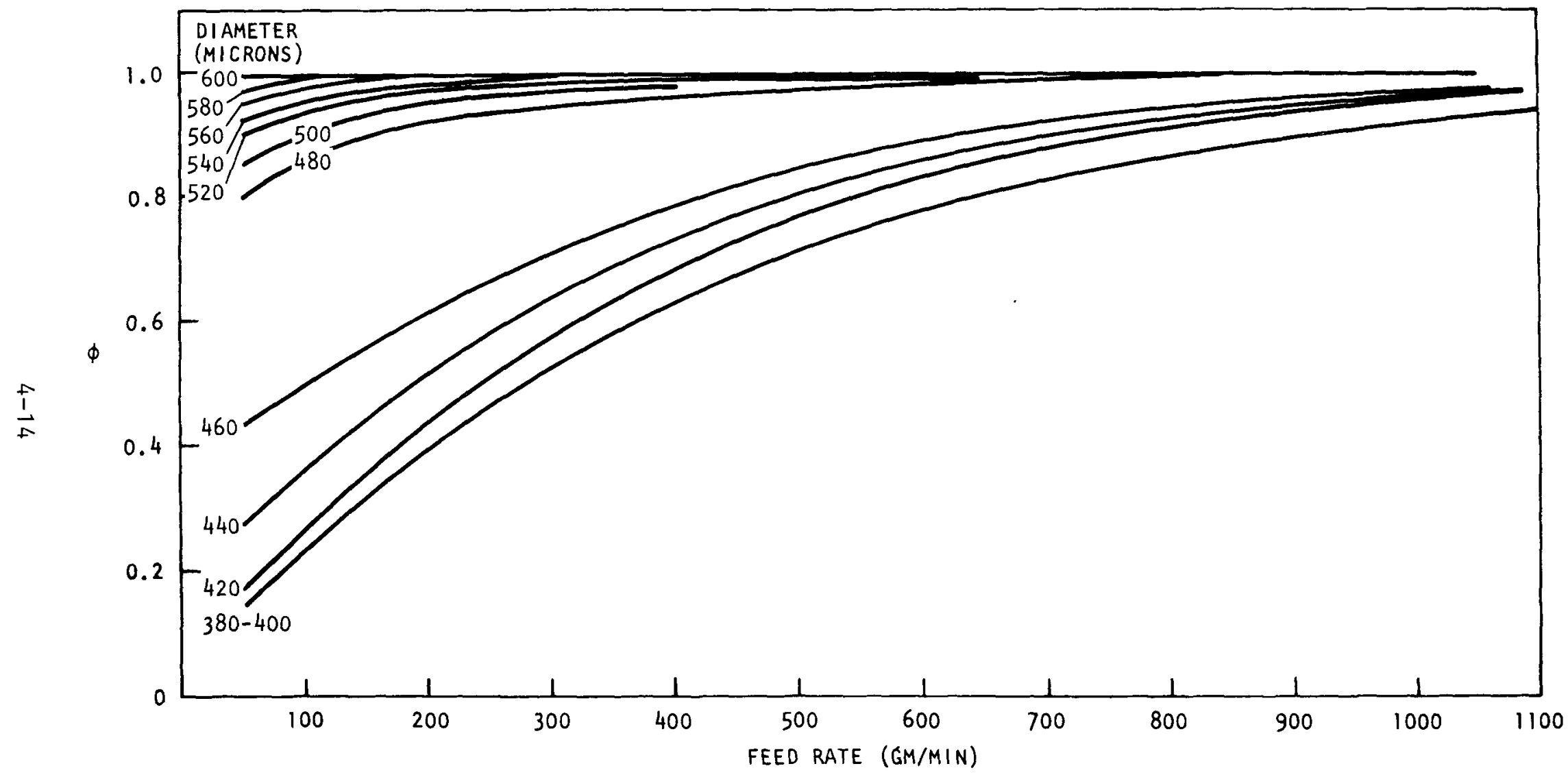

Fig. 4-7. Separation efficiency versus feed rate and diameter at constant air velocity of $3.15 \mathrm{~m} / \mathrm{sec}$ 


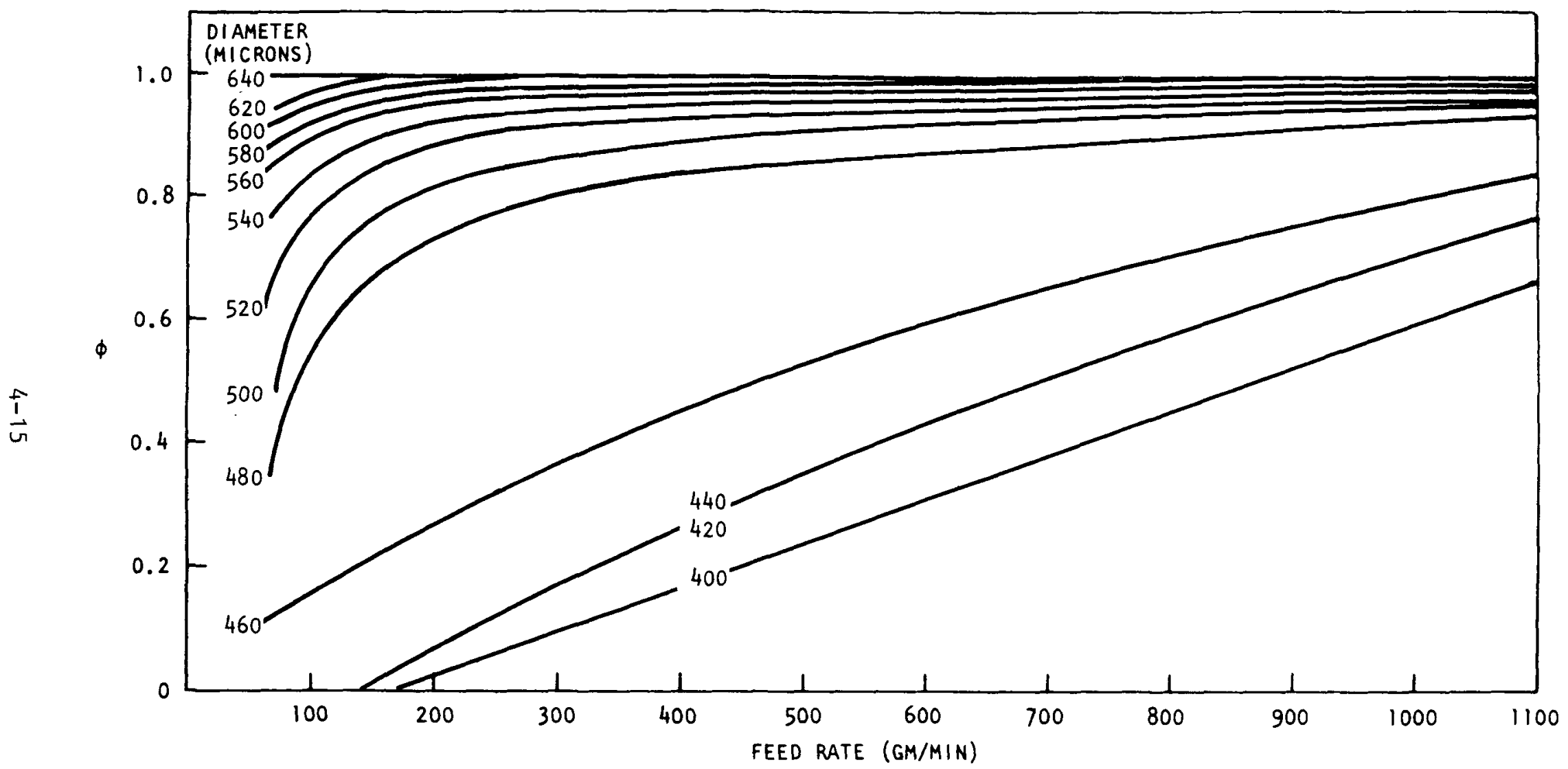

Fig. 4-8. Separation efficiency versus feed rate and diameter at constant air velocity of $3.70 \mathrm{~m} / \mathrm{sec}$ 


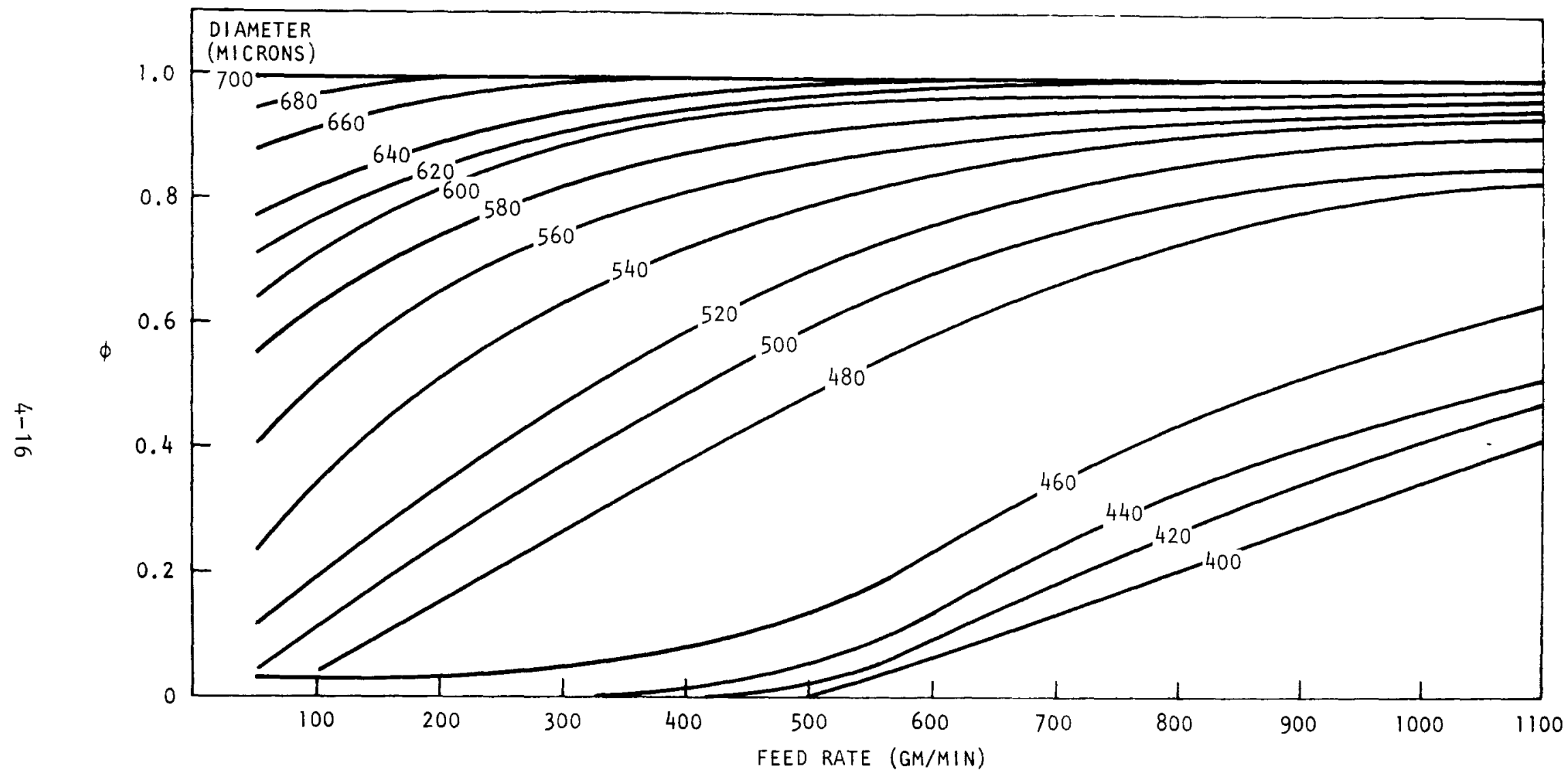

Fig. 4-9. Separation efficiency versus feed rate and diameter at constant air velocity of $4.25 \mathrm{~m} / \mathrm{sec}$ 


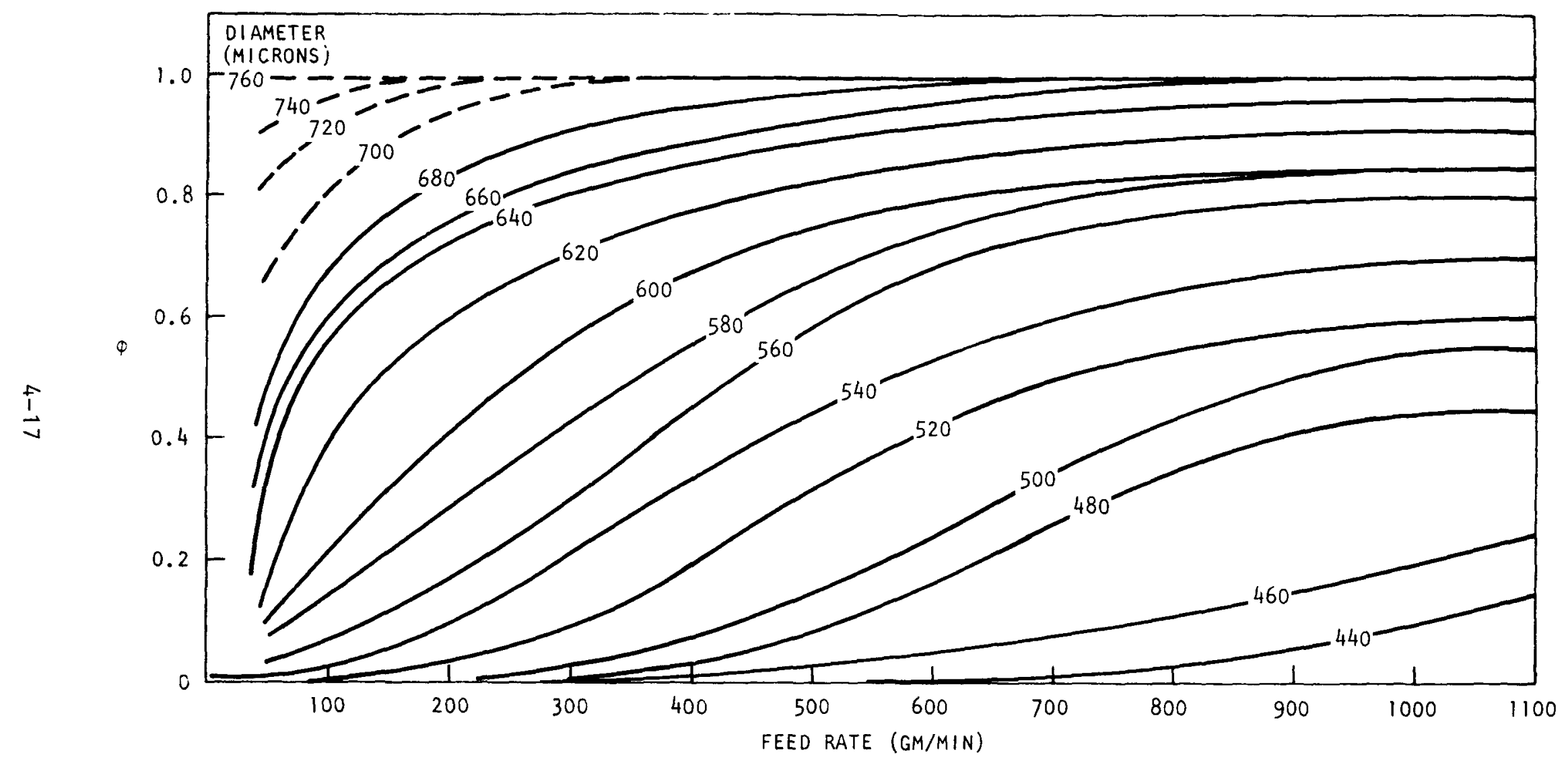

Fig. 4-10. Separation efficiency versus feed rate and diameter at constant air velocity of $4.80 \mathrm{~m} / \mathrm{sec}$ 
TABLE 4-5

CONSTANTS A AND B OF EOUATION $\phi=$ FEEDRATE $/ \mathrm{A}+\mathrm{B} \cdot$ FEEDRATE VERSUS AIR VELOCITY AND DIAMETER

\begin{tabular}{|c|c|c|c|c|c|c|c|c|}
\hline \multirow[b]{3}{*}{$\begin{array}{c}\text { Air velocity, } \\
\mathrm{m} / \mathrm{sec}\end{array}$} & \multicolumn{8}{|c|}{ Constant } \\
\hline & \multicolumn{4}{|c|}{ A } & \multicolumn{4}{|c|}{$B$} \\
\hline & 3.15 & 3.70 & 4.25 & 4.80 & 3.5 & 3.70 & 4.25 & 4.80 \\
\hline 400 & 340.3 & 7,511 & 131,140 & 297,980 & 0.827 & $-9 \cdot 34$ & -120.0 & -280.7 \\
\hline 420 & 226.0 & 9,701 & 64,800 & 312,880 & 0.904 & -18.8 & -58.3 & -299.7 \\
\hline 440 & 178.8 & 9,105 & 6,534 & 139,060 & 0.920 & -18.7 & -56.6 & -127.6 \\
\hline 460 & 88.6 & 493.9 & 7,479 & 49,715 & 1.024 & 1.054 & -7.64 & -48.7 \\
\hline 480 & 12.50 & 103.0 & 3,891 & 36,811 & 1.010 & 0.920 & -6.34 & -45.2 \\
\hline 500 & 6.57 & 70.5 & 1,080 & 17,139 & 1.010 & 0.925 & -0.501 & -20.6 \\
\hline 520 & 4.83 & 35.0 & 444.3 & 13,429 & 1.004 & 0.974 & 0.555 & -21.5 \\
\hline 540 & 2.66 & 18.9 & 200.1 & - & 1.004 & 0.996 & 0.855 & -- \\
\hline 560 & 1.91 & 16.1 & 89.4 & 4,044 & 0.999 & 0.981 & 0.989 & -8.38 \\
\hline 580 & -- & 10.56 & 53.5 & 1,991 & - & 0.982 & 0.995 & -3.66 \\
\hline 600 & 0 & 7.90 & 35.4 & 971.0 & 1 & 0.980 & 1.002 & -1.13 \\
\hline 620 & 0 & 3.74 & 29.5 & 465.1 & 1 & 0.988 & 0.981 & 0.445 \\
\hline 640 & 0 & 0.86 & 19.35 & 227.9 & 1 & 0.998 & 0.968 & 0.545 \\
\hline 660 & 0 & 0 & 11.32 & 85.3 & 1 & 1 & 0.974 & 0.906 \\
\hline 680 & 0 & 0 & 3.92 & 72.0 & 1 & 1 & 1 & 0.969 \\
\hline 700 & 0 & 0 & 0 & 21.94 & 1 & 1 & 1 & 0.969 \\
\hline 720 & 0 & 0 & 0 & 10.53 & 1 & 1 & 1 & 0.979 \\
\hline 740 & 0 & 0 & 0 & 5.18 & 1 & 1 & 1 & 0.989 \\
\hline
\end{tabular}




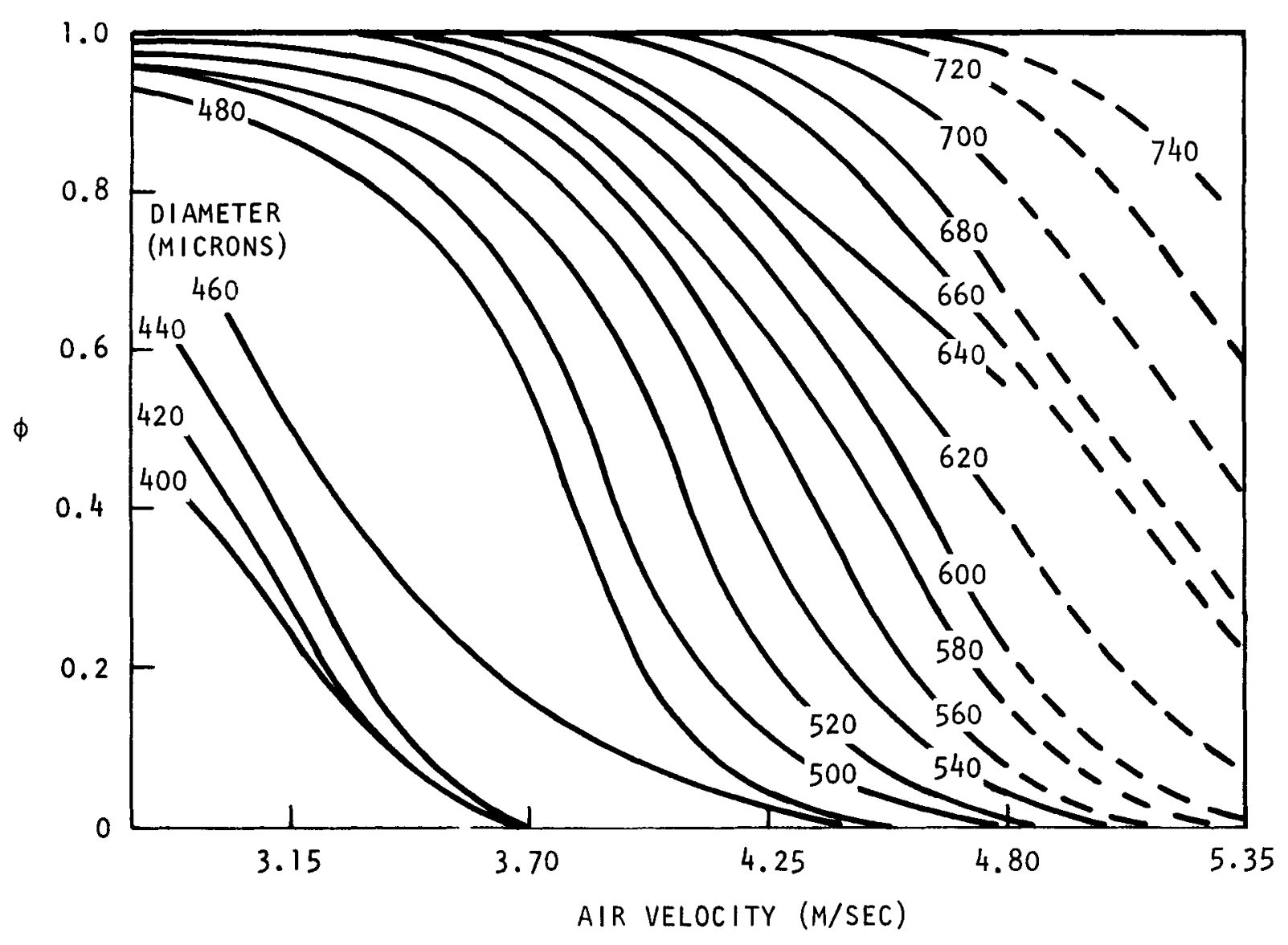

Fig. 4-11. Separation efficiency versus air velocity and diameter at constant feed rate of $100 \mathrm{~g} / \mathrm{min}$ 


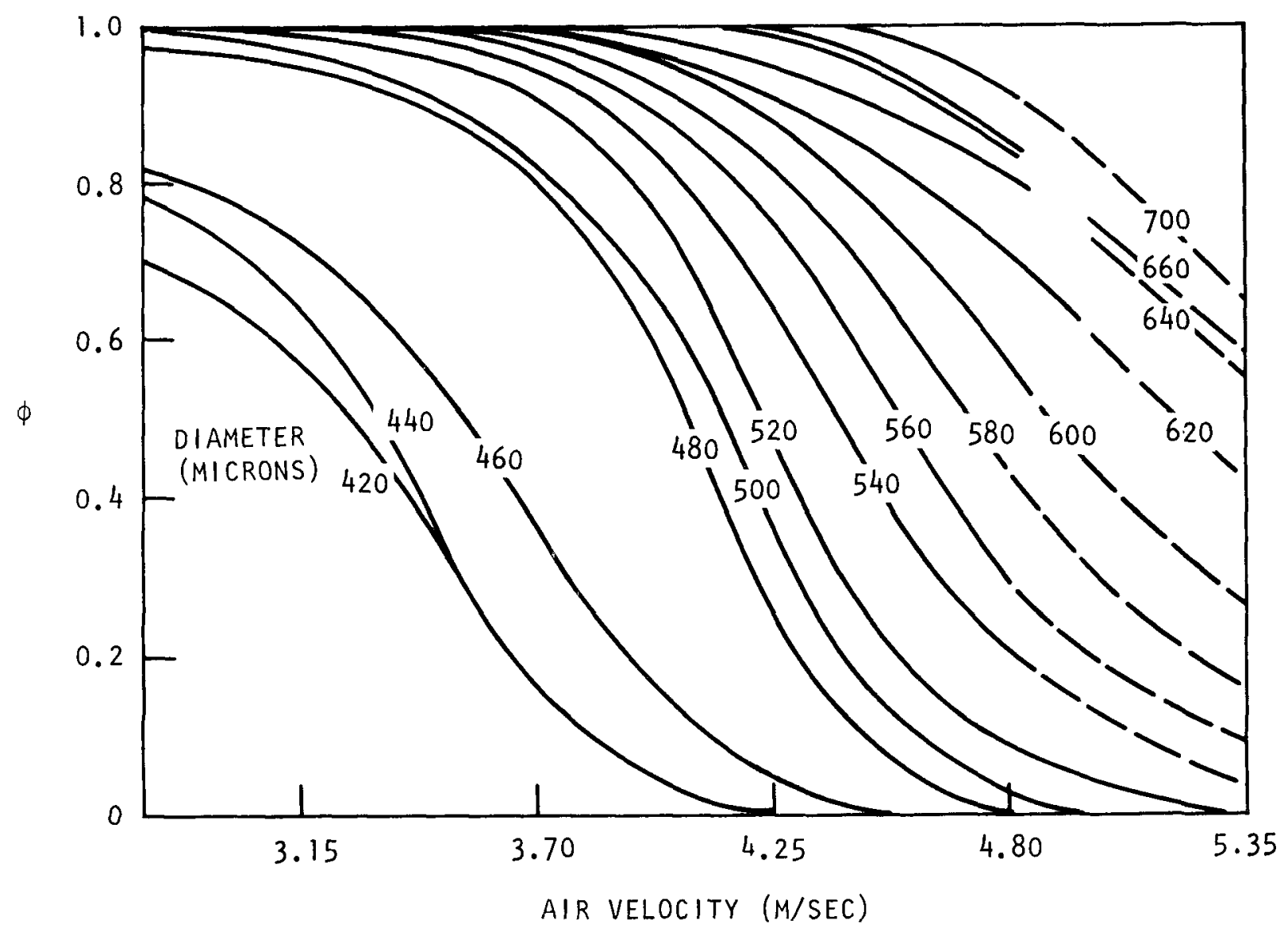

Fig. 4-12. Separation efficiency versus air velocity and diameter at constant feed rate of $300 \mathrm{~g} / \mathrm{min}$ 


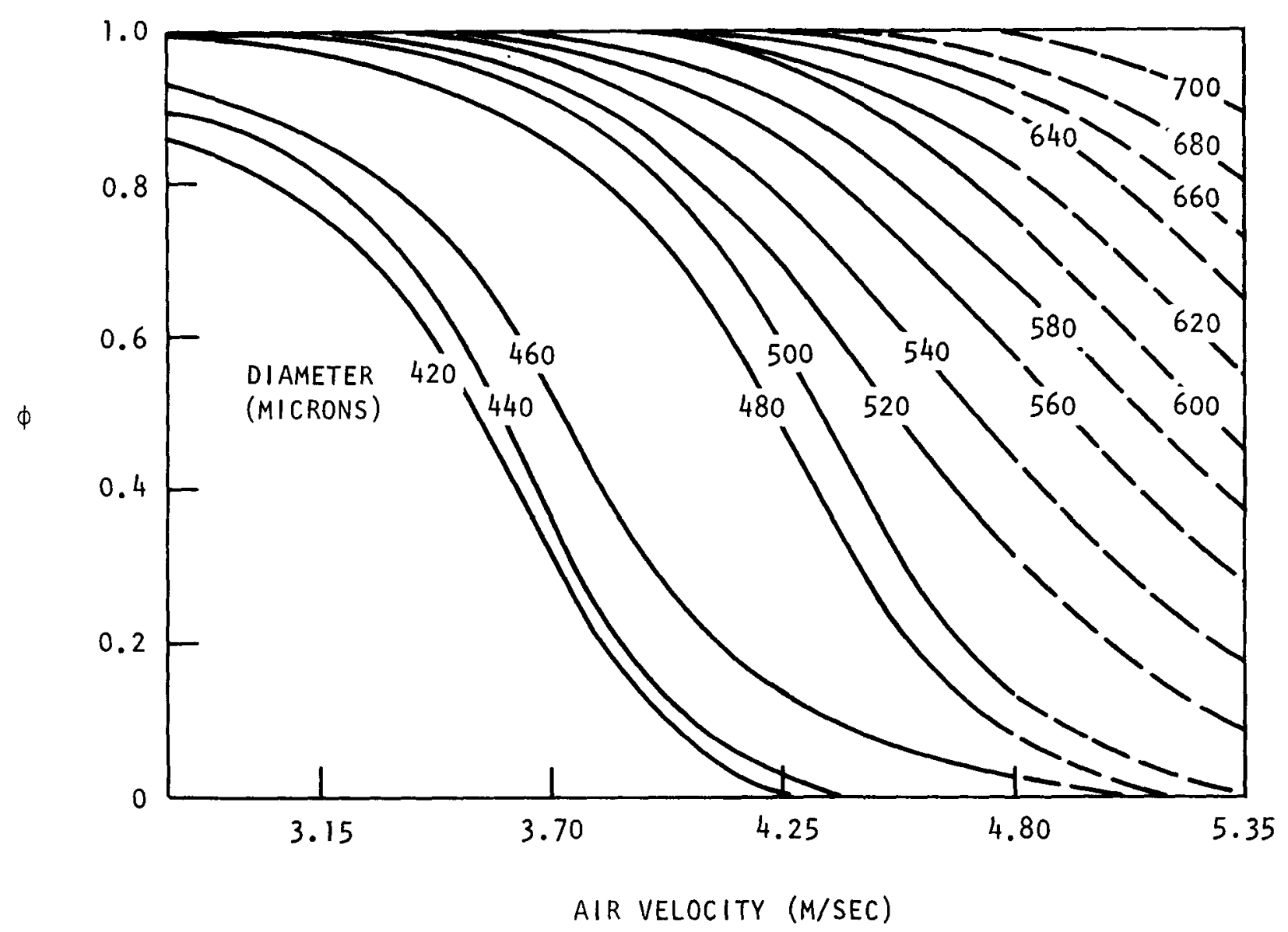

Fig. 4-13. Separation efficiency versus air velocity and diameter at constant feed rate of $500 \mathrm{~g} / \mathrm{min}$ 
$B$ with respect to a change in air velocity; (2) to find the relationship of $A$ and $B$ to diameter and then relate the change in air velocity as a shift of diameter; or (3) to keep the raw data in tabular form and use an interpolation method to obtain the correct value. The advantages of the first two alternatives are that they establish a direct relationship between the variables which could then be related to theory. The disadvantage would be the loss of accuracy when the data are curve fitted. The last alternative would be the most accurate method but would not give any relationship between the variables. Therefore, the approach taken was to relate the constants $A$ and $B$ to diameter and incorporate air velocity as a shift in diameter, resulting in the following equations:

$$
\begin{aligned}
& K=\frac{\text { Feed }}{A+B \cdot \text { Feed }} \\
& D=(26-\text { Air }) \frac{205}{9}+d \\
& A=\exp (28.52-0.03271 D) \\
& B=18-\frac{4225}{D-408} \quad \text { For } \begin{array}{l}
D<410 ; B \quad[=]-300 \\
D>656.5 ; B[=] 1
\end{array}
\end{aligned}
$$

\subsubsection{Separation of SiC Hulls from Fertile Kernels}

Another particulate system investigated using the Alpine classifier was the feed to the leachers. Reduction of the amount of insols (SiC hulls) going to the leacher simplifies the subsequent solid-liquid separation. Keeping in mind the principles of pneumatic classification, i.e., separation via differences in the hydraulic properties of either density or diameter or a combination of the two, the density and size distribution of the $\mathrm{SiC}$ hulls and the $\mathrm{ThO}_{2}$ powder leaving the secondary burner were examined. While the particle density of the SiC hulls was onethird of that for the $\mathrm{ThO}_{2}$ powder, the particle size distributions overlapped to such an extent that the two particle systems could not be separated. 
The following experiment was run to determine whether the degree of separation might be adequate if the hulls were separated from the kernels as they left the crusher. First, fertile particles were weighed and then crushed in a double roll particle crusher. The crusher product was immediately classified and the two products were weighed. Samples were taken from the feed and from the fine and coarse products, burned, and then analyzed for weight percent thorium. Table 4-6 gives the results of the analysis and data reduction for two air velocities. At $0.75 \mathrm{~m} / \mathrm{sec}$ air velocity, the separation resulted in the loss of less than $1 / 2 \%$ thorium to the fine stream containing the hulls and carbon, whereas in the thorium rich coarse stream, the product was stripped of $84 \mathrm{wt} \%$ of the SiC hulls and $89 \mathrm{wt} \%$ of the carbon coatings. This is a 6 to 1 and a 9 to 1 reduction in the SiC and carbon, respectively.

The product of the secondary burner continues to the dissolver/ centrifuge, where the heavy metals and fission products are leached away from the SiC hulls and the hulls separated from the mother liquor in the centrifuge. This separation would allow the capacity of the centrifuge to be reduced by a factor of six and would give the option of handling $89 \%$ of the carbon coatings and the entrapped fission products as a solid waste.

An additional run to see if the SiC hulls could be separated from crushed kernels was attempted but was unsuccessful because the kernels could not be crushed in any of the available equipment. It is possible that the separation of hulls from crushed kernels may not be adequate due to the larger overlap of the size distributions.

\subsubsection{Additional Findings}

\subsubsection{Density}

To reduce the number percent size distribution data to weight percent, the relationship of density to size must be known. To determine this relationship, simulated feed was selectively cut at four diameters and analyzed for size distribution and then for density by air pycnometer. 
TABLE 4-6

SEPARATION OF SIC HULLS AND CARBON COATINGS FROM ThC ${ }_{2}$ KERNELS

\begin{tabular}{|c|c|c|c|c|c|c|c|c|c|c|}
\hline \multirow[b]{2}{*}{$\begin{array}{l}\text { Run } \\
\text { IJo. }\end{array}$} & \multirow{2}{*}{$\begin{array}{l}\quad \text { Air } \\
\text { Velocity } \\
\text { (m/sec) }\end{array}$} & \multirow[b]{2}{*}{$\begin{array}{l}\text { Feedrate } \\
(\mathrm{gm} / \mathrm{min})\end{array}$} & \multicolumn{4}{|c|}{ Fine Product } & \multicolumn{4}{|c|}{ Coarse Product } \\
\hline & & & $\begin{array}{c}\mathrm{ThC}_{2} \\
\text { (wt \%) }\end{array}$ & $\begin{array}{c}c \\
(w t \%)\end{array}$ & $\begin{array}{c}\text { SiC } \\
(w t \%)\end{array}$ & $\begin{array}{l}\text { Total } \\
\text { (wt \%) }\end{array}$ & $\begin{array}{l}\mathrm{ThC}_{2} \\
(\mathrm{wt} \% \text { ) }\end{array}$ & $\begin{array}{c}\mathrm{C} \\
(\text { wt } \%)\end{array}$ & $\begin{array}{c}\mathrm{SiC} \\
(\mathrm{wt} \%)\end{array}$ & $\begin{array}{l}\text { Total } \\
\text { (wt \%) }\end{array}$ \\
\hline 1 & 0.75 & 46 & 0.26 & 16.77 & 15.17 & 32.20 & 62.76 & 2.05 & 2.98 & 67.79 \\
\hline 2 & 0.4 & 22 & 0.28 & 15.08 & 11.34 & 26.70 & 48.00 & 12.74 & 12.56 & 73.30 \\
\hline
\end{tabular}


Figure 4-14 illustrates the results of density versus mean size with a least squares straight line through the points. The equation of this line is:

$$
\rho=2.566+0.00246 \mathrm{~d}
$$

$$
\text { where } \begin{aligned}
\rho & =\text { density in } \mathrm{gm} / \mathrm{cm} \\
\mathrm{d} & =\text { particle diameter in microns }
\end{aligned}
$$

The data point at $300 \mu$ was ignored in the least squares calculation. If the density versus diameter relationship were described by two straight lines, one through the first two points and one through the last three, the change in the size analysis reduction would be less than $0.5 \%$. Since the difference is small, this single expression was used in the data reduction. The theoretical relationship between a particle's density and its size will be discussed in Section 7, which deals with the runs using FSV type fuel.

\subsubsection{Peak Height (Moda1 Effect)}

C1ose inspection of Fig. 4-8 shows that constant diameter lines decrease as diameter decreases until $380 \mu$, at which point the next few lines increase and then decrease again. To make this clearer, Fig. 4-15 gives the variation of $\phi$ versus size at constant feed and air velocities. The maximum at approximately $360 \mu$ corresponds to the minor mode whose peak is at $370 \mu$. The influence of additional modes and their relative height was first thought to be a pecullarity of this feed, but, as will be explained in Section 4.4.2, this effect is inherent in pneumatic classification.

\subsubsection{Effect of the Addition of Graphite}

A11 of the runs presented to this point used simulated feed consisting of fuel particles only. To study the effect of graphite on separation, several runs were made with a feed consisting of 5 and 10 wt \% carbon at an air velocity of $3.7 \mathrm{~m} / \mathrm{sec}$. By superimposing the results of the size distribution analysis on Fig. 4-8, the effect of graphite on the separation

$$
\text { 4-25 }
$$




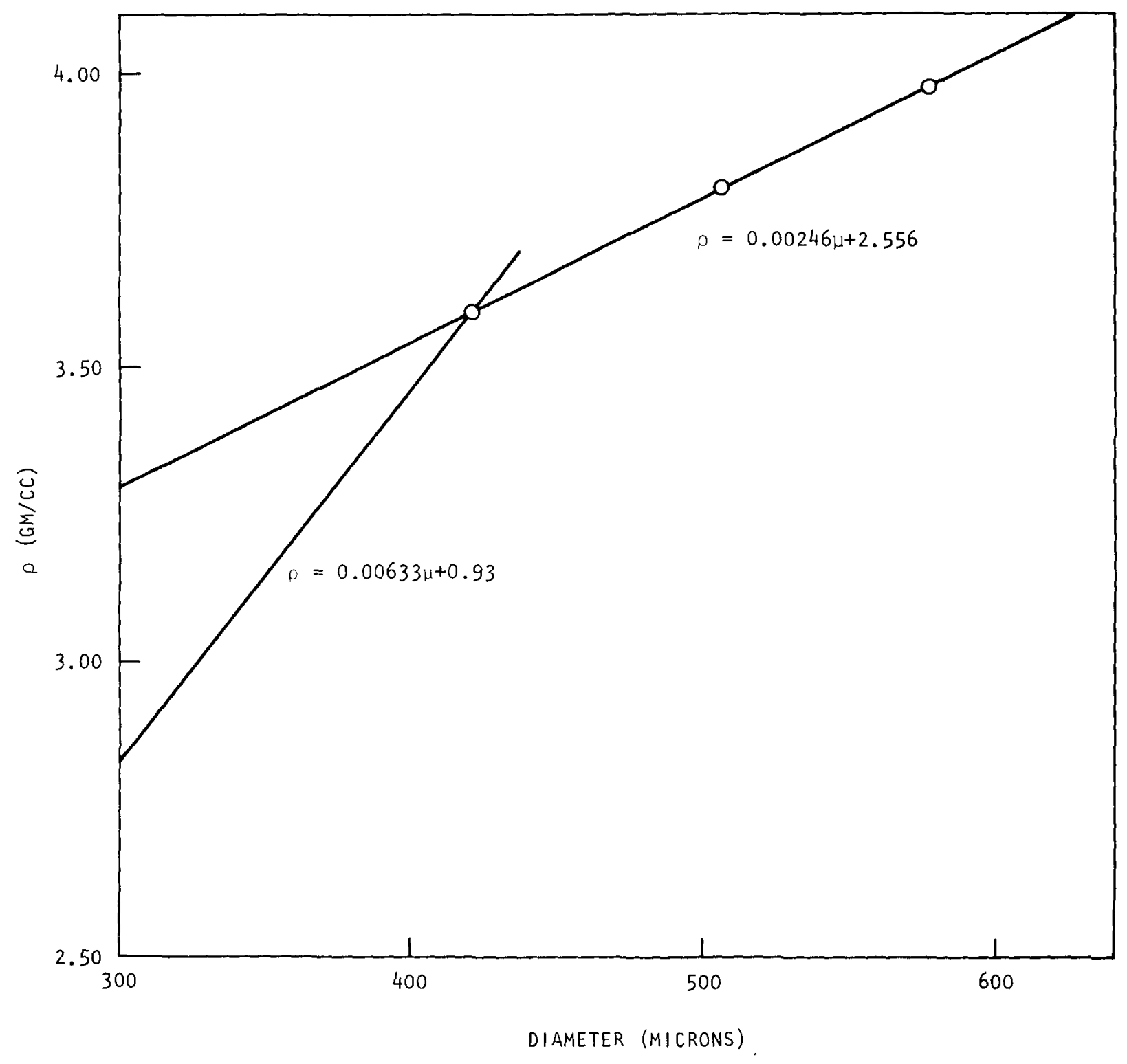

Fig. 4-14. Density versus particle size for simulated feed 


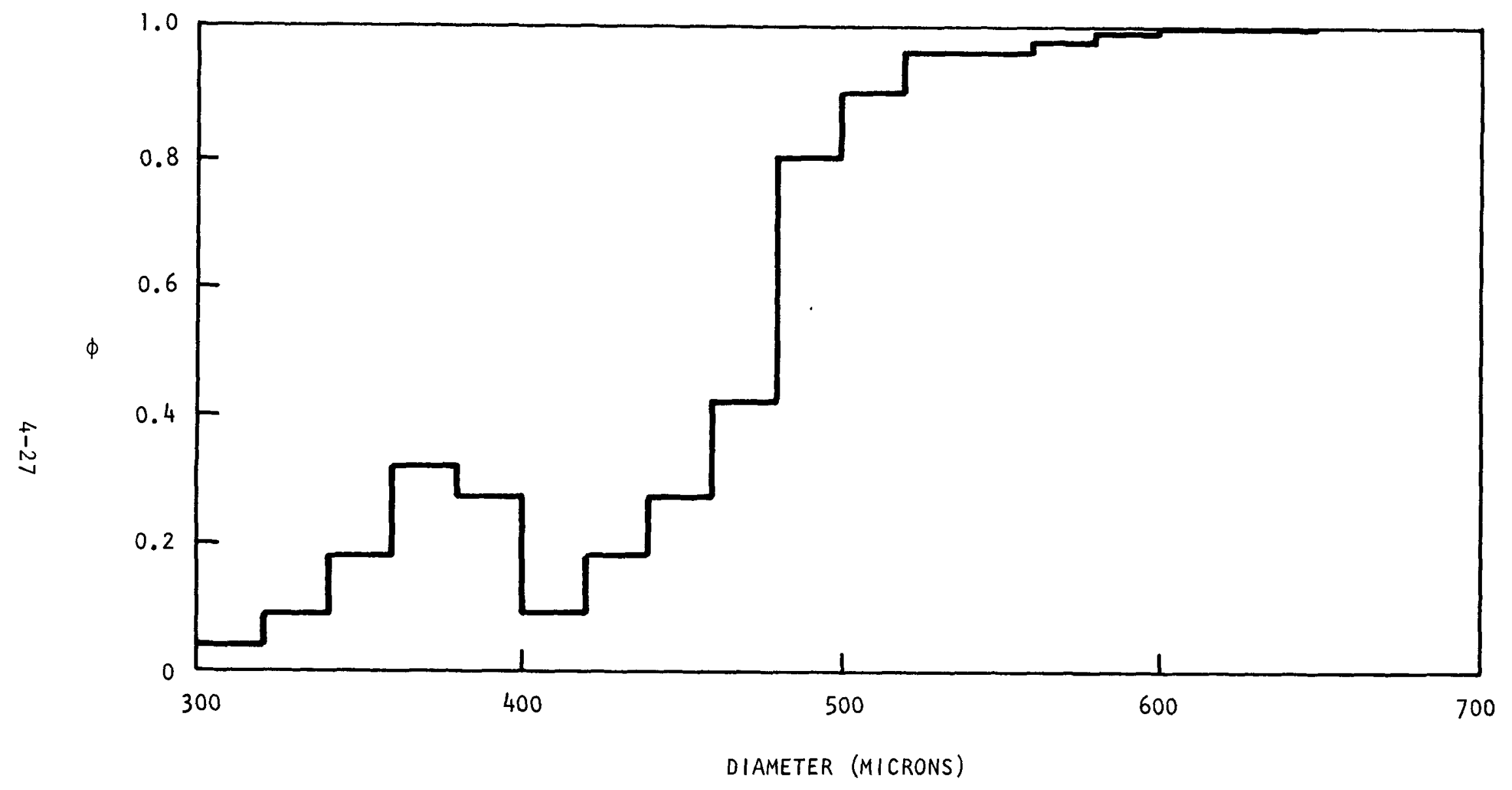

Fig. 4-15. Separation efficiency versus diameter at constant feed rate of $300 \mathrm{~g} / \mathrm{min}$ and air velocity of $3.70 \mathrm{~m} / \mathrm{sec}$ 
can be determined (Figs. 4-16 through 4-19). Table 4-7 summarizes the feed rates for the four runs. The percent increase of the effective feed rate of the second run over its total feed rate was inconsistent with the other three runs and was disregarded. The difference between the third and fourth runs can be explained by the fact that in the third run all graphite particles larger than $1000 \mu$ were removed, whereas in the fourth run, all graphite particles smaller than $1000 \mu$ were removed. Figure 4-20 gives the size distribution of the graphite particles used in those runs. The larger particles appear to have a much greater effect by weight than do the small particles. If these two runs are averaged to represent the effect of the entire graphite distribution, the following relation will describe the effect of graphite on the separation:

$$
\mathrm{Fe}=\mathrm{Fp}+2 \mathrm{Fg}
$$

where $\mathrm{Fe}=$ effective feed rate

$\mathrm{Fp}=$ particle feed rate

$\mathrm{Fg}=$ graphite feed rate

This expression was tested as reported in Section 4.4 .

4.3. INITIAL TESTS WITH FSV FUEL

\subsubsection{Description of FSV Fue1}

FSV fuel consists of four mean particle sizes: Fissile A, Fissile $B$, Fertile A, and Fertile B (Figs. 4-5 and 4-6). The need for four particle sizes rather than two stems from the requirement for proper uranium and thorium loading in the various regions of the reactor. Since pneumatic classification relies on the size of the particles being separated, the two extreme combinations encountered - Fissile A/Fertile B (Fig. 4-5) and Fissile B/Fertile A (Fig. 4-6) - were two rod batches used in these 


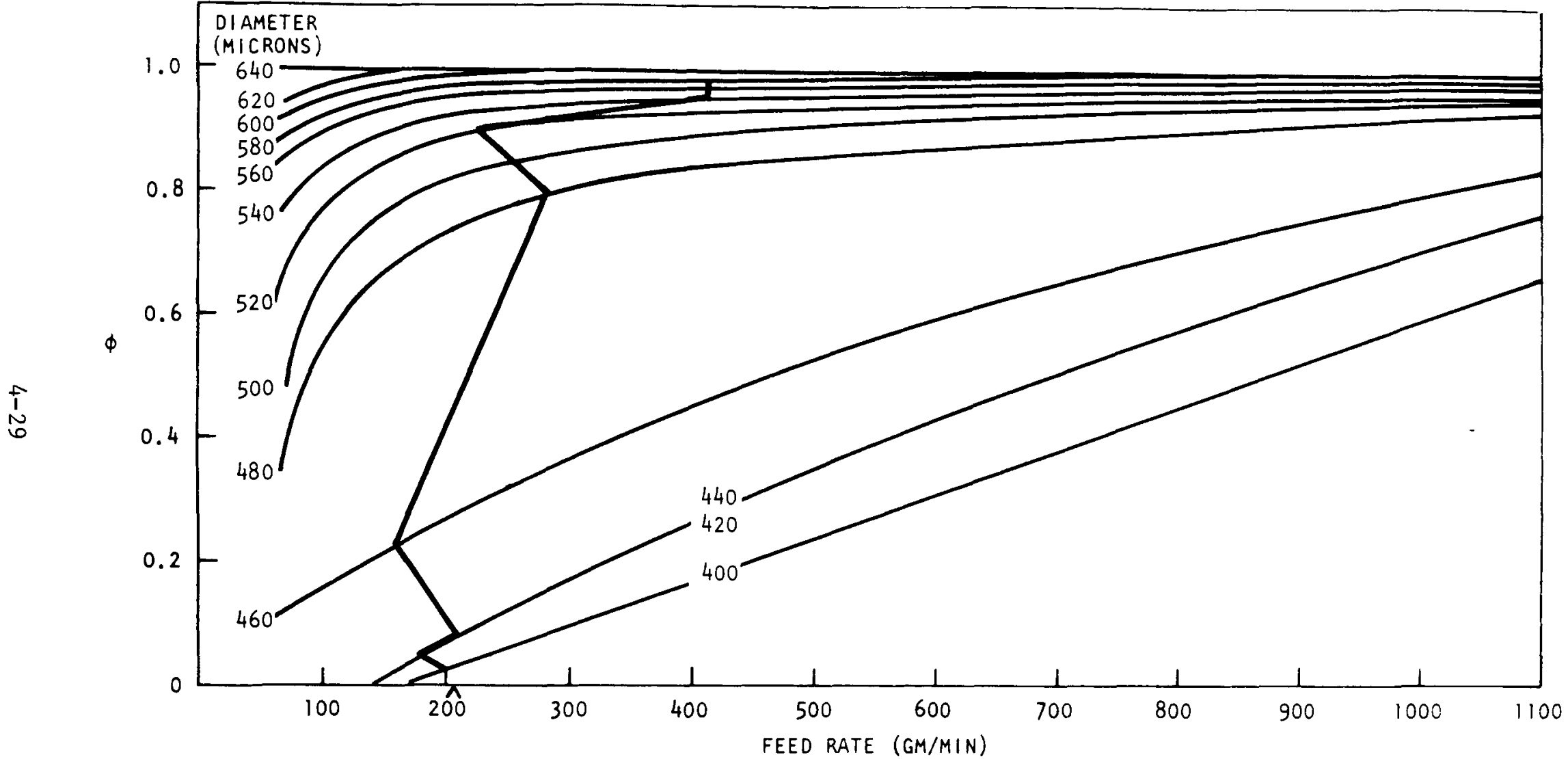

Fig. 4-16. Comparison of separation of simulated feed at $3.70 \mathrm{~m} / \mathrm{sec}$ air velocity with additional 5 wt $\%$ graphite and with no graphite 


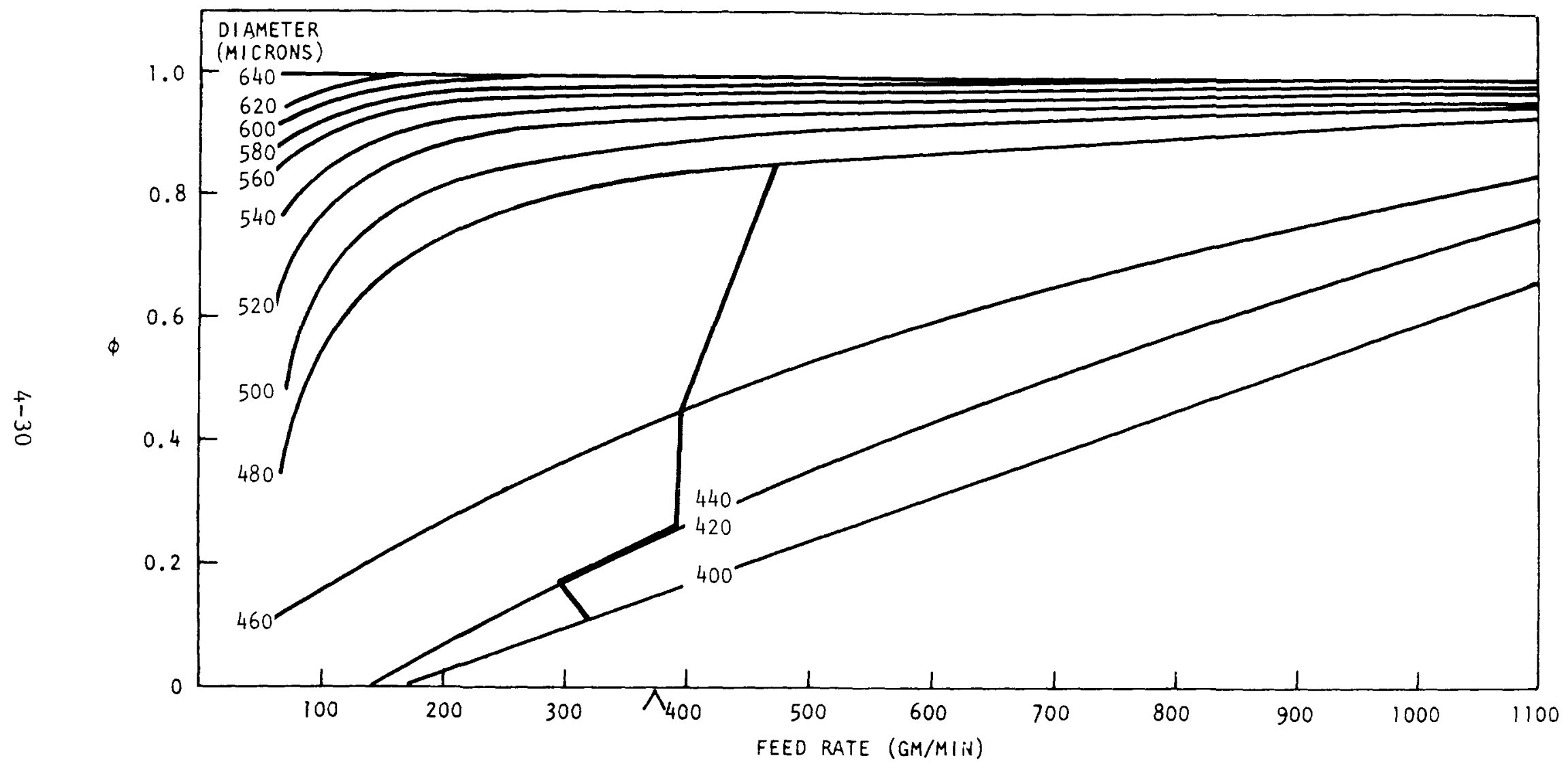

Fig. 4-17. Comparison of separation of simulated feed at $3.70 \mathrm{~m} / \mathrm{sec}$ air velocity with additional 10 wt $\%$ graphite and with no graphite 


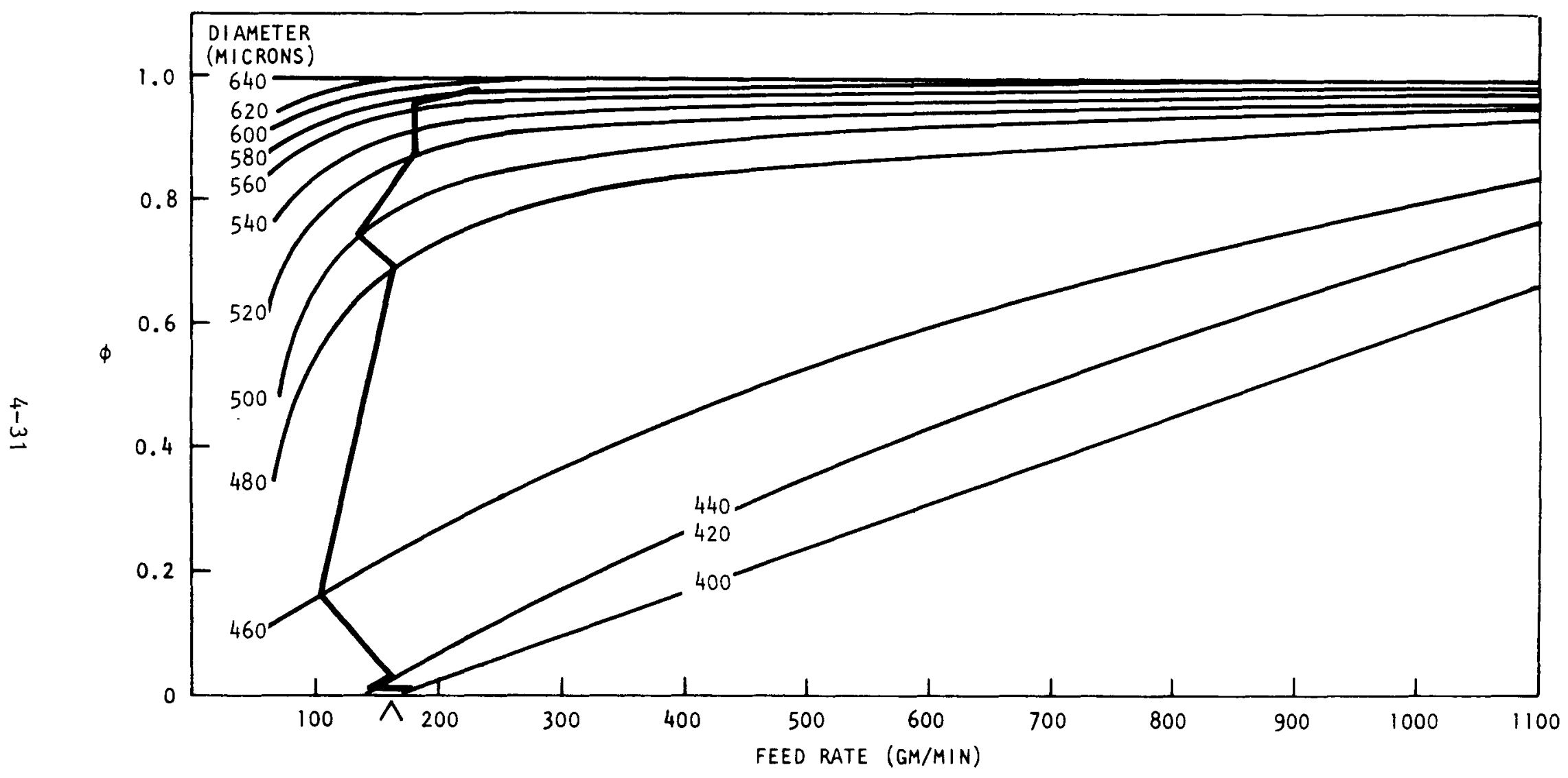

Fig. 4-18. Comparison of separation of simulated feed at $3.70 \mathrm{~m} / \mathrm{sec}$ air velocity with additional 10 wt $\%$ graphite (lower portion of size distribution) and with no graphite 


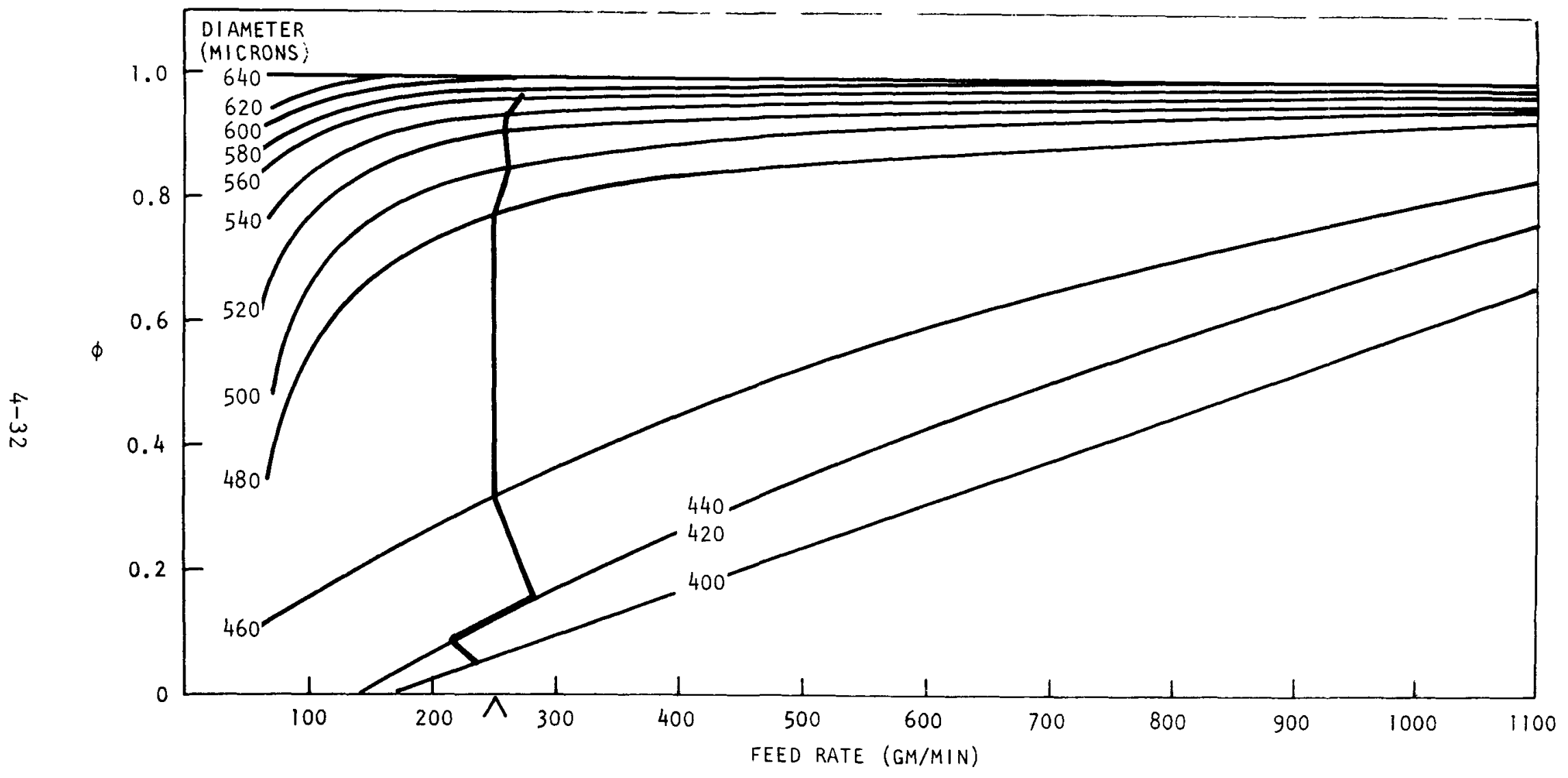

Fig. 4-19. Comparison of separation of simulated feed at $3.70 \mathrm{~m} / \mathrm{sec}$ air velocity with additional 10 wt $\%$ graphite (upper portion of size distribution) and with no graphite 
TABLE 4-7

EFFECT OF GRAPHITE ON SEPARATION

OF THE SIMULATED FEED

\begin{tabular}{|c|c|c|c|c|c|c|}
\hline Run No. & $\begin{array}{r}\text { Weight } \\
\left(\begin{array}{ll}\% & \end{array}\right)\end{array}$ & $\begin{array}{l}\text { Particle } \\
\text { Feed } \\
\text { Rate }\end{array}$ & $\begin{array}{c}\text { Carbon } \\
\text { Feed } \\
\text { Rate }\end{array}$ & $\begin{array}{r}\text { Total } \\
\text { Feed } \\
\text { Rate }\end{array}$ & $\begin{array}{c}\text { Effective } \\
\text { Feed } \\
\text { Rate }\end{array}$ & $\begin{array}{c}\text { Increase } \\
(\%)\end{array}$ \\
\hline 1 & 5 & 150 & 9.4 & 199.4 & 208 & 4.3 \\
\hline 2 & 10 & 162 & 17 & 179 & 375 & 109.5 \\
\hline 3 & $10(\mathrm{~L})^{(\mathrm{a})}$ & 144 & 16 & 160 & 165 & 3.1 \\
\hline 4 & $10(\mathrm{u})^{(\mathrm{b})}$ & 192 & 21 & 213 & 250 & 17.4 \\
\hline
\end{tabular}

(a) $\mathrm{L}$ - denotes lower portion of distribution.

(b) $u$ - denotes upper portion of distribution. 


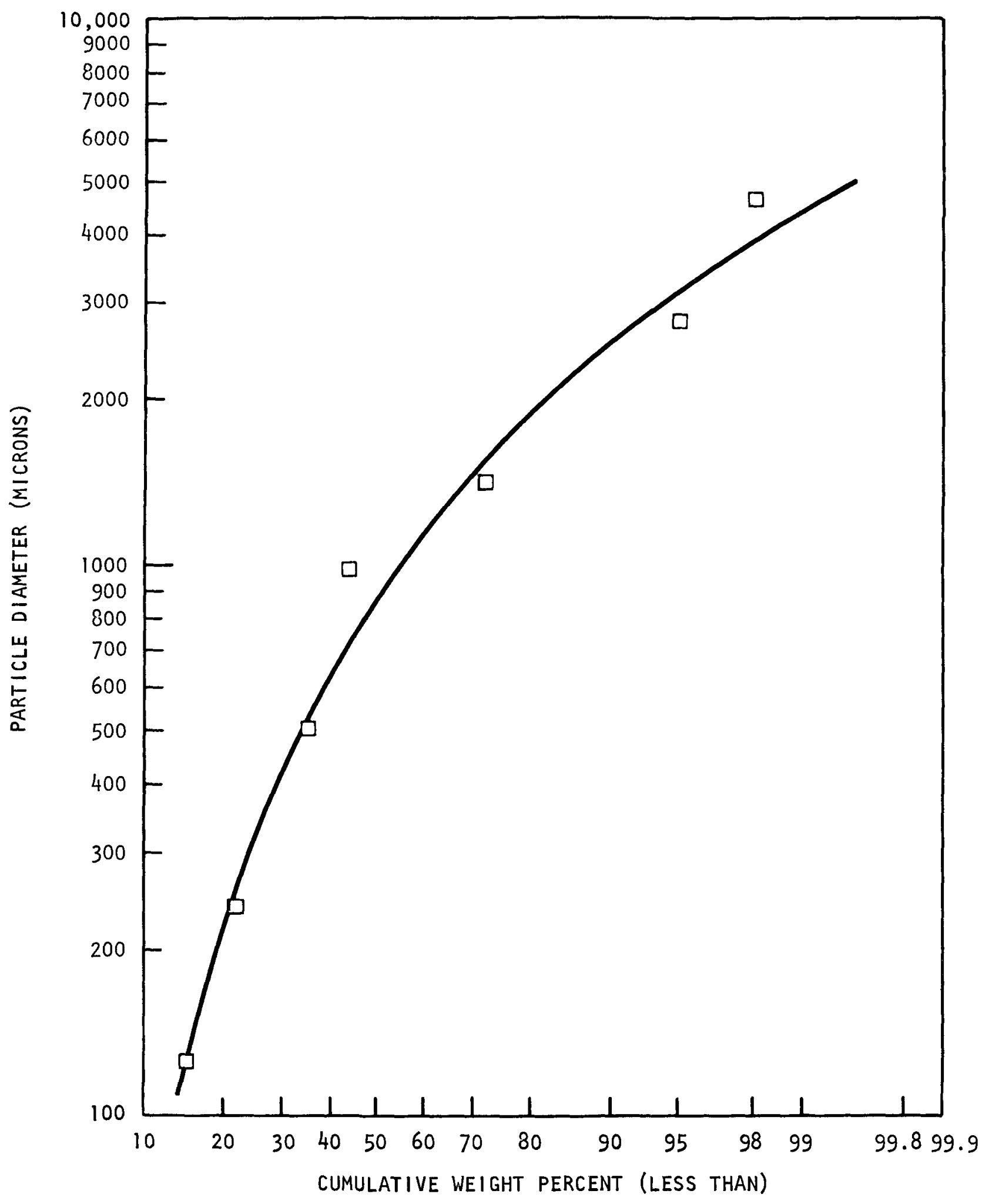

Fig. 4-20. Size distribution for tertiary crusher product 
experiments. By testing these two extreme combinations, the limits of classification efficiency were found. These limits represent the extremes that can be expected from reprocessing the numerous combinations of fissile and fertile particles found in reactor fuel.

Appendix A gives the Quality Assurance data for these two rod batches plus a third containing Fissile A, Fertile A, and Fertile B particles. This rod batch was chosen for the Scrap Rod Program in lieu of the Fissile A/Fertile B batch for the reasons given in Section 4.3 and in Ref. 16. All three rod batches were rejected due to matrix nonuniformity caused by the failure of the pitch filler to penetrate one end of the rod completely. Aside from this flaw, the rods and the particles contained in them were within the limits set for reactor use.

\subsubsection{Prediction of the Separation}

The model derived from the experiments using simulated fuel was used to predict the separation of FSV fuel. The first prediction of the runs using Fissile B/Fertile A fuel gave totally unsatisfactory results. Errors as large as 43.2 wt \% difference resulted. These errors result from differences between simulated feed and FSV type fuel. FSV fuel has a steeper slope for the density versus diameter curve and the modal intersection is shifted up by approximately $80 \mu$. Using these two explanations as a basis, the model was adjusted to apply to FSV type fuel.

As mentioned briefly in Section 4.2.3.2 on Simulated Feed, the point of intersection of two size distribution modes affects the efficiency of separation. The effect is to increase the efficiency in the proximity of the intersection. By having the model equispace the constant diameter lines, a diameter correction was applied in order to spread the lines at the intersection of the modes. In this manner the model is kept general for all types of fuel providing the location and magnitude of the 
correction shift is known. The intersection of the modes affects separation efficiency so that a diameter correction is needed to adjust the constant diameter lines of the equispace model.

The slope of the density curve also affects the spacing of the isodiameter lines. As the slope increases, the lines spread out indicating a better separation. This effect interacts with the effect of the modal intersection, and as a result they were hard to distinguish in this investigation. The effect of each could be studied if more time and the correct types of fuel were available. However, under the circumstances, a combined correction is required.

The uncorrected model (Fig. 4-21) was compared with the data taken in the runs. From this comparison, the shift of the constant diameter lines was determined and is given by the following equations:

$$
\left.\begin{array}{rl}
\mathrm{d}<520 & \mathrm{D}=15.2 \times\left(\frac{\mathrm{d}}{100}\right)^{2.15} \\
520<\mathrm{d}<560 & \mathrm{D}=\mathrm{d} \\
\mathrm{d}>560 & \mathrm{D}=22.7 \mathrm{~d}^{0.507} \\
\text { where } \mathrm{d}=\text { actual particle diameter } \\
\mathrm{D}=\text { particle diameter used in } \\
\text { model }
\end{array}\right\}(4-8)
$$

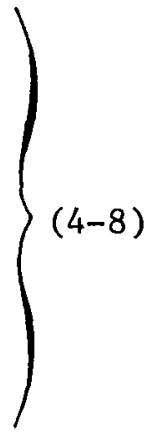

This corrected model (Fig. 4-22) agrees well with the spread distribution and with the close distribution at $200 \mathrm{gm} / \mathrm{min}$. The error for other feed rates can be reduced by an amount ranging from $\pm 19 \%$ to $\pm 4 \%$ by using a constant feed rate of $150 \mathrm{gm} / \mathrm{min}$. This implies that the effect of feed rate on separation is considerably reduced by the increased slope of the density curve. In Ref. 14, the rate of elutriation of fines from a fluidized bed increased for an increasing difference in the densities of the 


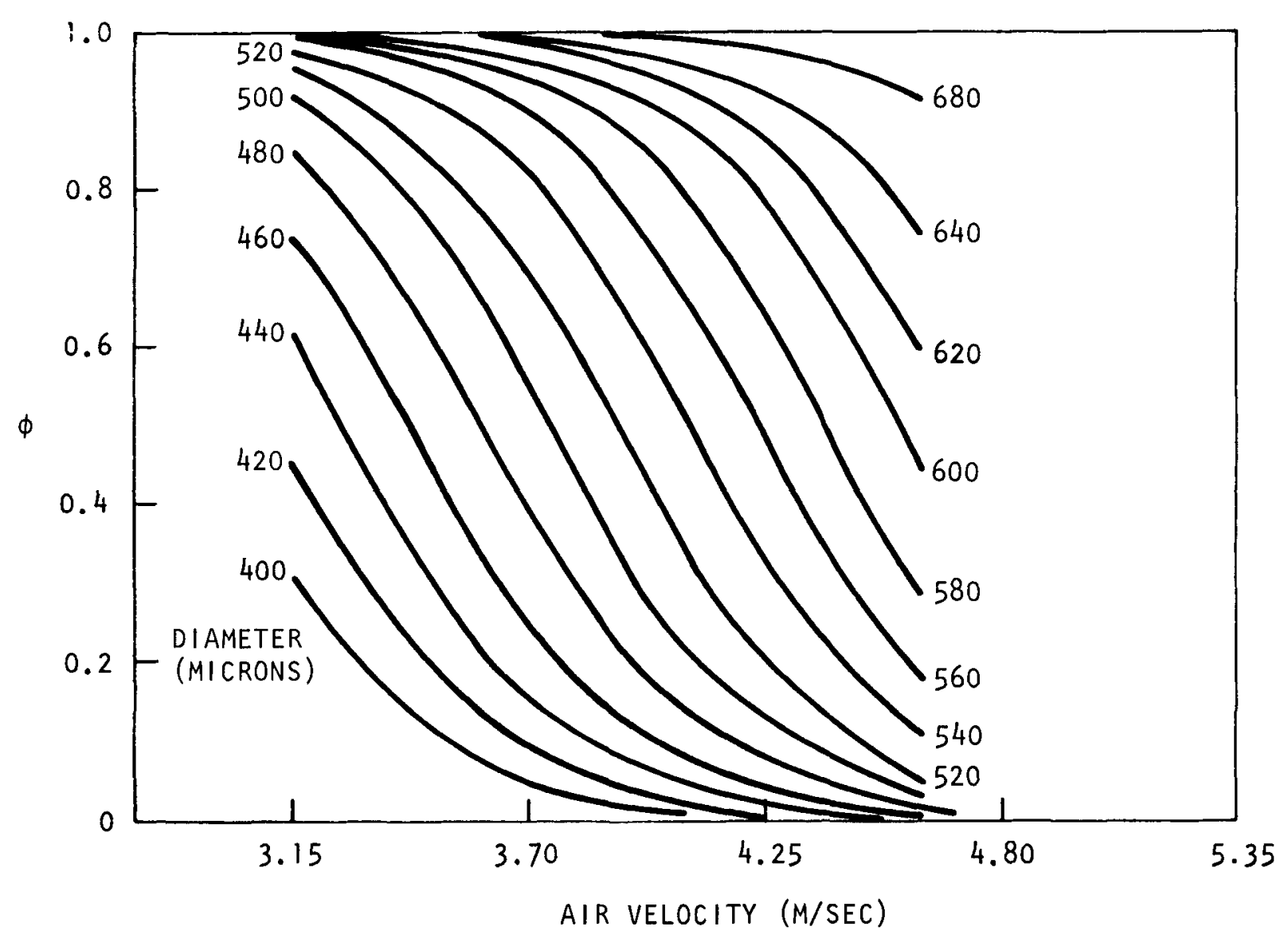

Fig. 4-21. Uncorrected model for separation efficiency versus air velocity and diameter at constant feed rate of $200 \mathrm{~g} / \mathrm{min}$ 


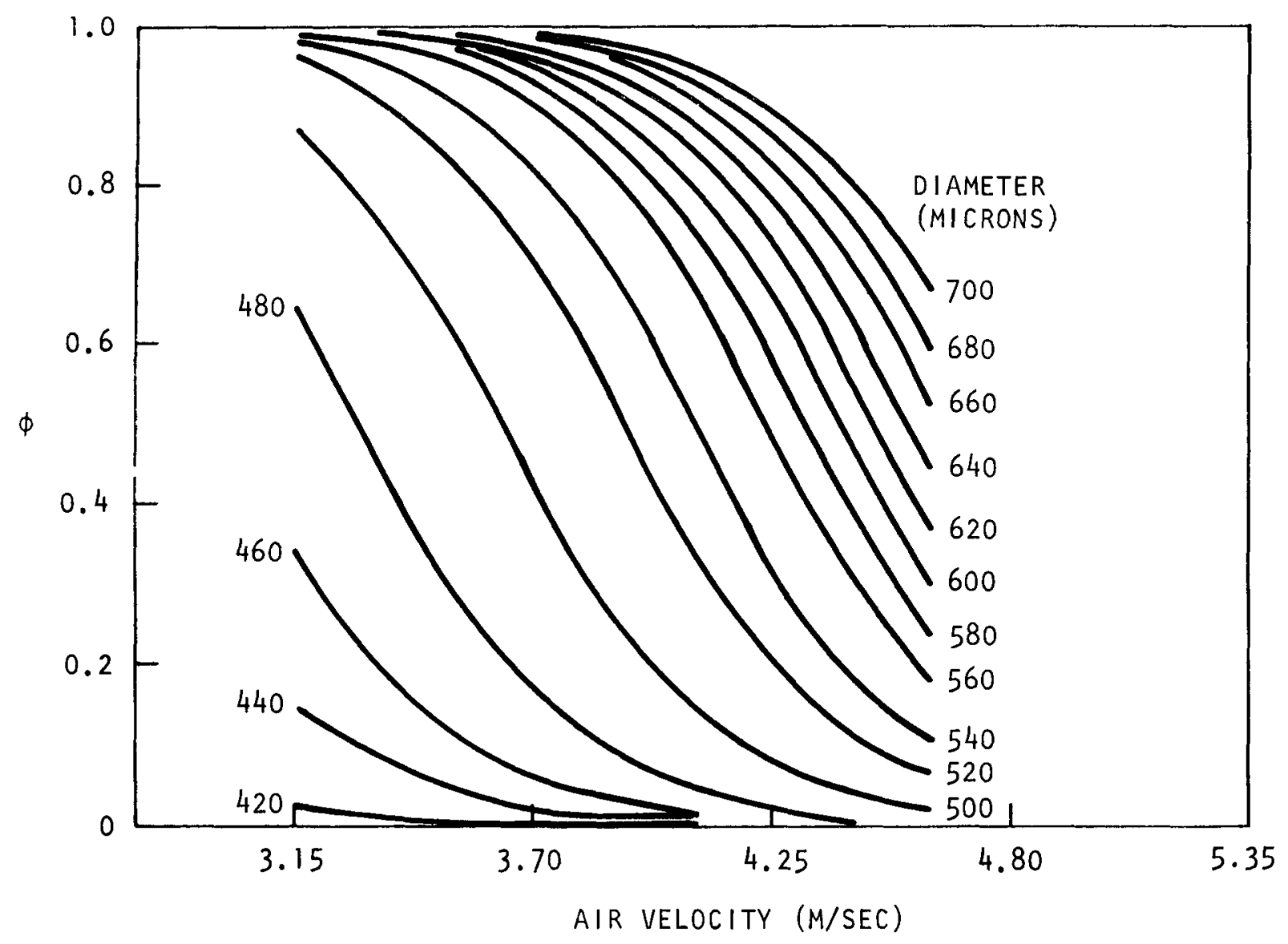

Fig. 4-22. Model corrected for the effect of density; separation efficiency versus air velocity and diameter at constant feed rate of $200 \mathrm{~g} / \mathrm{min}$ 
particles: the larger the difference, the better the segregation and the less dependence upon solids concentration or feed rate.

\subsubsection{Prediction of the Crossover}

The ultimate use of the model is to predict the crossover between the fissile and fertile streams. The calculation of the separation is only one step in the final answer needed. With this in mind, the crossovers of two runs of FSV fuel were determined by wet chemical analysis. From these results, the particle size distributions of the fissile and the fertile particles in the feed were determined. Once these distributions were known, the ratio of fissile to feed for each size increment was calculated. When the fissile and fertile particles are assumed to be the same density for the same size, the crossover is given by:

$$
\begin{aligned}
& x_{v}=\frac{\sum R_{i}^{\nu} W_{i}^{c}}{W_{v}} \\
& x_{\tau}=\frac{\sum R_{i}^{\tau} W_{i}^{f}}{W_{\tau}} \\
& R_{i}^{\nu}=1-R_{i}^{\tau}
\end{aligned}
$$

where $\mathrm{X}=$ crossover

$$
\begin{aligned}
& \mathrm{R}=\text { ratio of either fissile or fertile } \\
& W=\text { weight } \\
& \dot{i}=\text { size increment } \\
& \nu=\text { fissile } \\
& \tau=\text { fertile } \\
& c=\text { coarse fraction } \\
& \mathbf{f}=\text { fines fraction }
\end{aligned}
$$

When this assumption is used, however, large errors result from density differences between fissile and fertile particles. That is, the 
crossover predicted using the assumption is greater than that for the actual crossover. From this it is deduced that the fraction of fissile in a specific size increment in the feed is greater than the fraction of fissile in that increment in the coarse. The converse applies to the fertile fraction. In order to better predict the crossover based on this reasoning, the ratio of fissile in the coarse product per increment and the ratio of fertile in the fine product per increment was calculated using the weight percent crossover and the particle size distributions of the products. Using this ratio and the model, the predicted crossover of the other runs was within $\pm 14 \%$ error. An additional test of the model for prediction of separation and crossover was provided by the Scrap Rod Program and is detailed in Section 4.4.

4.3.4. Density and Its Effect on Separation

The relationship of density to size in FSV fuel is very complex due to the manufacturing process. The fuel starts with ThC or UC/ThC kernels to which coatings of carbon and silicon carbide are applied. The kernels and each of the coatings have means $(\bar{X})$ and standard deviations $(\sigma)$ associated with their diameter and thickness. The mean thickness for a particular coating is approximately equal for the four basic sizes of particles, leaving the difference of kernel diameters equal to the overall mean size difference. As a result, a fissile particle that has the same size as a fertile particle will have a larger than average coating thickness, while the fertile particles will have smaller than average coating thicknesses. This leaves the kernel of the fissile particle smaller than that of the fertile particle, and, since the kernel contributes the greatest fraction to particle mass, the fissile particle will also be less dense. From the data in Table 4-8, an average particle density was calculated for the Fissile $B$ and Fertile $A$ distributions at the following three particle sizes: 
TABLE 4-8

QA FUEL SPECIFICATIONS

\begin{tabular}{c|c|c|c}
\hline & $\begin{array}{c}\text { Mean Diameter or } \\
\text { Coating Thickness } \\
\text { (Microns) }\end{array}$ & $\begin{array}{c}\text { Standard } \\
\text { Deviation } \\
\text { (Microns) }\end{array}$ & $\begin{array}{c}\text { Density } \\
\text { (gm/cc) }\end{array}$ \\
\hline Fissile B & & & \\
Kernel & 240 & 20.0 & 9.5 \\
Buffer & 58 & 12.0 & 1.05 \\
IPyC & 32 & 5.7 & 1.90 \\
SiC & 25 & 3.3 & 3.19 \\
Fertile A & 370 & 33.0 & 9.5 \\
Kernel & 58 & 12.0 & 1.05 \\
Buffer & 32 & 5.7 & 1.90 \\
IPyC & 25 & 3.3 & 3.19 \\
SiC & & & \\
\hline
\end{tabular}




$$
\begin{aligned}
& \overline{\mathrm{x}}-2.25 \sigma \\
& \overline{\mathrm{x}} \\
& \overline{\mathrm{x}}+2.25 \sigma
\end{aligned}
$$

Figure 4-23 and Table 4-9 give these results of this calculation. Similar results would be expected for Fissile A and Fertile $B$ fuel. Due to the statistics of combination, any particular size would have a range of densities. For this reason and because the combination of these curves to give density as a function of size for a blend would be very complicated, another approach was taken for establishing the density-size relation for the data reduction.

This alternate approach involved the linear approximation for density over the entire size range. FSV type fuel was selectively cut at four diameters and several density analyses were done by air pycnometer and mercury immersion. Figure 4-24 11lustrates the results of the analyses with a least squares line drawn through the points. The equation for the lines is:

$$
\rho=0.8636+0.00488 d
$$

where $\rho=$ particle density in $\mathrm{gm} / \mathrm{cc}$

$\mathrm{d}=$ particle diameter in microns

Using this expression the number percent data may be reduced to an approximate weight percent relation. While this weight percent relation is an approximation, the deviation from the real value is within $0.5 \%$ as was the error mentioned in Section 4.2 on Simulated Feed. Any error that occurred as a result of this density approximation was corrected by the model through the various corrections used (see Section 4.4 for further details on the model). 


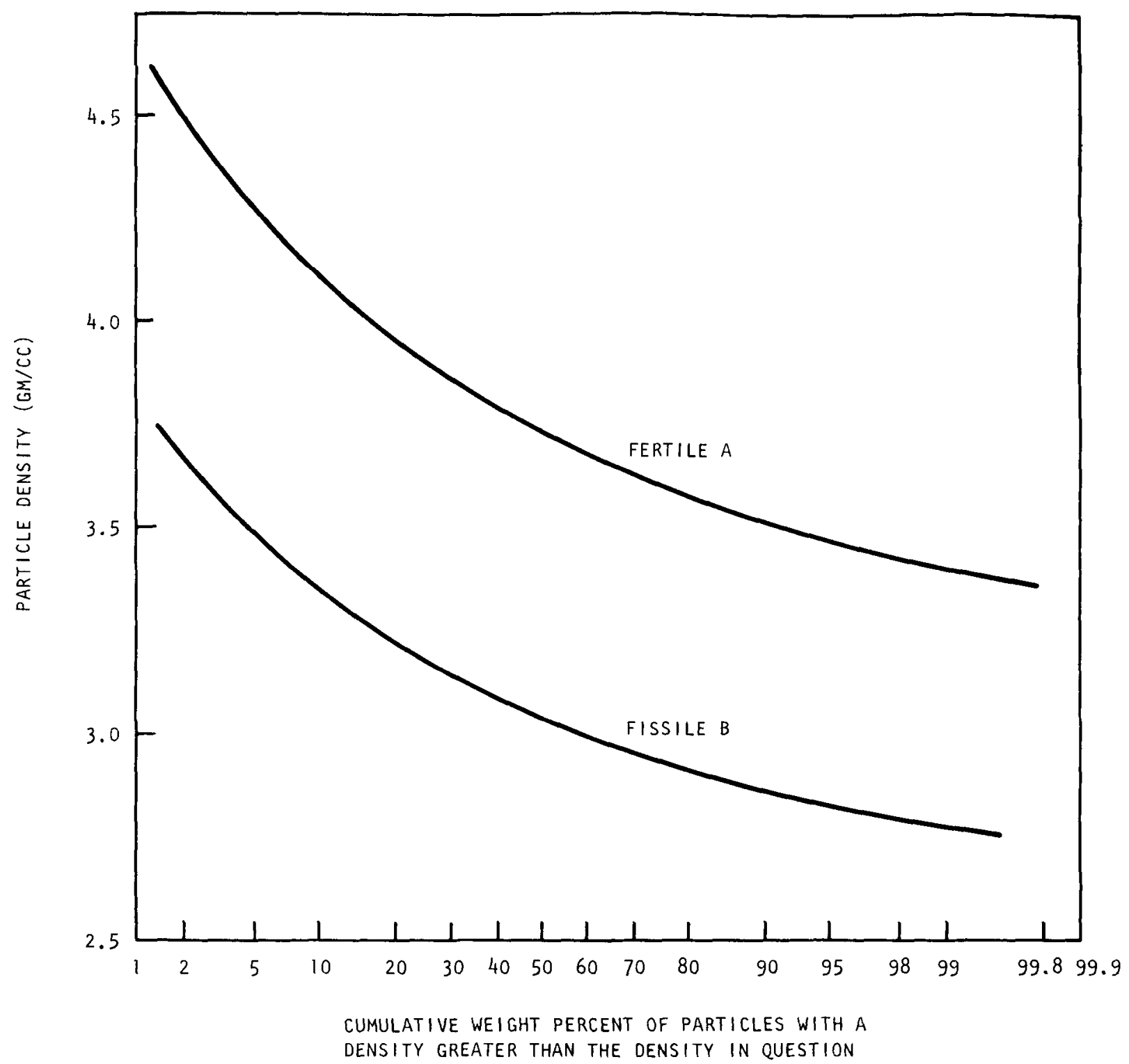

Fig. 4-23. Theoretical density versus cumulative weight percent of particles 
TABLE 4-9

THEORETICAL PARTICLE DENSITY VS PARTICLE DIAMETER

\begin{tabular}{c|c|c}
\hline & $\begin{array}{c}\text { Particle } \\
\text { Diameter } \\
\text { (Microns) }\end{array}$ & $\begin{array}{c}\text { Particle } \\
\text { Density } \\
\text { (gm/cc) }\end{array}$ \\
\hline Fissile B & 326 & 3.64 \\
& 470 & 3.03 \\
Fertile A & 614 & 2.77 \\
& 426 & 4.48 \\
& 600 & 3.73 \\
& 774 & 3.39 \\
\hline
\end{tabular}

4-44 


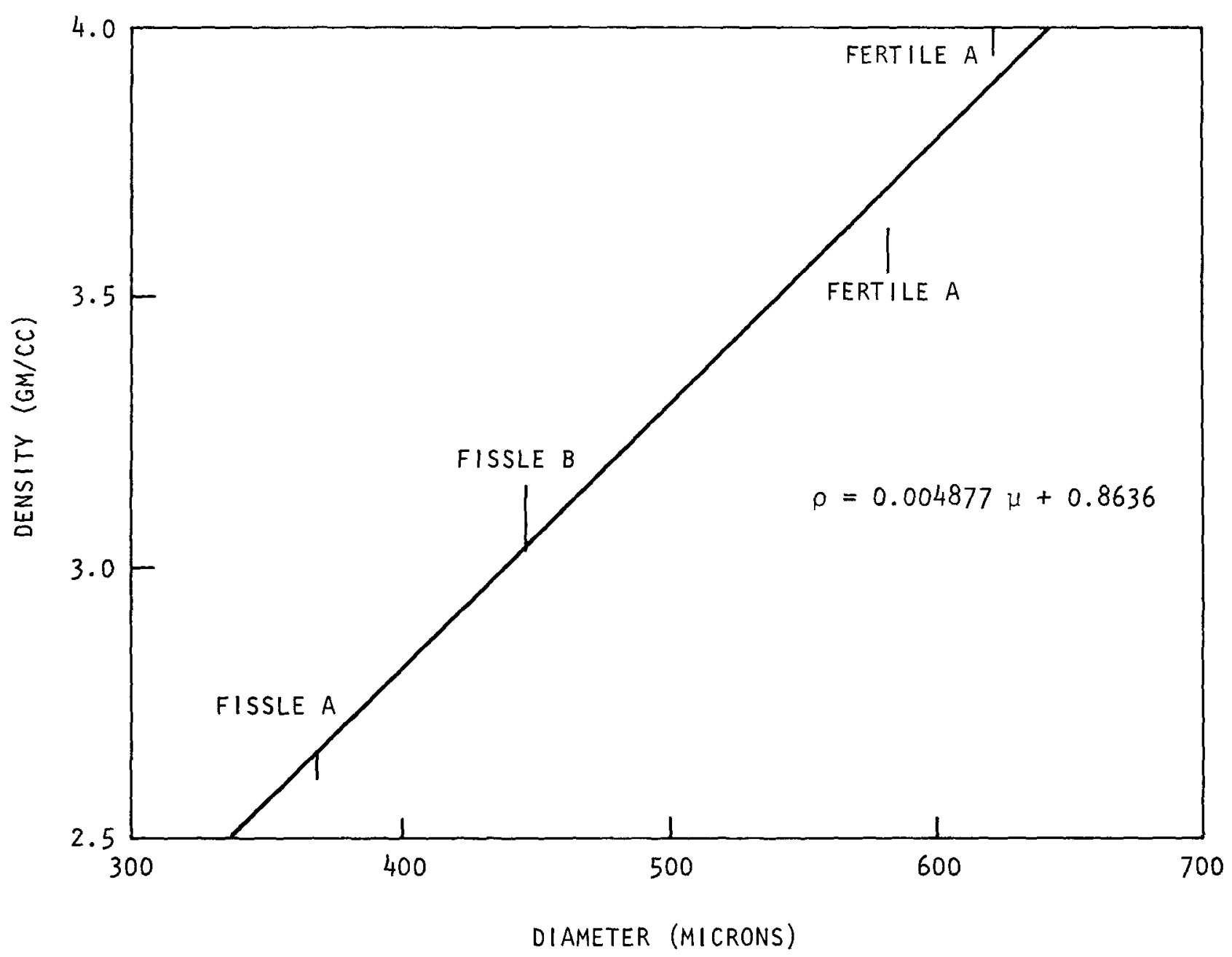

Fig. 4-24. Weight percent mean diameter versus density at SiC coating for FSV type fuel 
The purpose of the Scrap Rod Program was to provide the first reliable data on particle breakage and fissile/fertile crossover produced by headend reprocessing. To acquire these data, two one-half fuel blocks loaded with reject FSV type fuel were individually crushed, burned, and separated into a fissile rich stream and a fertile rich stream.

This section deals with the classification of the primary burner product produced in the program and, specifically, with the way in which this program served as a final test of both the Alpine pneumatic classifier and the model. Detailed analysis of each operation in the program is covered by Refs. 4, 5, 17, 18, and 19. This section is not meant to duplicate the documentation of the classification portion of the program, but to provide a link between this report and the work done previously (Ref. 4).

\subsubsection{The Feed}

Two batches of fuel rods were carefully chosen (Ref. 16) to represent the two extreme combinations of particle sizes and to provide traceability. Unfortunately, there were not enough Fissile A/Fertile B rods in storage to fill a half-length fuel block. Therefore, the closest combination to these was used: Fissile A/Fertile A/Fertile B. Figure 4-25 gives the size distribution. The other fuel rod batch that was used has the largest overlap of the fissile and fertile size distributions for any combination. Figure 4-6 gives the size distribution for the Fissile B/Fertile A batch.

These two rod batches were loaded into separate half-length fuel blocks and processed individually. The feed to the pneumatic classifier (the product of the primary burner) was drawn off continuously from a segregated bed, giving a varying fuel particle size distribution as well as 


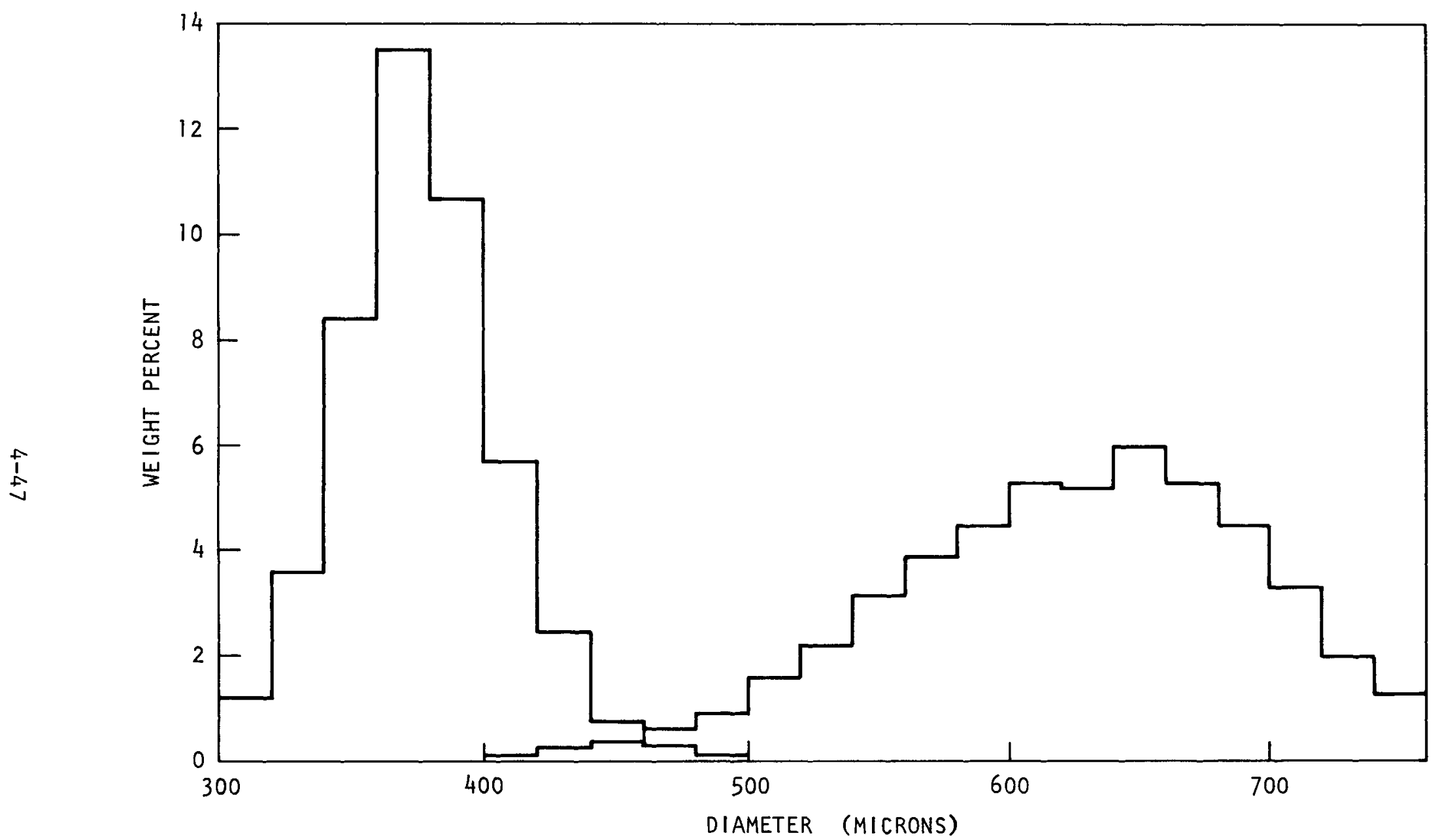

Fig. 4-25. Particle size distribution for Scrap Rod Run No. 1; Fissile A - Fertile A - Fertile B 
a varying carbon content. The five sequential batches comprising each of the two runs were classified individually to assist in distinguishing anv intra-run trends that might occur. The particle size distribution of the products produced from this separation is given in Appendix $B$.

Table 4-10 gives the weight percent carbon in the feed to and products from the pneumatic classifier. As can be seen, the diversity of feeds to the classifier in this program helped to distinguish many trends in the separation of TRISO/TRISO fuel. The identification of these trends and their effect on classification aided in the testing and optimization of the $\operatorname{mode1}$.

\subsubsection{Estimation of the Products}

The model derived from the results of separating simulated feed was modified to predict the tests using FSV type fuel and the results of the Scrap Rod Runs. The results were not in accord with the predictions because the feed to the classifier in this program contained varying amounts of graphite, whereas in the preliminary tests it did not. Another contributing factor to this deviation was the varying particle size distribution between batches of a particular run. These two factors necessitated a further modification of the program to allow for carbon and varying fuel particle size distribution. The final result is a model that will predict the products of the separation of FSV type TRISO/TRISO fuel.

In the previous section on FSV type feed, the dependence upon feed rate exhibited by simulated fuel became negligible for feed rates less than $350 \mathrm{gm} / \mathrm{min}$. For the model, a constant was used in place of the feed rate. By using this constant (150) in the model to predict the Scrap Rod Runs, large errors resulted (see Tables $\mathrm{C}-1$ through $\mathrm{C}-10$ in Appendix $\mathrm{C}$ ). By increasing this constant from 150 to 325, the errors were reduced in a.1 but two of the batches. This increase in the constant from 150 to 325 
TABLE $\quad 4-10$

FEED AND PRODUCT COMPOSITION

\begin{tabular}{|c|c|c|c|c|c|c|c|}
\hline \multirow{3}{*}{\multicolumn{2}{|c|}{ Batch iro. }} & \multirow{2}{*}{\multicolumn{2}{|c|}{ Feed Composition }} & \multicolumn{4}{|c|}{ Product Composition } \\
\hline & & & & \multicolumn{2}{|c|}{ Fines } & \multicolumn{2}{|c|}{ Coarse } \\
\hline & & $\begin{array}{l}\text { Carbon } \\
\text { (wt \%) }\end{array}$ & $\begin{array}{c}\text { Particles } \\
(\text { wt } \%)\end{array}$ & $\begin{array}{l}\text { Carbon } \\
\text { (wt \%) }\end{array}$ & $\begin{array}{c}\text { Particles } \\
(\text { wt } \%)\end{array}$ & $\begin{array}{l}\text { Carbon } \\
\text { (wt \%) }\end{array}$ & $\begin{array}{l}\text { Particles } \\
(w t \%)\end{array}$ \\
\hline \multicolumn{8}{|c|}{ Run No. 1} \\
\hline & 1 & 39.0 & 61.0 & 46.6 & 53.4 & 23.9 & 76.1 \\
\hline 2 & 2 & 29.7 & 70.3 & 34.9 & 65.1 & 22.9 & 77.1 \\
\hline & 3 & 23.5 & 76.5 & 29.5 & 70.5 & 14.8 & 85.2 \\
\hline 4 & 4 & 21.8 & 78.2 & 28.3 & 71.7 & 13.8 & 86.2 \\
\hline 5 & 5 & 6.2 & 93.8 & 9.9 & 90.1 & 4.4 & 95.6 \\
\hline & Total & 25.1 & 74.9 & 32.9 & 67.1 & 15.3 & 84.7 \\
\hline \multicolumn{8}{|c|}{ Run No. 2} \\
\hline 1 & 1 & 44.2 & 55.8 & 52.7 & 47.3 & 17.4 & 82.6 \\
\hline 2 & 2 & 25.5 & 74.5 & 39.4 & 60.6 & 10.6 & 89.4 \\
\hline 3 & 3 & 24.4 & 75.6 & 40.1 & 39.9 & 7.3 & 92.7 \\
\hline 4 & 4 & 20.2 & 79.8 & 35.0 & 65.0 & 5.5 & 94.5 \\
\hline 5 & 5 & 6.4 & 93.6 & 14.1 & 85.9 & 3.8 & 96.2 \\
\hline & Tota1 & 24.5 & 75.5 & 40.4 & 59.6 & 7.7 & 92.3 \\
\hline
\end{tabular}


represents the effect of graphite on the separation. In Section 4.1 this effect was examined and additional graphite was shown to affect separation the same way increasing feed rate does. A relationship between the effective feed rate and the actual feed rate of the particles and graphite was given. The addition of graphite to FSV type fuel had the same effect. However, in this case the effect of an increasing percentage of graphite replaced the effect of an increased feed rate. Through this change the model is now capable of predicting the separation of FSV type fuel for feed rates ranging from 0 to $350 \mathrm{gm} / \mathrm{min}$ and for concentrations of graphite ranging from 0 to $45 \%$.

The deviation of the crossover predictions for batches 1 and 5 of Run 2 from the actual crossovers arises from the different size distributions of the feeds. This correlation can be seen by comparing Tables C-11 through $\mathrm{C}-15$ in Appendix $\mathrm{C}$ with Figs. B-8 through B-12 in Appendix $\mathrm{B}$ and is illustrated by Fig. 4-26. For a given air velocity, solids feed rate, and concentration of graphite, the separation efficiency versus particle size resembles curve A of Fig. 4-26a for a balanced distribution of Fissile $B$ and Fertile A particles (Fig. 4-26b). If a greater percentage of the feed were Fissile $B$ (Fig. 4-26c), then the $\phi$ versus $d$ curve would be represented by curve B. Conversely, if the Fertile A particles comprised the majority of the feed (Fig. 4-26d), then the $\phi$ versus $d$ curve would be represented by curve $C$. As one mode of the distribution becomes more prominent, the separation efficiency relation is shifted in relation to particle size. This phenomenon results from the movement of the particles. If a majority of the particles are rising, then a greater percentage of the ones that would fall are entrained in the rising stream and, therefore, also rise. The same principle holds true for the situation where a majority of particles are falling. This effect is diminished when the modes of the distribution are further apart as in the case of the first Scrap Rod Run.

This modal effect was added to the model as a shift in diameter of the separation efficiency which varied linearly with the ratio of the percent 

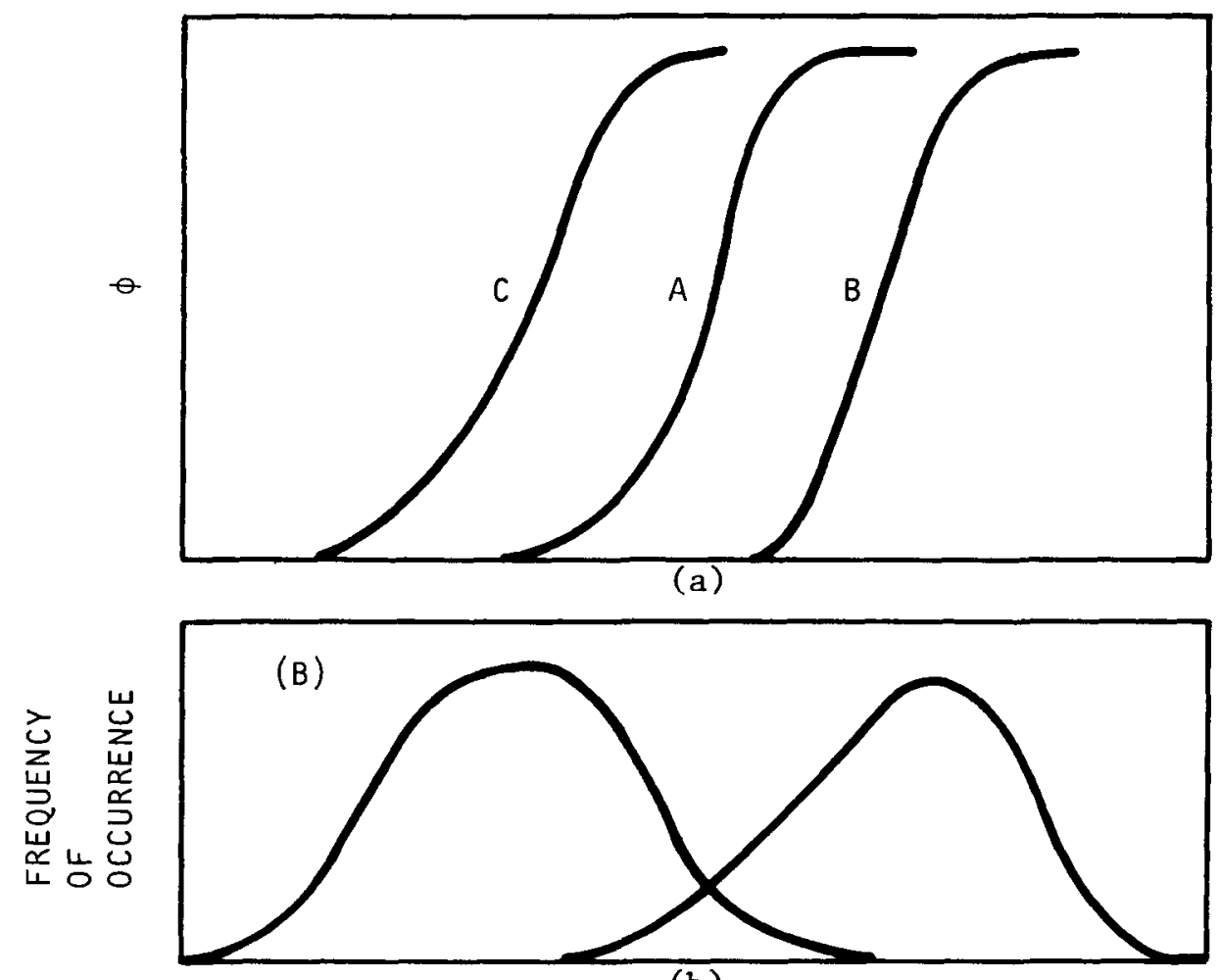

(b)

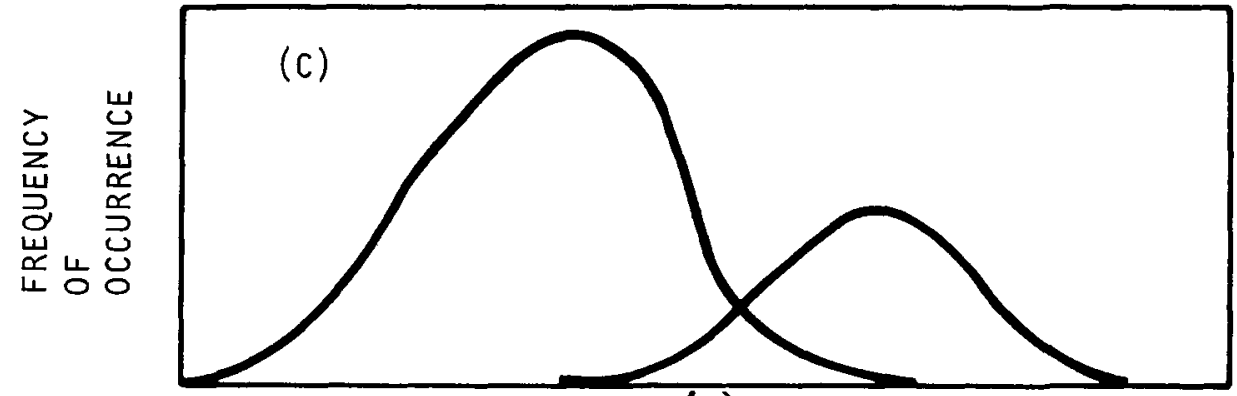

(c)

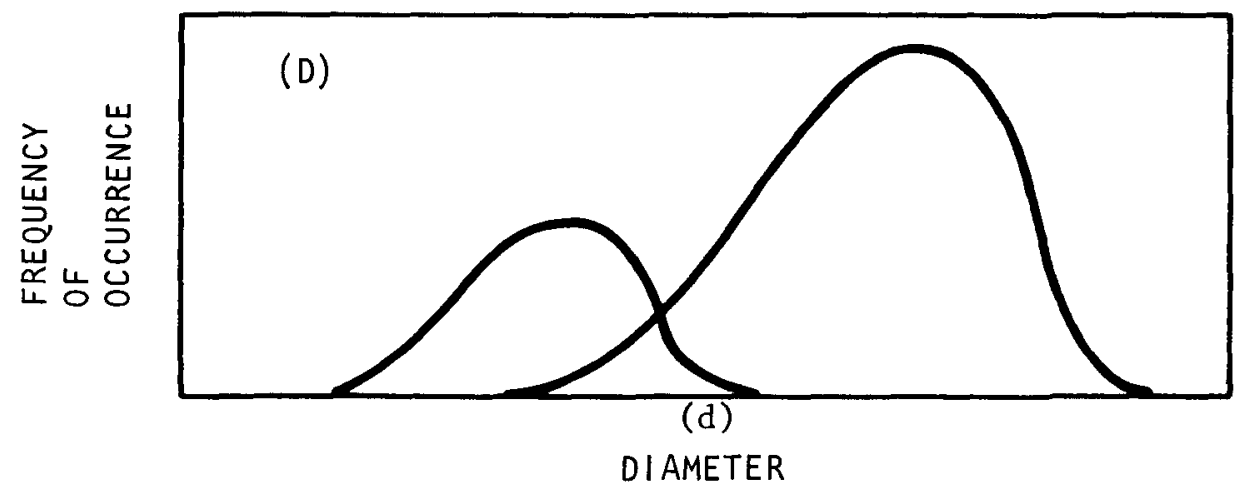

Fig. 4-26. Effect of relative size of modes upon separation efficiency 
of Fissile $B$ with the percent of Fertile A. Because of the interdependence of the effect of graphite and the effect of the size and proximity of the modes, the model was rechecked against the runs of FSV fuel without graphite. To compensate for the modal shift the graphite relation was reworked to provide a better prediction. With this final adfustment the model becomes:

Modal Shift

$$
\begin{aligned}
S_{m}= & -27.4-160\left(R_{\nu \beta}-R_{\tau \alpha}\right) \\
& \text { For } R_{\nu \beta}=0 \text { or } R_{\tau \alpha}=0, S_{m}[=] 0
\end{aligned}
$$

Graphite Influence

$$
G=100+9.25 R_{g}
$$

Air Velocity Rate Shift

$$
S_{a}=592.2-123.4 \mathrm{~V}
$$

Density Influence

$$
\begin{array}{rlrl}
\mathrm{d} & <520 & \mathrm{D} & =15.2\left(\frac{\mathrm{d}}{100}\right)^{2.15} \\
520<\mathrm{d} & <560 & \mathrm{D} & =\mathrm{d} \\
\mathrm{d} & >560 & \mathrm{D} & =22.7 \mathrm{~d}^{0.507}
\end{array}
$$

Separation Efficiency

$$
\begin{array}{ll}
\alpha=s_{m}+s_{a}+D & \\
\beta=e^{(25.9032-0.03271 \alpha)} & \left\{\begin{array}{ll}
\text { For } \alpha<330, \gamma[=]-300 \\
\text { For } \alpha>576.5, \gamma[=] 1
\end{array}\right\} \\
\gamma=18-\frac{4225}{(\alpha-328)} \quad & \left\{\begin{array}{lll}
\text { For } \phi<0, \text { then } \phi[=] & 0 \\
\text { For } \phi>1, \text { then } \phi[=] & 1
\end{array}\right\}
\end{array}
$$




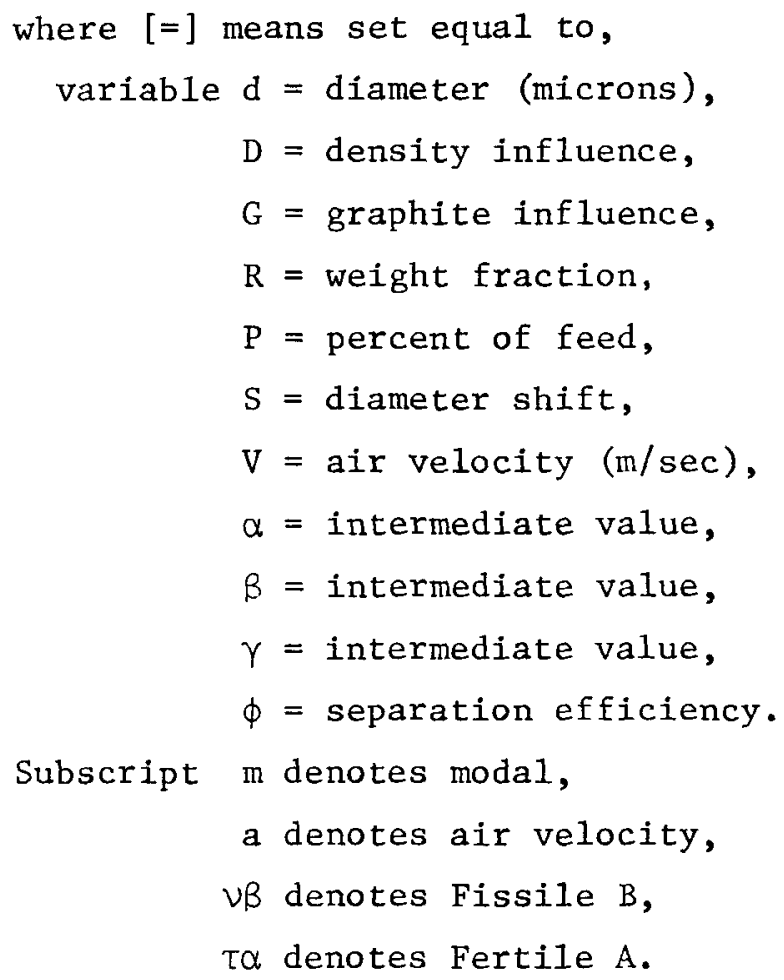

A final run of the model gave predicted results within the range of +0.8 to $-3.5 \mathrm{wt} \%$ of the actual or +3.3 to $-6.4 \%$ error. With the ability to make accurate predictions of the separation over a variety of conditions, the prediction of the accompanying crossover was investigated.

\subsubsection{Prediction of Crossover}

As mentioned in Section 4.3 on FSV type fuel, the ratio of the weight of fissile particles to the total weight of particles of any size increment (denoted as the fissile ratio) increased from the coarse to the fine portion of the feed. This arose because of the density difference between fissile and fertile particles of the same size. By comparing the size distributions of the feed and the products to the resulting crossover, the relationship between the fissile ratio and size was found. Upon comparison of the three functions, the only difference found between them was the 
position of the curves with respect to size. That is, the fissile ratio in the fines equalled the ratio for the feed in the next higher size increment $(20 \mu)$, whereas the ratio for the coarse was the same as that for the feed but in the next lower increment. Therefore, when the ratio for the feed is known, the ratios for the fine and coarse product may be found by shifting the size up for the fine fraction and down for the coarse. When this method was applied to the runs, the crossover was predicted within +3 to -1.5 wt \% or $\pm 14 \%$ error.

\subsubsection{Evaluation}

The model was developed to simulate the pneumatic classification of simulated feed. For this simulation, the separation efficiency, $\phi$, is a function of three parameters: feed rate, air velocity, and diameter. When this model was corrected to simulate FSV fuel, several changes resulted. First, since the efficiency of separation for FSV type fuel does not depend upon feed rates below $350 \mathrm{gm} / \mathrm{min}$ and the effect of an increasing percentage of graphite is the same as an increasing feed rate, the weight percent graphite was substituted for the solids feed rate. Second, the increased slope of the mean density relation resulted in the repositioning of the constant diameter lines. Third, the effect of dominate size distribution modes on the separation resulted in a variable diameter shift. Finally, the crossover prediction compensating for the density difference between equal sizes of fissile and fertile particles was added to the model.

The resulting model predicts separation and the accompanying crossover within \pm 4 and \pm 2 wt \% of the actual values, respectively. This accuracy is sufficient for predicting the separation and crossover of FSV type fuel for design, process, and economic decistons concerning a fuel reprocessing p1ant. 


\subsection{FEEDING PERFORMANCE}

In the earlier testing of the Alpine pneumatic classifier using simulated feed, the effect of feed rate on separation efficiency was pronounced (Figs. 4-7 through 4-10). For this reason two feeders were evaluated as to their suitability for metering simulated feed to the Alpine classifier.

\subsubsection{Vibratory Feeder}

The vibratory feeder (Fig. 4-27) supplied with the Alpine classifier had several deficiencies that were corrected. First, to eliminate fuel leakage caused by the loose fit of the bed level control gate on the feeding channel (which allowed fuel to flow around the sides and over the top), a rubber gasket was fitted to the gate providing a powder tight seal on the sides and top. Second, to lessen feed rate dependency upon the amount of material in the hopper, a funnel was fitted into the hopper with the outlet approximately 1 in. above the vibrating channel.

With these two modifications, testing proceeded to determine the feed rate accuracy and correlation with the potentiometer setting. With the hopper filled, the feed rate was measured at short time intervals ( 2 min) over a period of $75 \mathrm{~min}$. (Figure 4-28 gives the results.) The feed rate varied from $80 \mathrm{gm} / \mathrm{min}$ to $180 \mathrm{gm} / \mathrm{min}$.

Close examination of the system revealed two factors which contributed to the feed rate inaccuracy. First, the feed rate was found to depend unon the hopper inventory. Five average feed rates were tested ranging from 145 to $206 \mathrm{gm} / \mathrm{min}$. For each average, feed rate fluctuation was ratioed to maximum value, giving a normalized value. From Fig. 4-29, which gives the results for this normalized feed rate versus the amount in the hopper, the origin of the long term drift became obvious. As a result, feeding was discontinued before the hopper inventory dropped below $500 \mathrm{gm}$, the point at which the feed rate declines rapidly. 


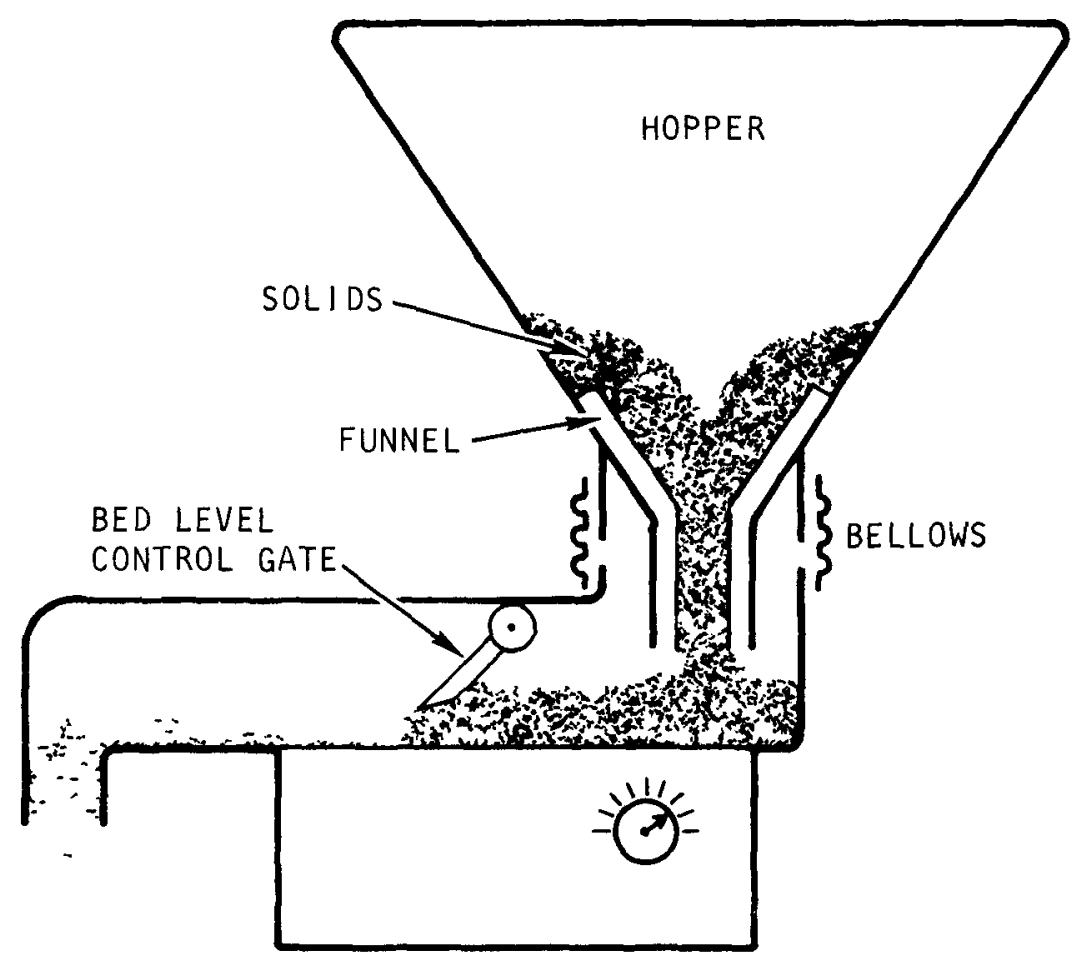

Fig. 4-27. Vibratory feeder 


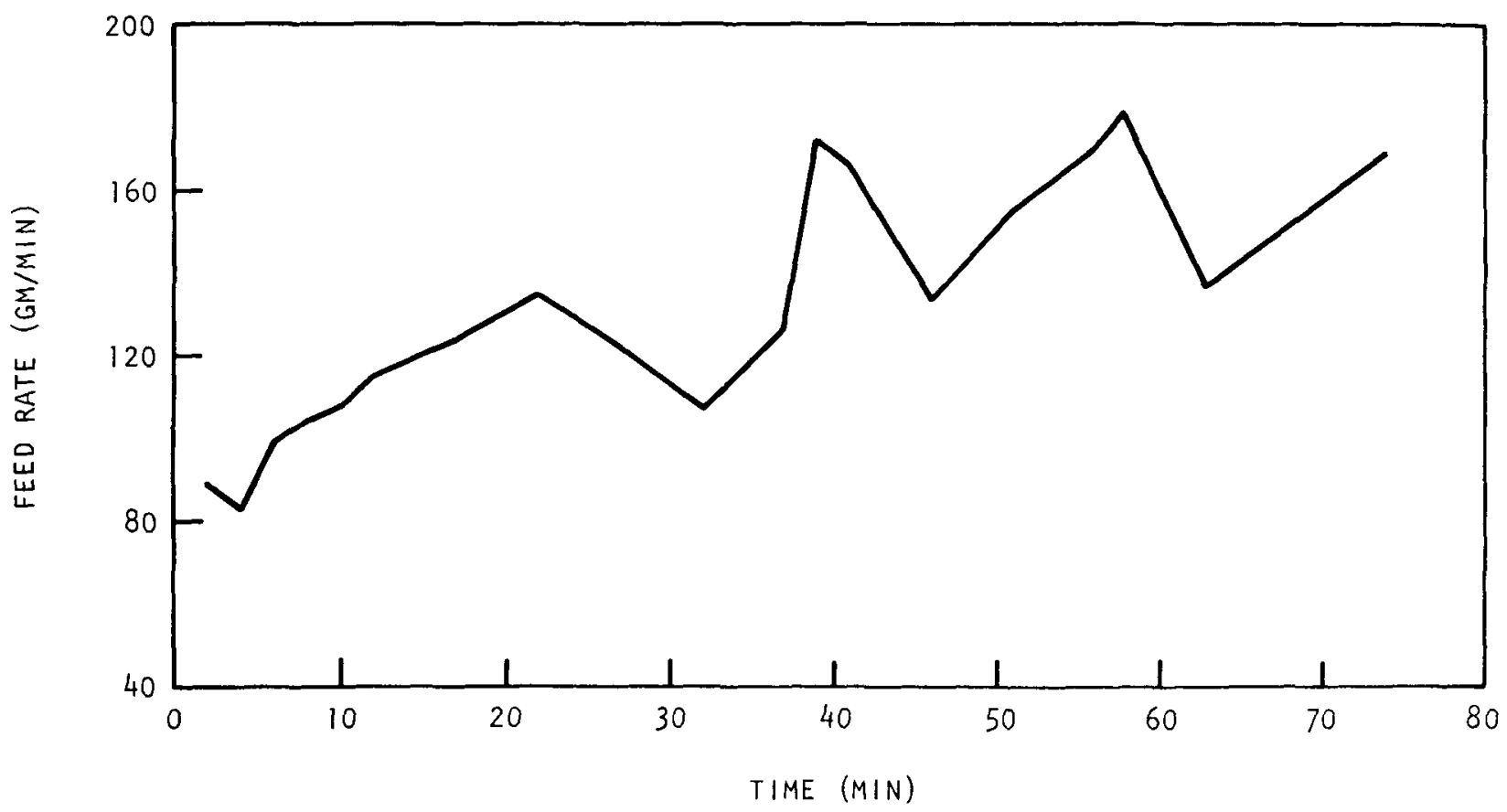

Fig. 4-28. Instantaneous feed rate of vibratory feeder 


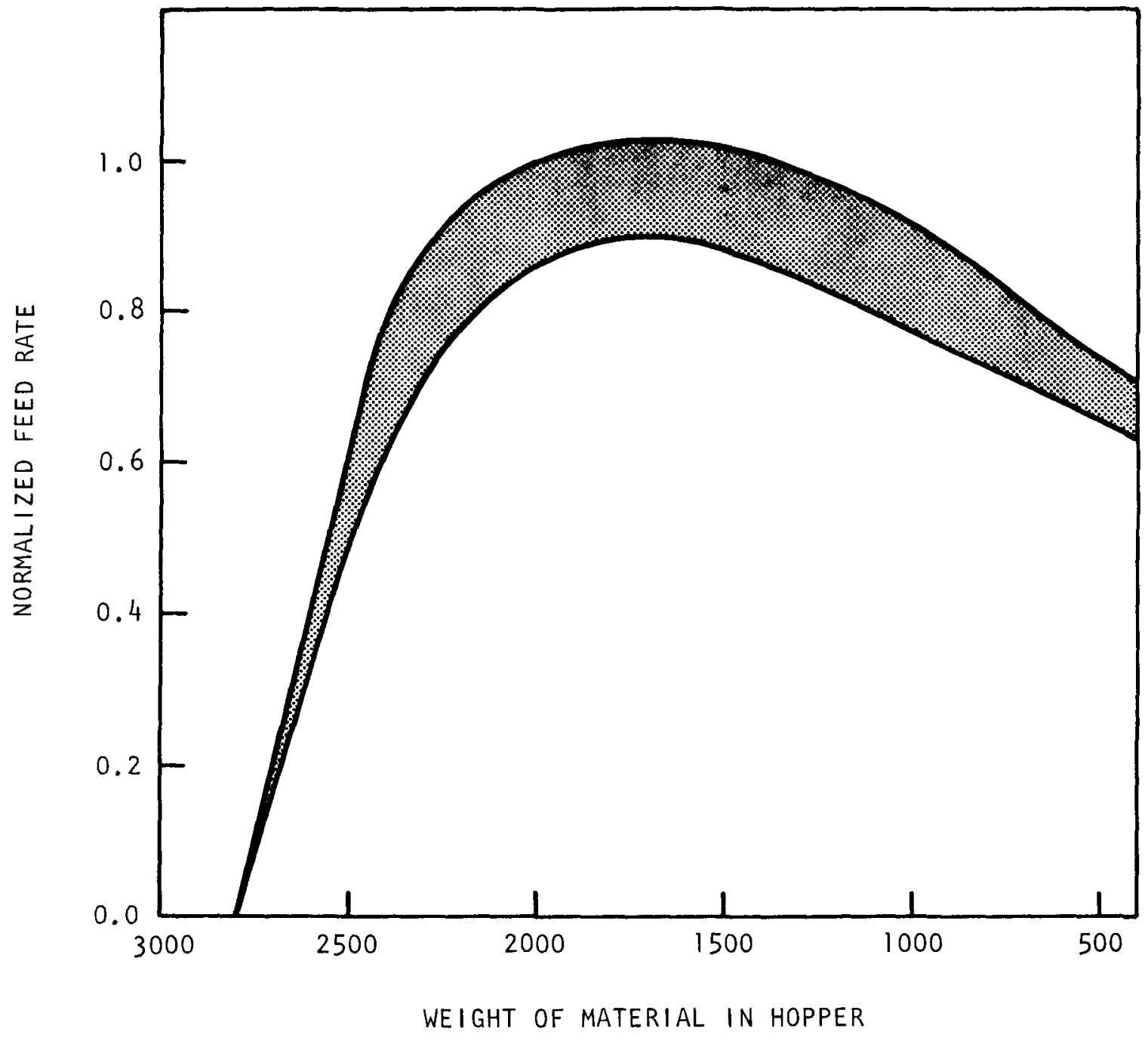

Fig. 4-29. Relationship of feed rate of vibratory feeder to material in hopper 
During these tests, another dependence was discovered. The feed rate was found to depend upon the vacuum in the system, which varies as a function of air velocity. Figure 4-30 1llustrates the approximate linear dependence of feed rate upon air velocity. As the vacuum increases (air velocity increases), the feeding channel is pulled down toward the feed inlet port by the flexible connector between the feeder and the classifier. This action produces a change in the vibrating frequency of the system and increases the incline of the channel. Both result in an increased feed rate.

In summary, the feed rate of the vibratory feeder depends upon the following parameters:

1. Bed level gate opening.

2. Potentiometer setting.

3. Air velocity (vacuum).

4. Incline of the feeding channe1.

5. Solids level in the hopper.

6. Structural support.

No correlation between feed rate and the potentiometer setting was found due to the effects of the other variables.

\subsubsection{Rotary Feeder}

Because the feed rate of the vibratory feeder was affected by a large number of parameters resulting in large errors, another method of feeding was investigated: the rotary feeder (see Fig. 4-3). This is the same feeder used on the $10-\mathrm{cm}$ primary burner in the product removal system (Ref. 20).

The accuracy and reproducibility of the rotary feeder were within \pm 1 wt $\%$, the relationship between feed rate and rpm was linear from 100 to 300 


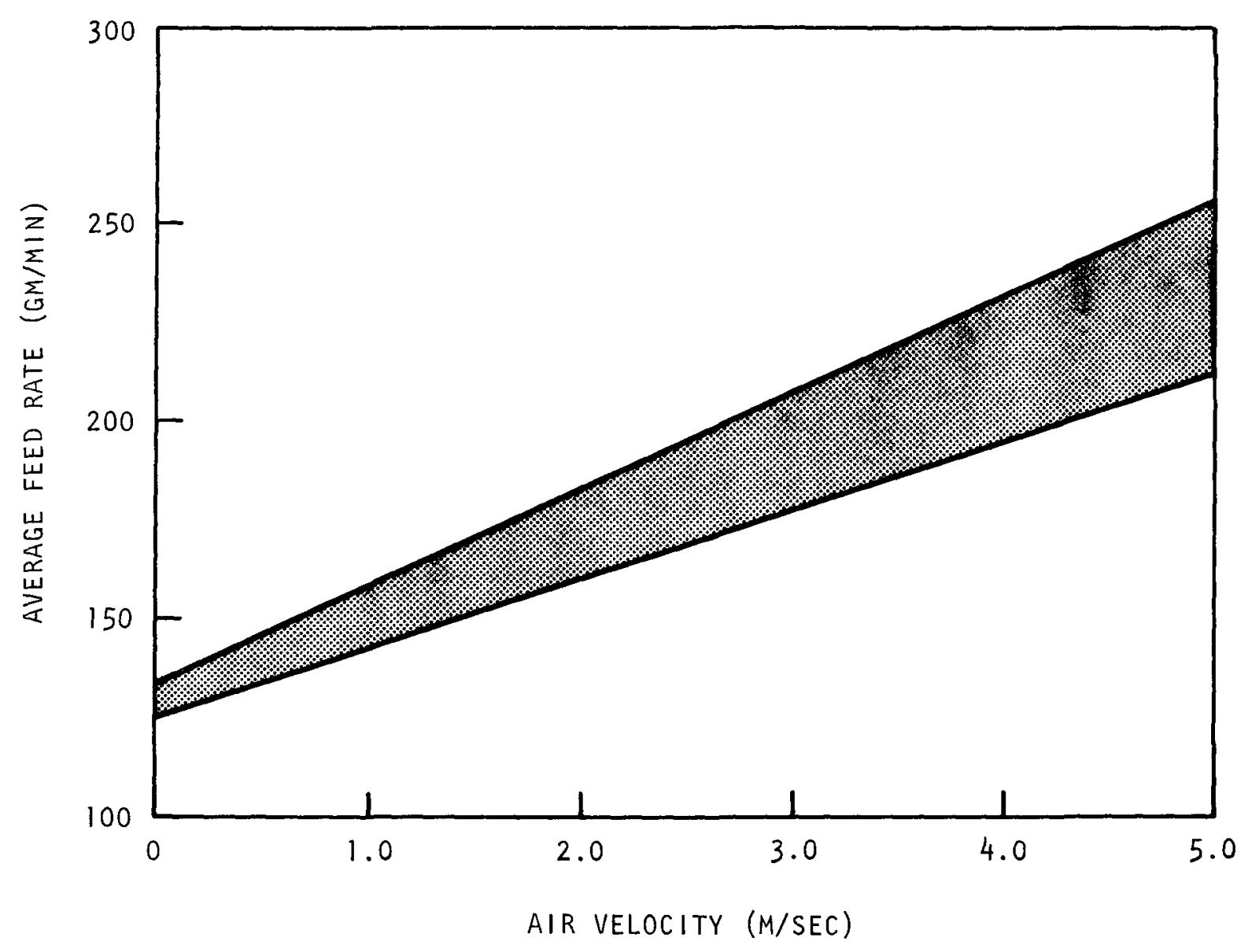

Fig. 4-30. Relationship between feed rate of vibratory feeder and air velocity rate (vacuum) 
gm/min (see Fig. 4-31), and the feed rate was unaffected by air velocity (vacuum), solids level in the hopper, or the structural support. The only parameters found to affect the rotary feeder's feed rate were turning speed and powder bulk density.

To compare the performance on the classifier of the rotary feeder with the vibratory one, the separation efficiency of the rotary was overlaid onto Figs. 4-11 and 4-12 (which describe the vibratory feeder), giving Figs. 4-32 and 4-33. From examination of these figures, the effect on separability can be determined. If the overlay produces a vertical line, then the feeders are the same. If, however, the overlay has a negative slope, the rotary feeder gives a better separation, and a positive slope indicates a poorer separation.

At $100 \mathrm{gm} / \mathrm{min}$ (Fig. 4-32), the run at $3.15 \mathrm{~m} / \mathrm{sec}$ showed a slight improvement in separation; at $3.70 \mathrm{~m} / \mathrm{sec}$ no improvement occurred. The effective air velocity (at $\phi=50 \%$ ) increased for the $3.15 \mathrm{~m} / \mathrm{sec}$ run to $3.25 \mathrm{~m} / \mathrm{sec}$; for the $3.70 \mathrm{~m} / \mathrm{sec}$ run it decreased to $3.40 \mathrm{~m} / \mathrm{sec}$. This apparent decrease in sensitivity to air velocity change becomes even more apparent in Fig. 4-33, where the runs at 3.15 and $3.70 \mathrm{~m} / \mathrm{sec}$ at $300 \mathrm{gm} / \mathrm{min}$ feed rate converge to $3.32 \mathrm{~m} / \mathrm{sec}$. These runs also exhibit a slight decrease in separability. Because of this insensitivity to changes in air velocity, the vibratory type of feeder was chosen over the rotary. To improve the accuracy of the vibratory feeder, a solids feed rate sensor is recommended in a closed control loop (Ref. 21). 


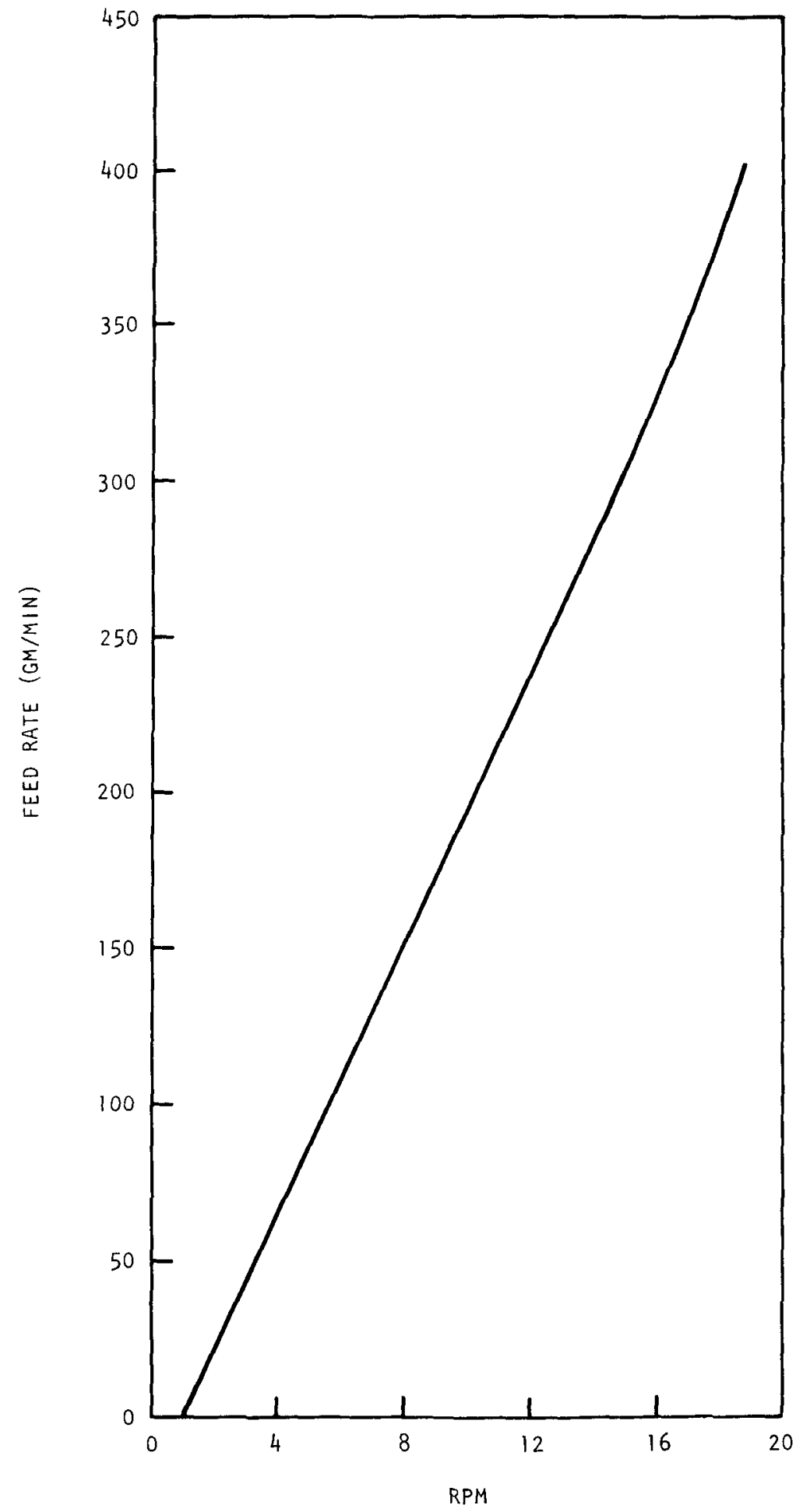

Fig. 4-31. Relationship between feed rate of rotary feeder and its rpm 4-62 


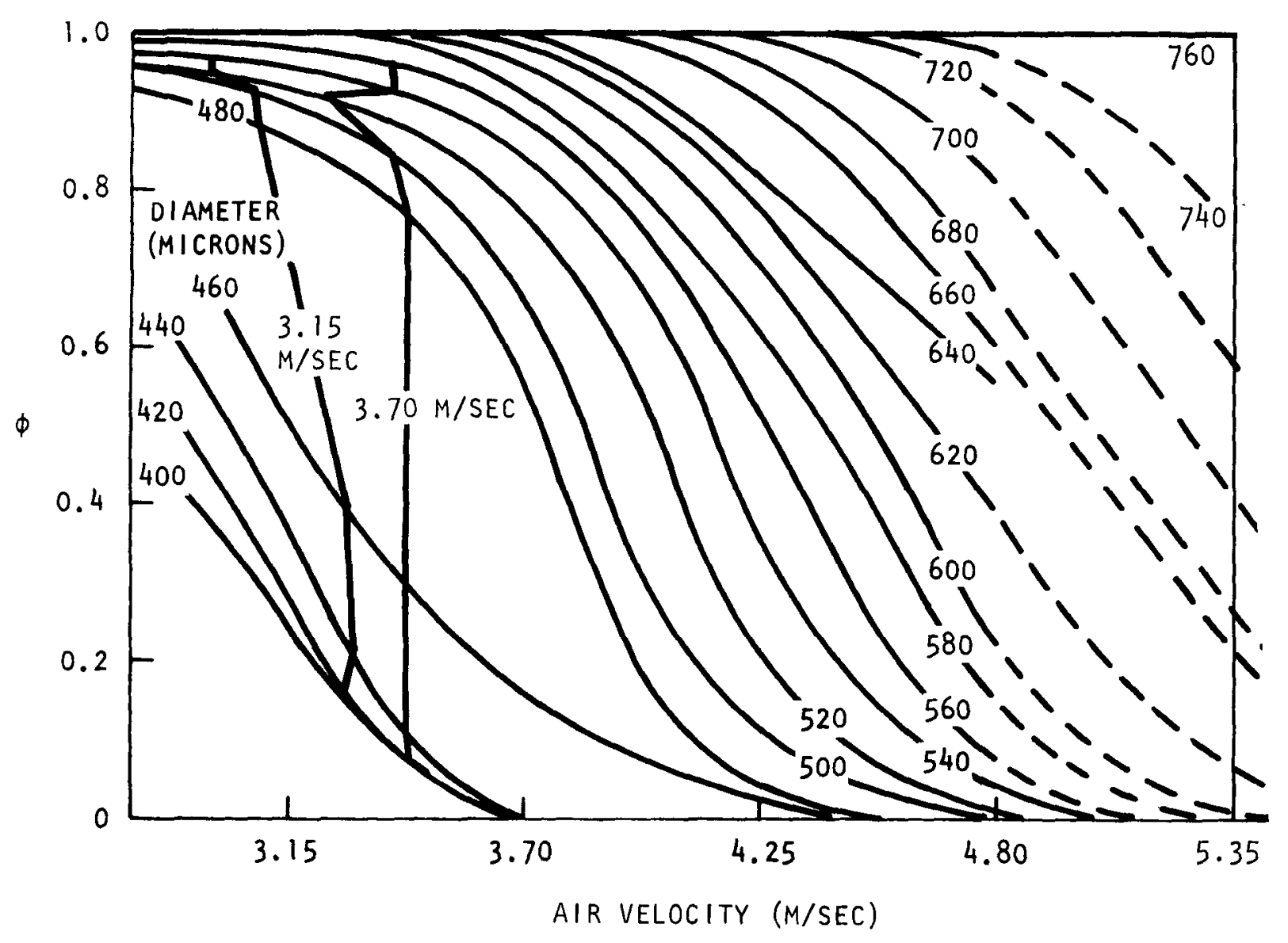

Fig. 4-32. Comparison of rotary feeder performance and vibratory feeder performance at $100 \mathrm{~g} / \mathrm{min}$ 


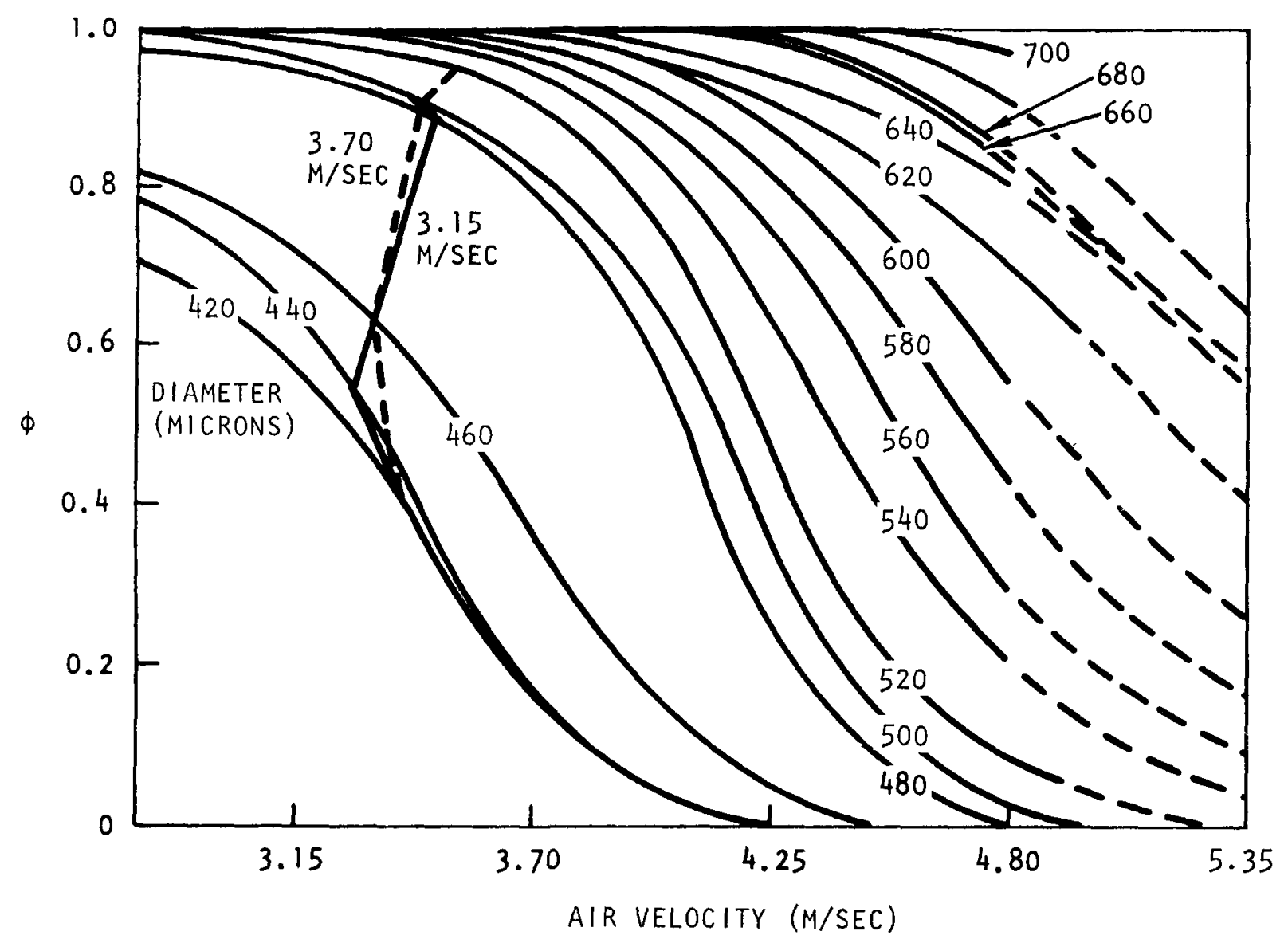

Fig. 4-33. Comparison of rotary feeder performance and vibratory feeder performance at $300 \mathrm{~g} / \mathrm{min}$ 


\section{MODULAR PNEUMATIC CLASSIPIER}

The entire work establishing the relationship between the operating parameters of pneumatic classification and crossover used the Alpine Multiplex Zigzag Classifier (Fig, 4-1). To increase the understanding of pneumatic classification and to verify the design of the Alpine, a modular classifier was constructed. Figures F-1 through F-6 in Appendix F detail the individual components of the unit, with Figs. 5-1 and 5-2 giving an assembled view. Where possible, the design and the dimensions of the modular unit were taken from the Alpine except that the zigzag column was sectioned and a baffle was installed in the coarse product take-off cone.

By making the column in sections, the total height and the position of feed could be varied, permitting extensive parametric studies in the area of pneumatic classification of HTGR fuel.

The studies centered around finding the optimum height and feed point for HTGR fuel. Of the numerous combinations of height and position of the feed zone, only a few were explored. Figure 5-3 shows the six different configurations studied. For each conformation, one air velocity (3.70 $\mathrm{m} / \mathrm{sec})$ and four feed rates $(100,300,500$, and $700 \mathrm{gm} / \mathrm{min})$ were used. From these 24 tests, the optimum design was deduced for TRISO/TRISO fuel.

\subsection{FEED}

In the 24 parametric tests on the modular pneumatic classifier, a common feed was utilized. With the availability of both simulated and FSV type fuel, the choice was based on previous testing. Simulated fuel was picked for the following reasons: 


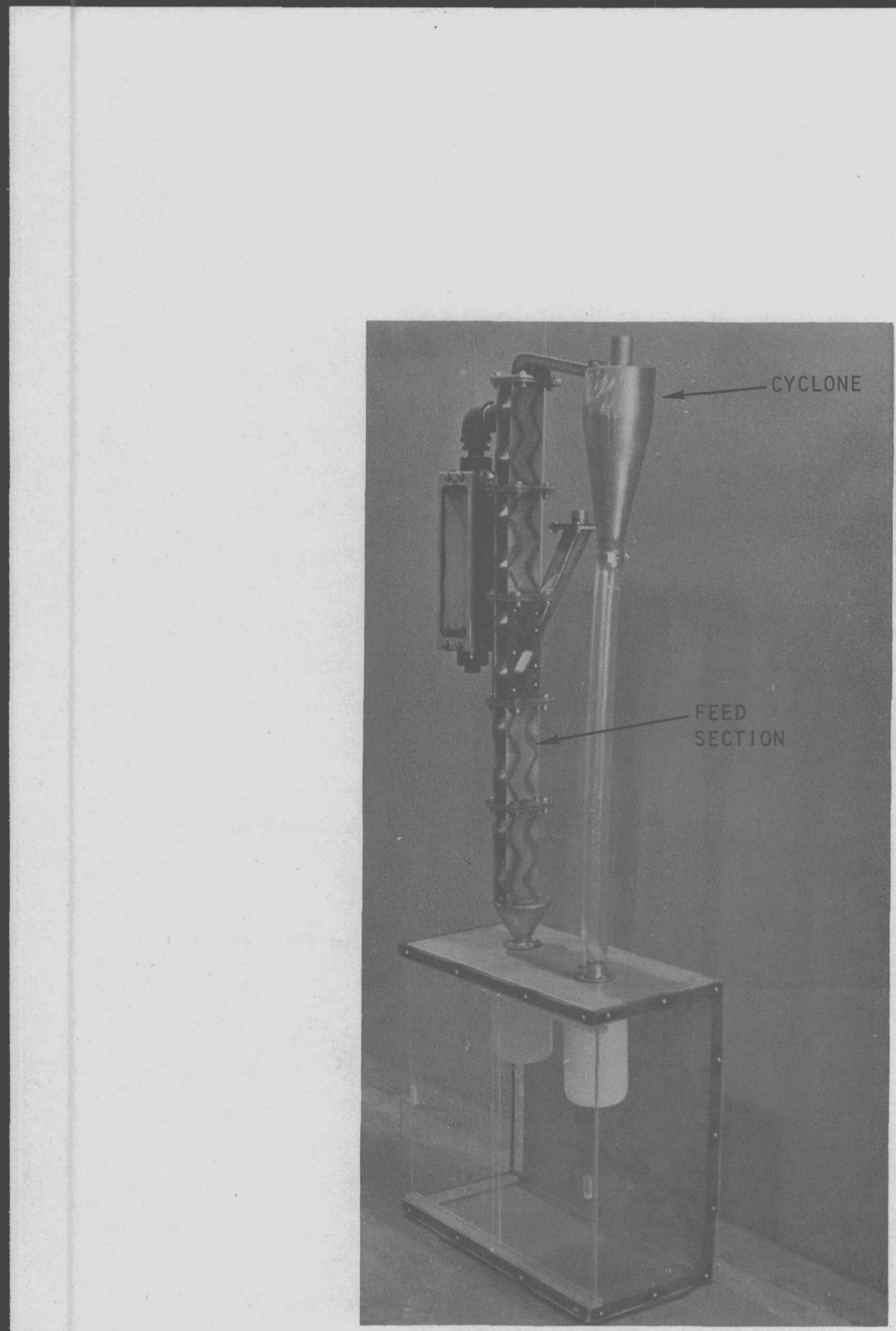

Fig. 5-1. Modular pneumatic classifier 


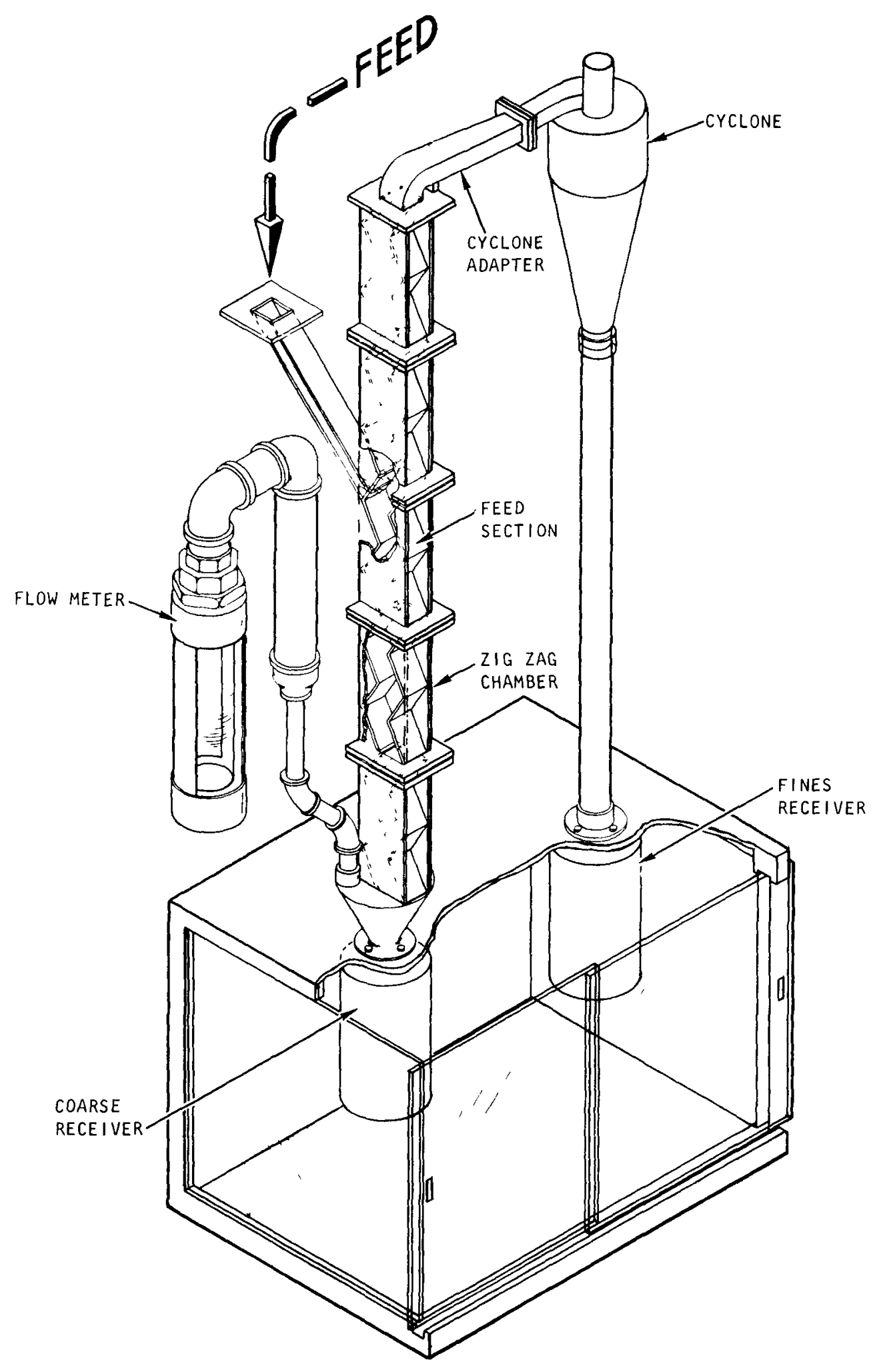

Fig. 5-2. Schematic of modular preumatic classifier 

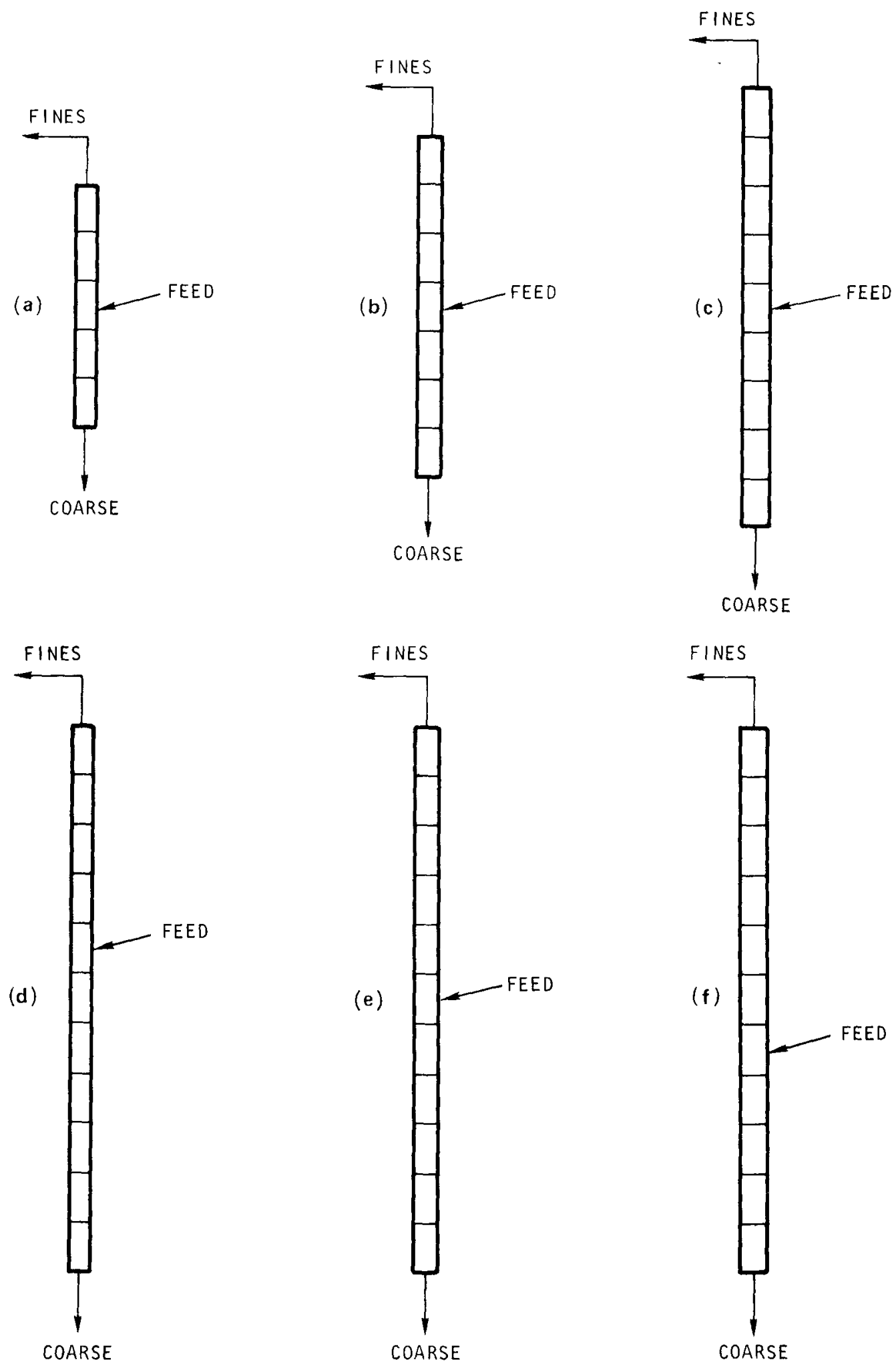

Fig. 5-3. Height and feed position configurations of modular classifier investigated 
1. It was more sensitive to changes in the operating parameters of the Alpine classifier.

2. Its operating characteristics were best known.

The characteristics of this feed are covered in Section 4.2, Simulated Feed.

\subsection{RESULTS}

\subsubsection{Effect of Height}

To determine the effect of height on the efficiency of separation, four configurations were used (Figs. 5-3a, 5-3b, 5-3c, and 5-3e). In all of these arrangements, the feed position remained in the center. An equal number of sections was added above and below it to increase the height from the size of the Alpine classifier to over twice as high.

For evaluating the test, the separation efficiency data were overlaid on Figs. 4-11, 4-12, and 4-13. For the overlay, the feed rate and the separation efficiency for each size increment were used to locate the curve. This curve represents an equivalent air velocity at $\phi=0.50$, and as this line deviates from the vertical, the separability of the modular classifier deviates from that of the Alpine. A negatively sloped line Indicates an improved separation, while a positive slope indicates a poorer separation. Figures 5-4 through 5-6 illustrate the results of the overlaying for three feed rates, 100, 300, and $500 \mathrm{gm} / \mathrm{min}$. From the comparison of these figures, the effect of the height of the column was found to depend upon the feed rate. At $100 \mathrm{gm} / \mathrm{min}$ (Fig. 5-4), there was no difference in the slopes of the curves for the four different heights. However, at $300 \mathrm{gm} / \mathrm{min}$ (Fig. 5-5) the efficiency began to improve for the coarse region $(\phi<0.50)$, and at $500 \mathrm{gm} / \mathrm{min}(\mathrm{Fig} .5-6)$ there was improvement over the entire range. This indicates the increased height is only needed for increased feed rates. Reference 22 states that increased height above five diameters has little effect upon separation. However, those tests 


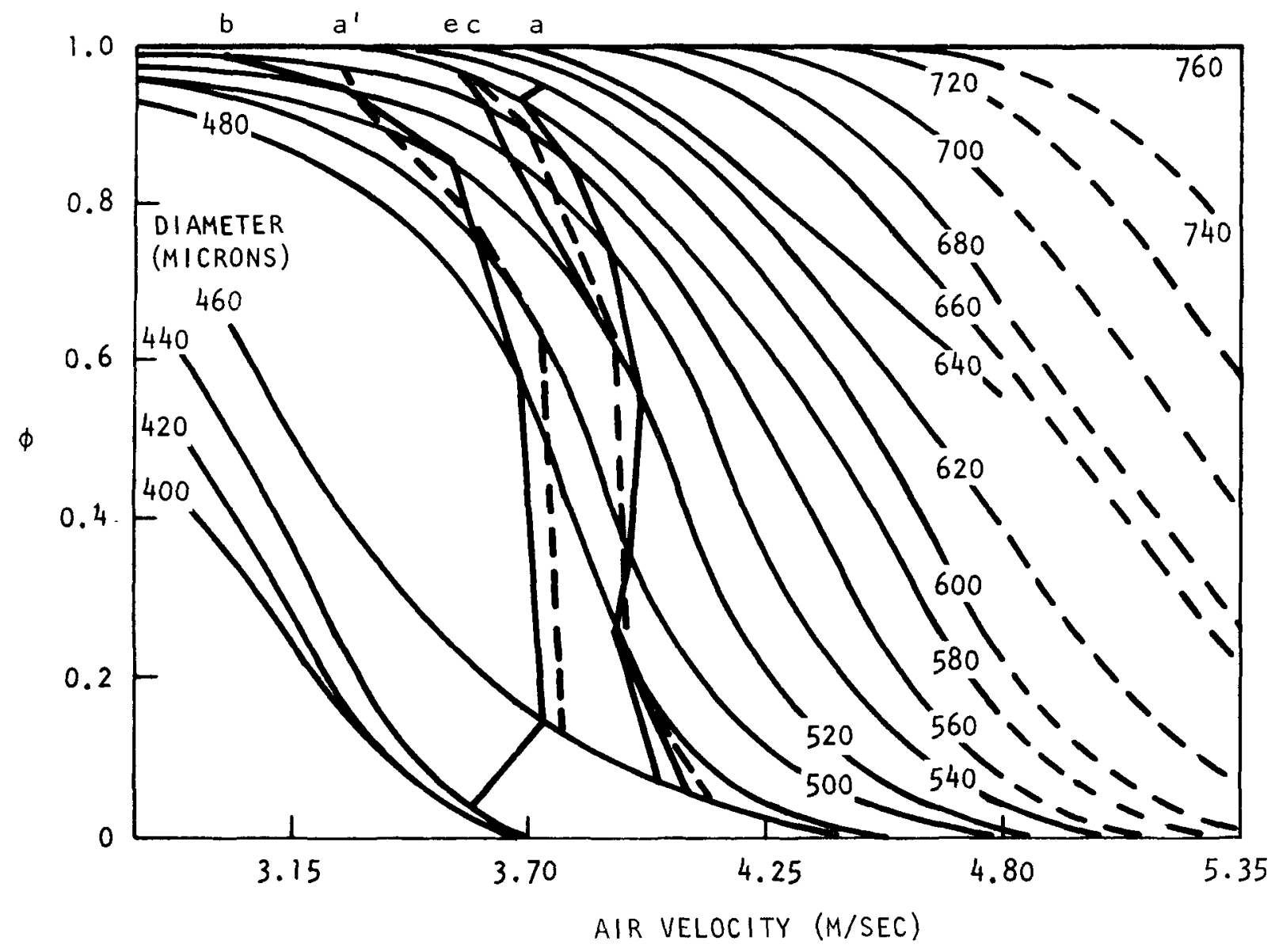

Fig. 5-4. Comparison with respect to height of separation efficiency of modular classifier configurations with that of Alpine classifier at a constant solids feed rate of $100 \mathrm{~g} / \mathrm{min}$ 


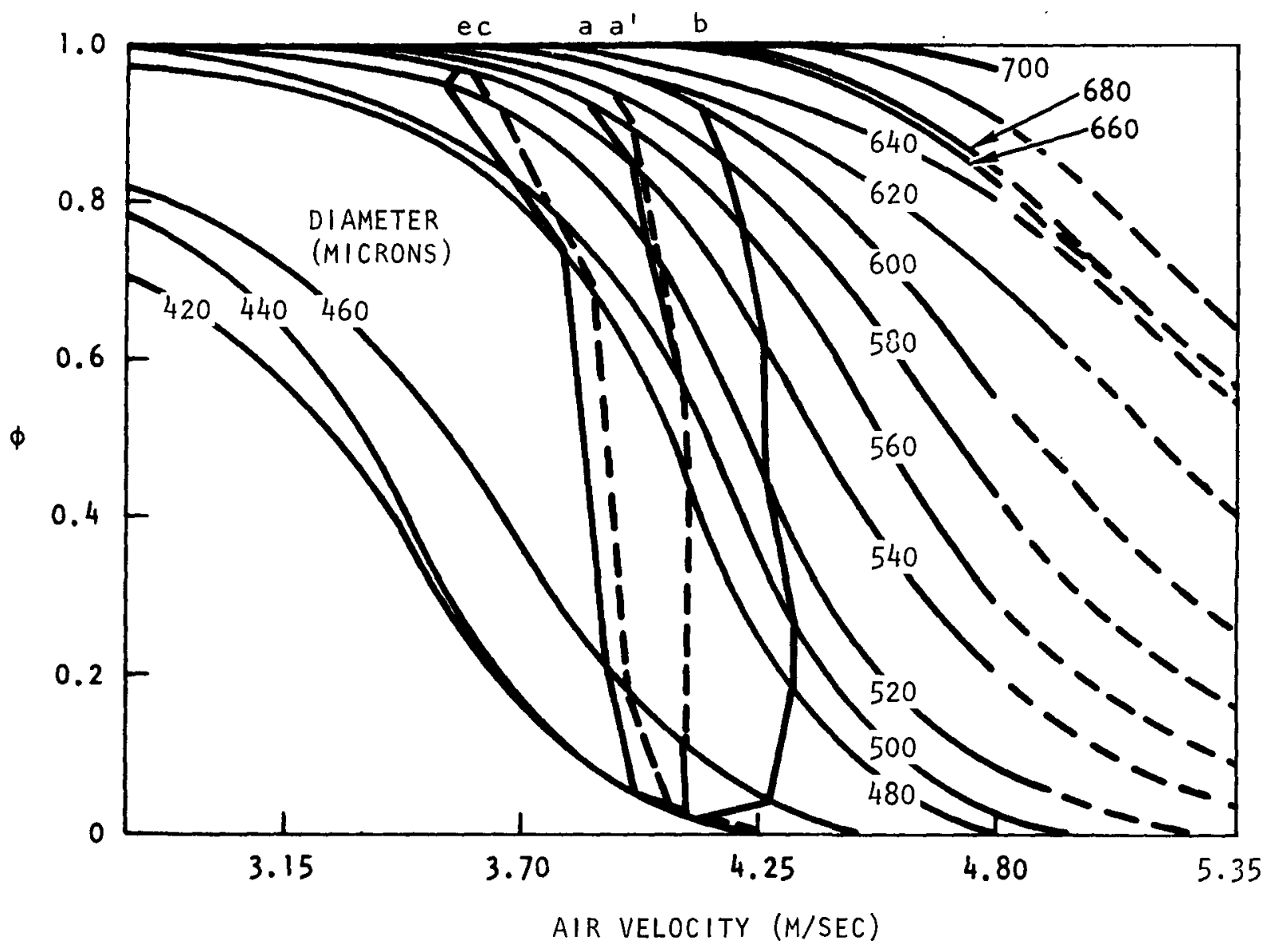

Fig. 5-5. Comparison with respect to height of separation efficiency of modular classifier configurations with that of Alpine classifier at a constant solids feed rate of $300 \mathrm{~g} / \mathrm{min}$ 


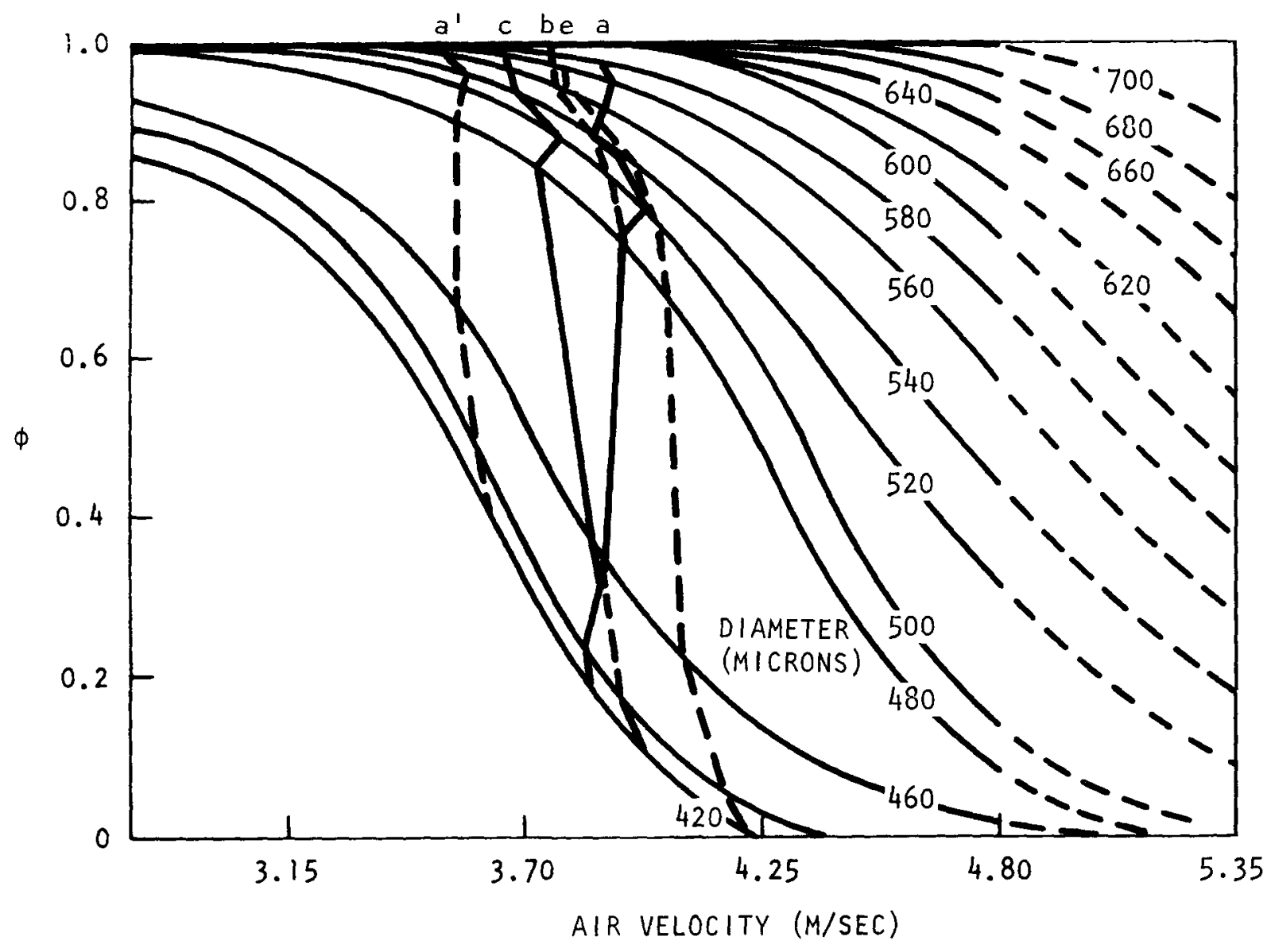

Fig. 5-6. Comparison with respect to height of separation efficiency of modular classifier configurations with that of Alpine classifier at a constant solids feed rate of $500 \mathrm{~g} / \mathrm{min}$ 
were on a much larger scale with more tolerance allowed in the separation efficiency. For the classification of HTGR fuel a higher column will allow higher feed rates and therefore greater capacity.

\subsubsection{Effect of Feed Position}

The same method used to determine the effect of height was used to determine the effect of the feed position. The data which resulted from the tests of configurations 5-3d, 5-3e, and 5-3f were overlaid on Figs. $4-11,4-12$, and $4-13$ and represented in Figs. 5-7, 5-8, and 5-9. Again, when the figures and curves are compared, the effect of feed position is negligible at a feed rate of $100 \mathrm{gm} / \mathrm{min}$ (Fig. 5-7), but as the feed rates increase, the effect of the feed position becomes clear. In Fig. 5-8, the effect of raising the feed zone can be evaluated. As would be expected, the separation efficiency for the coarse region $(\phi>0.50)$ improved while that for the fine region $(\phi<0.50)$ worsened. In Fig. 5-9, the effect of lowering the feed zone was found to give the opposite effect of raising the zone. Again, the effect of the changes in the design of the classifier was not seen until the higher feed rates were tested.

\subsection{GENERAL}

Having thus established the effects of the column height and the position of the feed zone, it can be seen that the one common point in all figures is that in every case the modular classifier gave better separation in the coarse region than the Alpine classifier. This has been attributed to the addition of the baffle to the coarse product takeoff cone. (See Figs. 5-4 through 5-9.) 


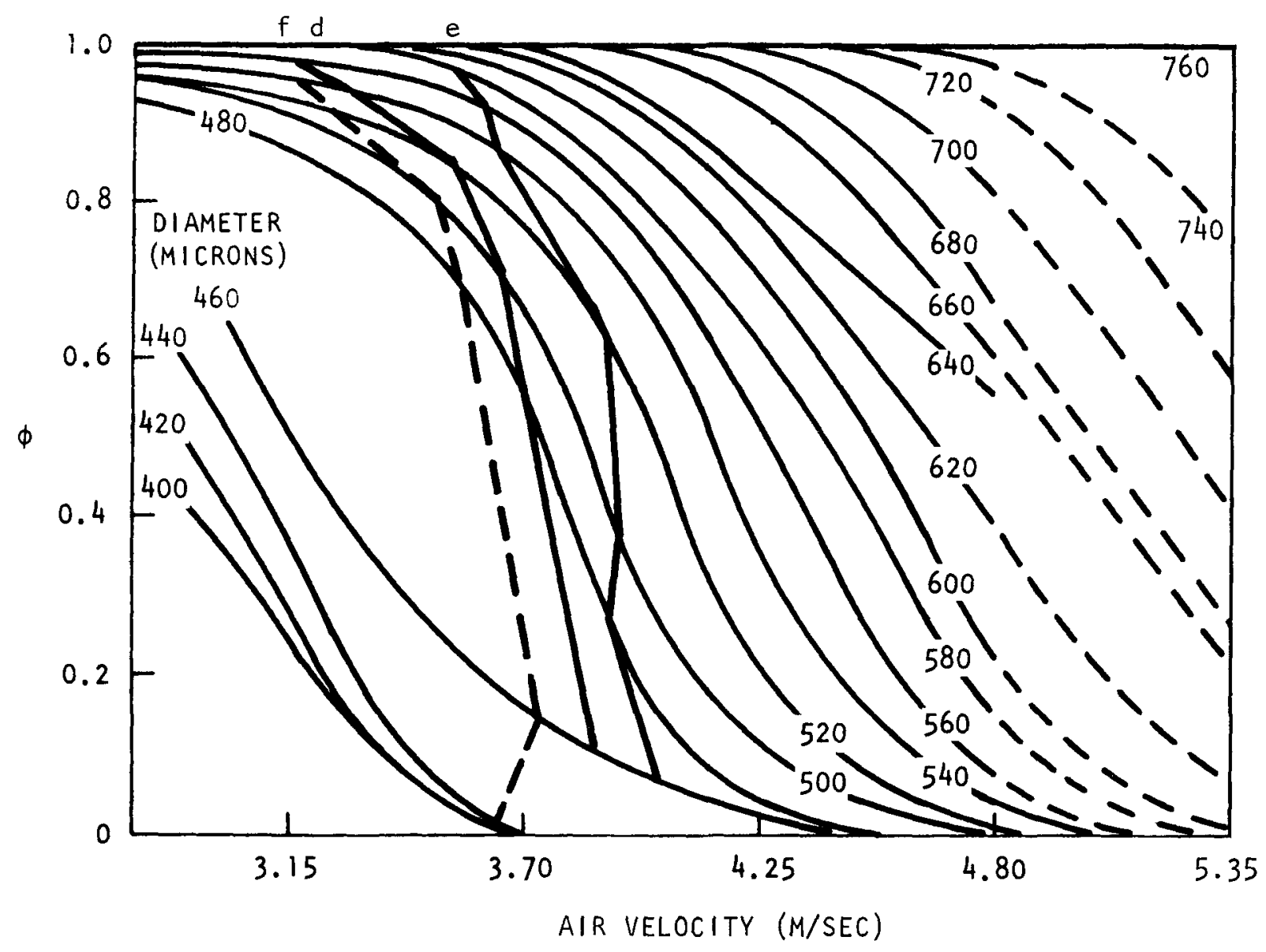

Fig. 5-7. Comparison with respect to feed position of separation efficiency of modular classifier configurations with that of Alpine classifier at a constant solids feed rate of $100 \mathrm{~g} / \mathrm{min}$ 


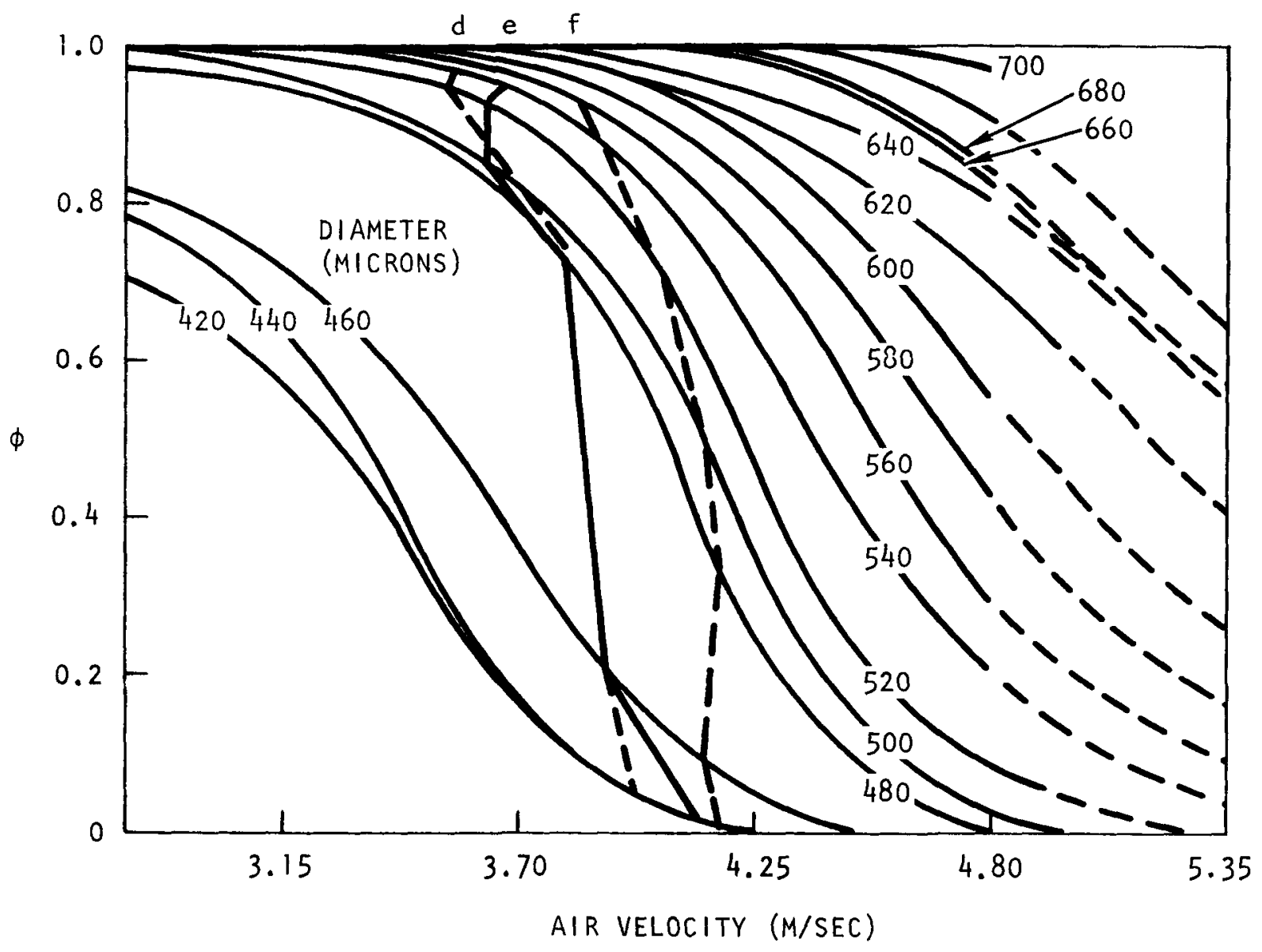

Fig. 5-8. Comparison with respect to feed position of separation efficiency of modular classifier configurations with that of Alpine classifier at a constant solids feed rate of $300 \mathrm{~g} / \mathrm{min}$ 


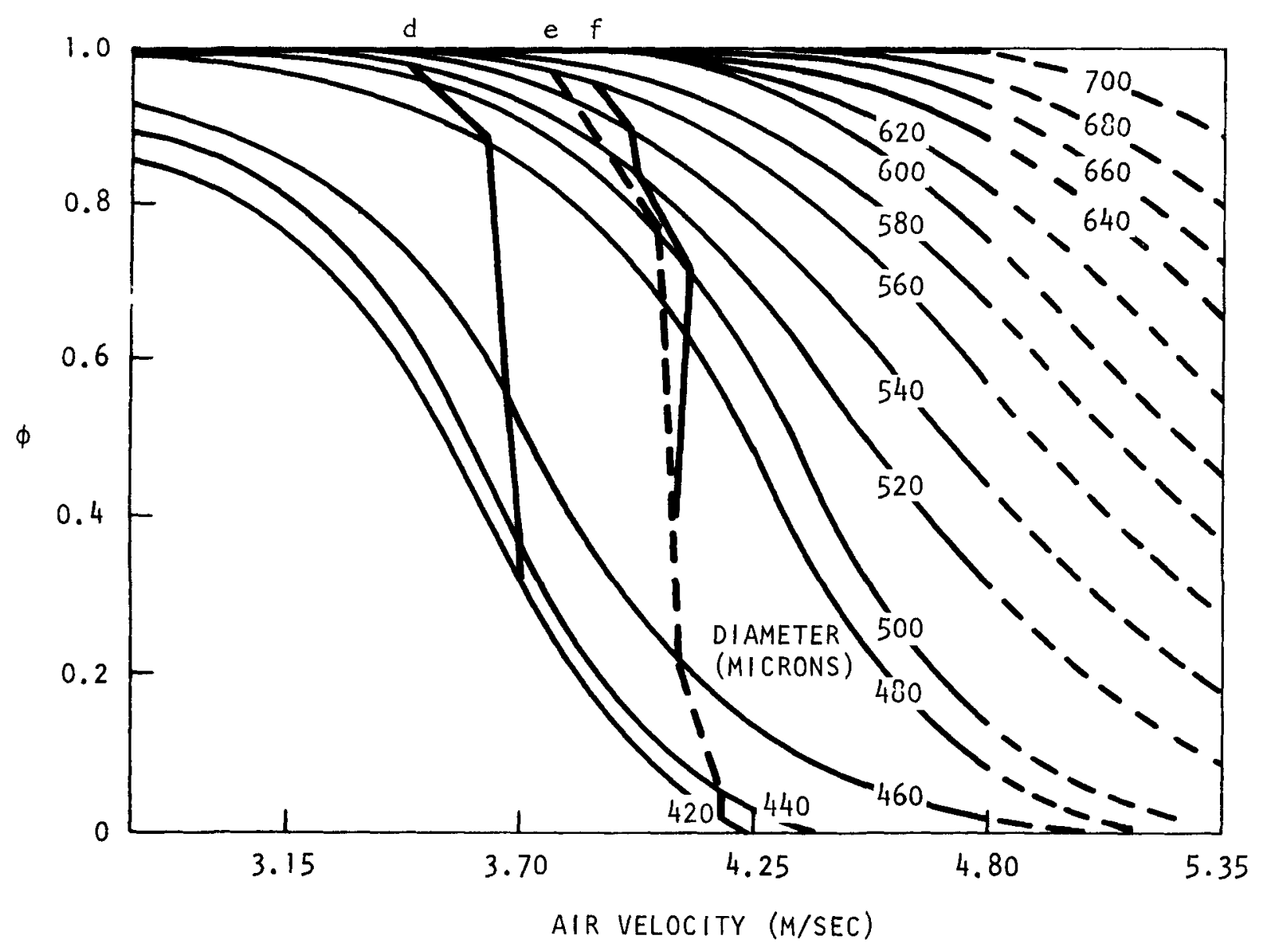

Fig. 5-9. Comparison with respect to feed position of separation efficiency of modular classifier configurations with that of Alpine classifier at a constant solids feed rate of $500 \mathrm{~g} / \mathrm{min}$ 


\section{SIEVING}

The preceding sections have dealt with the pneumatic classification of HTGR fuel particles. For comparison, sieving was investigated. This investigation involved establishing the blinding rate of the screen, the throughput of the particles, the efficiency of separation, and comparison of these with their counterparts in pneumatic classification.

For the test three fuel compositions were used: simulated feed, Fissile A/Fertile $B$, and Fissile B/Fertile $A$. The first was used for comparison with the majority of pneumatic classification tests. The second and third types represent the two extreme combinations of distributions (minimum and maximum overlaping) encountered. The characteristics of these feeds have been discussed in Sections 4.1,4.2, and 4.3.

\subsection{DESCRIPTION OF EXPERIMENTAL PROCEDURE}

A11 of the experiments were carried out on a Rotap sieve shaker using a $500 \mu, 8$ in. Tyler sieve to separate the fissile and fertile streams. A typical run entailed loading $200 \mathrm{gm}$ of particles onto the screen and shaking it for a set time interval which varied from 5 min upward in multiples of five. When shaking was completed, the undersize and oversize fractions were weighed along with the amount accumulated on the screen. Without cleaning the screen, the fines were replaced on the screen and the shaking continued for a prescribed length of time. When the change in weight of the products was greater than $1 \mathrm{wt} \% / 5 \mathrm{~min}$, this procedure was repeated. When the weight change was less than $1 \%$, the two fractions were removed and an additional $200 \mathrm{gm}$ of particles loaded onto the screen without cleaning it.

This procedure was followed until the percent passing through the screen plotted against time yielded identical results for the last two 
charges. Similar runs were made for 400 and $800 \mathrm{gm}$ charges, and the series was repeated for the various fuel compositions.

In this manner a relationship between the type of feed, solids loading, blinding rate, throughput, and separation efficiency was found. Once this was established, a comparison between pneumatic classification and sieving was drawn.

\subsection{BLINDING RATE}

Basically, blinding rate describes how fast the screen openings plug with feed material. For irregularly shaped particles this rate is low, while for spherical particles like HTGR fuel particles the rate is high. This rate can be described either as the percent of the screen that is filled or as the weight percent of the feed passing through the screen, and these in turn can be described as functions either of the sieving time or of the cumulative weight of the feed passing through the screen. In this report, the percent of screen filled versus the cumulative weight of undersize feed will be used as the blinding rate.

Figures 6-1 through 6-3 give the blinding rates for the various types of feed. Simulated feed and Fissile B/Fertile A feed have similarly shaped curves; both approach the limiting value of 98 to $99 \%$ filled after only 225 to $325 \mathrm{gm}$ of undersize feed have been collected. On the other hand, Fissile A/Fertile $B$ feed has a much slower blinding rate, and the end result of $99 \%$ plugged will be achieved only after approximately 1700 gm of undersize feed have been collected.

\subsection{THROUGHPUT}

Throughput for a screen is defined as mass per unit screen area per unit time; this mass may be either the total feed weight or the feed weight 


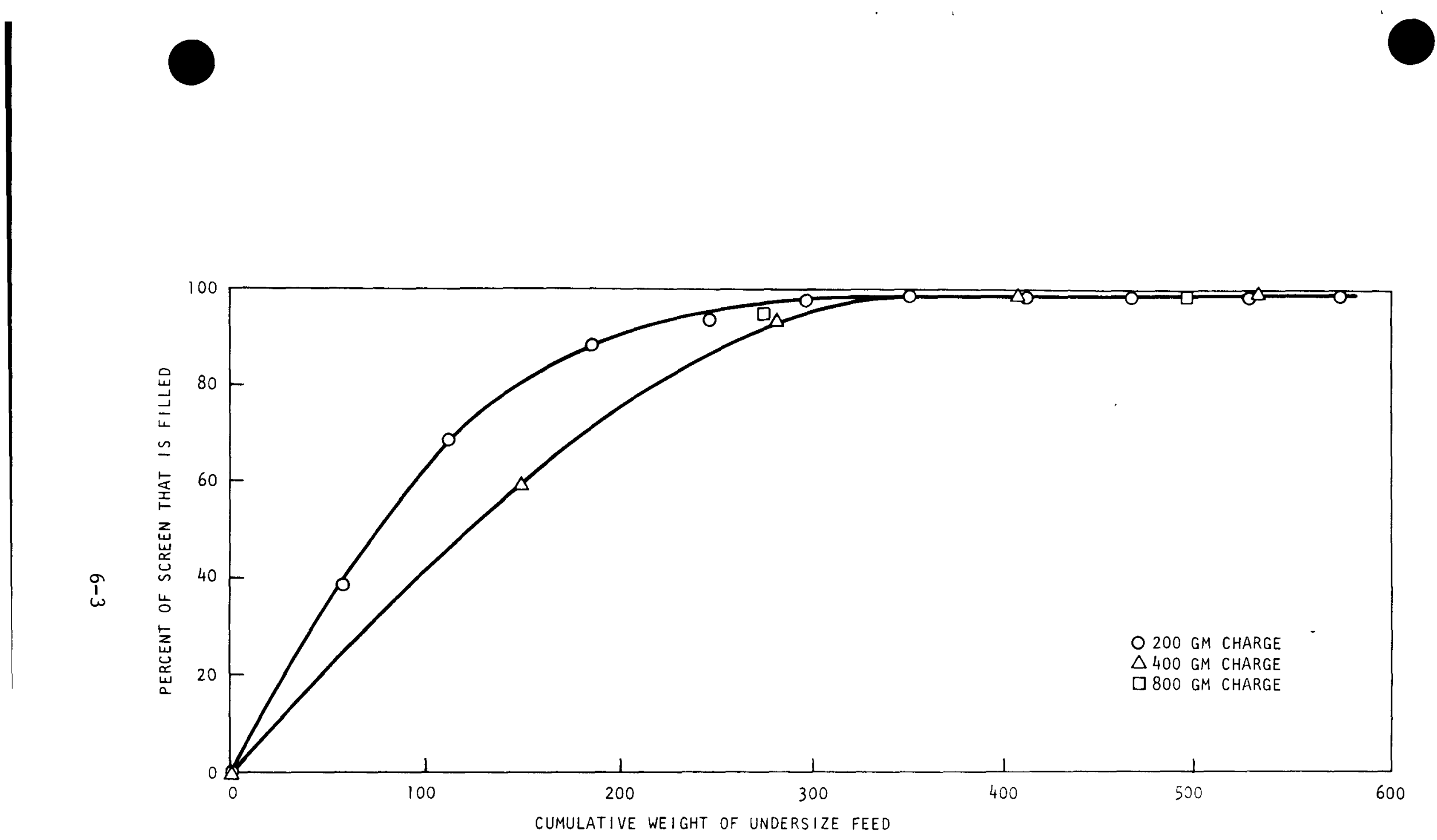

Fig. 6-1. Blinding rate of simulated feed 


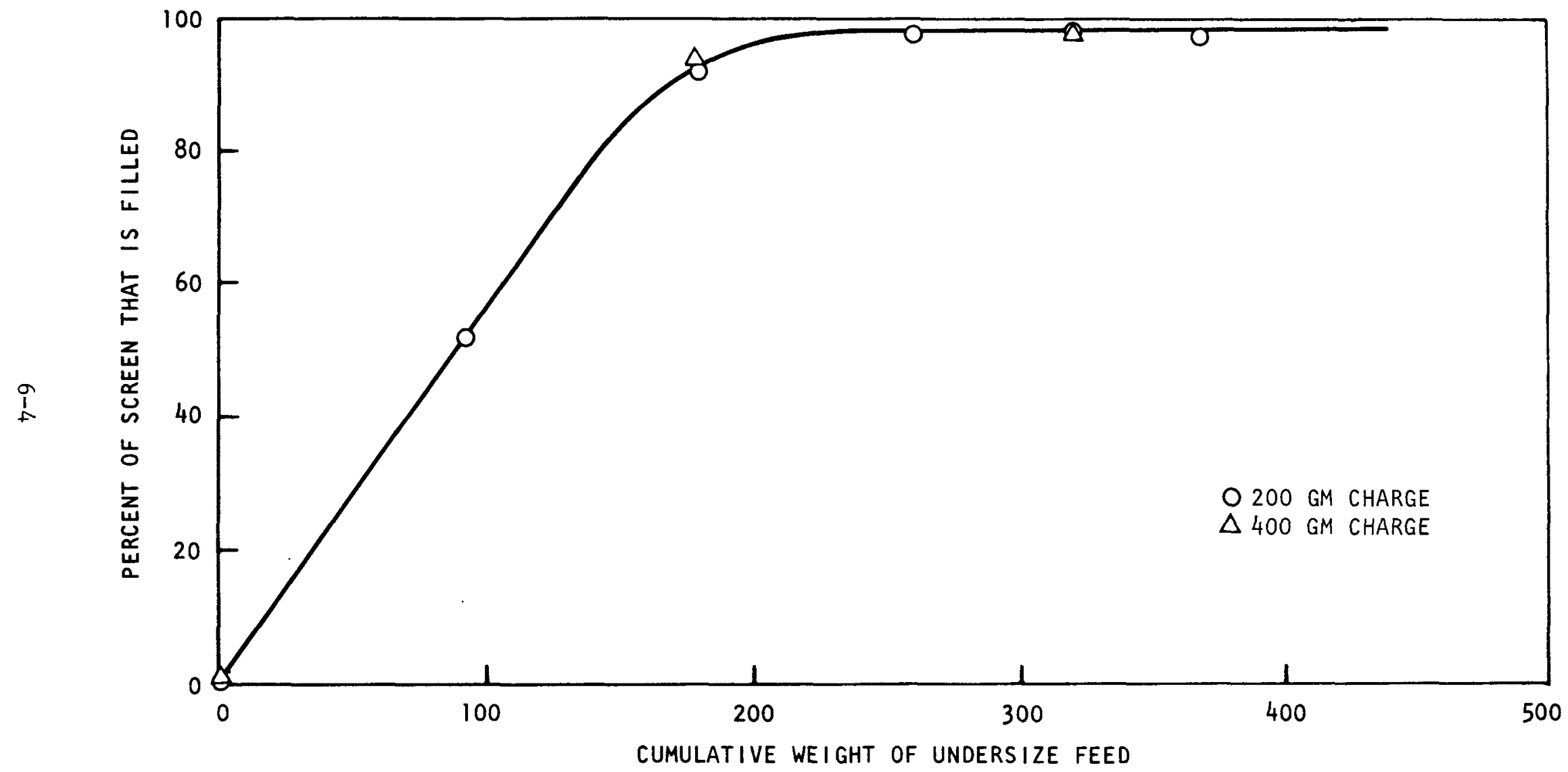

Fig. 6-2. Blinding rate of Fissile B - Fertile A FSV fuel 


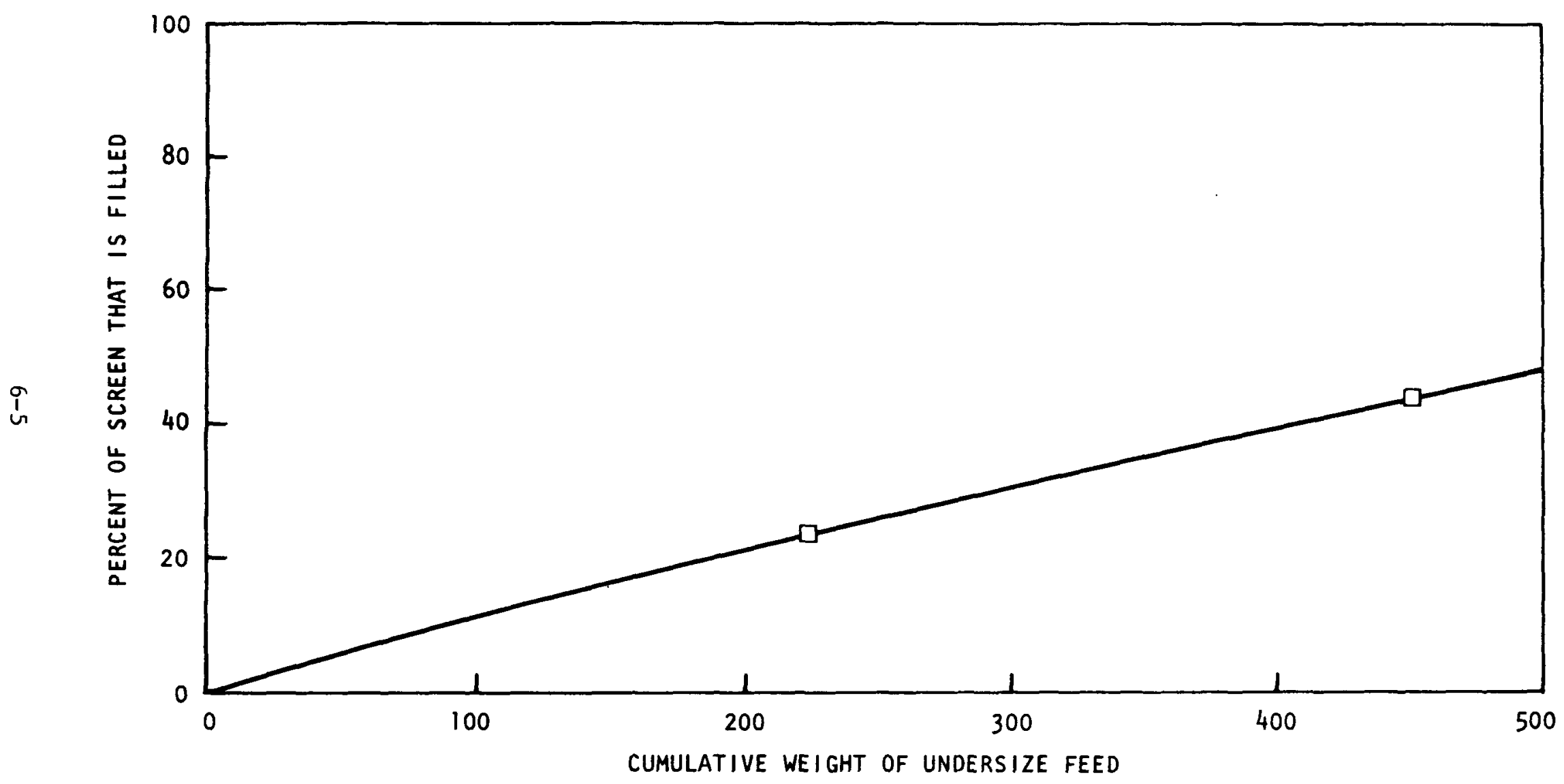

Fig. 6-3. Blinding rate of Fissile A - Fertile B FSV fuel 
passing through the screen. The throughput of a screen is proportional to the load on the screen, the blinding rate of the screen, and the amplitude and frequency of the shaker vibration. Basically, the throughput of a screen parallels the blinding rate. This becomes apparent by comparing Figs. 6-4 through 6-9 with Figs. 6-1 through 6-3. Table 6-1 gives the throughput for the various runs.

From these figures two distinct rates can be seen. The first rate is controlled by the probability of a particle smaller than the opening coming in contact with the opening (Ref. 23). During this first rate the mean size of the particles passing through is greater than that specified for the screen; however, as the screen becomes filled, the mean size reduces to the value specified for the screen. At this point the second rate becomes controlling.

Whereas the first rate constant depends upon the number of particles per unit time that are close in size to the aperture, the second rate constant depends upon the frequency and amplitude of the shaker, and the mass of particles on the screen. The second rate results from an equilibrium in which the rate at which holes become plugged is equal to the rate at which they become unplugged. The second rate decreases with time as more and more holes become permanently plugged until the amount passing through the screen approaches zero.

\subsection{EFFICIENCY OF SEPARATION}

As defined earlier, the efficiency of separation, $\phi$, is the ratio of the coarse product to the feed for a specified size interval. Figures 6-10 through 6-15 give the efficiency curves for the first and last charges for each run. A comparison of the curves for the first and last charges shows that the cut point $(\phi=50)$ decreases to a value equal to the screen size as the screen blinds with particles. In addition to the cut point 


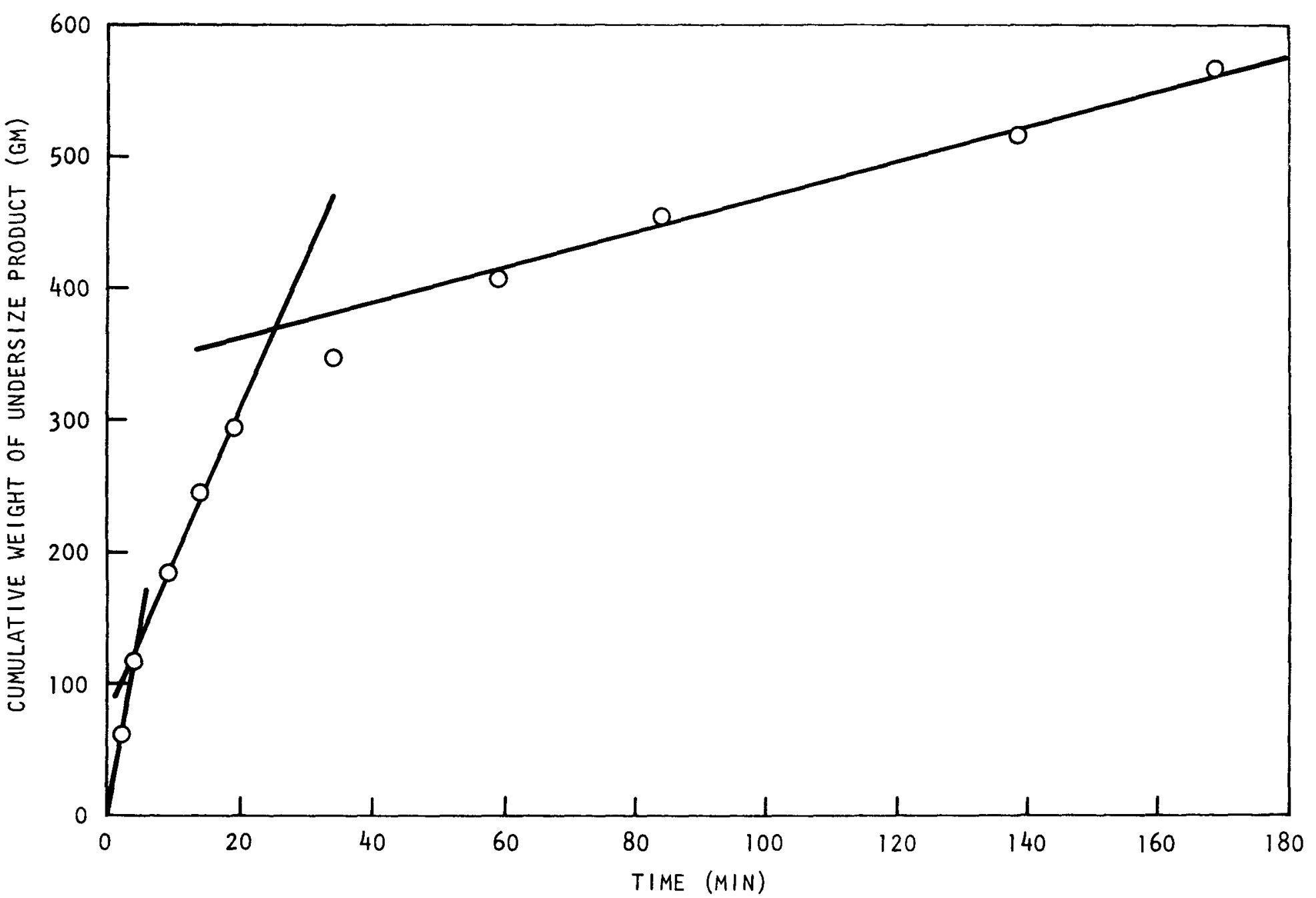

Fig. 6-4. Throughput of simulated feed, 200 gm charge 


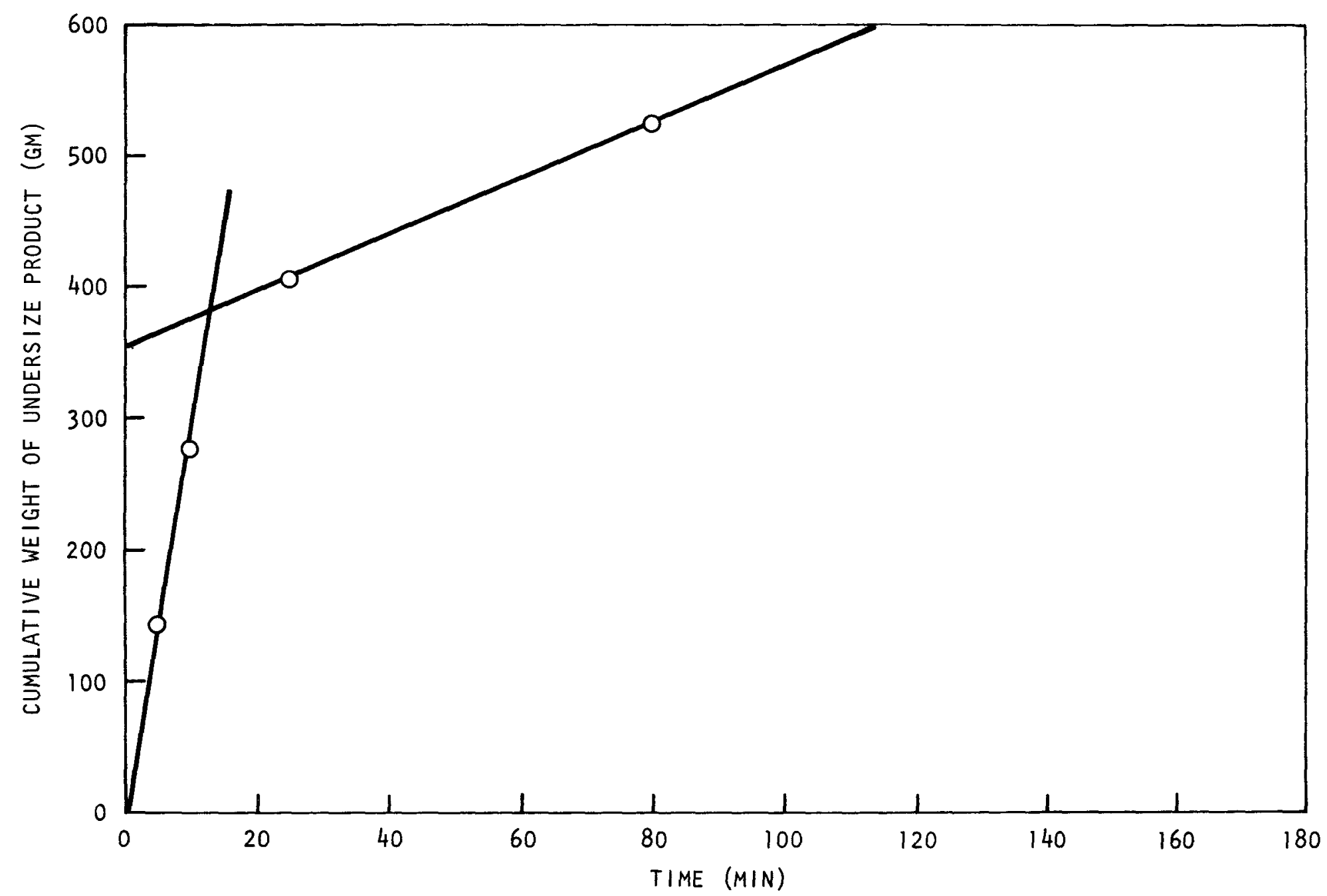

Fig. 6-5. Throughput of simulated feed, 400 gm charge 


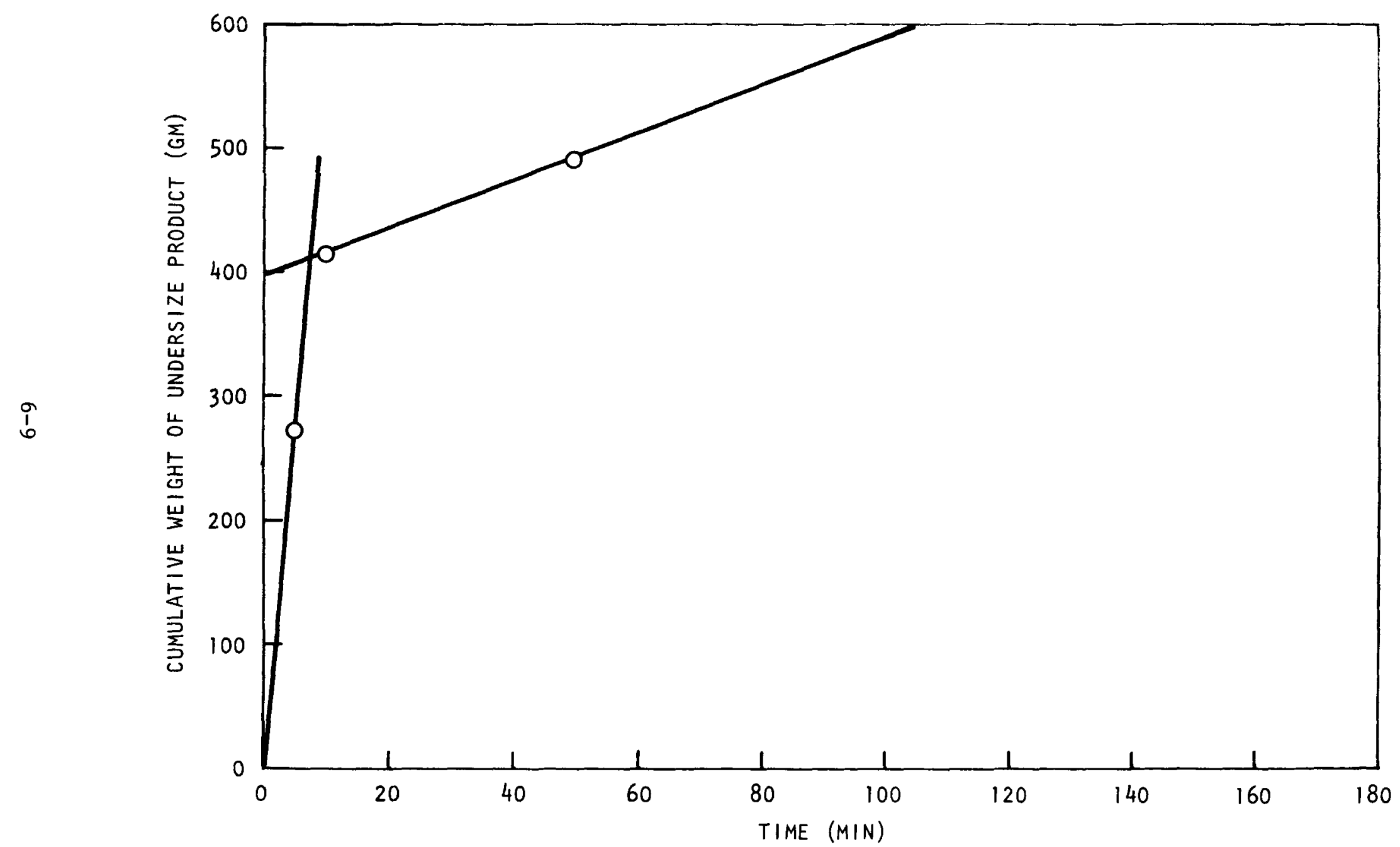

Fig. 6-6. Throughput of simulated feed, $800 \mathrm{gm}$ charge 


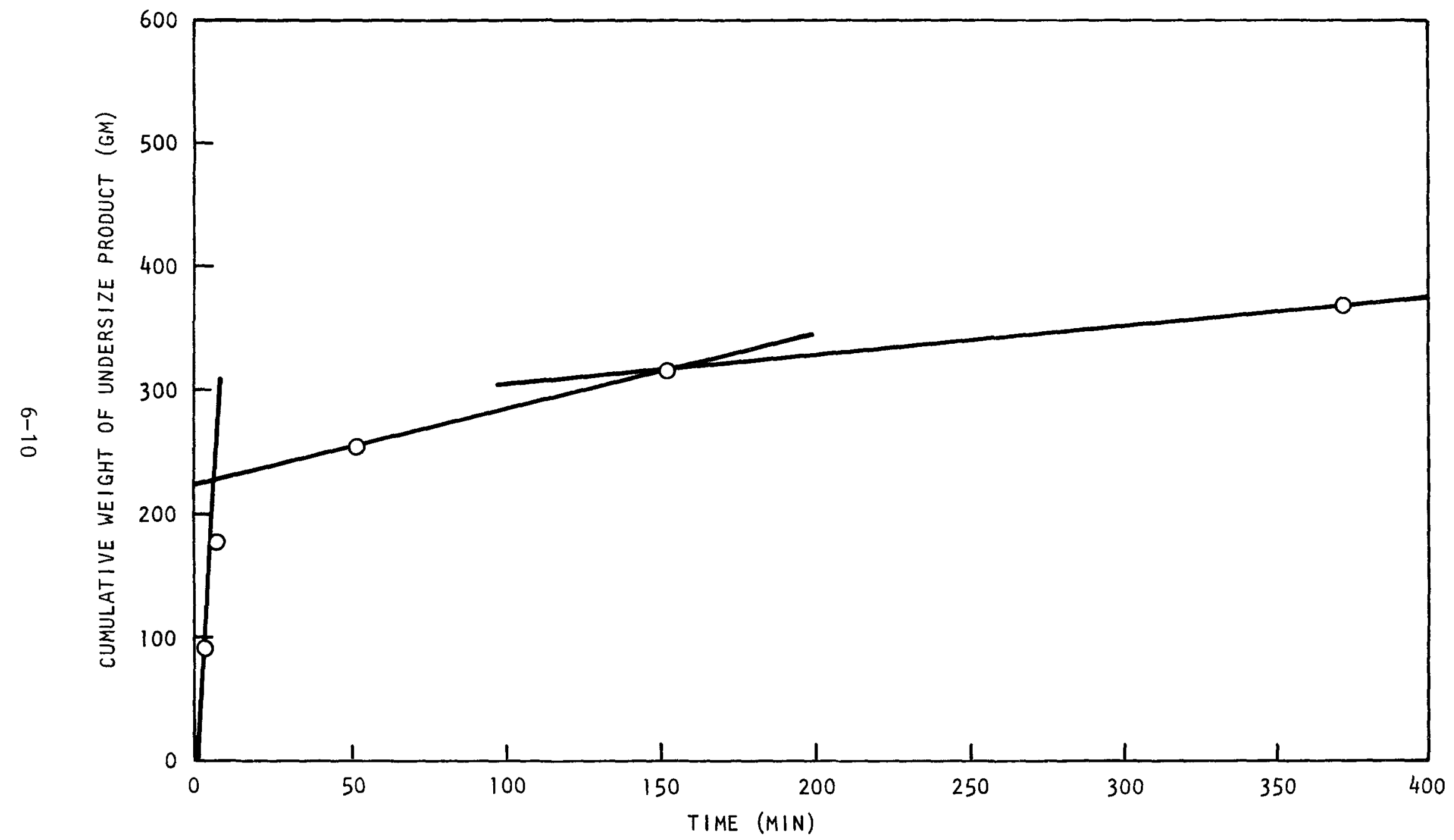

Fig. 6-7. Throughput of Fissile B - Fertile A FSV fuel, 200 gm charge 
0

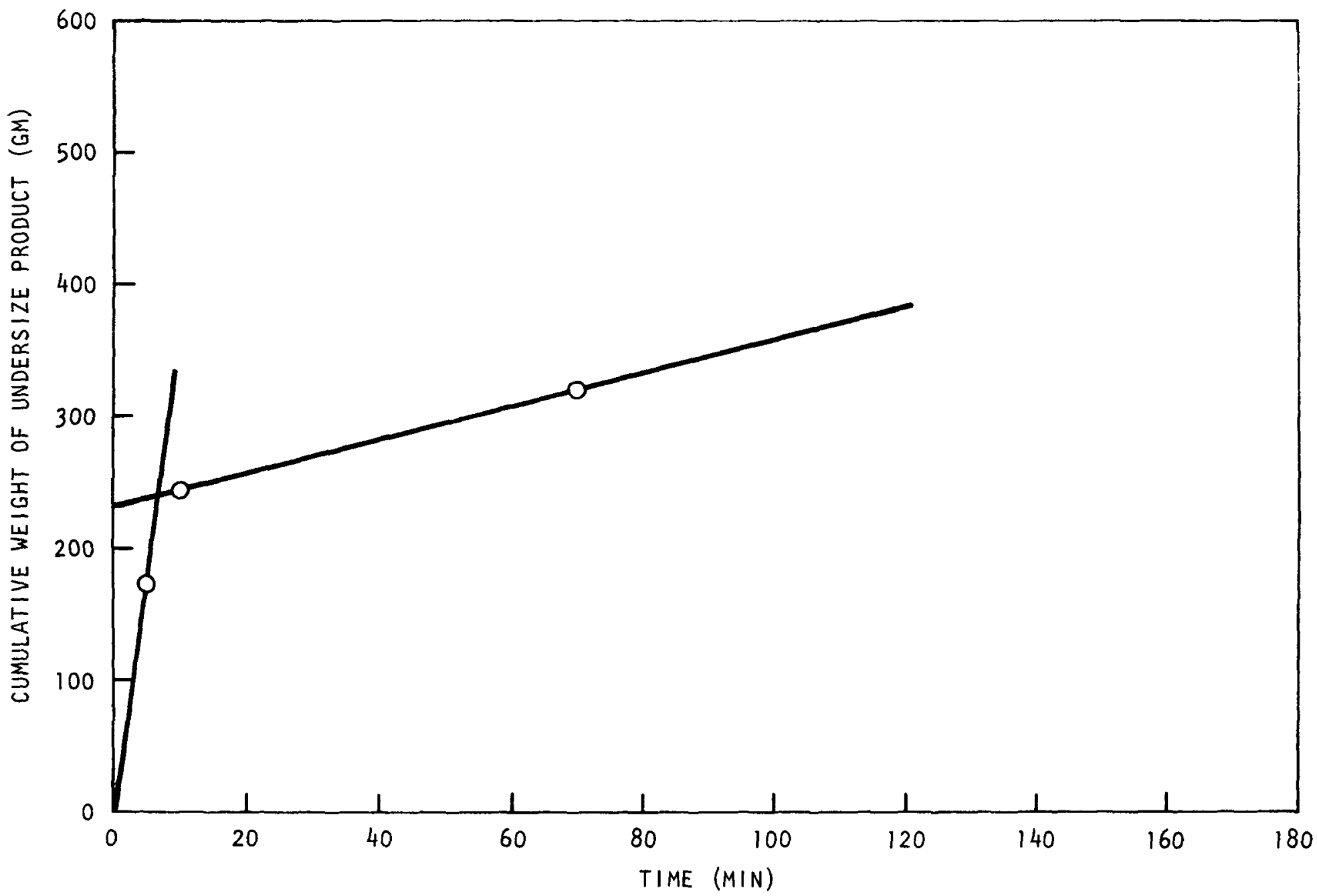

Fig. 6-8. Throughput of Fissile B - Fertile A FSV fuel, 400 gm charge 


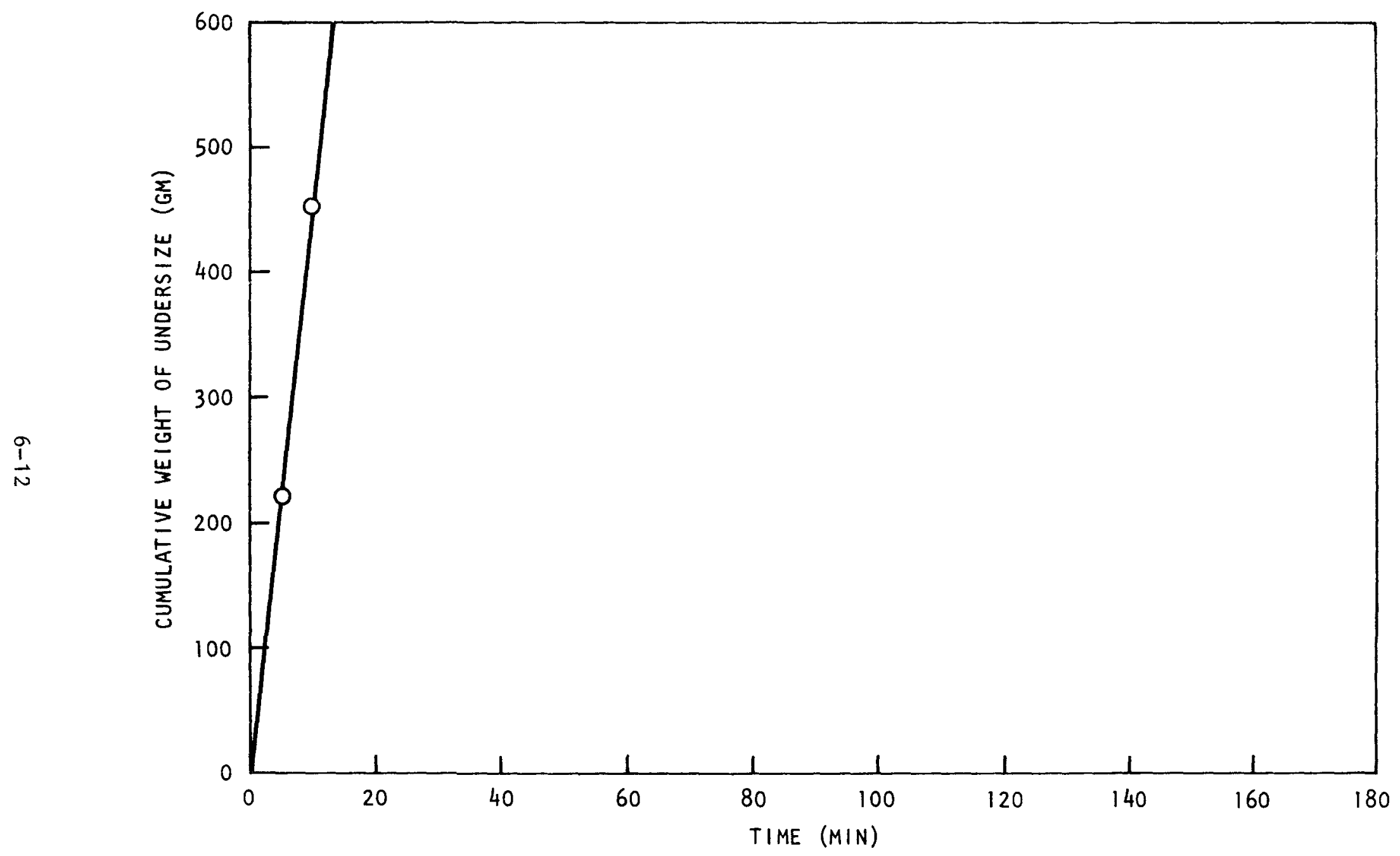

Fig. 6-9. Throughput of Fissile A - Fertile B FSV fuel, $800 \mathrm{~g}$ charge 
TABLE 6-1

THROUGHPUT OF VARIOUS FEEDS

\begin{tabular}{l|c|c|c|c}
\hline \multicolumn{1}{c|}{ Type of Feed } & $\begin{array}{c}\text { Charge } \\
\text { Size } \\
(\mathrm{gm})\end{array}$ & $\begin{array}{c}\text { 1st Rate } \\
\text { (gm/min-in.2) }\end{array}$ & $\begin{array}{c}\text { 2nd Rate } \\
\text { (gm/min-in.2) }\end{array}$ & $\begin{array}{c}\text { 3rd Rate } \\
\text { (gm/min-in.2) }\end{array}$ \\
\hline Simulated & 200 & 0.41 & 0.047 & -- \\
& 400 & 1.03 & 0.075 & -- \\
& 800 & 1.68 & 0.067 & -- \\
Fissile B-Fertile A & 200 & 1.33 & 0.024 & 0.019 \\
& 400 & 1.33 & 0.040 & -- \\
Fissile A-Fertile B & 800 & 1.61 & -- & - \\
\hline
\end{tabular}




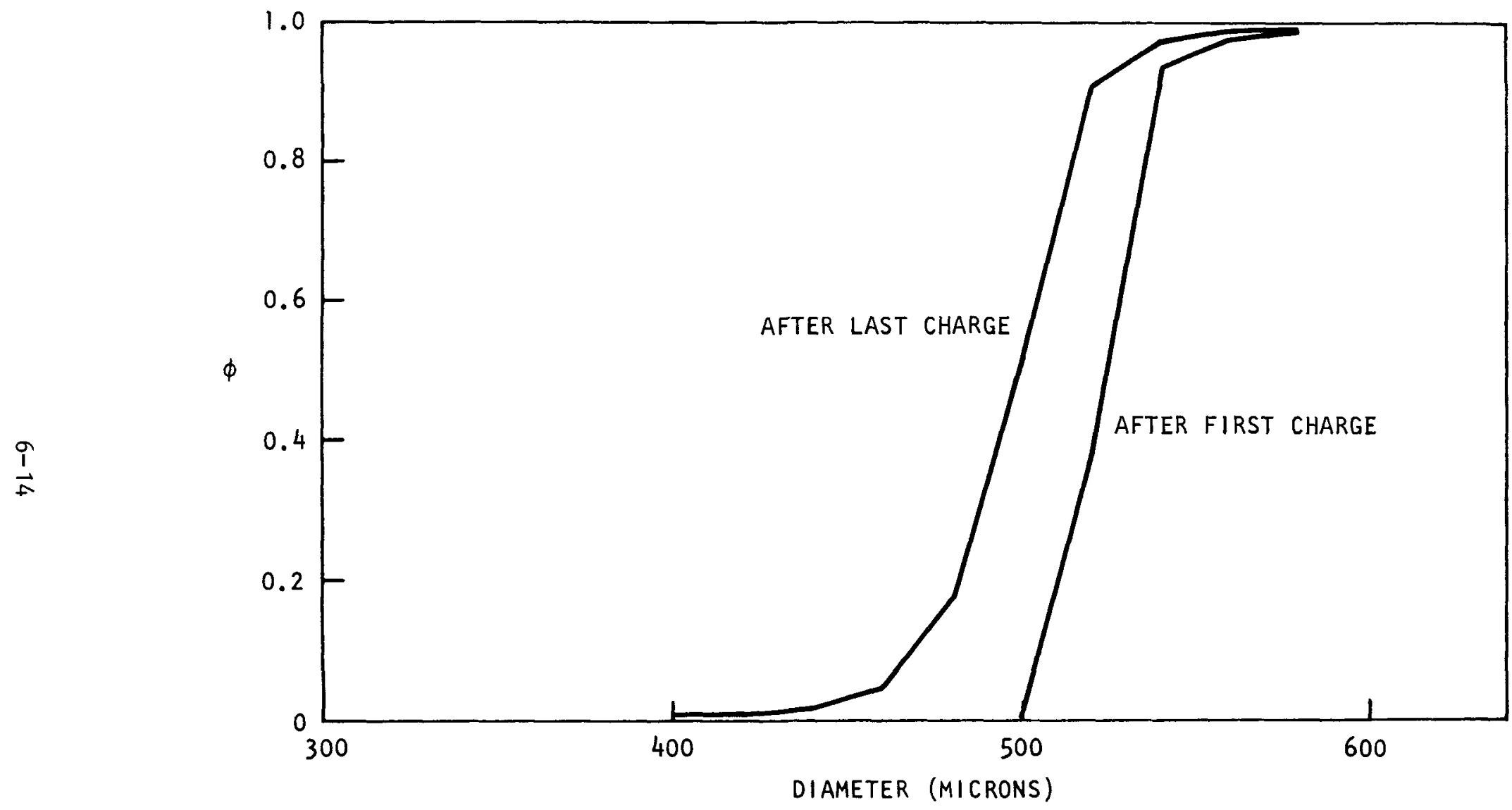

Fig. 6-10. Separation efficiency of simulated feed with 200 gm charge 



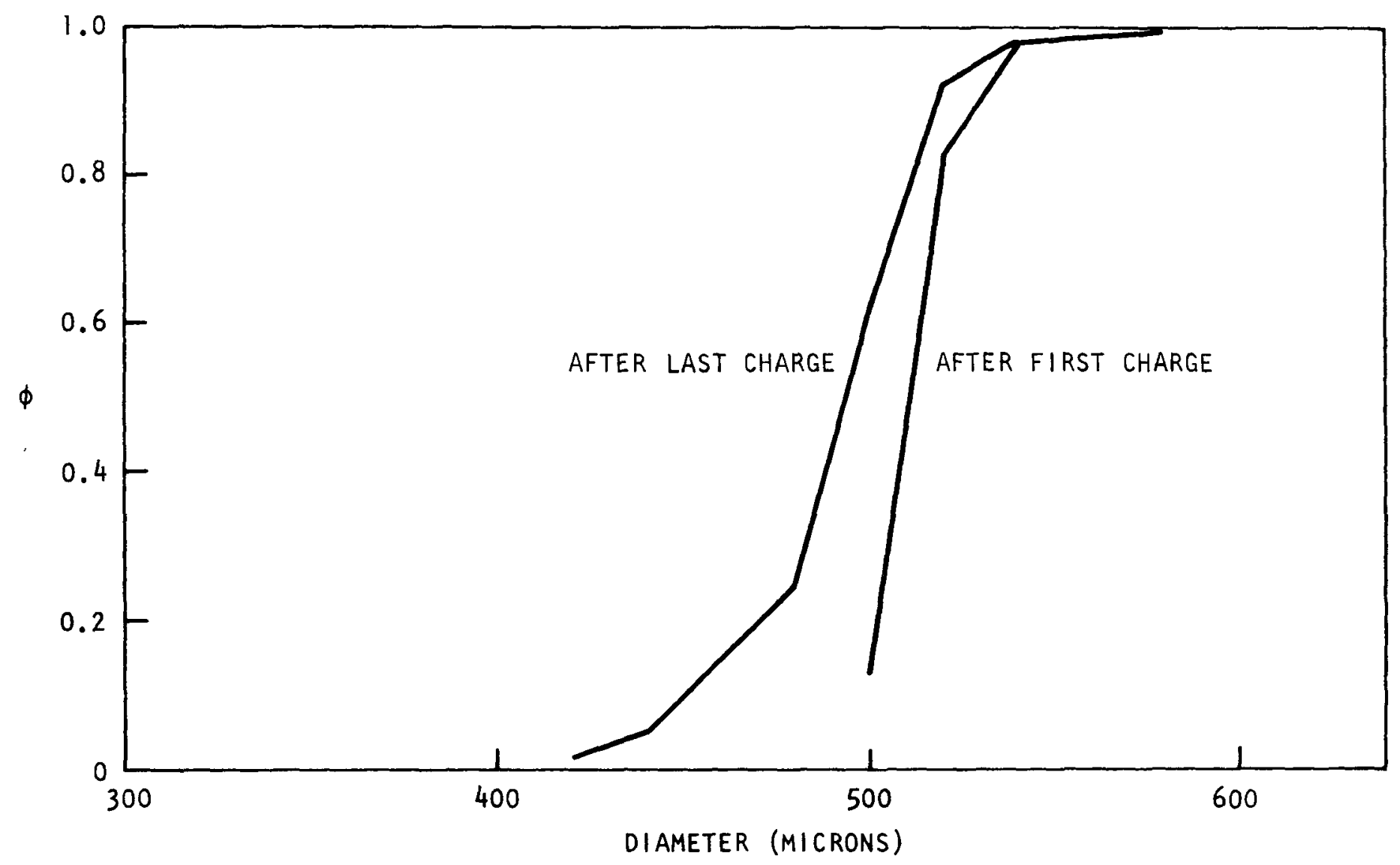

Fig. 6-12. Separation efficiency of simulated feed with $800 \mathrm{gm}$ charge 


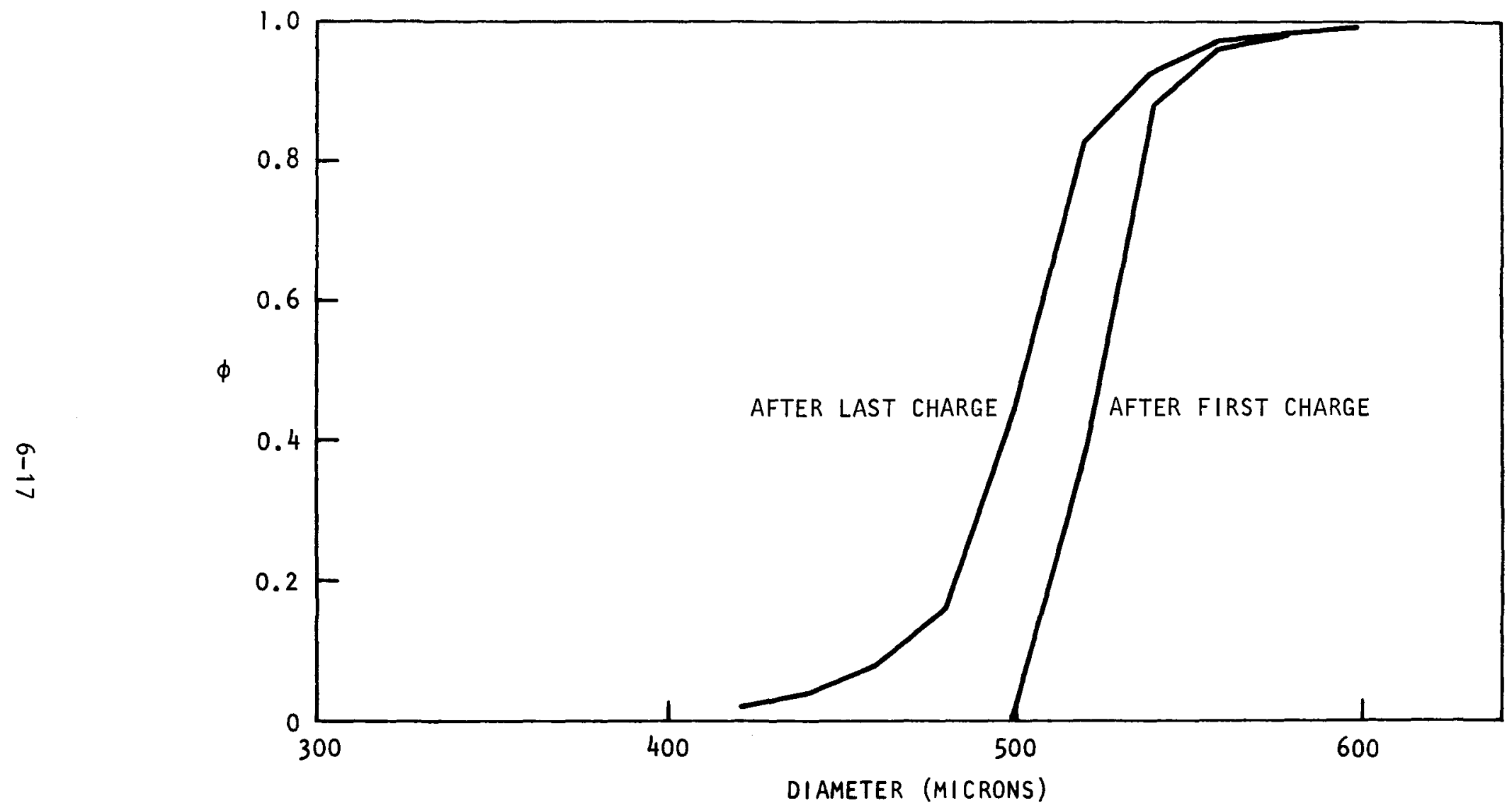

Fig. 6-13. Separation efficiency of Fissile B - Fertile A FSV fuel with 400 gm charge 


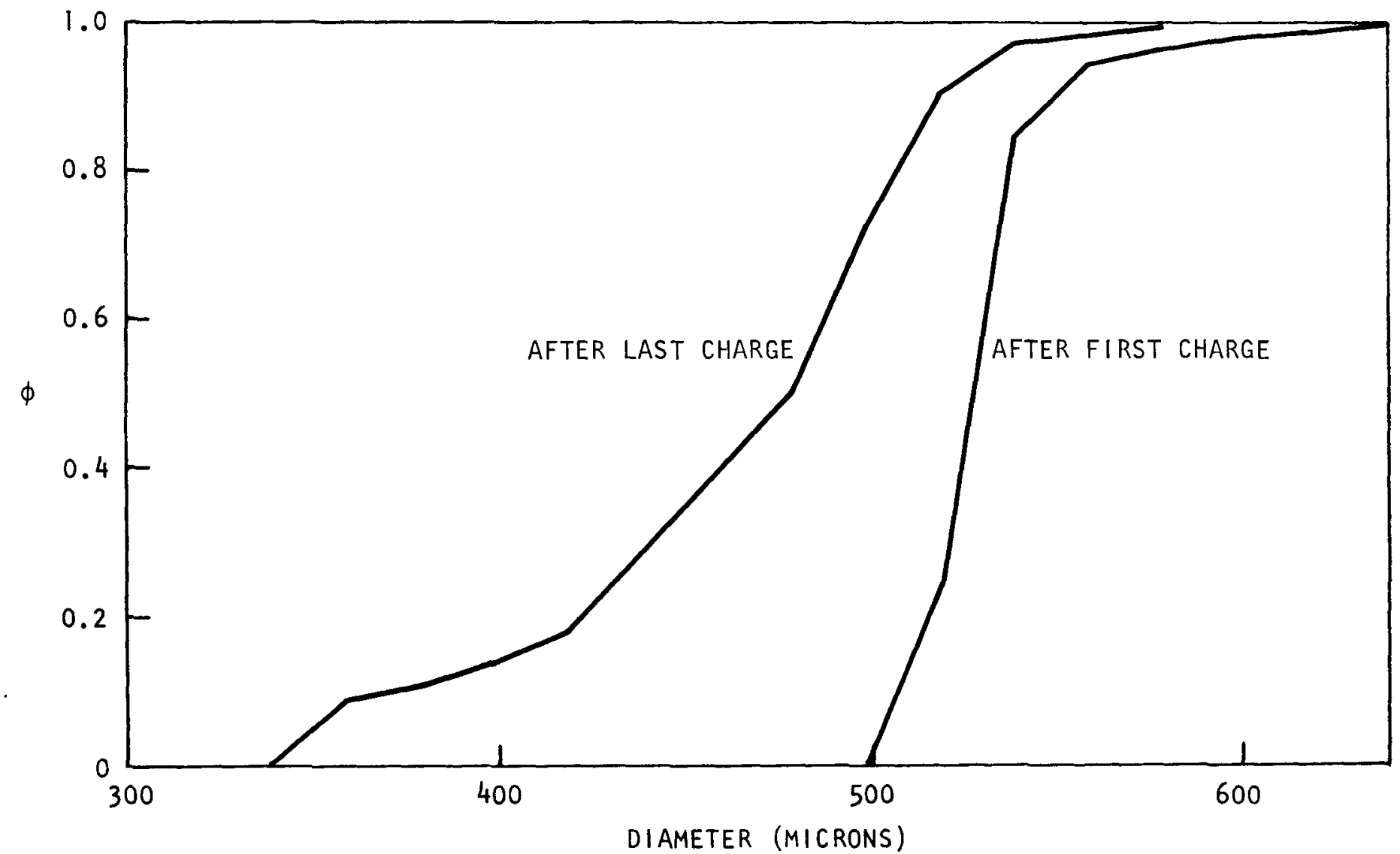

Fig. 6-14. Separation efficiency of Fissile B - Fertile A FSV fuel with 200 gm charge 


\section{.}

$\frac{i}{0}$

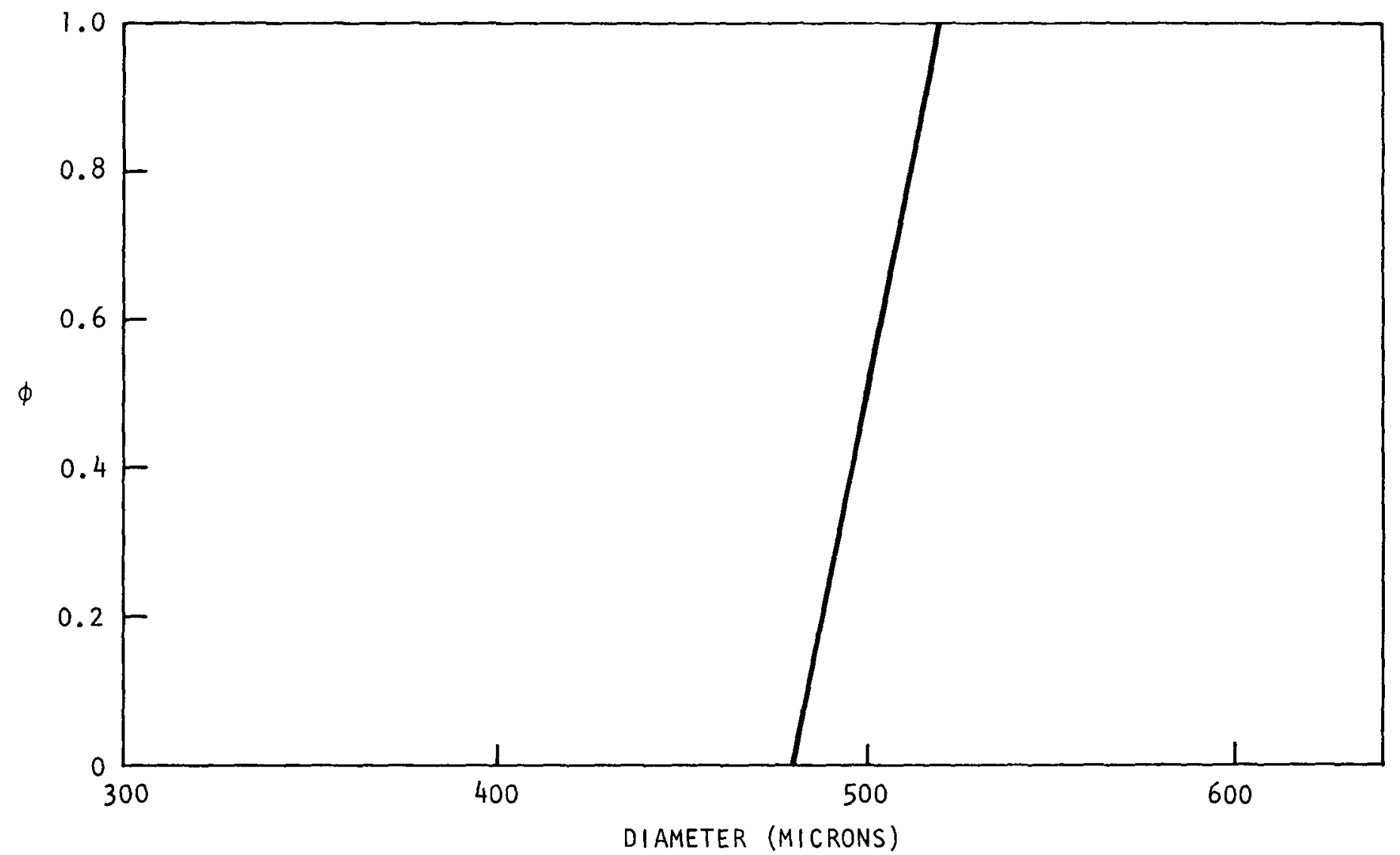

Fig. 6-15. Separation efficiency of Fissile A - Fertile B FSV fuel with 800 gm charge 
decreasing, the slope of the curve also decreases, indicating a poorer quality separation. In one case, Fissile B/Fertile A with a 200 gm charge, the final separation was extremely poor. Finally, Fig. 6-16 gives the size distribution of the particles that were trapped in the screen.

\subsection{COMPARISON OF SIEVING WITH PNEUMATIC CLASSIFICATION}

Sieving and pneumatic classification each have certain advantages and disadvantages which governed the final selection of which separation method to use. Sieving during the first and second rate periods has a better separation efficiency than pneumatic classification. Unfortunately, when permanent blinding occurs, as in Fig. 6-14, the efficiency of screening becomes worse than that of pneumatic classification. Further, as the screen becomes more and more blind, the $50 \%$ cut point shifts downward in diameter. This causes a varying quality and accuracy of separation over the life of the screen, which in effect is less desirable than poorer separation efficiency. Pneumatic classification has been chosen over sieving because:

1. The pneumatic classifier's cut point only changes when the air velocity changes or the particle size distribution changes.

2. The cut point of the classifier can be controlled by the air flow rate and thereby changed as needed, whereas the screen has only one cut point.

3. As the screen becomes permanently plugged, it must be removed from service. 


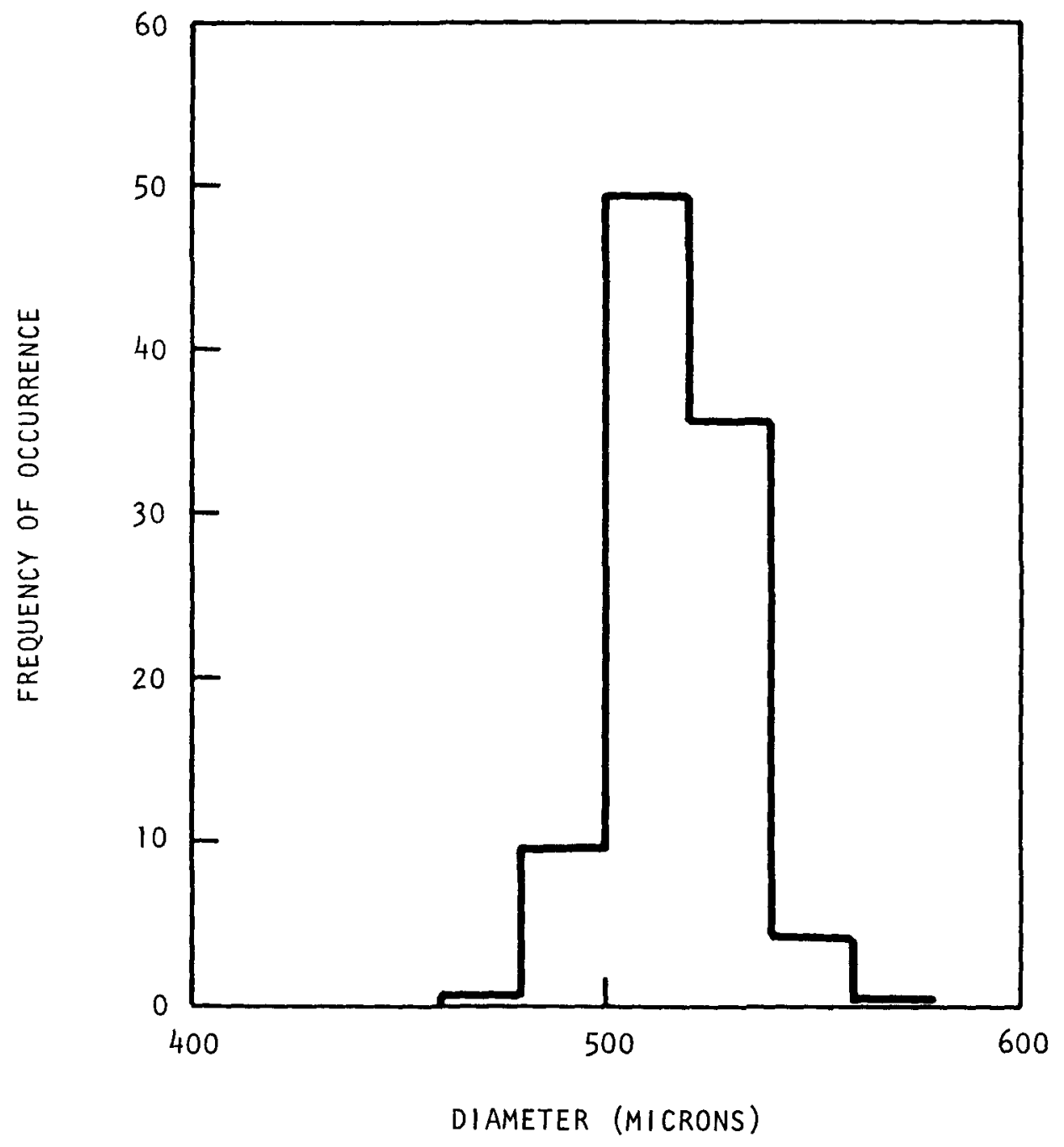

Fig. 6-16. Size distribution of particles plugging a 500 micron sieve 


\section{DATA REDUCTION AND ANALYSIS}

\subsection{PARTICLE SIZE DISTRIBUTION}

The conclusions drawn in this report derive mainly from the analysis and reduction of particle size distributions for the fine and coarse products. The analysis of these products was accomplished using a coated particle analyzer which operates on the assumption that the particles are spherical. The reduction of the data relied on the density versus size relationship, which was assumed to be linear. Thus, the accuracy and validity of the test results depend on the correspondence of these two assumptions with reality.

The coated particle analyzer sizes a particle by dropping it through a collimated light beam which causes the particle's image to pass across a $100 \pm 0.1 \mu$ wide slit. The light passing through the slit is measured by a photodetector. A logic circuit takes the maximum light blockage for the particle and transmits a corresponding pulse to a PDP 8 computer. The computer relates the pulse to a diameter (assuming a spherical shape), and adds one to a counting register for the corresponding size. The registers cover a size range from 300 to $1500 \mu$ in $2 \mu$ increments. Due to the speed of the instrument (approximately 20 particles per second), a statistically representative sample of 5000 particles (Ref. 24) can be analyzed in a short period of time. The results of this analysis are in the form of number of particles per size increment (e.g., 48 particles within the range of 420 to $439 \mu$ ). A detailed description of the coated particle analyzer and a sample of its output are given in Appendix D.

To reduce all these data to a usable form, a computer program (Appendix E) was written to accept the data as they came from the analyzer. The program first calculates the number percent size distribution and then converts the number percent size distribution to a volume percent size 
distribution using a volume ratio.* Finally, this is converted to a weight percent size distribution using a density ratio.** The weight percent size distribution is needed for a comparison of the feed with the fine and coarse products, which are related by weight fraction. The comparison is made by proportioning the fine and coarse products, adding their weight distributions to obtain the distribution for the feed, and dividing the coarse product weight percent size distribution by the feed weight percent size distribution to obtain the fraction of the feed that becomes the coarse product for each size increment. This value, $\phi$, describes the separation obtainable for a given feed under certain conditions.

For a discussion of the possible errors, see Section 4.2. Appendix E gives a typical printout for the program.

\subsection{CROSSOVER ANALYSIS}

The percent crossover of the fissile and fertile streams was calculated by two methods. The first method used a wet chemical determination of thorium and uranium in the fine and coarse products to establish the net crossover of these streams. The second method compared the size distributions of the feed and the products. Of the two methods, the former is the more accurate because it depends only upon the accuracy of the sampling, and the analysis and the auxiliary data needed, whereas, in addition to the above sources of error, the latter method depends upon the accuracy of the density relation.

\subsubsection{Wet Chemical Method}

After analyzing the samples for uranium and thorium content, the heavy metal from the fissile and the fertile particles in the products was calculated as follows:

"Volume Ratio - the average diameter of a size increment cubed divided by the sum of all of the elements' diameters cubed. $* *$

Density Ratio - the increment's average density divided by the sum of a11 of the elements' average density. 


$$
\begin{aligned}
& \text { Sample contains } \begin{cases}A \% & \mathrm{U} \\
\mathrm{B} \% & \mathrm{Th}\end{cases} \\
& \mathrm{r}=\frac{\% \mathrm{Th}}{\% \mathrm{U}} \text { in fissile (App. A) }
\end{aligned}
$$

Then, for every $100 \mathrm{gm}$

$$
\text { Fissile heavy metal }=\mathrm{A} \%+\mathrm{A} \% \cdot \mathrm{r}
$$

and

$$
\text { Fertile heavy metal }=B \%-A \% \cdot r
$$

From this analysis, the heavy metal weight of the fissile particles in the fine and coarse product is obtained, and therefore the weight percent of fissile heavy metal lost to the coarse stream is known. This logic also applies to the fertile stream.

The error of this analysis depends upon the sum of the errors for each step. The error of riffle splitting has been shown to be as much as \pm 5.35 wt \% (Refs. 25 and 26), while the accuracy of the thorium and uranium determinations was within $\pm 0.1 \%$ (Ref. 27). The final source of error is in the ratio of the uranium to thorium as given in the Quality Assurance data. When this ratio was used there was no error, but in the calculations for the Scrap Rod Run (Ref. 4), several of the ratios in the first runs were greater than the value given. The maximum deviation from the Quality Assurance data was $+2.0 \%$. Since lack of the proper amount of thorium is the only direction in which error can be detected, the negative error cannot be checked. However, if the value in the Quality Assurance data given is assumed to be an average, then the $+2.0 \%$ deviation should have a $-2.0 \%$ counterpart. The possibility of attributing this error to sampling does not exist since the uranium and thorium are intimately mixed in the kernel. The sum of these errors gives a total error of $\pm 7.45 \%$. Applied to a 10.00 wt \% crossover, this error yields a range of 9.25 to 10.75 . 


\subsubsection{Particle Size Analysis Method}

This method defines crossover as the loss of either fissile or fertile particles to the other stream. The crossover obtained from particle size analysis has the sources of error previously mentioned. These arise because the prediction of the crossover from size distribution analysis involves knowing the weight ratios of the fissile and fertile particles to the total feed for each size increment. The sum of the fissile and fertile ratios is unity. These ratios were found by a trial and error method utilizing wet chemistry data in conjunction with size distribution data. Once the ratios were established, the correlation between them and the resulting crossover was determined.

The initial prediction for the fissile ratio resulted from fitting the overlap of the smooth curves of Fig. B-7 in Appendix B to the fissile and the fertile modes. Using this ratio, the crossover for FSV fuel and the Scrap Rod Run was estimated from Eqs. 4-9, 4-10, and 4-11. The different densities for the fissile and fertile particles caused large errors $(+60.6 \%$ for the fissile loss and $+9.4 \%$ for the fertile loss). By shifting the fissile ratio up by $20 \mu$ and the fertile ratio down by $20 \mu$, the error was reduced to $+12 \%$ for the fissile loss and $-14 \%$ for the fertile loss. Then minor adjustments in the fissile and fertile ratios to give a smooth transition led to a final error of $+14 \%$. This final adjustment yielded the particle size distributions for Fissile $B$ and Fertile A fuel (Fig. 4-6). 


\section{SUMMARY}

In most solid-solid separation processes, the accuracy of the separation is not as critical as it is in the separation of the fissile and fertile fuel particles used in HTGRs. The existing theory on separation was not adequate for the prediction of this separation because of both the tight separation limits imposed by the fuel cycle economics (Ref. 1) and the closeness of the particle size distributions. For these two reasons, the efficiency of separation of fissile from fertile fuel particles was determined experimentally and an empirical matrix model found that would be able to predict the behavior of this separation. The basic equations governing the model were established from experimental data on a simulated fuel distribution because of the unavailability of FSV fuel.

The relationship that was established was between the separation efficiency $(\phi)$ and the solids feed rate (F) for each size increment and for several air velocities or

$$
\phi=\frac{F}{A+B F}
$$

The relationship between separation efficiency and feed rate which occurs with simulated fuel and is described by this equation is as follows. Due to the increased concentration of particles in the classifier with increased feed rate, the separation efficiency worsens and the cut point shifts downward in size.

The constants $A$ and $B$ were then related to diameter (d) at one air velocity

- (V). Then the change in air velocity was incorporated as a diameter shift

(D) giving the following relationships:

$$
D=592.2-123.4 V+d
$$




$$
\begin{aligned}
& A=e^{(28.52-0.03271 D)} \\
& B=18-\frac{4225}{(D-408)} \quad \text { For } \begin{array}{l}
D<410, B[=]-300 \\
D>656.5, B[=] 1
\end{array}
\end{aligned}
$$

These four equations were the starting point for the model. Once these equations were formulated, the effect of graphite and the effect of the relative size of the distribution modes were incorporated. After a few tests, which indicated the presence of graphite gave similar results to tests without graphite only at higher feed rates, were run, FSV fuel became available.

With FSV type fuel available for testing, the experiments shifted to the study of this feed material to determine if there were any differences in the separation. The first difference noted was the shift and the spacing of the constant diameter lines. This shift was explained by the shift in the intersection of the size distributions and by the increased slope of the relationship between density and particle size. After making this correction, the lack of dependence upon feed rate, which also stems from the increased slope of the density relation, was noticed (Ref. 14) and the feed rate term in Eq. 8-1 was replaced by a constant.

The next step in refining the model occurred in predicting the results of the Scrap Rod Program. The ten feed batches used contained varying particle size distributions and varying amounts of carbon. When the runs which had similar distribution to the earlier FSV fuel were used, the prediction of the separation was good only when the constant that replaced the variable feed rate was increased. This increase was related to the addition of graphite in the feed. When using simulated feed earlier, similar results had occurred. The constant that replaced the feed rate in the simulated feed model correctly described the effect of graphite on the separation of FSV fuel, and a linear relationship between this constant and the percent graphite was added to the model. 
Once the influence of graphite was established, the effect stemning from the relative breadth of the size distribution modes could be investigated. This investigation showed that the separation efficiency versus particle size shifted toward the smaller mode in an amount that is proportional to the net difference in the weight of the Fissile $B$ and Fertile A particles in the feed. This result agrees with the observations made earlier in connection with the runs using simulated feed. With this last adjustment the model can now predict the separation within the range of +3.3 to $-6.4 \%$ error. The model has as inputs the air velocity, percent carbon, and percent Fissile A, Fissile B, Fertile A, and Fertile B.

The final addition to the model converts separation parameters to percent crossover of the fissile and fertile streams. For this, the percent fissile in a particular size increment in the fine and coarse products must be related to the ratio in the feed. Fortunately, the relationship was straightforward. First, the fissile ratio of the fine product for any size increment is equal to the ratio for a $20 \mu$ larger size in the feed. The reverse is the case for the coarse. That is, the fissile ratio is equal to the ratio for a $20 \mu$ smaller size in the feed. With this added to the model, the percent crossover calculated was within $\pm 14 \%$ error (e.g., if predicted crossover is $10 \mathrm{wt} \%$, actual crossover will be between 8.6 and $11.4 \mathrm{wt} \%$ ). The necessity for this shift supports the contention that on the average a fissile particle of the same size as a fertile particle is less dense.

The use of this model is its application to the reprocessing of FSV fue1. By knowing the particle size distribution of any batch, the optimum air velocity to give the least crossover can be determined. This crossover can then be related directly to the cost penalty. In the Scrap Rod Program, the two extreme size distributions encountered, Fissile A - Fertile A Fertile B and Fissile B - Fertile A, were processed through the classification step of the head-end flowsheet. The fissile and fertile crossover which resulted from misclassification of whole particles was 2.8 and 0.3 wt \% for the spread distribution, and 14.6 and 9.1 wt \% for the overlapping distribution. An additional source of crossover is that due to the dust of 
broken particles, a majority of which was classified with the fissile stream, giving a total fissile crossover of 3.4 and 8.6 wt \% for the first case and 14.8 and 13.4 wt \% for the second case. Cost penalties of $0.05 \mathrm{mils} / \mathrm{kWhr}$ and $0.09 \mathrm{mils} / \mathrm{kWhr}$, respectively, can be attributed to the above total crossovers. (These figures are taken from the upper curves of Figs. 2-1 and 2-2.) In this manner, the economics of reprocessing can be estimated with greater accuracy, and optimum separation of the fuel can be assured. The only information required is the percent carbon in the feed and the amount of Fissile A, Fissile B, Fertile A, and Fertile B fuel in the feed. The former has been imposed by the design criteria for the secondary burner on the primary burner, and the latter may be obtained from Quality Assurance data on FSV fuel (Ref. 28).

With the separation process characterized for a set height and feed point, tests were conducted to determine the effect of height and feed point. First it was found that the increased height of the column gave no improvement of feed rates of around $100 \mathrm{gm} / \mathrm{min}$. However, as the rate increased toward $500 \mathrm{gm} / \mathrm{min}$, a marked improvement was noted. As the feed point was moved up, the efficiency of separation improved for both coarse and fine fractions. The reverse occurred when the feed point was lowered.

Up to this point the discussion has been concerned with the separation of the fissile from the fertile fuel after the fuel leaves the primary burner and before it enters the roll crushers. One other particulate system was investigated: crushed fertile particles. By classifying the fuel as it leaves the roll crushers, $84 \mathrm{wt} \%$ of the SiC hulls and $89 \mathrm{wt} \%$ of the carbon coatings can be removed from the kernels while only losing $0.5 \mathrm{wt} \%$ heavy metal. This has four advantages:

1. The load on the centrifuge would be reduced by a factor of six.

2. The carbon coatings, which are laden with fission products, could be diverted for disposal as a solid waste.

3. The burning load on the secondary burner would be reduced. 
4. The liquid waste from the aqueous separation would be reduced.

However, this would require the separation of the heavy metal dust resulting from broken particles before the roll crusher. The dust would then be routed to the secondary burner. The weight percent broken particles, as given in Ref. 4, is

$\begin{array}{ll}\text { Fissile A } & -3.7 \text { wt } \% \\ \text { Fissile B } & -3.2 \text { wt } \% \\ \text { Fertile A } & -7.5 \text { wt } \% \\ \text { Fertile A \& B }-17.1 \text { wt } \%\end{array}$

with an average of 0.7 wt $\%$ broken in the classifier.

Extensive testing showed that although sieving leads to a better instantaneous separation efficiency, the overall separation efficiency of sieving is poorer than separation by pneumatic classification because the cut point decreases with time as the screen becomes plugged. Sieving also has the disadvantage of permanent plugging of the screen openings so that after a period of time the screen must be replaced. Further, the cut point of the screen cannot be changed except by replacement, and a 64 in. screen is required to give a $200 \mathrm{gm} / \mathrm{min}$ throughput. Finally, the screener is harder to maintain because of the larger number of moving parts. Sieving was therefore eliminated as an alternative and pneumatic classification was adopted as the method of choice. 


\section{RECOMMENDATIONS}

For the separation of HTGR fissile and fertile TRISO/TRISO fuel it is recommended that:

1. The method be pneumatic classification using the zigzag configuration.

2. The height and feed point of the classifier be of the configuration of Fig. 5-4e.

3. The cross sectional dimensions of the prototype classifier be increased to $1.5 \mathrm{in.} \times 3.0 \mathrm{in.}$ from $1.5 \mathrm{in.} \times 1.5 \mathrm{in}$. with the $3.0 \mathrm{in.}$ dimension corresponding to that of the feed opening.

4. A baffle be installed in the coarse product take-off cone to improve the separation efficiency for the coarse fraction.

5. A vibratory feeder be used with a solids flow rate sensor coupled in a closed control loop. 


\section{REFERENCES}

1. "National HTGR Fuel Recycle Development Program Plan," USAEC Report ORNL-4702, Oak Ridge National Laboratory, August 1973.

2. Stewart, H. B., et al., "Utilization of the Thorium Cycle in the HTGR," Fourth Geneva Conference, Vol. 4, United Nations, Geneva, 1972, p. 433.

3. Valentine, M. K., "Development of a Gas-Classification Method for Separating Fort St. Vrain TRISO/TRISO Fuel Particles," Allied Chemical Corporation Report ICP-1051, April 1974.

4. delesdernier, D., "Crossover and Particle Breakage Analysis of the Air Classification Step in the Scrap Rod Program," General Atomic Company, unpublished data.

5. Cook, E., "Particle Breakage Analysis of Head-End Crushing Operations," General Atomic Company, unpublished data.

6. Bennett, L., and W. Thomas, "Cost Penalties Associated with CrossMixing of HTGR Particle Types During Fuel Processing," USAEC Report ORNL-TM-3852, Oak Ridge National Laboratory, December 1972.

7. Bird, R. B., W. E. Stewart, and E. N. Lightfoot, Transport Phenomena, J. Wiley \& Sons, New York, 1960, p. 80.

8. Stokes, G. G., Trans, Camb. Phil. Soc. 9 8, (1851).

9. Garner, F., V. Jenson, and R. Keey, "Flow Patterns Around Spheres and the Reynolds Analogy," Trans. Inst. Chem. Engrs. 37, 191-197 (1959).

10. Perry, J. (ed), Chemical Engineers' Handbook, 3rd ed., McGraw-Hill Book Company, New York, 1950, p. 1018.

11. Kaye, B., and P. Boardman, "Symposium on the Interaction Between Fluids and Particles," Inst. Chem. Engrs., London A.17 (1962).

12. Rompf, H., et al., Berichte der Bunsengesellshaft 71(3), 253 (1967).

13. Bernotat, S., and H. Umhauer, "Application of 'Spark Tracing' Method to Flow Measurements in an Air Classifier," Opto-Electronics 5, 107118 (1973). 
14. Guha, S., A. Kumar, and P. Gupta, "Mechanism of Elutriation From Fluidized Beds," Canad. J. Chem. Engr. 50, 602-606 (Oct. 1972).

15. Treasure, C. R. G., "Additional Mathematical Techniques," in Particle Workshop Manual, Loughborough University of Technology/Warm Springs Laboratory, Liestershire, England, 1972.

16. deLesdernier, D., "Description of the QA Identification Scheme for Particle and Rod Batches; and Rod Selection for the Scrap Rod Program," General Atomic Company, unpublished data.

17. Stula, R., "10 cm Primary Burner Scrap Rod Run \#1 - Run 38 (June 4-5, 1974)," General Atomic Company, unpublished data.

18. Stula, R., "10 cm Primary Burner Scrap Rod Run \#2 - Run 39 (June 1920, 1974)," General Atomic Company, unpublished data.

19. Cook, E., and D. delesdernier, "Sumnary of the Scrap Rod Program, Crush-Burn-Classify," General Atomic Company, unpublished data.

20. Stallings, D., "Product Take-Off Rotary Valve," General Atomic Company, unpublished data.

21. Papadatos, K., and W. Y. Svrcek, "Low Range Flowmeter for Pulverized Solids," Instr. Tech. 21 (8), 38-40 (1974).

22. Rees, D., and P. Toynbee, "Pneumatic Classification of Slack Coal," Fue1, 52, 112-114 (April 1973).

23. Orr, C., Particulate Technology, MacMillian Company, 1966, pp. 356357.

24. Jackson, M., H. Iglarsh, and M. Salkowski, "Sample Size Induced Errors in the Transformation of Particle Size Distributions," Powder Tech. 3 317-322, (1969/1970).

25. Whiting, C., "Memo on Riffle Sample Splitter (2-Way)," General Atomic Company, unpublished data.

26. Whiting, C., "Final Report - Hobeg Percentage, Variable Speed Rotary Splitter," General Atomic Company, unpublished data.

27. Wilbourn, R., General Atomic Company, private communication.

28. delesdernier, D., "Computer Model Simulation of Pneumatic Classification of FSV Fuel," General Atomic Company, unpublished data. 


\section{ACKNOWLEDGMENTS}

I wish to thank B. J. Baxter, who provided direction and technical consultation during the experimental work described in this report. I would further like to thank A. H. Bond, A. L. Gasparovic, and M. D. True for the fabrication, installation, and operation of the pneumatic classification equipment. The heart of this report lies in the particle size distribution analysis performed by $C$. Whiting of the Fuels Test Techniques Branch under the direction and generosity of A. Haubold. Finally, I want to thank my editor, P. Whipple, who patiently translated my rough draft into this final form. 
APPENDIX A

ROD PROPERTIES 
• 
ROD PROPERTIES

Batch No.

Fissile A-Batch No. CU6AWeight (gm/rod)

Fissile B-Batch No. CU6BWeight $(\mathrm{gm} / \mathrm{rod})$

Fertile A-Batch No. CT6AWeight $(\mathrm{gm} / \mathrm{rod})$

Fertile B-Batch No. CT6BWeight (gm/rod)

Estimated Cross-Over (Wt.\%)

Uranium to Thorium Ratio in the Fissile

Packing Fraction

Electrical Resistivity $(\%<0.5)$

Matrix Uniformity Min. 23 Max. 24

Volume \% Macro.

Diameter

Length

End Cap

Fuel Homogeneity Mean Std. Deviation

Uranium Weight Mean (gm/rod) Std. Deviation

Thorium Weight Mean (gm/rod) Std. Deviation

Carbon Weight (gm/rod)

Silicon Weight (gm/rod)
CR-14-N60126-3

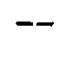

$-$

$6049 \mathrm{C} \quad 6050 \mathrm{C}$

1.95

1.94

$6056 \mathrm{C}$

5.39

$6064 \mathrm{C}$

0.94

$-$

$--$

9

0.2346

61.0

100.0

39

0.488

1.940

0.07

1.040

0.020

0.2169

0.003

3.377

0.06

6.86

1.25
CR-14-K30152-6 $\mathrm{CR}-14-\mathrm{K} 14228-13$

$3198 \mathrm{C} \quad 6196 \mathrm{C} \quad 1274 \mathrm{C}$

2.82

$2.38 \quad 3.22$

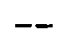

$3087 \mathrm{C}$

2.37

$3016 \mathrm{C}$

2.45

2

0.2359

0.2408

61.5

61.6

100.0

100.0

21

32

26

34

24

35

0.488

0.489

1.940

1.950

0.13

0.13

1.060

0.060

1.000

0.050

0.1786

0.1298

0.007

0.003

3.154

4.621

0.07

0.10

6.71

6.50

1.46

1.35 
Batch No.

Surface Contamination

Fission Gas Release $(R / B)$

Thorium (gm/gm)

Broken SiC

Uranium (gm/gm)

Thorium ( $\mathrm{gm} / \mathrm{gm}$ )

Impurities (ppm)

Boron Equivalent

Iron

Sulfur

Titanium

Vanadium

Hydrogen

Ash

Water

Production Status

\section{CR-14-N60126-3 CR-14-K30152-6}

$\mathrm{CR}-14-\mathrm{K} 14228-13$
$9 \times 10^{-6}$
$3.3 \times 10^{-5}$
$8.5 \times 10^{-6}$
$3.9 \times 10^{-5}$
$2.4 \times 10^{-4}$
$1.2 \times 10^{-4}$
$5.5 \times 10^{-4}$
$6.2 \times 10^{-3}$
0
0
0
0

2

40

520

40

40

30

1600

1

3
2

40

1140

40

40

460

1470

2

AA 
APPENDIX B

\section{PARTICLE SIZE DISTRIBUTIONS OF PRODUCTS FROM SCRAP ROD PROGRAM}





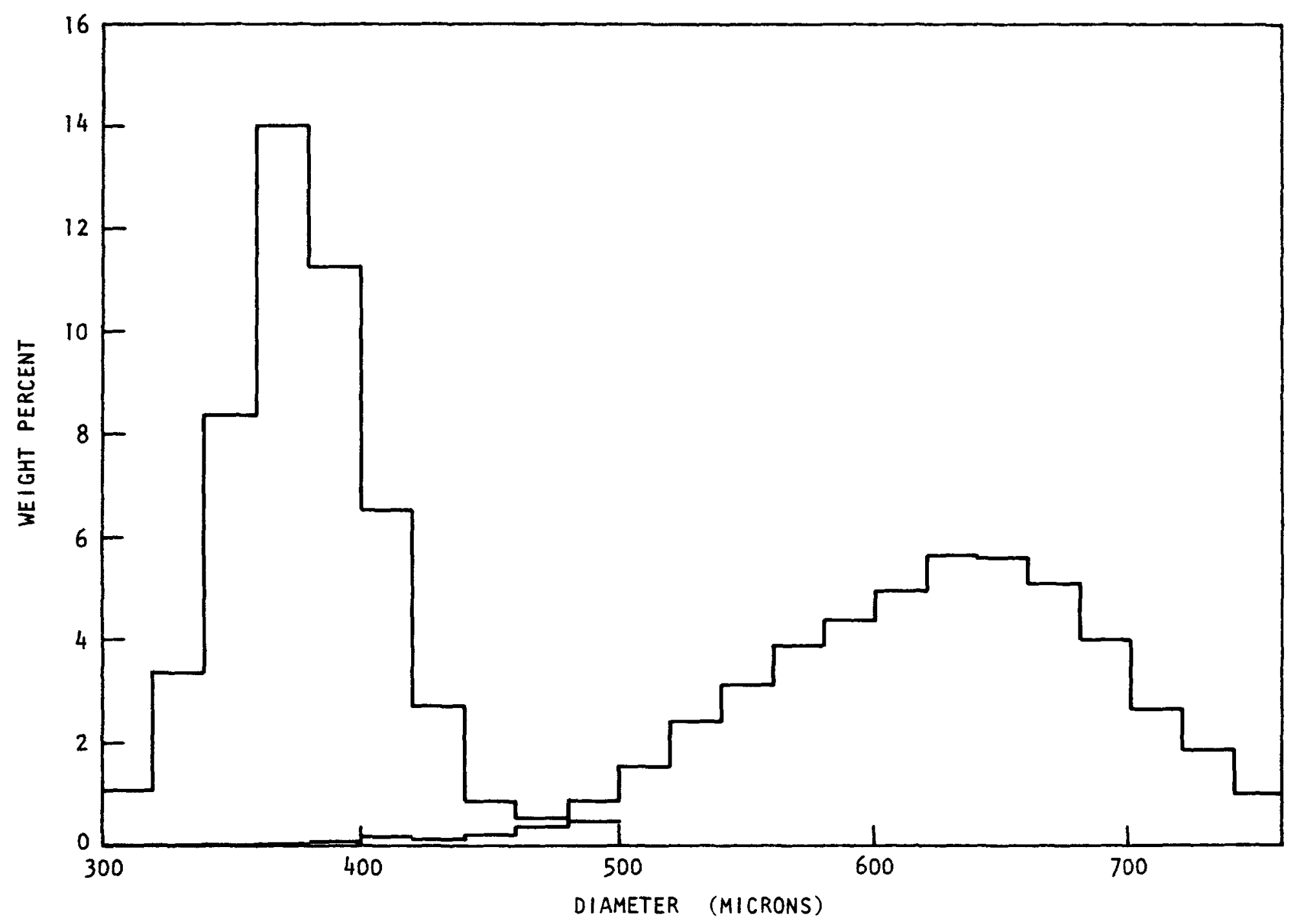

Fig. B-1. Particle size distribution for Scrap Rod Run No. 1, batch combination 


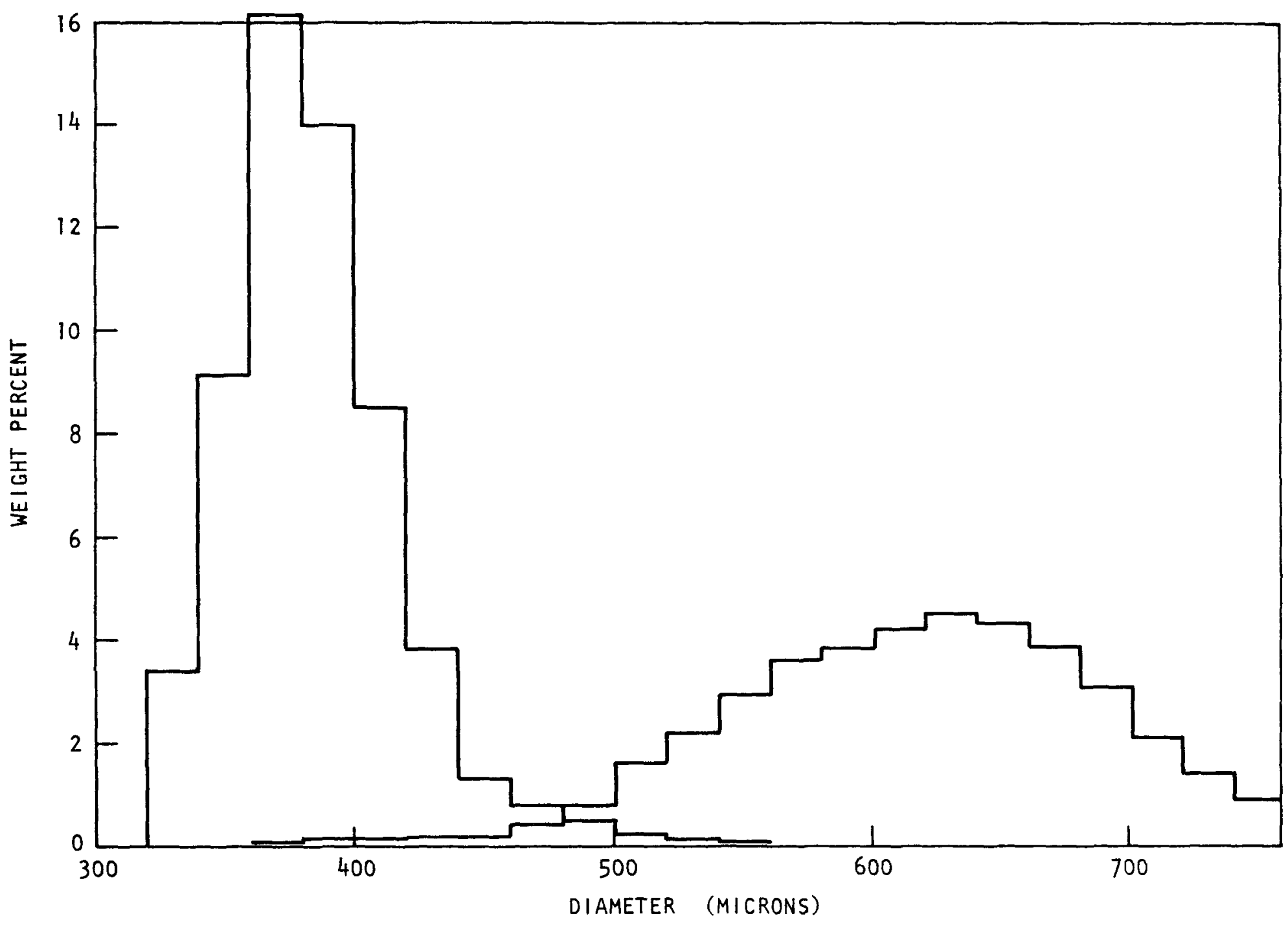

Fig. B-2, Particle size distribution, Scrap Rod Run No. 1, Batch No. 1 


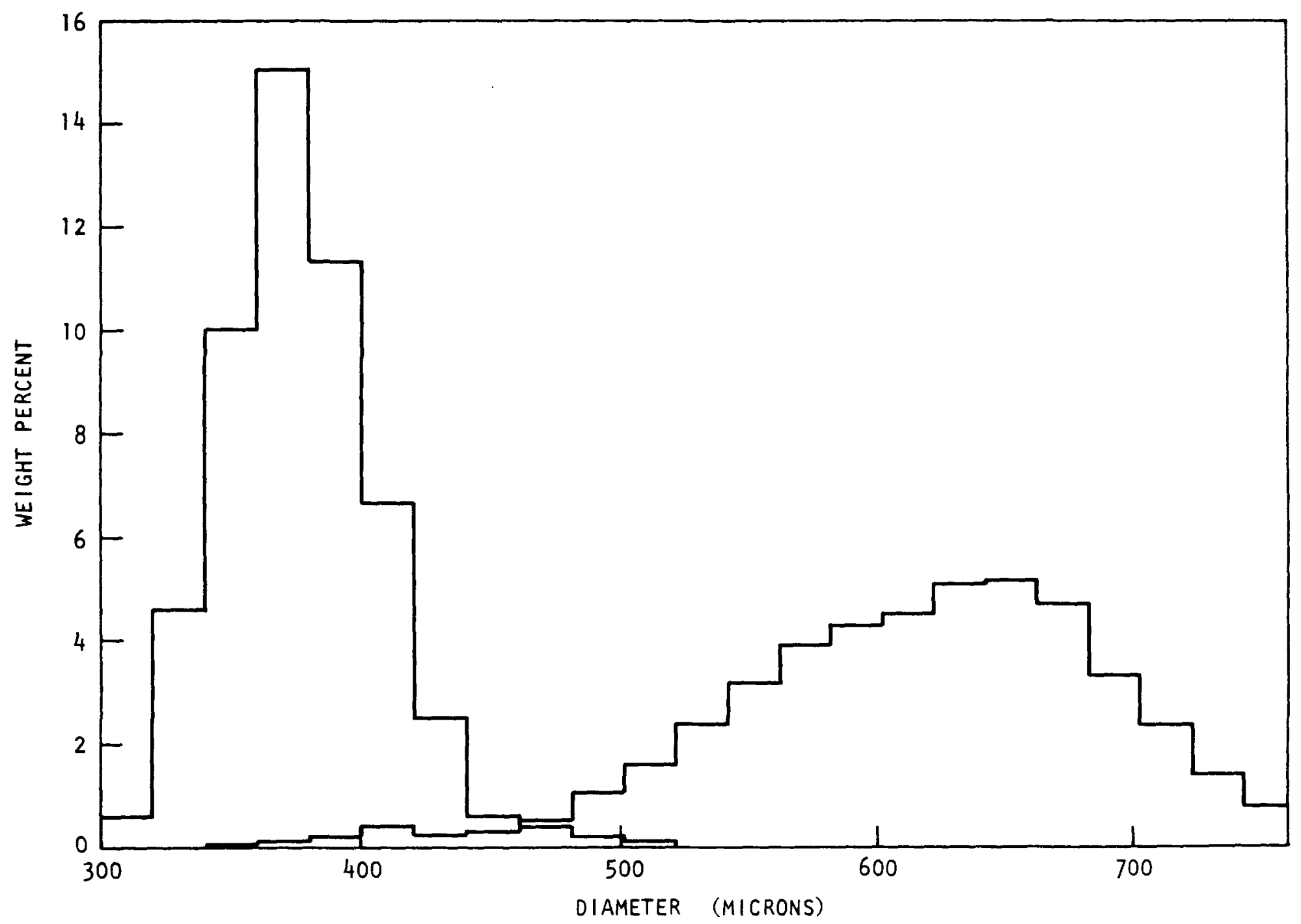

Fig. B-3. Particle size distribution, Scrap Rod Run No. 1, Batch No. 2 


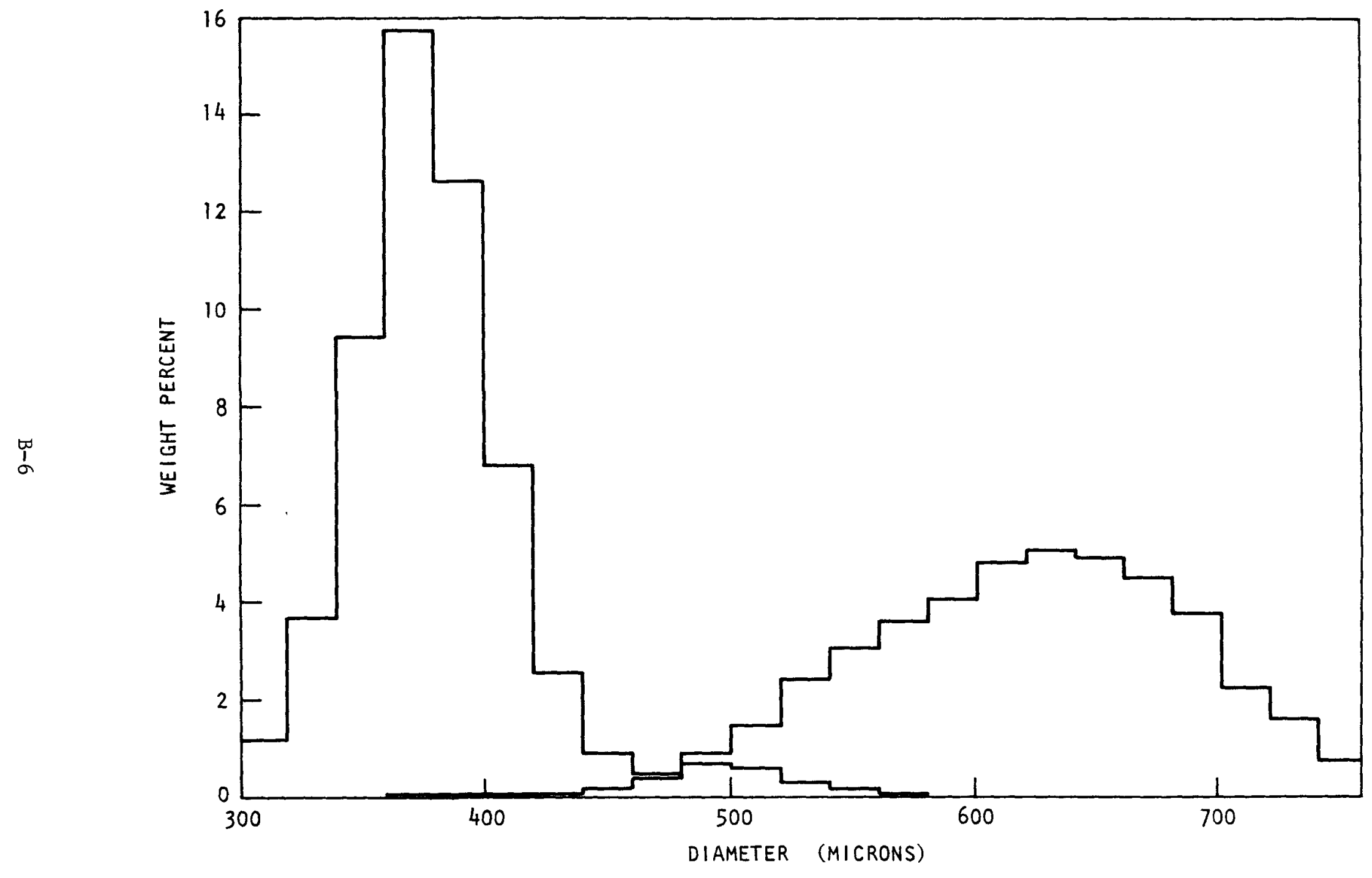

Fig. B-4. Particle size distribution, Scrap Rod Run No. 1, Batch No. 3 



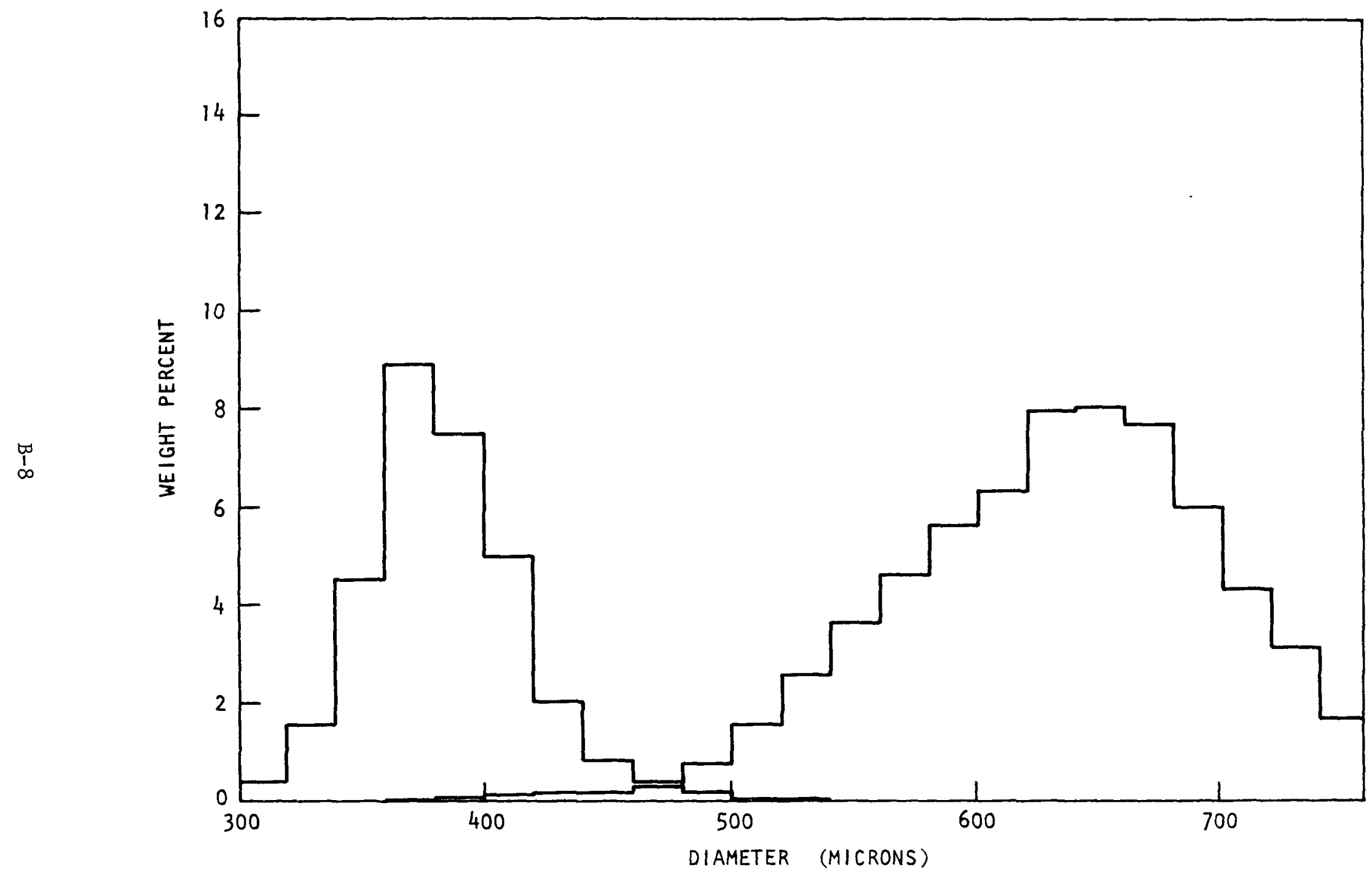

Fig. B-6. Particle size distribution, Scrap Rod Run No. 1, Batch No. 5 


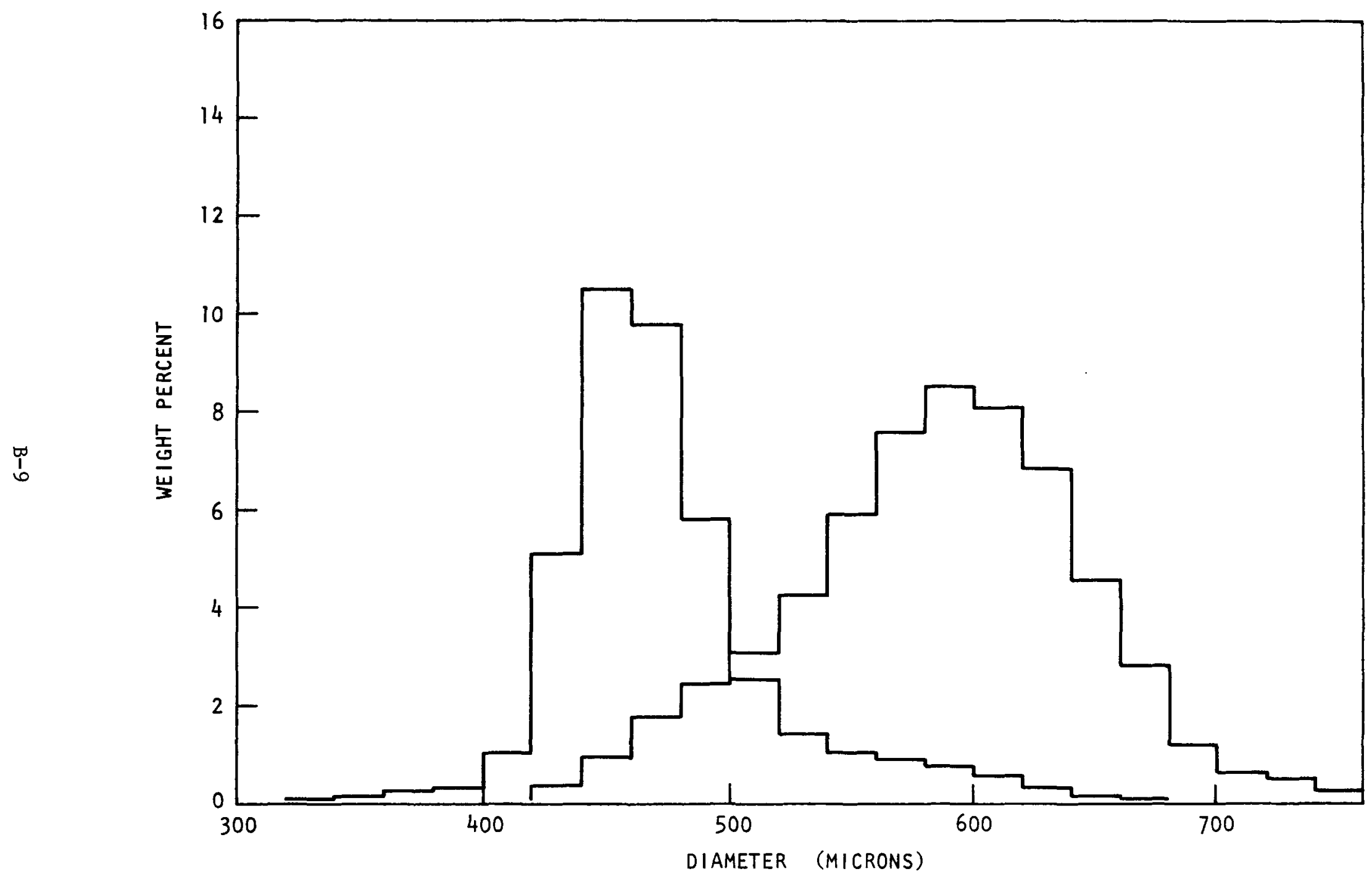

Fig. B-7. Particle size distribution, Scrap Rod Run No. 2, batch combination 


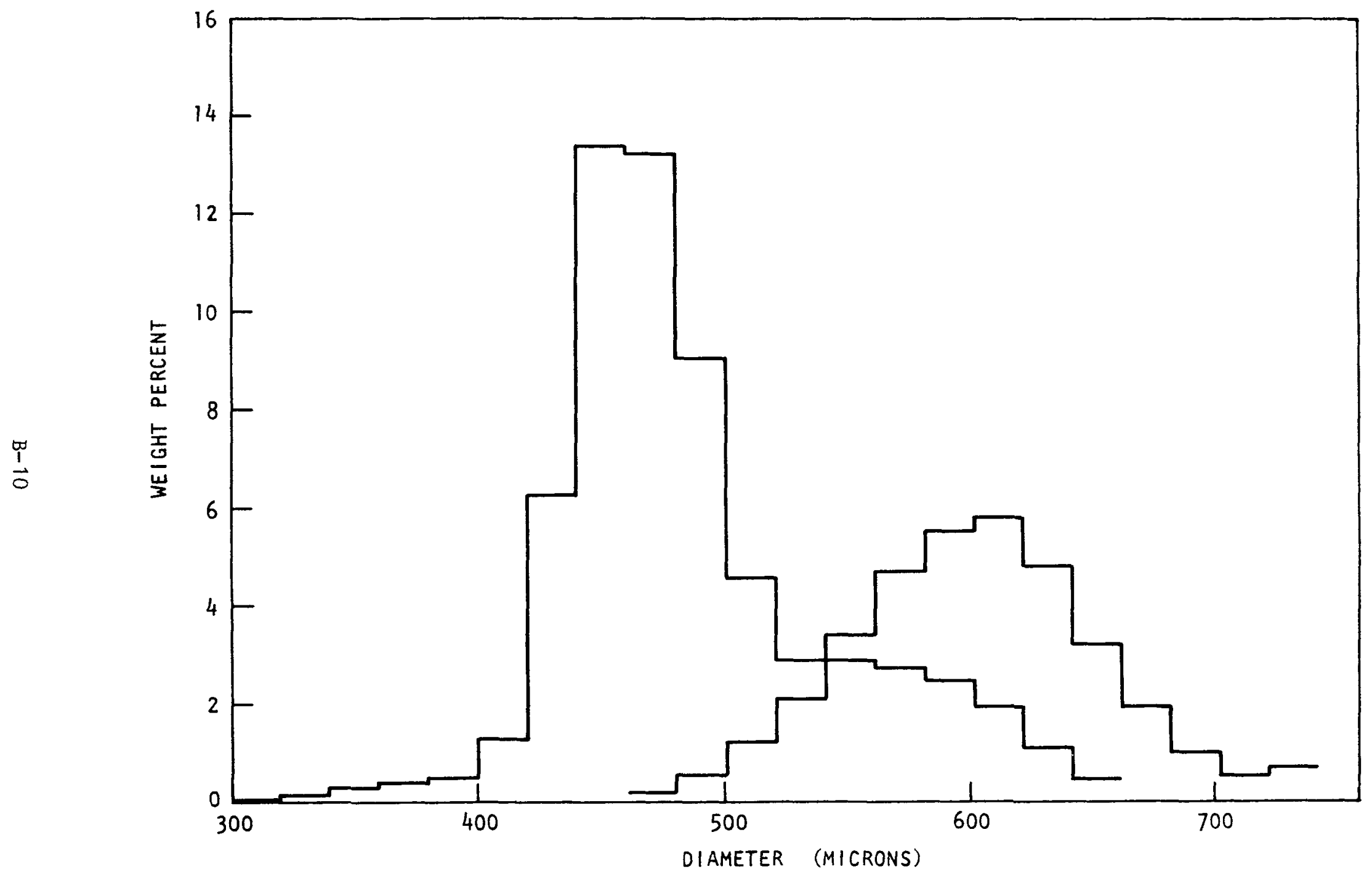

Fig. B-8. Particle size distribution, Scrap Rod Run No. 2, Batch No. 1 


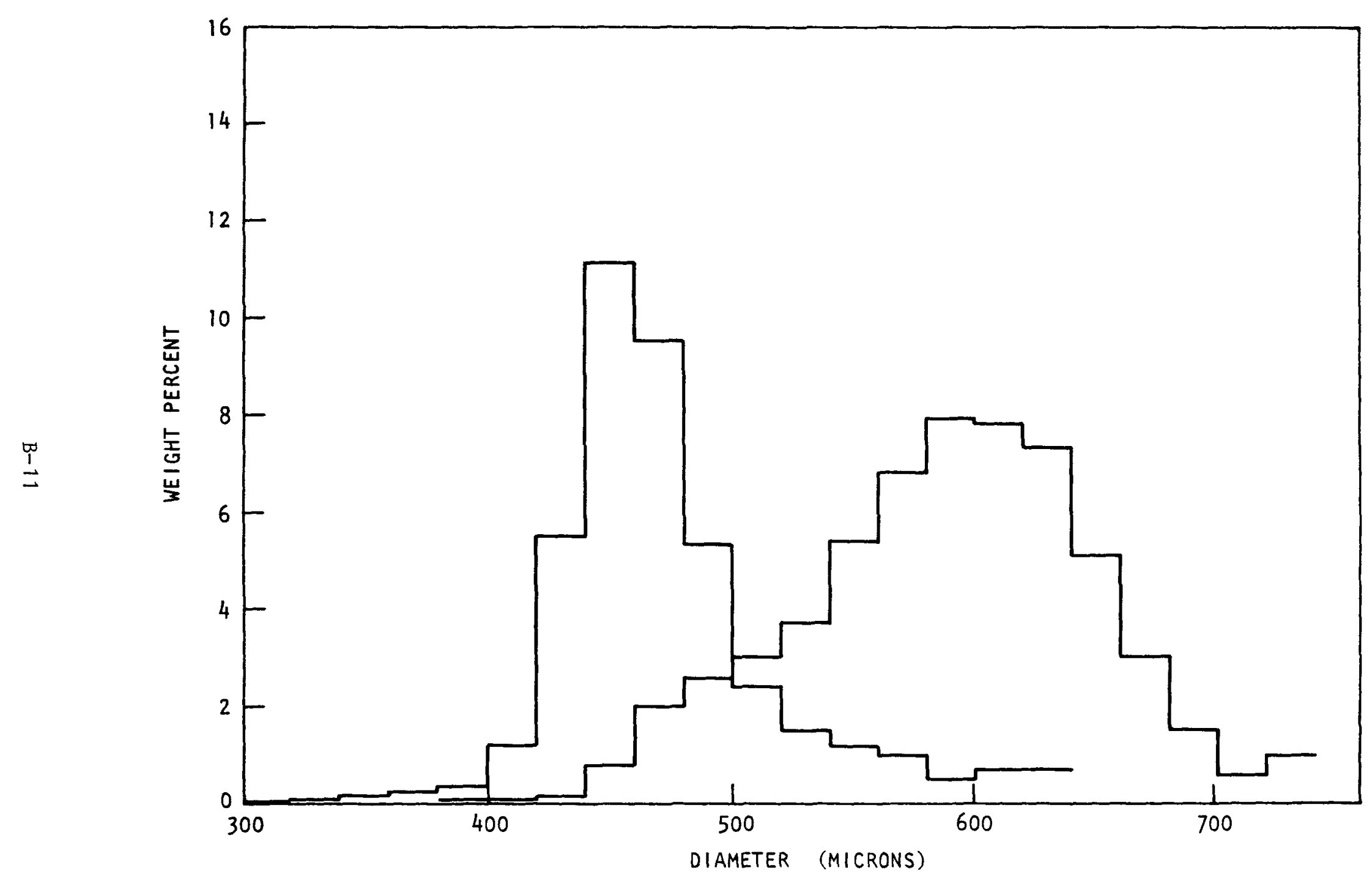

Fig. B-9. Particle size distribution, Scrap Rod Run No. 2, Batch No. 2 


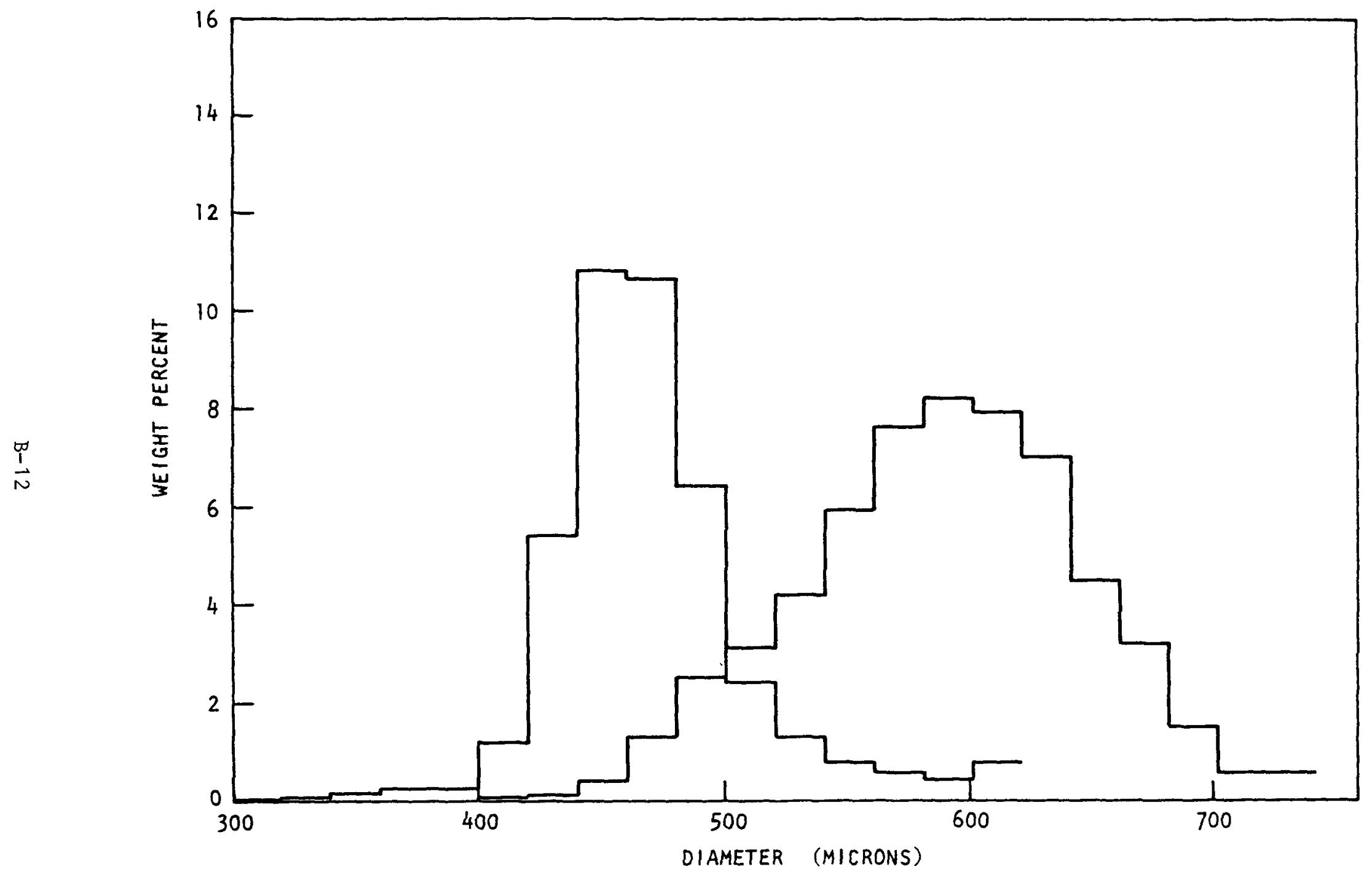

Fig. B-10. Particle size distribution, Scrap Rod Run No. 2, Batch No. 3 



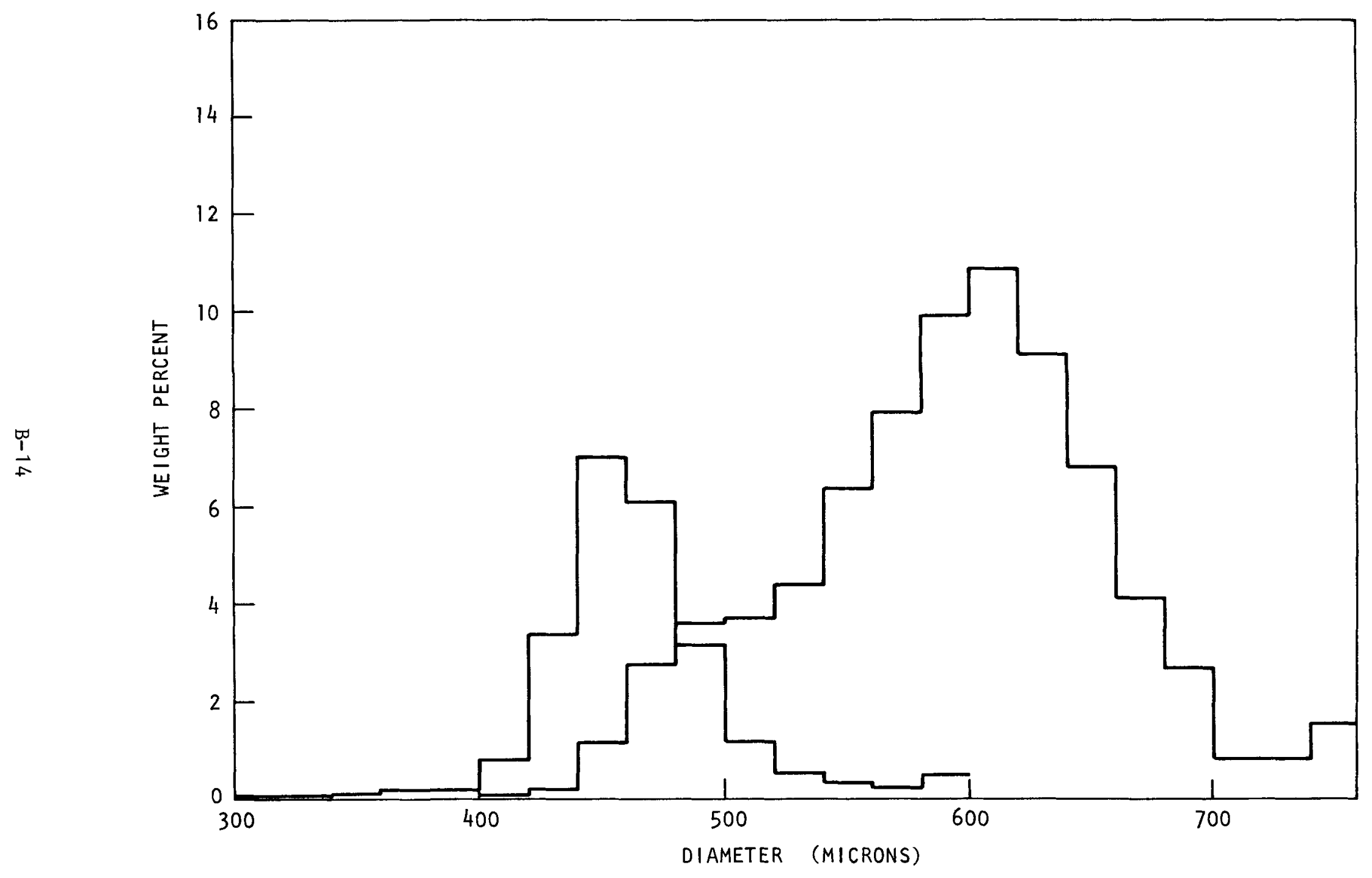

Fig. B-12. Particle size distribution, Scrap Rod Run No. 2, Batch No. 5 


\section{APPENDIX C}

PREDICTIONS OF SEPARATIONS FOR SCRAP ROD RUNS

C-1 
•. 
TABLE $\mathrm{C}-1$

PREDICTION OF THE SEPARATION FOR SCRAP ROD RUN NO. 1, BATCH NO. 1 (Constant $=150.0$, Air Velocity $=2.97 \mathrm{~m} / \mathrm{sec}$ )

\begin{tabular}{|c|c|c|c|c|c|c|c|}
\hline Diameter & Feed & Actual & $\begin{array}{c}\text { Fines } \\
\text { Predicted } \\
\end{array}$ & Error & Actual & $\begin{array}{c}\text { Coarse } \\
\text { Predicted } \\
\end{array}$ & Error \\
\hline 300 & 0.97 & 1.0 & 1.0 & 0.0 & 0.0 & 0.0 & -0.0 \\
\hline 320 & 3.38 & 3.4 & 3.4 & 0.0 & 0.0 & 0.0 & -0.0 \\
\hline 340 & 9.06 & 9.0 & 9.0 & 0.0 & 0.0 & 0.0 & -0.0 \\
\hline 360 & 16.08 & 16.0 & 16.0 & -0.0 & 0.0 & 0.1 & 0.0 \\
\hline 380 & 13.98 & 13.9 & 13.8 & -0.0 & 0.1 & 0.1 & 0.0 \\
\hline 400 & 8.68 & 8.5 & 8.4 & -0.1 & 0.2 & 0.2 & 0.1 \\
\hline 420 & 3.99 & 3.8 & 3.7 & -0.1 & 0.2 & 0.3 & 0.1 \\
\hline 440 & 1.51 & 1.3 & 1.2 & -0.1 & 0.2 & 0.3 & 0.1 \\
\hline 460 & 1.13 & 0.7 & 0.6 & -0.1 & 0.4 & 0.5 & 0.1 \\
\hline 480 & 1.83 & 1.1 & 0.5 & -0.6 & 0.8 & 1.4 & 0.6 \\
\hline 500 & 1.60 & 0.0 & 0.1 & 0.1 & 1.6 & 1.5 & -0.1 \\
\hline 520 & 2.22 & 0.0 & 0.1 & 0.1 & 2.2 & 2.2 & -0.1 \\
\hline 540 & 2.93 & 0.0 & 0.0 & 0.0 & 2.9 & 2.9 & -0.0 \\
\hline 560 & 3.60 & 0.0 & 0.0 & 0.0 & 3.6 & 3.6 & -0.0 \\
\hline 580 & 3.83 & 0.0 & 0.0 & 0.0 & 3.8 & 3.8 & -0.0 \\
\hline 600 & 4.24 & 0.0 & 0.0 & 0.0 & 4.2 & 4.2 & -0.0 \\
\hline 620 & 4.48 & 0.0 & 0.0 & 0.0 & 4.5 & 4.5 & -0.0 \\
\hline 640 & 4.29 & 0.0 & 0.0 & 0.0 & 4.3 & 4.3 & -0.0 \\
\hline 660 & 3.86 & 0.0 & 0.0 & 0.0 & 3.9 & 3.9 & -0.0 \\
\hline 680 & 3.06 & 0.0 & 0.0 & 0.0 & 3.1 & 3.1 & -0.0 \\
\hline 700 & 2.09 & 0.0 & 0.0 & 0.0 & 2.1 & 2.1 & -0.0 \\
\hline 720 & 1.41 & 0.0 & 0.0 & 0.0 & 1.4 & 1.4 & -0.0 \\
\hline 740 & 0.87 & 0.0 & 0.0 & 0.0 & 0.9 & 0.9 & -0.0 \\
\hline 760 & 0.34 & 0.0 & 0.0 & 0.0 & 0.3 & 0.3 & -0.0 \\
\hline 780 & 0.57 & 0.0 & 0.0 & 0.0 & 0.6 & 0.6 & -0.0 \\
\hline 800 & 0.00 & 0.0 & 0.0 & 0.0 & 0.0 & 0.0 & 0.0 \\
\hline 820 & 0.00 & 0.0 & 0.0 & 0.0 & 0.0 & 0.0 & 0.0 \\
\hline 840 & 0.00 & 0.0 & 0.0 & 0.0 & 0.0 & 0.0 & 0.0 \\
\hline 860 & 0.00 & 0.0 & 0.0 & 0.0 & 0.0 & 0.0 & 0.0 \\
\hline 880 & 0.00 & 0.0 & 0.0 & 0.0 & 0.0 & 0.0 & 0.0 \\
\hline 900 & 0.00 & 0.0 & 0.0 & 0.0 & 0.0 & 0.0 & 0.0 \\
\hline TOTAL $=$ & 100.00 & 58.6 & 58.0 & -0.6 & 41.4 & 42.0 & 0.6 \\
\hline
\end{tabular}


TABLE $C-2$

PREDICTION OF THE SEPARATION FOR SCRAP ROD RUN NO. 1, BATCH NO. 2 (Constant $=150.0$, Air Velocity $=2.97 \mathrm{~m} / \mathrm{sec})$

\begin{tabular}{|c|c|c|c|c|c|c|c|}
\hline Diameter & Feed & Actua 1 & $\begin{array}{c}\text { Fines } \\
\text { Predicted } \\
\end{array}$ & Error & Actual & $\begin{array}{c}\text { Coarse } \\
\text { Predicted } \\
\end{array}$ & Error \\
\hline 300 & 1.56 & 1.6 & 1.6 & -0.0 & 0.0 & 0.0 & 0.0 \\
\hline 320 & 4.64 & 4.6 & 4.6 & 0.0 & 0.0 & 0.0 & -0.0 \\
\hline 340 & 10.00 & 10.0 & 10.0 & 0.0 & 0.0 & 0.0 & -0.0 \\
\hline 360 & 15.12 & 15.0 & 15.1 & 0.1 & 0.1 & 0.1 & -0.1 \\
\hline 380 & 11.51 & 11.3 & 11.4 & 0.1 & 0.2 & 0.1 & -0.1 \\
\hline 400 & 7.02 & 6.6 & 6.8 & 0.2 & 0.4 & 0.2 & -0.2 \\
\hline 420 & 2.73 & 2.5 & 2.5 & 0.0 & 0.3 & 0.2 & -0.0 \\
\hline 440 & 0.92 & 0.6 & 0.7 & 0.1 & 0.3 & 0.2 & -0.1 \\
\hline 460 & 1.32 & 0.8 & 0.7 & -0.1 & 0.5 & 0.6 & 0.1 \\
\hline 480 & 1.05 & 0.0 & 0.3 & 0.3 & 1.1 & 0.8 & -0.3 \\
\hline 500 & 1.59 & 0.0 & 0.1 & 0.1 & 1.6 & 1.5 & -0.1 \\
\hline 520 & 2.39 & 0.0 & 0.1 & 0.1 & 2.4 & 2.3 & -0.1 \\
\hline 540 & 3.15 & 0.0 & 0.0 & 0.0 & 3.2 & 3.1 & -0.0 \\
\hline 560 & 3.92 & 0.0 & 0.0 & 0.0 & 3.9 & 3.9 & -0.0 \\
\hline 580 & 4.28 & 0.0 & 0.0 & 0.0 & 4.3 & 4.3 & -0.0 \\
\hline 600 & 4.54 & 0.0 & 0.0 & 0.0 & 4.5 & 4.5 & -0.0 \\
\hline 620 & 5.07 & 0.0 & 0.0 & 0.0 & 5.1 & 5.1 & -0.0 \\
\hline 640 & 5.14 & 0.0 & 0.0 & 0.0 & 5.1 & 5.1 & -0.0 \\
\hline 660 & 4.70 & 0.0 & 0.0 & 0.0 & 4.7 & 4.7 & -0.0 \\
\hline 680 & 3.33 & 0.0 & 0.0 & 0.0 & 3.3 & 3.3 & -0.0 \\
\hline 700 & 2.33 & 0.0 & 0.0 & 0.0 & 2.3 & 2.3 & -0.0 \\
\hline 720 & 1.42 & 0.0 & 0.0 & 0.0 & 1.4 & 1.4 & -0.0 \\
\hline 740 & 0.80 & 0.0 & 0.0 & 0.0 & 0.8 & 0.8 & -0.0 \\
\hline 760 & 0.60 & 0.0 & 0.0 & 0.0 & 0.6 & 0.6 & -0.0 \\
\hline 780 & 0.87 & 0.0 & 0.0 & 0.0 & 0.9 & 0.9 & -0.0 \\
\hline 800 & 0.00 & 0.0 & 0.0 & 0.0 & 0.0 & 0.0 & 0.0 \\
\hline 820 & 0.00 & 0.0 & 0.0 & $0 ; 0$ & 0.0 & 0.0 & 0.0 \\
\hline 840 & 0.00 & 0.0 & 0.0 & 0.0 & 0.0 & 0.0 & 0.0 \\
\hline 860 & 0.00 & 0.0 & 0.0 & 0.0 & 0.0 & 0.0 & 0.0 \\
\hline 880 & 0.00 & 0.0 & 0.0 & 0.0 & 0.0 & 0.0 & 0.0 \\
\hline 900 & 0.00 & 0.0 & 0.0 & 0.0 & 0.0 & 0.0 & 0.0 \\
\hline TOTAL $=$ & 100.00 & 53.0 & 54.1 & 1.1 & 47.0 & 45.9 & -1.1 \\
\hline
\end{tabular}


TABLE $C-3$

PREDICTION OF THE SEPARATION FOR SCRAP ROD RUN NO. 1, BATCH NO. 3

$($ Constant $=150.0$, Air Velocity $=2.97 \mathrm{~m} / \mathrm{sec})$

\begin{tabular}{|c|c|c|c|c|c|c|c|}
\hline Diameter & Feed & Actua1 & $\begin{array}{c}\text { Fines } \\
\text { Predicted }\end{array}$ & Error & Actual & $\begin{array}{c}\text { Coarse } \\
\text { Predicted }\end{array}$ & Error \\
\hline 300 & 1.20 & 1.2 & 1.2 & -0.0 & 0.0 & 0.0 & 0.0 \\
\hline 320 & 3.67 & 3.7 & 3.7 & -0.0 & 0.0 & 0.0 & 0.0 \\
\hline 340 & 9.43 & 9.4 & 9.4 & -0.0 & 0.0 & 0.0 & 0.0 \\
\hline 360 & 15.68 & 15.7 & 15.6 & -0.1 & 0.0 & 0.1 & 0.1 \\
\hline 380 & 12.70 & 12.6 & 12.6 & -0.0 & 0.1 & 0.1 & 0.0 \\
\hline 400 & 6.89 & 6.8 & 6.7 & -0.1 & 0.1 & 0.2 & 0.1 \\
\hline 420 & 2.59 & 2.5 & 2.4 & -0.2 & 0.0 & 0.2 & 0.2 \\
\hline 440 & 1.02 & 0.9 & 0.8 & -0.1 & 0.1 & 0.2 & 0.1 \\
\hline 460 & 0.86 & 0.5 & 0.5 & 0.0 & 0.4 & 0.4 & -0.0 \\
\hline 480 & 1.59 & 0.7 & 0.4 & -0.3 & 0.9 & 1.2 & 0.3 \\
\hline 500 & 2.66 & 1.2 & 0.2 & -1.0 & 1.5 & 2.4 & 1.0 \\
\hline 520 & 2.41 & 0.0 & 0.1 & 0.1 & 2.4 & 2.3 & -0.1 \\
\hline 540 & 3.03 & 0.0 & 0.0 & 0.0 & 3.0 & 3.0 & -0.0 \\
\hline 560 & 3.60 & 0.0 & 0.0 & 0.0 & 3.6 & 3.6 & -0.0 \\
\hline 580 & 4.04 & 0.0 & 0.0 & 0.0 & 4.0 & 4.0 & -0.0 \\
\hline 600 & 4.78 & 0.0 & 0.0 & 0.0 & 4.8 & 4.8 & -0.0 \\
\hline 620 & 5.05 & 0.0 & 0.0 & 0.0 & 5.1 & 5.0 & -0.0 \\
\hline 640 & 4.91 & 0.0 & 0.0 & 0.0 & 4.9 & 4.9 & -0.0 \\
\hline 660 & 4.50 & 0.0 & 0.0 & 0.0 & 4.5 & 4.5 & -0.0 \\
\hline 680 & 3.72 & 0.0 & 0.0 & 0.0 & 3.7 & 3.7 & -0.0 \\
\hline 700 & 2.27 & 0.0 & 0.0 & 0.0 & 2.3 & 2.3 & -0.0 \\
\hline 720 & 1.62 & 0.0 & 0.0 & 0.0 & 1.6 & 1.6 & -0.0 \\
\hline 740 & 0.75 & 0.0 & 0.0 & 0.0 & 0.7 & 0.7 & -0.0 \\
\hline 760 & 1.04 & 0.0 & 0.0 & 0.0 & 1.0 & 1.0 & -0.0 \\
\hline 780 & 0.00 & 0.0 & 0.0 & 0.0 & 0.0 & 0.0 & 0.0 \\
\hline 800 & 0.00 & 0.0 & 0.0 & 0.0 & 0.0 & 0.0 & 0.0 \\
\hline 820 & 0.00 & 0.0 & 0.0 & 0.0 & 0.0 & 0.0 & 0.0 \\
\hline 840 & 0.00 & 0.0 & 0.0 & 0.0 & 0.0 & 0.0 & 0.0 \\
\hline 860 & 0.00 & 0.0 & 0.0 & 0.0 & 0.0 & 0.0 & 0.0 \\
\hline 880 & 0.00 & 0.0 & 0.0 & 0.0 & 0.0 & 0.0 & 0.0 \\
\hline 900 & 0.00 & 0.0 & 0.0 & 0.0 & 0.0 & 0.0 & 0.0 \\
\hline TOTAL $=$ & 100.00 & 55.2 & 53.7 & -1.5 & 44.8 & 46.3 & 1.5 \\
\hline
\end{tabular}


TABLE $\mathrm{C}-4$

PREDICTION OF THE SEPARATION FOR SCRAP ROD RUN NO. 1, BATCH NO. 4 (Constant $=150.0$, Air Velocity $=2.97 \mathrm{~m} / \mathrm{sec}$ )

\begin{tabular}{|c|c|c|c|c|c|c|c|}
\hline Diameter & Feed & Actual & $\begin{array}{c}\text { Fines } \\
\text { Predicted } \\
\end{array}$ & Error & Actua1 & $\begin{array}{c}\text { Coarse } \\
\text { Predicted }\end{array}$ & Error \\
\hline 300 & 1.27 & 1.3 & 1.3 & -0.0 & 0.0 & 0.0 & 0.0 \\
\hline 320 & 3.66 & 3.7 & 3.7 & -0.0 & 0.0 & 0.0 & 0.0 \\
\hline 340 & 8.78 & 8.8 & 8.8 & 0.0 & 0.0 & 0.0 & -0.0 \\
\hline 360 & 14.41 & 14.4 & 14.4 & -0.0 & 0.0 & 0.1 & 0.0 \\
\hline 380 & 11.44 & 11.3 & 11.3 & 0.0 & 0.1 & 0.1 & -0.0 \\
\hline 400 & 6.92 & 6.7 & 6.7 & 0.1 & 0.3 & 0.2 & -0.1 \\
\hline 420 & 3.15 & 2.9 & 2.9 & 0.0 & 0.3 & 0.2 & -0.0 \\
\hline 440 & 1.17 & 1.0 & 0.9 & -0.0 & 0.2 & 0.2 & 0.0 \\
\hline 460 & 0.83 & 0.4 & 0.5 & 0.0 & 0.4 & 0.4 & -0.0 \\
\hline 480 & 1.51 & 0.6 & 0.4 & -0.2 & 0.9 & 1.1 & 0.2 \\
\hline 500 & 1.53 & 0.0 & 0.1 & 0.1 & 1.5 & 1.4 & -0.1 \\
\hline 520 & 2.45 & 0.0 & 0.1 & 0.1 & 2.4 & 2.4 & -0.1 \\
\hline 540 & 2.98 & 0.0 & 0.0 & 0.0 & 3.0 & 2.9 & -0.0 \\
\hline 560 & 3.78 & 0.0 & 0.0 & 0.0 & 3.8 & 3.8 & -0.0 \\
\hline 580 & 4.33 & 0.0 & 0.0 & 0.0 & 4.3 & 4.3 & -0.0 \\
\hline 600 & 4.93 & 0.0 & 0.0 & 0.0 & 4.9 & 4.9 & -0.0 \\
\hline 620 & 5.67 & 0.0 & 0.0 & 0.0 & 5.7 & 5.7 & -0.0 \\
\hline 640 & 5.65 & 0.0 & 0.0 & 0.0 & 5.6 & 5.6 & -0.0 \\
\hline 660 & 4.69 & 0.0 & 0.0 & 0.0 & 4.7 & 4.7 & -0.0 \\
\hline 680 & 4.04 & 0.0 & 0.0 & 0.0 & 4.0 & 4.0 & -0.0 \\
\hline 700 & 2.68 & 0.0 & 0.0 & 0.0 & 2.7 & 2.7 & -0.0 \\
\hline 720 & 1.75 & 0.0 & 0.0 & 0.0 & 1.7 & 1.7 & -0.0 \\
\hline 740 & 0.92 & 0.0 & 0.0 & 0.0 & 0.9 & 0.9 & -0.0 \\
\hline 760 & 0.69 & 0.0 & 0.0 & 0.0 & 0.7 & 0.7 & -0.0 \\
\hline 780 & 0.79 & 0.0 & 0.0 & 0.0 & 0.8 & 0.8 & -0.0 \\
\hline 800 & 0.00 & 0.0 & 0.0 & 0.0 & 0.0 & 0.0 & 0.0 \\
\hline 820 & 0.00 & 0.0 & 0.0 & 0.0 & 0.0 & 0.0 & 0.0 \\
\hline 840 & 0.00 & 0.0 & 0.0 & 0.0 & 0.0 & 0.0 & 0.0 \\
\hline 860 & 0.00 & 0.0 & 0.0 & 0.0 & 0.0 & 0.0 & 0.0 \\
\hline 880 & 0.00 & 0.0 & 0.0 & 0.0 & 0.0 & 0.0 & 0.0 \\
\hline 900 & 0.00 & 0.0 & 0.0 & 0.0 & 0.0 & 0.0 & 0.0 \\
\hline TOTAL $=$ & 100.00 & 50.9 & 51.1 & 0.3 & 49.1 & 48.9 & -0.3 \\
\hline
\end{tabular}


TABLE C-5

PREDICTION OF THE SEPARATION FOR SCRAP ROD RUN NO. 1 , BATCH NO. 5

$($ Constant $=150.0$, Air Velocity $=2.97 \mathrm{~m} / \mathrm{sec})$

\begin{tabular}{|c|c|c|c|c|c|c|c|}
\hline Diameter & Feed & Actual & $\begin{array}{c}\text { Fines } \\
\text { Predicted }\end{array}$ & Error & Actual & $\begin{array}{c}\text { Coarse } \\
\text { Predicted }\end{array}$ & Error \\
\hline 300 & 0.47 & 0.5 & 0.5 & 0.0 & 0.0 & 0.0 & -0.0 \\
\hline 320 & 1.58 & 1.6 & 1.6 & 0.0 & 0.0 & 0.0 & -0.0 \\
\hline 340 & 4.56 & 4.6 & 4.6 & 0.0 & 0.0 & 0.0 & -0.0 \\
\hline 360 & 8.94 & 8.9 & 8.9 & -0.0 & 0.0 & 0.0 & 0.0 \\
\hline 380 & 7.57 & 7.5 & 7.5 & 0.0 & 0.1 & 0.1 & -0.0 \\
\hline 400 & 5.17 & 5.0 & 5.0 & 0.0 & 0.2 & 0.1 & -0.0 \\
\hline 420 & 2.26 & 2.1 & 2.1 & 0.0 & 0.2 & 0.2 & -0.0 \\
\hline 440 & 1.05 & 0.9 & 0.8 & -0.0 & 0.2 & 0.2 & 0.0 \\
\hline 460 & 0.76 & 0.4 & 0.4 & 0.0 & 0.4 & 0.3 & -0.0 \\
\hline 480 & 1.25 & 0.4 & 0.3 & -0.1 & 0.8 & 0.9 & 0.1 \\
\hline 500 & 1.60 & 0.0 & 0.1 & 0.1 & 1.6 & 1.5 & -0.1 \\
\hline 520 & 2.59 & 0.0 & 0.1 & 0.1 & 2.6 & 2.5 & -0.1 \\
\hline 540 & 3.65 & 0.0 & 0.1 & 0.1 & 3.7 & 3.6 & -0.1 \\
\hline 560 & 4.57 & 0.0 & 0.0 & 0.0 & 4.6 & 4.5 & -0.0 \\
\hline 580 & 5.68 & 0.0 & 0.0 & 0.0 & 5.7 & 5.6 & -0.0 \\
\hline 600 & 6.32 & 0.0 & 0.0 & 0.0 & 6.3 & 6.3 & -0.0 \\
\hline 620 & 7.97 & 0.0 & 0.0 & 0.0 & 8.0 & 7.9 & -0.0 \\
\hline 640 & 8.04 & 0.0 & 0.0 & 0.0 & 8.0 & 8.0 & -0.0 \\
\hline 660 & 7.71 & 0.0 & 0.0 & 0.0 & 7.7 & 7.7 & -0.0 \\
\hline 680 & 6.04 & 0.0 & 0.0 & 0.0 & 6.0 & 6.0 & -0.0 \\
\hline 700 & 4.33 & 0.0 & 0.0 & 0.0 & 4.3 & 4.3 & -0.0 \\
\hline 720 & 3.14 & 0.0 & 0.0 & 0.0 & 3.1 & 3.1 & -0.0 \\
\hline 740 & 1.70 & 0.0 & 0.0 & 0.0 & 1.7 & 1.7 & -0.0 \\
\hline 760 & 1.10 & 0.0 & 0.0 & 0.0 & 1.1 & 1.1 & -0.0 \\
\hline 780 & 0.70 & 0.0 & 0.0 & 0.0 & 0.7 & 0.7 & -0.0 \\
\hline 800 & 1.23 & 0.0 & 0.0 & 0.0 & 1.2 & 1.2 & -0.0 \\
\hline 820 & 0.00 & 0.0 & 0.0 & 0.0 & 0.0 & 0.0 & 0.0 \\
\hline 840 & 0.00 & 0.0 & 0.0 & 0.0 & 0.0 & 0.0 & 0.0 \\
\hline 860 & 0.00 & 0.0 & 0.0 & 0.0 & 0.0 & 0.0 & 0.0 \\
\hline 880 & 0.00 & 0.0 & 0.0 & 0.0 & 0.0 & 0.0 & 0.0 \\
\hline 900 & 0.00 & 0.0 & 0.0 & 0.0 & 0.0 & 0.0 & 0.0 \\
\hline TOTAL $=$ & 100.00 & 31.8 & 32.1 & 0.4 & 68.3 & 67.9 & -0.4 \\
\hline
\end{tabular}


TABLE C-6

PREDICTION OF THE SEPARATION FOR SCRAP ROD RUN NO. 2, BATCH NO. 1 (Constant $=150.0$, Air Velocity $=3.70 \mathrm{~m} / \mathrm{sec})$

\begin{tabular}{|c|c|c|c|c|c|c|c|}
\hline Diameter & Feed & Actual & $\begin{array}{c}\text { Fines } \\
\text { Predicted }\end{array}$ & Error & Actual & $\begin{array}{c}\text { Coarse } \\
\text { Predicted }\end{array}$ & Error \\
\hline 300 & 0.04 & 0.0 & 0.0 & -0.0 & 0.0 & 0.0 & 0.0 \\
\hline 320 & 0.16 & 0.2 & 0.2 & -0.0 & 0.0 & 0.0 & 0.0 \\
\hline 340 & 0.29 & 0.3 & 0.3 & -0.0 & 0.0 & 0.0 & 0.0 \\
\hline 360 & 0.38 & 0.4 & 0.4 & -0.0 & 0.0 & 0.0 & 0.0 \\
\hline 380 & 0.49 & 0.5 & 0.5 & -0.0 & 0.0 & 0.0 & 0.0 \\
\hline 400 & 1.31 & 1.3 & 1.3 & -0.0 & 0.0 & 0.0 & 0.0 \\
\hline 420 & 6.28 & 6.2 & 6.3 & 0.0 & 0.0 & 0.0 & -0.0 \\
\hline 440 & 13.33 & 13.3 & 13.1 & -0.1 & 0.0 & 0.2 & 0.1 \\
\hline 460 & 13.36 & 13.2 & 12.8 & -0.4 & 0.2 & 0.6 & 0.4 \\
\hline 480 & 9.54 & 9.0 & 8.3 & -0.7 & 0.5 & 1.2 & 0.7 \\
\hline 500 & 5.81 & 4.6 & 3.7 & -0.8 & 1.2 & 2.1 & 0.8 \\
\hline 520 & 4.96 & 2.9 & 1.8 & -1.1 & 2.1 & 3.2 & 1.1 \\
\hline 540 & 6.31 & 2.9 & 1.4 & -1.5 & 3.4 & 4.9 & 1.5 \\
\hline 560 & 7.31 & 2.7 & 1.0 & -1.7 & 4.6 & 6.4 & 1.7 \\
\hline 580 & 7.97 & 2.4 & 0.7 & -1.7 & 5.5 & 7.2 & 1.7 \\
\hline 600 & 7.71 & 1.9 & 0.5 & -1.4 & 5.8 & 7.2 & 1.4 \\
\hline 620 & 5.90 & 1.1 & 0.3 & -0.8 & 4.8 & 5.6 & 0.9 \\
\hline 640 & 3.65 & 0.5 & 0.1 & -0.3 & 3.2 & 3.5 & 0.3 \\
\hline 660 & 2.95 & 1.0 & 0.1 & -0.9 & 1.9 & 2.9 & 0.9 \\
\hline 680 & 1.03 & 0.0 & 0.0 & 0.0 & 1.0 & 1.0 & -0.0 \\
\hline 700 & 0.51 & 0.0 & 0.0 & 0.0 & 0.5 & 0.5 & -0.0 \\
\hline 720 & 0.73 & 0.0 & 0.0 & 0.0 & 0.7 & 0.7 & -0.0 \\
\hline 740 & 0.00 & 0.0 & 0.0 & 0.0 & 0.0 & 0.0 & 0.0 \\
\hline 760 & 0.00 & 0.0 & 0.0 & 0.0 & 0.0 & 0.0 & 0.0 \\
\hline 780 & 0.00 & 0.0 & 0.0 & 0.0 & 0.0 & 0.0 & 0.0 \\
\hline 800 & 0.00 & 0.0 & 0.0 & 0.0 & 0.0 & 0.0 & 0.0 \\
\hline 820 & 0.00 & 0.0 & 0.0 & 0.0 & 0.0 & 0.0 & 0.0 \\
\hline 840 & 0.00 & 0.0 & 0.0 & 0.0 & 0.0 & 0.0 & 0.0 \\
\hline 860 & 0.00 & 0.0 & 0.0 & 0.0 & 0.0 & 0.0 & 0.0 \\
\hline 880 & 0.00 & 0.0 & 0.0 & 0.0 & 0.0 & 0.0 & 0.0 \\
\hline 900 & 0.00 & 0.0 & 0.0 & 0.0 & 0.0 & 0.0 & 0.0 \\
\hline TOTAL = & 100.00 & 64.3 & 52.9 & -11.4 & 35.7 & 47.1 & 11.4 \\
\hline
\end{tabular}


TABLE $C-7$

PREDICTION OF THE SEPARATION FOR SCRAP ROD RUN NO. 2, BATCH NO. 2 (Constant $=150.0$, Air Velocity $=3.70 \mathrm{~m} / \mathrm{sec})$

\begin{tabular}{|c|c|c|c|c|c|c|c|}
\hline Diameter & Feed & Actual & $\begin{array}{c}\text { Fines } \\
\text { Predicted }\end{array}$ & Error & Actual & $\begin{array}{c}\text { Coarse } \\
\text { Predicted }\end{array}$ & Error \\
\hline 300 & 0.03 & 0.0 & 0.0 & -0.0 & 0.0 & 0.0 & 0.0 \\
\hline 320 & 0.08 & 0.1 & 0.1 & -0.0 & 0.0 & 0.0 & 0.0 \\
\hline 340 & 0.18 & 0.2 & 0.2 & -0.0 & 0.0 & 0.0 & 0.0 \\
\hline 360 & 0.25 & 0.2 & 0.2 & -0.0 & 0.0 & 0.0 & 0.0 \\
\hline 380 & 0.38 & 0.3 & 0.4 & 0.0 & 0.0 & 0.0 & -0.0 \\
\hline 400 & 1.21 & 1.2 & 1.2 & 0.0 & 0.0 & 0.0 & -0.0 \\
\hline 420 & 5.62 & 5.5 & 5.6 & 0.1 & 0.2 & 0.0 & -0.1 \\
\hline 440 & 11.89 & 11.1 & 11.7 & 0.6 & 0.8 & 0.2 & -0.6 \\
\hline 460 & 11.44 & 9.4 & 10.9 & 1.5 & 2.0 & 0.5 & -1.5 \\
\hline 480 & 7.87 & 5.3 & 6.9 & 1.6 & 2.6 & 1.0 & -1.6 \\
\hline 500 & 5.35 & 2.3 & 3.5 & 1.1 & 3.0 & 1.9 & -1.1 \\
\hline 520 & 5.19 & 1.5 & 1.9 & 0.4 & 3.7 & 3.3 & -0.4 \\
\hline 540 & 6.59 & 1.2 & 1.5 & 0.3 & 5.4 & 5.1 & -0.3 \\
\hline 560 & 7.75 & 1.0 & 1.0 & 0.0 & 6.8 & 6.7 & -0.0 \\
\hline 580 & 8.46 & 0.5 & 0.8 & 0.3 & 7.9 & 7.7 & -0.3 \\
\hline 600 & 8.57 & 0.7 & 0.6 & -0.1 & 7.8 & 8.0 & 0.1 \\
\hline 620 & 7.99 & 0.7 & 0.4 & -0.3 & 7.3 & 7.6 & 0.3 \\
\hline 640 & 5.07 & 0.0 & 0.2 & 0.2 & 5.1 & 4.9 & -0.2 \\
\hline 660 & 2.98 & 0.0 & 0.1 & 0.1 & 3.0 & 2.9 & -0.1 \\
\hline 680 & 1.47 & 0.0 & 0.0 & 0.0 & 1.5 & 1.4 & -0.0 \\
\hline 700 & 0.64 & 0.0 & 0.0 & 0.0 & 0.6 & 0.6 & -0.0 \\
\hline 720 & 1.01 & 0.0 & 0.0 & 0.0 & 1.0 & 1.0 & -0.0 \\
\hline 740 & 0.00 & 0.0 & 0.0 & 0.0 & 0.0 & 0.0 & 0.0 \\
\hline 760 & 0.00 & 0.0 & 0.0 & 0.0 & 0.0 & 0.0 & 0.0 \\
\hline 780 & 0.00 & 0.0 & 0.0 & 0.0 & 0.0 & 0.0 & 0.0 \\
\hline 800 & 0.00 & 0.0 & 0.0 & 0.0 & 0.0 & 0.0 & 0.0 \\
\hline 820 & 0.00 & 0.0 & 0.0 & 0.0 & 0.0 & 0.0 & 0.0 \\
\hline 840 & 0.00 & 0.0 & 0.0 & 0.0 & 0.0 & 0.0 & 0.0 \\
\hline 860 & 0.00 & 0.0 & 0.0 & 0.0 & 0.0 & 0.0 & 0.0 \\
\hline 880 & 0.00 & 0.0 & 0.0 & 0.0 & 0.0 & 0.0 & 0.0 \\
\hline 900 & 0.00 & 0.0 & 0.0 & 0.0 & 0.0 & 0.0 & 0.0 \\
\hline TOTAL $=$ & 100.00 & 41.4 & 47.2 & 5.8 & 58.6 & 52.8 & -5.8 \\
\hline
\end{tabular}


TABLE C-8

PREDICTION OF THE SEPARATION FOR SCRAP ROD RUN NO. 2, BATCH NO. 3 (Constant $=150.0$, Air Velocity $=3.70 \mathrm{~m} / \mathrm{sec})$

\begin{tabular}{|c|c|c|c|c|c|c|c|}
\hline Diameter & Feed & Actual & $\begin{array}{c}\text { Fines } \\
\text { Predicted } \\
\end{array}$ & Error & Actual & $\begin{array}{c}\text { Coarse } \\
\text { Predicted }\end{array}$ & Error \\
\hline 300 & 0.02 & 0.0 & 0.0 & -0.0 & 0.0 & 0.0 & 0.0 \\
\hline 320 & 0.07 & 0.1 & 0.1 & -0.0 & 0.0 & 0.0 & 0.0 \\
\hline 340 & 0.17 & 0.2 & 0.2 & -0.0 & 0.0 & 0.0 & 0.0 \\
\hline 360 & 0.23 & 0.2 & 0.2 & -0.0 & 0.0 & 0.0 & 0.0 \\
\hline 380 & 0.25 & 0.2 & 0.2 & -0.0 & 0.0 & 0.0 & 0.0 \\
\hline 400 & 1.25 & 1.2 & 1.2 & 0.0 & 0.0 & 0.0 & -0.0 \\
\hline 420 & 5.52 & 5.4 & 5.5 & 0.1 & 0.1 & 0.0 & -0.1 \\
\hline 440 & 11.15 & 10.7 & 11.0 & 0.3 & 0.4 & 0.1 & -0.3 \\
\hline 460 & 11.94 & 10.6 & 11.4 & 0.8 & 1.3 & 0.5 & -0.8 \\
\hline 480 & 8.93 & 6.4 & 7.8 & 1.4 & 2.5 & 1.1 & -1.4 \\
\hline 500 & 5.53 & 2.4 & 3.6 & 1.2 & 3.1 & 2.0 & -1.2 \\
\hline 520 & 5.49 & 1.3 & 2.0 & 0.7 & 4.2 & 3.5 & -0.7 \\
\hline 540 & 6.71 & 0.8 & 1.5 & 0.7 & 5.9 & 5.2 & -0.7 \\
\hline 560 & 8.23 & 0.6 & 1.1 & 0.5 & 7.6 & 7.2 & -0.5 \\
\hline 580 & 8.63 & 0.5 & 0.8 & 0.3 & 8.2 & 7.8 & -0.3 \\
\hline 600 & 8.65 & 0.8 & 0.6 & -0.2 & 7.9 & 8.0 & 0.2 \\
\hline 620 & 6.98 & 0.0 & 0.4 & 0.4 & 7.0 & 6.6 & -0.4 \\
\hline 640 & 4.45 & 0.0 & 0.2 & 0.2 & 4.4 & 4.3 & -0.2 \\
\hline 660 & 3.17 & 0.0 & 0.1 & 0.1 & 3.2 & 3.1 & -0.1 \\
\hline 680 & 1.49 & 0.0 & 0.0 & 0.0 & 1.5 & 1.5 & -0.0 \\
\hline 700 & 0.59 & 0.0 & 0.0 & 0.0 & 0.6 & 0.6 & -0.0 \\
\hline 720 & 0.58 & 0.0 & 0.0 & 0.0 & 0.6 & 0.6 & -0.0 \\
\hline 740 & 0.00 & 0.0 & 0.0 & 0.0 & 0.0 & 0.0 & 0.0 \\
\hline 760 & 0.00 & 0.0 & 0.0 & 0.0 & 0.0 & 0.0 & 0.0 \\
\hline 780 & 0.00 & 0.0 & 0.0 & 0.0 & 0.0 & 0.0 & 0.0 \\
\hline 800 & 0.00 & 0.0 & 0.0 & 0.0 & 0.0 & 0.0 & 0.0 \\
\hline 820 & 0.00 & 0.0 & 0.0 & 0.0 & 0.0 & 0.0 & 0.0 \\
\hline 840 & 0.00 & 0.0 & 0.0 & 0.0 & 0.0 & 0.0 & 0.0 \\
\hline 860 & 0.00 & 0.0 & 0.0 & 0.0 & 0.0 & 0.0 & 0.0 \\
\hline 880 & 0.00 & 0.0 & 0.0 & 0.0 & 0.0 & 0.0 & 0.0 \\
\hline 900 & 0.00 & 0.0 & 0.0 & 0.0 & 0.0 & 0.0 & 0.0 \\
\hline TOTAL $=$ & 100.00 & 41.4 & 47.8 & 6.4 & 58.6 & 52.2 & -6.4 \\
\hline
\end{tabular}


TABLE C-9

PREDICTION OF THE SEPARATION FOR SCRAP ROD RUN NO. 2, BATCH NO. 4 $($ Constant $=150.0$, Air Velocity $=3.70 \mathrm{~m} / \mathrm{sec})$

\begin{tabular}{|c|c|c|c|c|c|c|c|}
\hline Diameter & Feed & Actual & $\begin{array}{c}\text { Fines } \\
\text { Predicted } \\
\end{array}$ & Error & Actual & $\begin{array}{c}\text { Coarse } \\
\text { Predicted }\end{array}$ & Error \\
\hline 300 & 0.03 & 0.0 & 0.0 & -0.0 & 0.0 & 0.0 & 0.0 \\
\hline 320 & 0.07 & 0.1 & 0.1 & -0.0 & 0.0 & 0.0 & 0.0 \\
\hline 340 & 0.15 & 0.2 & 0.2 & -0.0 & 0.0 & 0.0 & 0.0 \\
\hline 360 & 0.21 & 0.2 & 0.2 & -0.0 & 0.0 & 0.0 & 0.0 \\
\hline 380 & 0.34 & 0.3 & 0.3 & -0.0 & 0.0 & 0.0 & 0.0 \\
\hline 400 & 1.18 & 1.1 & 1.2 & 0.0 & 0.0 & 0.0 & -0.0 \\
\hline 420 & 5.30 & 5.2 & 5.3 & 0.0 & 0.1 & 0.0 & -0.0 \\
\hline 440 & 11.20 & 10.9 & 11.1 & 0.2 & 0.3 & 0.1 & -0.2 \\
\hline 460 & 11.48 & 10.4 & 11.0 & 0.6 & 1.1 & 0.5 & -0.6 \\
\hline 480 & 8.21 & 6.0 & 7.2 & 1.1 & 2.2 & 1.0 & -1.1 \\
\hline 500 & 5.42 & 2.6 & 3.5 & 0.9 & 2.8 & 1.9 & -0.9 \\
\hline 520 & 5.11 & 1.2 & 1.8 & 0.6 & 3.9 & 3.3 & -0.6 \\
\hline 540 & 6.44 & 0.6 & 1.4 & 0.8 & 5.8 & 5.0 & -0.8 \\
\hline 560 & 8.19 & 0.5 & 1.1 & 0.6 & 7.7 & 7.1 & -0.6 \\
\hline 580 & 9.07 & 0.5 & 0.8 & 0.4 & 8.6 & 8.2 & -0.4 \\
\hline 600 & 9.22 & 0.6 & 0.6 & 0.1 & 8.6 & 8.6 & -0.1 \\
\hline 620 & 7.21 & 0.0 & 0.4 & 0.4 & 7.2 & 6.8 & -0.4 \\
\hline 640 & 5.23 & 0.0 & 0.2 & 0.2 & 5.2 & 5.0 & -0.2 \\
\hline 660 & 2.94 & 0.0 & 0.1 & 0.1 & 2.9 & 2.9 & -0.1 \\
\hline 680 & 1.42 & 0.0 & 0.0 & 0.0 & 1.4 & 1.4 & -0.0 \\
\hline 700 & 0.63 & 0.0 & 0.0 & 0.0 & 0.6 & 0.6 & -0.0 \\
\hline 720 & 0.95 & 0.0 & 0.0 & 0.0 & 1.0 & 0.9 & -0.0 \\
\hline 740 & 0.00 & 0.0 & 0.0 & 0.0 & 0.0 & 0.0 & 0.0 \\
\hline 760 & 0.00 & 0.0 & 0.0 & 0.0 & 0.0 & 0.0 & 0.0 \\
\hline 780 & 0.00 & 0.0 & 0.0 & 0.0 & 0.0 & 0.0 & 0.0 \\
\hline 800 & 0.00 & 0.0 & 0.0 & 0.0 & 0.0 & 0.0 & 0.0 \\
\hline 820 & 0.00 & 0.0 & 0.0 & 0.0 & 0.0 & 0.0 & 0.0 \\
\hline 840 & 0.00 & 0.0 & 0.0 & 0.0 & 0.0 & 0.0 & 0.0 \\
\hline 860 & 0.00 & 0.0 & 0.0 & 0.0 & 0.0 & 0.0 & 0.0 \\
\hline 880 & 0.00 & 0.0 & 0.0 & 0.0 & 0.0 & 0.0 & 0.0 \\
\hline 900 & 0.00 & 0.0 & 0.0 & 0.0 & 0.0 & 0.0 & 0.0 \\
\hline TOTAL = & 100.00 & 40.4 & 46.5 & 6.0 & 59.6 & 53.5 & -6.0 \\
\hline
\end{tabular}


TABLE $\mathrm{C}-10$

PREDICTION OF THE SEPARATION FOR SCRAP ROD RUN NO. 2, BATCH NO. 5 (Constant $=150.0$, Air Velocity $=3.70 \mathrm{~m} / \mathrm{sec}$ )

\begin{tabular}{|c|c|c|c|c|c|c|c|}
\hline Diameter & Feed & Actual & $\begin{array}{c}\text { Fines } \\
\text { Predicted }\end{array}$ & Error & Actual & $\begin{array}{l}\text { Coarse } \\
\text { Predicted }\end{array}$ & Error \\
\hline 300 & 0.01 & 0.0 & 0.0 & -0.0 & 0.0 & 0.0 & 0.0 \\
\hline 320 & 0.02 & 0.0 & 0.0 & -0.0 & 0.0 & 0.0 & 0.0 \\
\hline 340 & 0.09 & 0.1 & 0.1 & -0.0 & 0.0 & 0.0 & 0.0 \\
\hline 360 & 0.14 & 0.1 & 0.1 & -0.0 & 0.0 & 0.0 & 0.0 \\
\hline 380 & 0.16 & 0.2 & 0.2 & -0.0 & 0.0 & 0.0 & 0.0 \\
\hline 400 & 0.82 & 0.8 & 0.8 & 0.0 & 0.0 & 0.0 & -0.0 \\
\hline 420 & 3.52 & 3.4 & 3.5 & 0.1 & 0.2 & 0.0 & -0.1 \\
\hline 440 & 8.13 & 7.0 & 8.0 & 1.0 & 1.2 & 0.1 & -1.0 \\
\hline 460 & 8.82 & 6.1 & 8.4 & 2.4 & 2.7 & 0.4 & -2.4 \\
\hline 480 & 6.73 & 3.2 & 5.9 & 2.7 & 3.6 & 0.9 & -2.7 \\
\hline 500 & 4.85 & 1.1 & 3.1 & 2.0 & 3.7 & 1.7 & -2.0 \\
\hline 520 & 4.89 & 0.5 & 1.7 & 1.2 & 4.4 & 3.1 & -1.2 \\
\hline 540 & 6.63 & 0.3 & 1.5 & 1.2 & 6.3 & 5.1 & -1.2 \\
\hline 560 & 8.14 & 0.2 & 1.1 & 0.8 & 7.9 & 7.1 & -0.8 \\
\hline 580 & 10.38 & 0.5 & 1.0 & 0.5 & 9.9 & 9.4 & -0.5 \\
\hline 600 & 10.88 & 0.0 & 0.8 & 0.8 & 10.9 & 10.1 & -0.8 \\
\hline 620 & 9.09 & 0.0 & 0.5 & 0.5 & 9.1 & 8.6 & -0.5 \\
\hline 640 & 6.83 & 0.0 & 0.3 & 0.3 & 6.8 & 6.6 & -0.3 \\
\hline 660 & 4.11 & 0.0 & 0.1 & 0.1 & 4.1 & 4.0 & -0.1 \\
\hline 680 & 2.65 & 0.0 & 0.1 & 0.1 & 2.7 & 2.6 & -0.1 \\
\hline 700 & 0.81 & 0.0 & 0.0 & 0.0 & 0.8 & 0.8 & -0.0 \\
\hline 720 & 0.78 & 0.0 & 0.0 & 0.0 & 0.8 & 0.8 & -0.0 \\
\hline 740 & 1.51 & 0.0 & 0.0 & 0.0 & 1.5 & 1.5 & -0.0 \\
\hline 760 & 0.00 & 0.0 & 0.0 & 0.0 & 0.0 & 0.0 & 0.0 \\
\hline 780 & 0.00 & 0.0 & 0.0 & 0.0 & 0.0 & 0.0 & 0.0 \\
\hline 800 & 0.00 & 0.0 & 0.0 & 0.0 & 0.0 & 0.0 & 0.0 \\
\hline 820 & 0.00 & 0.0 & 0.0 & 0.0 & 0.0 & 0.0 & 0.0 \\
\hline 840 & 0.00 & 0.0 & 0.0 & 0.0 & 0.0 & 0.0 & 0.0 \\
\hline 860 & 0.00 & 0.0 & 0.0 & 0.0 & 0.0 & 0.0 & 0.0 \\
\hline 880 & 0.00 & 0.0 & 0.0 & 0.0 & 0.0 & 0.0 & 0.0 \\
\hline 900 & 0.00 & 0.0 & 0.0 & 0.0 & 0.0 & 0.0 & 0.0 \\
\hline TOTAL = & 100.00 & 23.4 & 37.2 & 13.7 & 76.6 & 62.8 & -13.7 \\
\hline
\end{tabular}


TABLE $C-11$

PREDICTION OF SEPARATION FOR SCRAP ROD RUN NO. 2, BATCH NO. 1 (Constant $=325.0$, Air Velocity $=3.70 \mathrm{~m} / \mathrm{sec}$ )

\begin{tabular}{|c|c|c|c|c|c|c|c|}
\hline Diameter & Feed & Actual & $\begin{array}{c}\text { Fines } \\
\text { Predicted }\end{array}$ & Error & Actual & $\begin{array}{c}\text { Coarse } \\
\text { Predicted }\end{array}$ & Error \\
\hline 300 & 0.04 & 0.0 & 0.0 & -0.0 & 0.0 & 0.0 & 0.0 \\
\hline 320 & 0.16 & 0.2 & 0.2 & -0.0 & 0.0 & 0.0 & 0.0 \\
\hline 340 & 0.29 & 0.3 & 0.3 & -0.0 & 0.0 & 0.0 & 0.0 \\
\hline 360 & 0.38 & 0.4 & 0.4 & -0.0 & 0.0 & 0.0 & 0.0 \\
\hline 380 & 0.49 & 0.5 & 0.5 & -0.0 & 0.0 & 0.0 & 0.0 \\
\hline 400 & 1.31 & 1.3 & 1.3 & -0.0 & 0.0 & 0.0 & 0.0 \\
\hline 420 & 6.28 & 6.2 & 6.2 & -0.0 & 0.0 & 0.1 & 0.0 \\
\hline 440 & 13.33 & 13.3 & 12.9 & -0.4 & 0.0 & 0.4 & 0.4 \\
\hline 460 & 13.36 & 13.2 & 11.9 & -1.2 & 0.2 & 1.4 & 1.2 \\
\hline 480 & 9.54 & 9.0 & 7.3 & -1.7 & 0.5 & 2.3 & 1.7 \\
\hline 500 & 5.81 & 4.6 & 2.6 & -1.9 & 1.2 & 3.2 & 1.9 \\
\hline 520 & 4.96 & 2.9 & 1.0 & -1.8 & 2.1 & 3.9 & 1.8 \\
\hline 540 & 6.31 & 2.9 & 0.7 & -2.1 & 3.4 & 5.6 & 2.1 \\
\hline 560 & 7.31 & 2.7 & 0.5 & -2.2 & 4.6 & 6.8 & 2.2 \\
\hline 580 & 7.97 & 2.4 & 0.4 & -2.1 & 5.5 & 7.6 & 2.1 \\
\hline 600 & 7.71 & 1.9 & 0.3 & -1.7 & 5.8 & 7.5 & 1.7 \\
\hline 620 & 5.90 & 1.1 & 0.1 & -1.0 & 4.8 & 5.8 & 1.0 \\
\hline 640 & 3.65 & 0.5 & 0.1 & -0.4 & 3.2 & 3.6 & 0.4 \\
\hline 660 & 2.95 & 1.0 & 0.0 & -1.0 & 1.9 & 2.9 & 1.0 \\
\hline 680 & 1.03 & 0.0 & 0.0 & 0.0 & 1.0 & 1.0 & -0.0 \\
\hline 700 & 0.51 & 0.0 & 0.0 & 0.0 & 0.5 & 0.5 & -0.0 \\
\hline 720 & 0.73 & 0.0 & 0.0 & 0.0 & 0.7 & 0.7 & -0.0 \\
\hline 740 & 0.00 & 0.0 & 0.0 & 0.0 & 0.0 & 0.0 & 0.0 \\
\hline 760 & 0.00 & 0.0 & 0.0 & 0.0 & 0.0 & 0.0 & 0.0 \\
\hline 780 & 0.00 & 0.0 & 0.0 & 0.0 & 0.0 & 0.0 & 0.0 \\
\hline 800 & 0.00 & 0.0 & 0.0 & 0.0 & 0.0 & 0.0 & 0.0 \\
\hline 820 & 0.00 & 0.0 & 0.0 & 0.0 & 0.0 & 0.0 & 0.0 \\
\hline 840 & 0.00 & 0.0 & 0.0 & 0.0 & 0.0 & 0.0 & 0.0 \\
\hline 860 & 0.00 & 0.0 & 0.0 & 0.0 & 0.0 & 0.0 & 0.0 \\
\hline 880 & 0.00 & 0.0 & 0.0 & 0.0 & 0.0 & 0.0 & 0.0 \\
\hline 900 & 0.00 & 0.0 & 0.0 & 0.0 & 0.0 & 0.0 & 0.0 \\
\hline TOTAL $=$ & 100.00 & 64.3 & 46.8 & -17.5 & 35.7 & 53.2 & 17.5 \\
\hline
\end{tabular}


TABLE $\mathrm{C}-12$

PREDICTION OF SEPARATION FOR SCRAP ROD RUN NO. 2, BATCH NO. 2 (Constant $=325.0$, Air Velocity $=3.70 \mathrm{~m} / \mathrm{sec}$ )

\begin{tabular}{|c|c|c|c|c|c|c|c|}
\hline Diameter & Feed & Actual & $\begin{array}{c}\text { Fines } \\
\text { Predicted }\end{array}$ & Error & Actual & $\begin{array}{c}\text { Coarse } \\
\text { Predicted }\end{array}$ & Error \\
\hline 300 & 0.03 & 0.0 & 0.0 & -0.0 & 0.0 & 0.0 & 0.0 \\
\hline 320 & 0.08 & 0.1 & 0.1 & -0.0 & 0.0 & 0.0 & 0.0 \\
\hline 340 & 0.18 & 0.2 & 0.2 & -0.0 & 0.0 & 0.0 & 0.0 \\
\hline 360 & 0.25 & 0.2 & 0.2 & -0.0 & 0.0 & 0.0 & 0.0 \\
\hline 380 & 0.38 & 0.3 & 0.4 & 0.0 & 0.0 & 0.0 & -0.0 \\
\hline 400 & 1.21 & 1.2 & 1.2 & 0.0 & 0.0 & 0.0 & -0.0 \\
\hline 420 & 5.62 & 5.5 & 5.6 & 0.1 & 0.2 & 0.1 & -0.1 \\
\hline 440 & 11.89 & 11.1 & 11.5 & 0.4 & 0.8 & 0.4 & -0.4 \\
\hline 460 & 11.44 & 9.4 & 10.2 & 0.8 & 2.0 & 1.2 & -0.8 \\
\hline 480 & 7.87 & 5.3 & 6.0 & 0.7 & 2.6 & 1.9 & -0.7 \\
\hline 500 & 5.35 & 2.3 & 2.4 & 0.1 & 3.0 & 2.9 & -0.1 \\
\hline 520 & 5.19 & 1.5 & 1.1 & -0.4 & 3.7 & 4.1 & 0.4 \\
\hline 540 & 6.59 & 1.2 & 0.8 & -0.4 & 5.4 & 5.8 & 0.4 \\
\hline 560 & 7.75 & 1.0 & 0.5 & -0.5 & 6.8 & 7.2 & 0.5 \\
\hline 580 & 8.46 & 0.5 & 0.4 & -0.2 & 7.9 & 8.1 & 0.2 \\
\hline 600 & 8.57 & 0.7 & 0.3 & -0.4 & 7.8 & 8.3 & 0.4 \\
\hline 620 & 7.99 & 0.7 & 0.2 & -0.5 & 7.3 & 7.8 & 0.5 \\
\hline 640 & 5.07 & 0.0 & 0.1 & 0.1 & 5.1 & 5.0 & -0.1 \\
\hline 660 & 2.98 & 0.0 & 0.0 & 0.0 & 3.0 & 2.9 & -0.0 \\
\hline 680 & 1.47 & 0.0 & 0.0 & 0.0 & 1.5 & 1.5 & -0.0 \\
\hline 700 & 0.64 & 0.0 & 0.0 & 0.0 & 0.6 & 0.6 & -0.0 \\
\hline 720 & 1.01 & 0.0 & 0.0 & 0.0 & 1.0 & 1.0 & -0.0 \\
\hline 740 & 0.00 & 0.0 & 0.0 & 0.0 & 0.0 & 0.0 & 0.0 \\
\hline 760 & 0.00 & 0.0 & 0.0 & 0.0 & 0.0 & 0.0 & 0.0 \\
\hline 780 & 0.00 & 0.0 & 0.0 & 0.0 & 0.0 & 0.0 & 0.0 \\
\hline 800 & 0.00 & 0.0 & 0.0 & 0.0 & 0.0 & 0.0 & 0.0 \\
\hline 820 & 0.00 & 0.0 & 0.0 & 0.0 & 0.0 & 0.0 & 0.0 \\
\hline 840 & 0.00 & 0.0 & 0.0 & 0.0 & 0.0 & 0.0 & 0.0 \\
\hline 860 & 0.00 & 0.0 & 0.0 & 0.0 & 0.0 & 0.0 & 0.0 \\
\hline 880 & 0.00 & 0.0 & 0.0 & 0.0 & 0.0 & 0.0 & 0.0 \\
\hline 900 & 0.00 & 0.0 & 0.0 & 0.0 & 0.0 & 0.0 & 0.0 \\
\hline TOTAL $=$ & 100.00 & 41.4 & 41.2 & -0.2 & 58.6 & 58.8 & 0.2 \\
\hline
\end{tabular}


TABLE $C-13$

PREDICTION OF SEPARATION FOR SCRAP ROD RUN NO. 2, BATCH NO. 3 (Constant $=325.0$, Air Velocity $=3.70 \mathrm{~m} / \mathrm{sec})$

\begin{tabular}{|c|c|c|c|c|c|c|c|}
\hline Diameter & Feed & Actual & $\begin{array}{c}\text { Fines } \\
\text { Predicted }\end{array}$ & Error & Actual & $\begin{array}{l}\text { Coarse } \\
\text { Predicted }\end{array}$ & Errox \\
\hline 300 & 0.02 & 0.0 & 0.0 & -0.0 & 0.0 & 0.0 & 0.0 \\
\hline 320 & 0.07 & 0.1 & 0.1 & -0.0 & 0.0 & 0.0 & 0.0 \\
\hline 340 & 0.17 & 0.2 & 0.2 & -0.0 & 0.0 & 0.0 & 0.0 \\
\hline 360 & 0.23 & 0.2 & 0.2 & -0.0 & 0.0 & 0.0 & 0.0 \\
\hline 380 & 0.25 & 0.2 & 0.2 & -0.0 & 0.0 & 0.0 & 0.0 \\
\hline 400 & 1.25 & 1.2 & 1.2 & 0.0 & 0.0 & 0.0 & -0.0 \\
\hline 420 & 5.52 & 5.4 & 5.5 & 0.0 & 0.1 & 0.1 & -0.0 \\
\hline 440 & 11.15 & 10.7 & 10.8 & 0.0 & 0.4 & 0.4 & -0.0 \\
\hline 460 & 11.94 & 10.6 & 10.7 & 0.1 & 1.3 & 1.3 & -0.1 \\
\hline 480 & 8.93 & 6.4 & 6.8 & 0.4 & 2.5 & 2.1 & -0.4 \\
\hline 500 & 5.53 & 2.4 & 2.5 & 0.1 & 3.1 & 3.0 & -0.1 \\
\hline 520 & 5.49 & 1.3 & 1.1 & -0.2 & 4.2 & 4.4 & 0.2 \\
\hline 540 & 6.71 & 0.8 & 0.8 & 0.0 & 5.9 & 5.9 & -0.0 \\
\hline 560 & 8.23 & 0.6 & 0.5 & -0.1 & 7.6 & 7.7 & 0.1 \\
\hline 580 & 8.63 & 0.5 & 0.4 & -0.1 & 8.2 & 8.2 & 0.1 \\
\hline 600 & 8.65 & 0.8 & 0.3 & -0.5 & 7.9 & 8.4 & 0.5 \\
\hline 620 & 6.98 & 0.0 & 0.2 & 0.2 & 7.0 & 6.8 & -0.2 \\
\hline 640 & 4.45 & 0.0 & 0.1 & 0.1 & 4.4 & 4.4 & -0.1 \\
\hline 660 & 3.17 & 0.0 & 0.0 & 0.0 & 3.2 & 3.1 & -0.0 \\
\hline 680 & 1.49 & 0.0 & 0.0 & 0.0 & 1.5 & 1.5 & -0.0 \\
\hline 700 & 0.59 & 0.0 & 0.0 & 0.0 & 0.6 & 0.6 & -0.0 \\
\hline 720 & 0.58 & 0.0 & 0.0 & 0.0 & 0.6 & 0.6 & -0.0 \\
\hline 740 & 0.00 & 0.0 & 0.0 & 0.0 & 0.0 & 0.0 & 0.0 \\
\hline 760 & 0.00 & 0.0 & 0.0 & 0.0 & 0.0 & 0.0 & 0.0 \\
\hline 780 & 0.00 & 0.0 & 0.0 & 0.0 & 0.0 & 0.0 & 0.0 \\
\hline 800 & 0.00 & 0.0 & 0.0 & 0.0 & 0.0 & 0.0 & 0.0 \\
\hline 820 & 0.00 & 0.0 & 0.0 & 0.0 & 0.0 & 0.0 & 0.0 \\
\hline 840 & 0.00 & 0.0 & 0.0 & 0.0 & 0.0 & 0.0 & 0.0 \\
\hline 860 & 0.00 & 0.0 & 0.0 & 0.0 & 0.0 & 0.0 & 0.0 \\
\hline 880 & 0.00 & 0.0 & 0.0 & 0.0 & 0.0 & 0.0 & 0.0 \\
\hline 900 & 0.00 & 0.0 & 0.0 & 0.0 & 0.0 & 0.0 & 0.0 \\
\hline TOTAL $=$ & 100.00 & 41.4 & 41.6 & 0.2 & 58.6 & 58.4 & -0.2 \\
\hline
\end{tabular}


TABLE $\mathrm{C}-14$

PREDICTION OF SEPARATION FOR SCRAP ROD RUN NO. 2, BATCH NO. 4 $($ Constant $=325.0$, Air Velocity $=3.70 \mathrm{~m} / \mathrm{sec})$

\begin{tabular}{|c|c|c|c|c|c|c|c|}
\hline Diameter & Feed & Actual & $\begin{array}{c}\text { Fines } \\
\text { Predicted }\end{array}$ & Error & Actual & $\begin{array}{c}\text { Coarse } \\
\text { Predicted }\end{array}$ & Error \\
\hline 300 & 0.03 & 0.0 & 0.0 & -0.0 & 0.0 & 0.0 & 0.0 \\
\hline 320 & 0.07 & 0.1 & 0.1 & -0.0 & 0.0 & 0.0 & 0.0 \\
\hline 340 & 0.15 & 0.2 & 0.2 & -0.0 & 0.0 & 0.0 & 0.0 \\
\hline 360 & 0.21 & 0.2 & 0.2 & -0.0 & 0.0 & 0.0 & 0.0 \\
\hline 380 & 0.34 & 0.3 & 0.3 & -0.0 & 0.0 & 0.0 & 0.0 \\
\hline 400 & 1.18 & 1.1 & 1.2 & 0.0 & 0.0 & 0.0 & -0.0 \\
\hline 420 & 5.30 & 5.2 & 5.2 & 0.0 & 0.1 & 0.0 & -0.0 \\
\hline 440 & 11.20 & 10.9 & 10.8 & -0.0 & 0.3 & 0.4 & 0.0 \\
\hline 460 & 11.48 & 10.4 & 10.3 & -0.1 & 1.1 & 1.2 & 0.1 \\
\hline 480 & 8.21 & 6.0 & 6.2 & 0.2 & 2.2 & 2.0 & -0.2 \\
\hline 500 & 5.42 & 2.6 & 2.5 & -0.1 & 2.8 & 2.9 & 0.1 \\
\hline 520 & 5.11 & 1.2 & 1.0 & -0.2 & 3.9 & 4.1 & 0.2 \\
\hline 540 & 6.44 & 0.6 & 0.8 & 0.1 & 5.8 & 5.7 & -0.1 \\
\hline 560 & 8.19 & 0.5 & 0.5 & 0.0 & 7.7 & 7.7 & -0.0 \\
\hline 580 & 9.07 & 0.5 & 0.4 & -0.1 & 8.6 & 8.7 & 0.1 \\
\hline 600 & 9.22 & 0.6 & 0.3 & -0.3 & 8.6 & 8.9 & 0.3 \\
\hline 620 & 7.21 & 0.0 & 0.2 & 0.2 & 7.2 & 7.0 & -0.2 \\
\hline 640 & 5.23 & 0.0 & 0.1 & 0.1 & 5.2 & 5.1 & -0.1 \\
\hline 660 & 2.94 & 0.0 & 0.0 & 0.0 & 2.9 & 2.9 & -0.0 \\
\hline 680 & 1.42 & 0.0 & 0.0 & 0.0 & 1.4 & 1.4 & -0.0 \\
\hline 700 & 0.63 & 0.0 & 0.0 & 0.0 & 0.6 & 0.6 & -0.0 \\
\hline 720 & 0.95 & 0.0 & 0.0 & 0.0 & 1.0 & 0.9 & -0.0 \\
\hline 740 & 0.00 & 0.0 & 0.0 & 0.0 & 0.0 & 0.0 & 0.0 \\
\hline 760 & 0.00 & 0.0 & 0.0 & 0.0 & 0.0 & 0.0 & 0.0 \\
\hline 780 & 0.00 & 0.0 & 0.0 & 0.0 & 0.0 & 0.0 & 0.0 \\
\hline 800 & 0.00 & 0.0 & 0.0 & 0.0 & 0.0 & 0.0 & 0.0 \\
\hline 820 & 0.00 & 0.0 & 0.0 & 0.0 & 0.0 & 0.0 & 0.0 \\
\hline 840 & 0.00 & 0.0 & 0.0 & 0.0 & 0.0 & 0.0 & 0.0 \\
\hline 860 & 0.00 & 0.0 & 0.0 & 0.0 & 0.0 & 0.0 & 0.0 \\
\hline 880 & 0.00 & 0.0 & 0.0 & 0.0 & 0.0 & 0.0 & 0.0 \\
\hline 900 & 0.00 & 0.0 & 0.0 & 0.0 & 0.0 & 0.0 & 0.0 \\
\hline TOTAL $=$ & 100.00 & 40.4 & 40.4 & -0.0 & 59.6 & 59.6 & 0.0 \\
\hline
\end{tabular}


TABLE $C-15$

PREDICTION OF SEPARATION FOR SCRAP ROD RUN NO. 2, BATCH NO. 5 (Constant $=325.0$, Air Velocity $=3.70 \mathrm{~m} / \mathrm{sec}$ )

\begin{tabular}{|c|c|c|c|c|c|c|c|}
\hline Diameter & Feed & Actua1 & $\begin{array}{c}\text { Fines } \\
\text { Predicted }\end{array}$ & Error & Actual & $\begin{array}{l}\text { Coarse } \\
\text { Predicted }\end{array}$ & Error \\
\hline 300 & 0.01 & 0.0 & 0.0 & -0.0 & 0.0 & 0.0 & 0.0 \\
\hline 320 & 0.02 & 0.0 & 0.0 & -0.0 & 0.0 & 0.0 & 0.0 \\
\hline 340 & 0.09 & 0.1 & 0.1 & -0.0 & 0.0 & 0.0 & 0.0 \\
\hline 360 & 0.14 & 0.1 & 0.1 & -0.0 & 0.0 & 0.0 & 0.0 \\
\hline 380 & 0.16 & 0.2 & 0.2 & -0.0 & 0.0 & 0.0 & 0.0 \\
\hline 400 & 0.82 & 0.8 & 0.8 & 0.0 & 0.0 & 0.0 & -0.0 \\
\hline 420 & 3.52 & 3.4 & 3.5 & 0.1 & 0.2 & 0.0 & -0.1 \\
\hline 440 & 8.13 & 7.0 & 7.9 & 0.9 & 1.2 & 0.3 & -0.9 \\
\hline 460 & 8.82 & 6.1 & 7.9 & 1.8 & 2.7 & 0.9 & -1.8 \\
\hline 480 & 6.73 & 3.2 & 5.1 & 2.0 & 3.6 & 1.6 & -2.0 \\
\hline 500 & 4.85 & 1.1 & 2.2 & 1.1 & 3.7 & 2.6 & -1.1 \\
\hline 520 & 4.89 & 0.5 & 1.0 & 0.5 & 4.4 & 3.9 & -0.5 \\
\hline 540 & 6.63 & 0.3 & 0.8 & 0.5 & 6.3 & 5.8 & -0.5 \\
\hline 560 & 8.14 & 0.2 & 0.5 & 0.3 & 7.9 & 7.6 & -0.3 \\
\hline 580 & 10.38 & 0.5 & 0.5 & 0.0 & 9.9 & 9.9 & -0.0 \\
\hline 600 & 10.88 & 0.0 & 0.4 & 0.4 & 10.9 & 10.5 & -0.4 \\
\hline 620 & 9.09 & 0.0 & 0.2 & 0.2 & 9.1 & 8.9 & -0.2 \\
\hline 640 & 6.83 & 0.0 & 0.1 & 0.1 & 6.8 & 6.7 & -0.1 \\
\hline 660 & 4.11 & 0.0 & 0.1 & 0.1 & 4.1 & 4.1 & -0.1 \\
\hline 680 & 2.65 & 0.0 & 0.0 & 0.0 & 2.7 & 2.6 & -0.0 \\
\hline 700 & 0.81 & 0.0 & 0.0 & 0.0 & 0.8 & 0.8 & -0.0 \\
\hline 720 & 0.78 & 0.0 & 0.0 & 0.0 & 0.8 & 0.8 & -0.0 \\
\hline 740 & 1.51 & 0.0 & 0.0 & 0.0 & 1.5 & 1.5 & -0.0 \\
\hline 760 & 0.00 & 0.0 & 0.0 & 0.0 & 0.0 & 0.0 & 0.0 \\
\hline 780 & 0.00 & 0.0 & 0.0 & 0.0 & 0.0 & 0.0 & 0.0 \\
\hline 800 & 0.00 & 0.0 & 0.0 & 0.0 & 0.0 & 0.0 & 0.0 \\
\hline 820 & 0.00 & 0.0 & 0.0 & 0.0 & 0.0 & 0.0 & 0.0 \\
\hline 840 & 0.00 & 0.0 & 0.0 & 0.0 & 0.0 & 0.0 & 0.0 \\
\hline 860 & 0.00 & 0.0 & 0.0 & 0.0 & 0.0 & 0.0 & 0.0 \\
\hline 880 & 0.00 & 0.0 & 0.0 & 0.0 & 0.0 & 0.0 & 0.0 \\
\hline 900 & 0.00 & 0.0 & 0.0 & 0.0 & 0.0 & 0.0 & 0.0 \\
\hline TOTAL = & 100.00 & 23.4 & 31.4 & 8.0 & 76.6 & 68.6 & -8.0 \\
\hline
\end{tabular}


APPENDIX D

DESCRIPTION AND OPERATION OF THE

COATED PARTICLE ANALYSER

$\mathrm{D}-1$ 
• 


\section{AUTOMATIC SIZE ANALYSIS OF COATED FUEL PARTICLES}

by

K. WALLISCH

P. KOSS

(SGAE Seibersdorf

Report No. 2342)

ABSTRACT

An optical system for the fast determination of diameters, coating thicknesses and densities of coated fuel particles is described. The results of four measurements are compared with the results obtained by other methods and demonstrate the high accuracy and the reproducibility of the technique used. 


\section{INTRODUCTION}

A number of different methods are used for determining particle diameter coating thickness and density of coated fuel particles. The major disadvantage of all these techniques is the relatively long time required for measuring a certain number of particles and the necessity to use different methods for the determination of density.

An alternative method described in this paper avoids these disadvantages by utilizing a fast optical data collecting system of high accuracy. This system allows the determination of the diameter of particles in the range $300 \mu \mathrm{m}-1500 \mu \mathrm{m}$ with an error of better than $\pm 2 \mu \mathrm{m}$ and with a rate of 20 - 100 particles per second. An on-line computer stores the measured data and calculates all parameters required.

By weighing the particles before and after the measurement and taking into account the number and the mean volume of the particles measured the mean particle density can be determined

$$
\begin{aligned}
& \rho=\frac{G}{\bar{V} \cdot \mathrm{n}} \\
& \mathrm{G} \ldots \text { weight of measured particles } \\
& \overrightarrow{\mathrm{V}} \ldots \text { mean volume of particles } \\
& \mathrm{n} \ldots \text { number of measured particles }
\end{aligned}
$$

By measuring before and after a coating step the mean coating thickness and the mean coating density $\rho_{i}$ can be determined.

$$
\rho_{i}=\frac{\frac{G_{i}}{n_{i}}-\frac{G_{i-1}}{n_{i-1}}}{\bar{V}_{i}-\bar{V}_{i-1}}
$$




\section{PRINCIPLE OF MEASUREMENT}

A parallel light beam fllustrates a narrow parallel slit. The beam is partially interrupted by the measured particle. The reduction of the light current which is measured by a photo-sensitive diode is proportional to the particle diameter (perpendicular to the direction of motion). The peakvalue is detected, digitalized and passed on into a PDP-8/E computer via CAMAC and stored. Preceding the measurement the system is calibrated with high precision steel balls.

\section{EQUIPMENT FOR PARTICLE SIZE ANALYSIS (PSA)}

3.1. The opto-mechanical part (Fig. 1) includes the particle feed system, the optical system, a pre-amplifier and the necessary control devices. The particles to be measured are poured into the feed system where they are picked up and carried along by a pneumatic system. After passing the optical measuring device they are collected in a container. For checking the correct function of the optlcal as well as the detection system a testing device is built into the equipment.

3.2. Figure 2 shows the processing of the pulse delivered by the photo diode which is carried out by a special CAMAC unit (KDM-1). The plug-in panel of this unit includes a baseline stabilized amplifier, the peak detector, control logic, an analog to digital converter, and the brightness control for the lamp used in the optical system. The digital values of particle diameters are stored in a $\mathrm{PDP}-8 / \mathrm{E}$ computer with the following subunits: $12 \mathrm{k}$ memory, mass storage (tape or disc), VR 14 display, Calcomp Plotter Model 565.

3.3. After stating the measuring conditions and after calibrating the system, the programe classifies the particle diameters and stores them in a software multichannel. The channels cover the diameter range from $300 \mu \mathrm{m}$ 
- $1500 \mu \mathrm{m}$. Each channel is calibrated in microns and has a width of $2 \mu \mathrm{m}$. The maximum storage capacity of one channel is 4095 particles. The content of the storage is visible on the display during the measurement and evaluation. The computer evaluates the data after the measurement is completed and the limits for the evaluation range are defined by the operator. The software includes the following calculations (output on teletype): Number of particles measured, mean particle diameter, standard deviation, variation factor, limiting values, total volume of particles measured, mean particle volume.

\section{RESULTS}

In Figs. 3 to 10 the print-out and the plotting of four different measurements are demonstrated.

Figures 3 and 4 show the results of the measurement of steel balls with the diameter of $1000 \mu \mathrm{m} \pm 1 \mu \mathrm{m}$ (specified by the supplier), which are used for the calibration of the equipment. Results obtained from fuel particles are shown in Figs. 5 and 6 (kernels) and in Figs. 7 and 8 (coated particles).

Provided that the difference of diameter is large enough, mixed samples can be measured as wel1. Figures 9 and 10 demonstrate the simultaneous measurement of kernels (same as Figs. 5 and 6) and of coated particles (same as Figs. 7 and 8).

A comparison of results for the overall diameter, particle density, mean coating thickness, and coating density measured with conventional methods and with the Particle Size Analyser for two coating steps is given in Table 1. Taking into account the limits of error of the different methods the values are in good agreement. 


\section{CONCLUSION}

The Particle Size Analyser described allows the fast determination of particle size as well as layer thickness and the density of coatings. The examples shown demonstrate the high accuracy and reproducibility of the results. Since a skilled operator needs only a few minutes for performing the measurements and the evaluation of the results, this equipment is especially suited for the on-line control of the coating process in production units. 


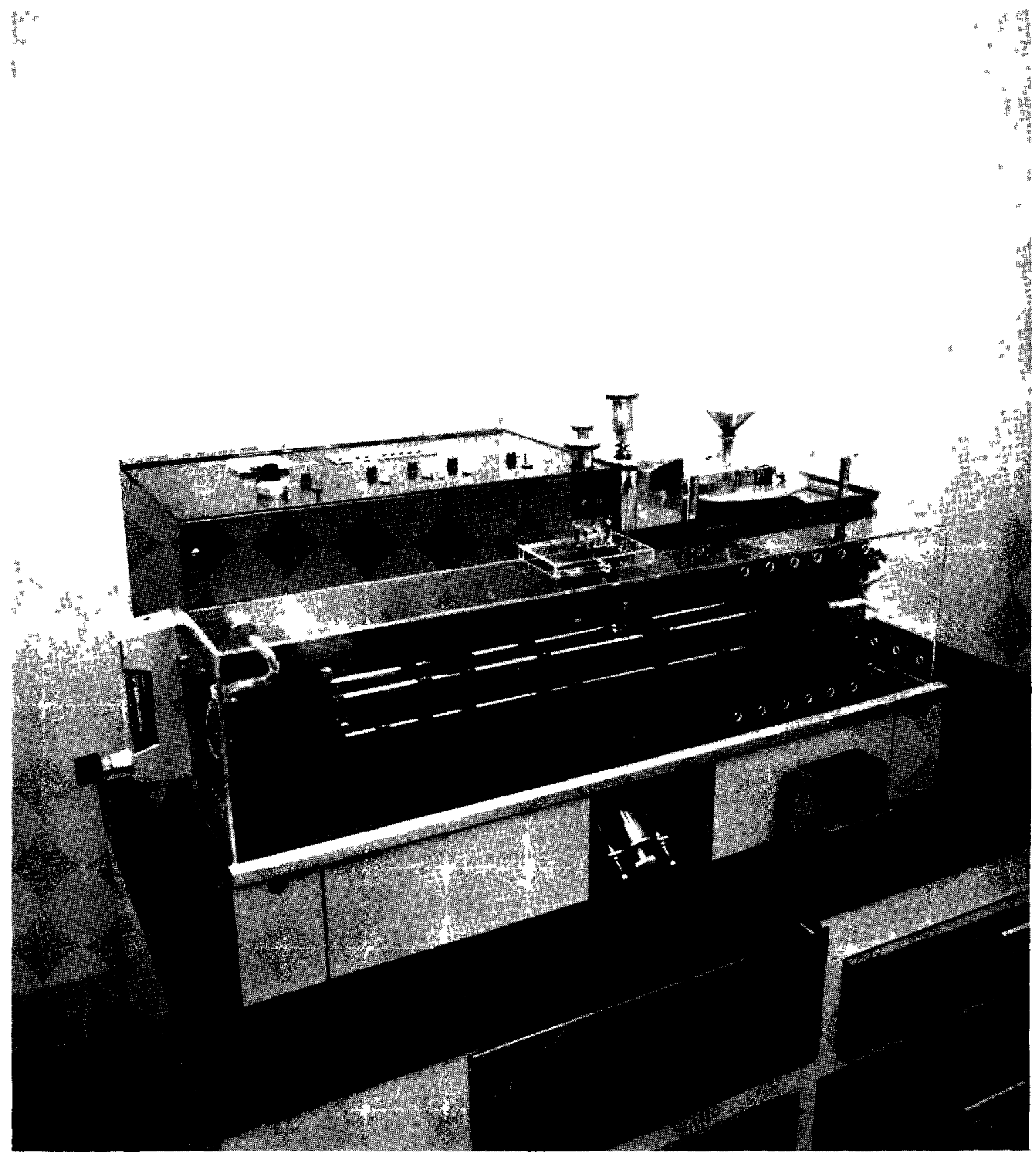

Fig. 1. Particle size analyser 


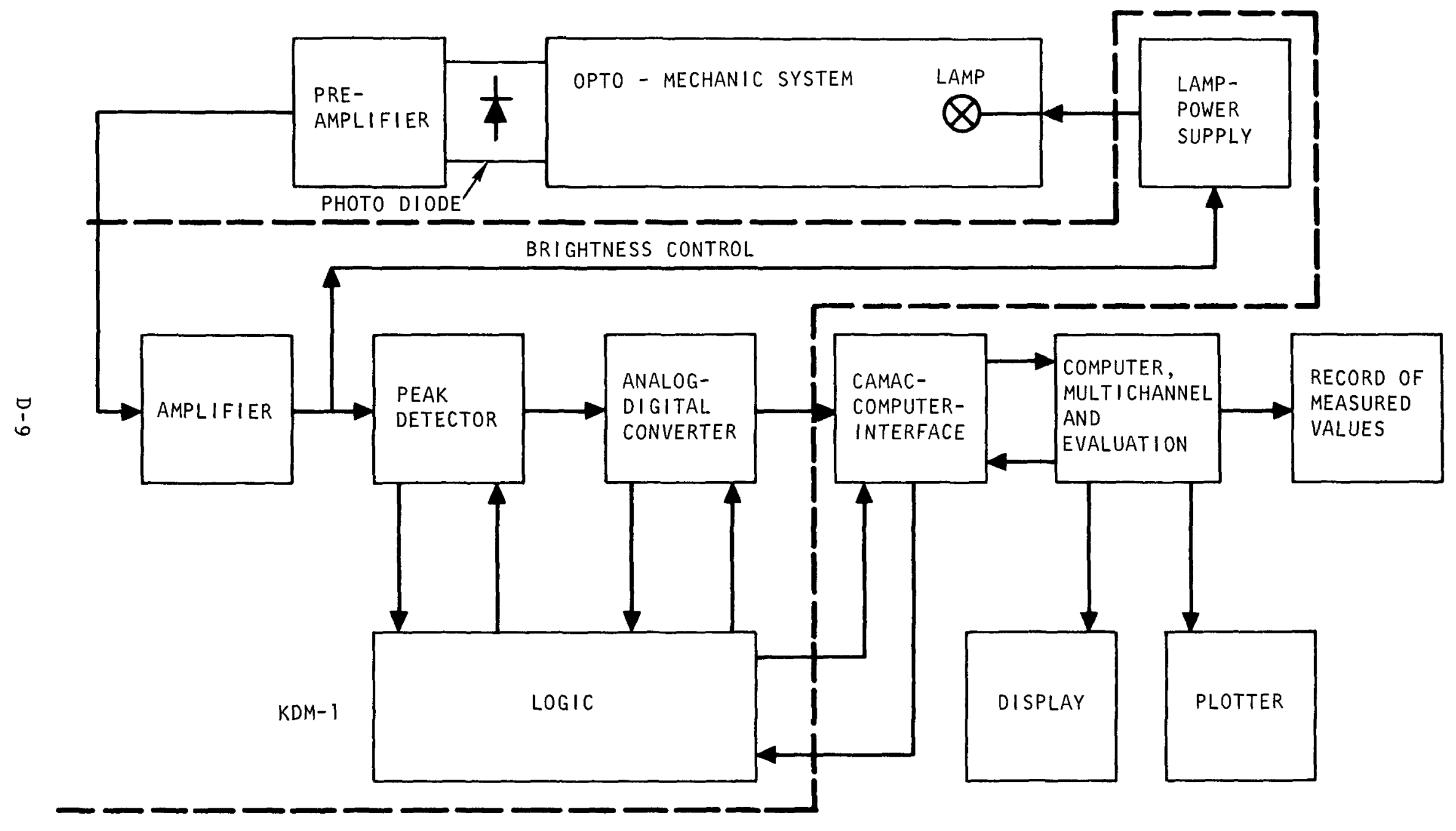

Fig. 2. Block diagram of the electronic data processing 


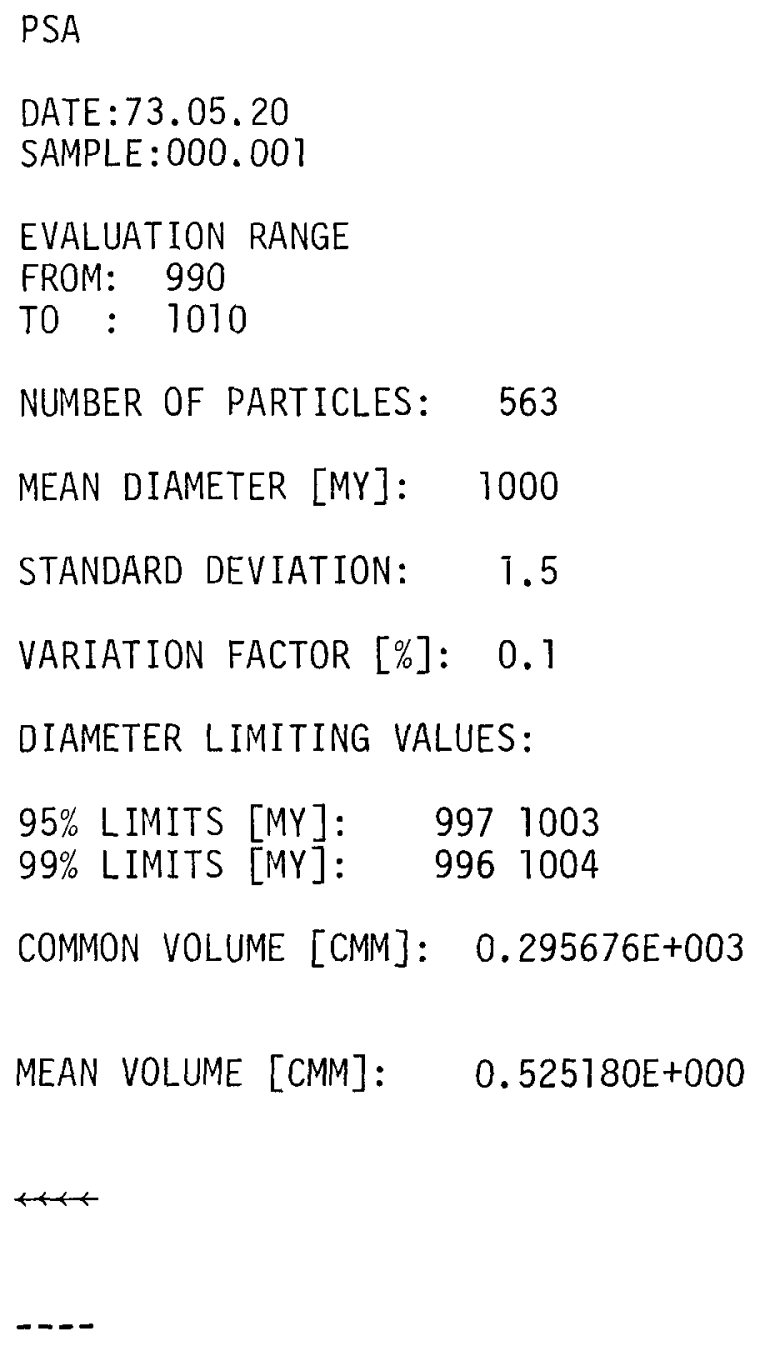

Fig. 3. Dimensions and distribution of calibration balls 
O

$\stackrel{P}{\Xi}$

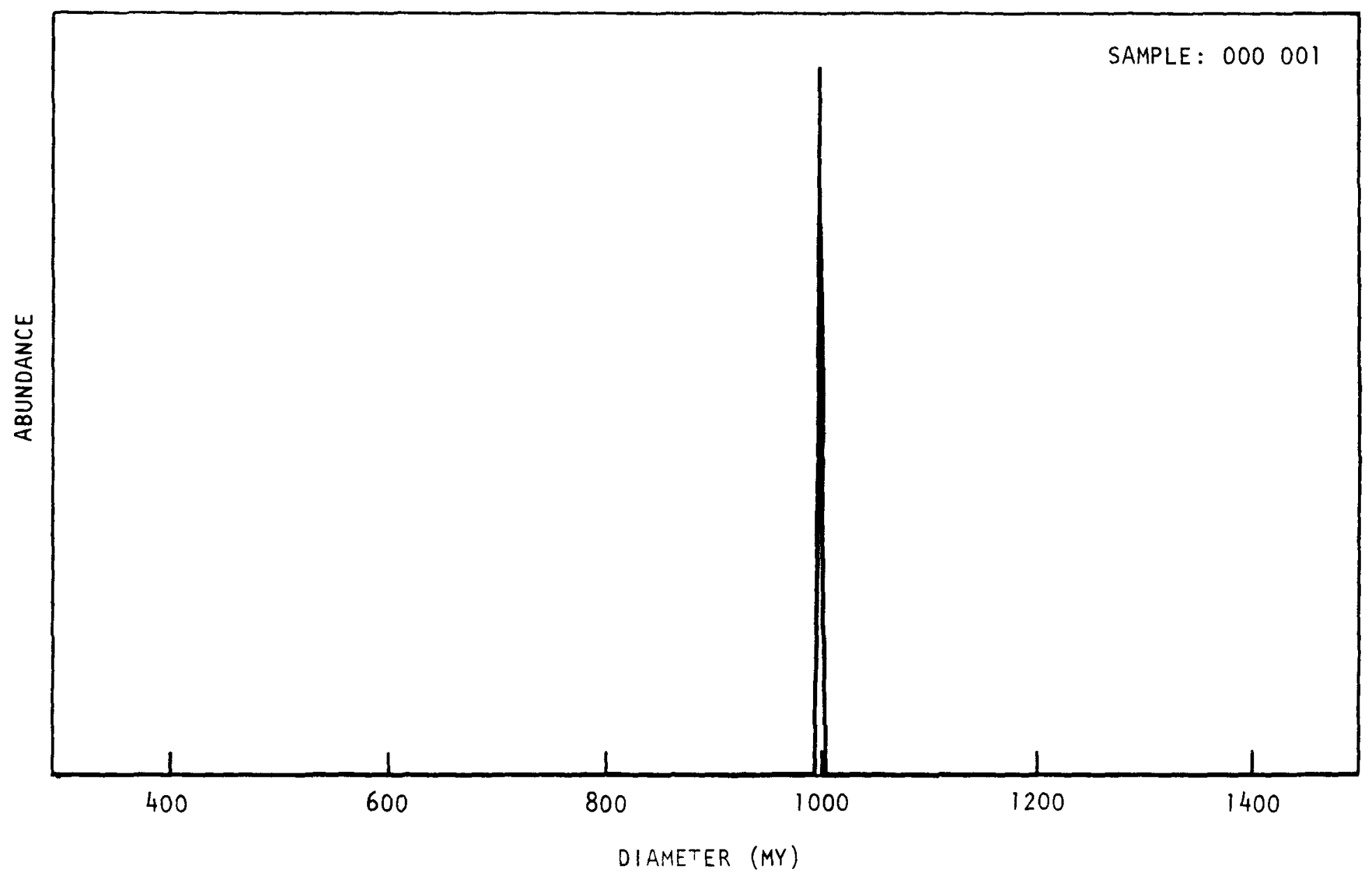

Fig. 4. Size distribution of calibration balls 


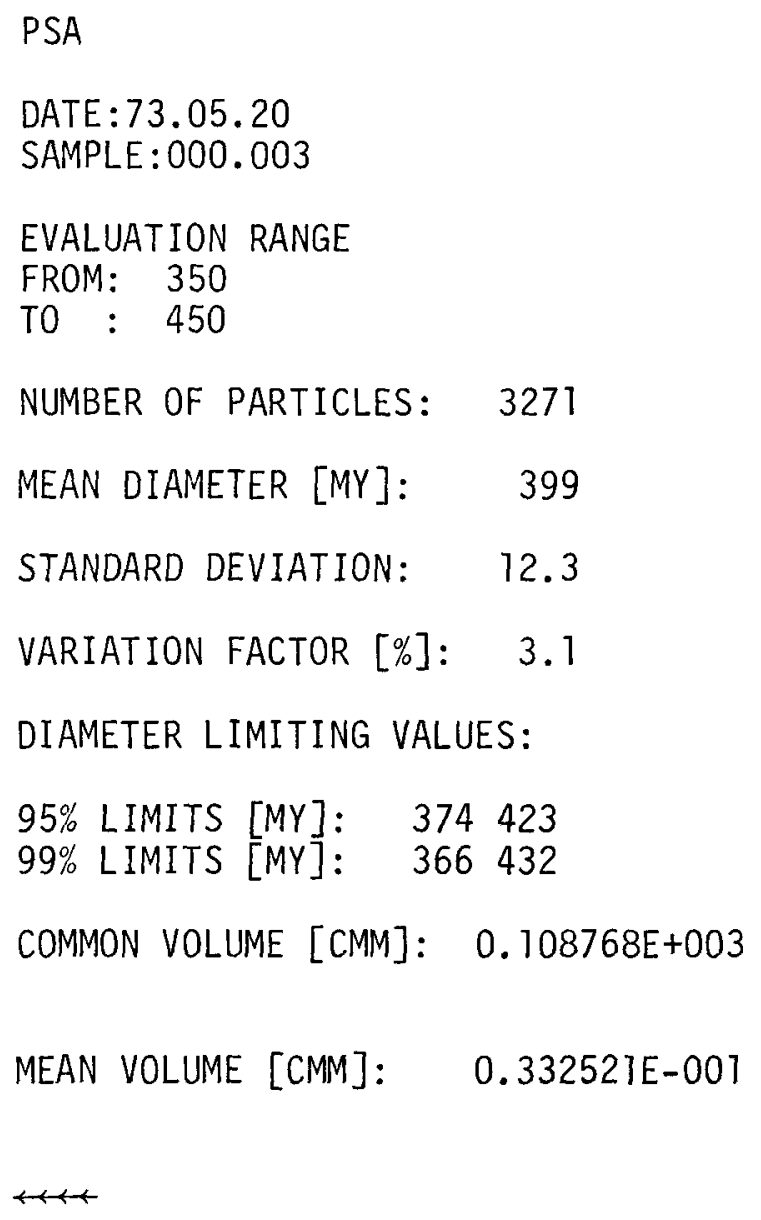

Fig. 5. Dimensions and distribution of kernels 


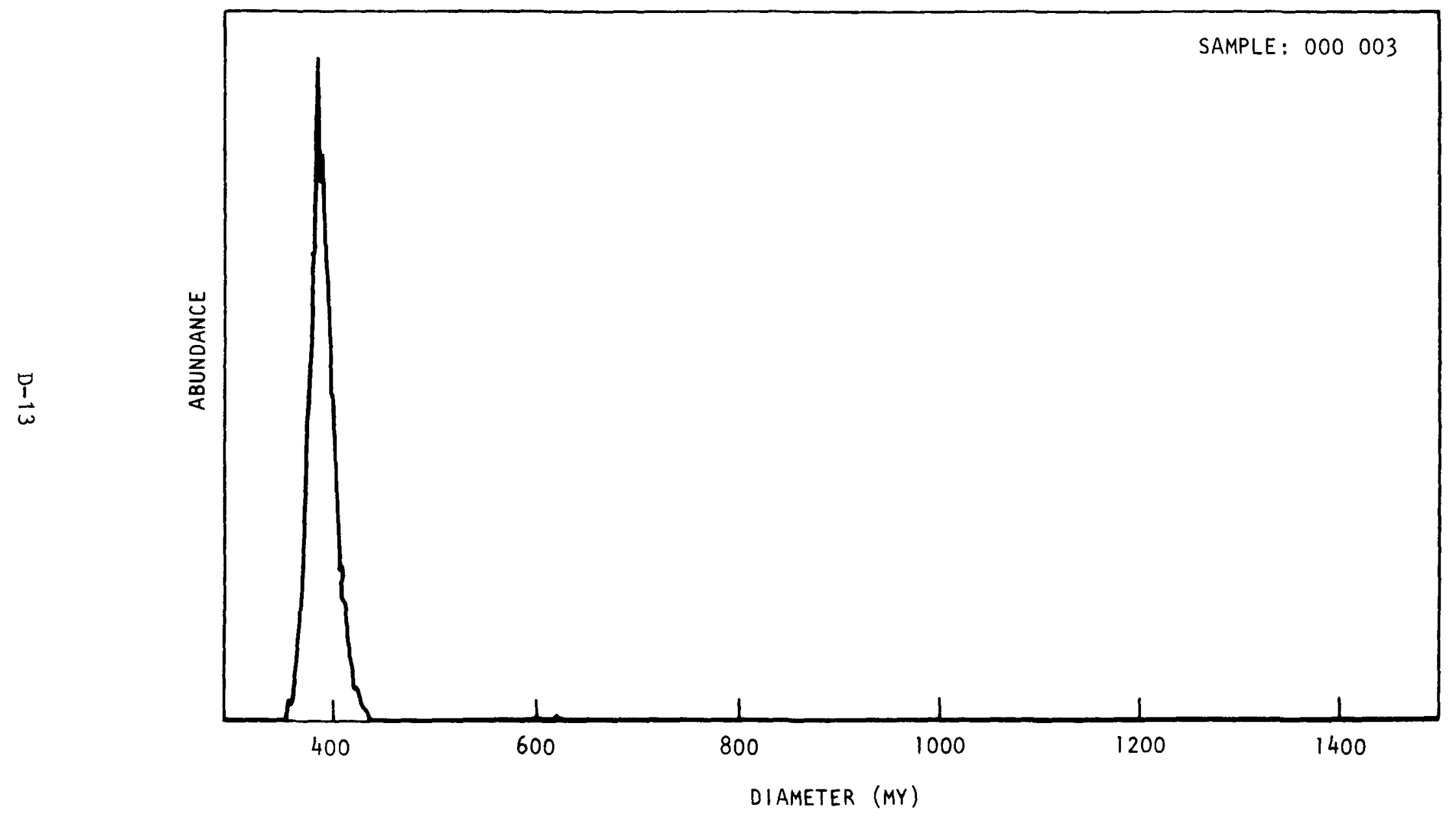

Fig. 6. Size distribution of kernels 


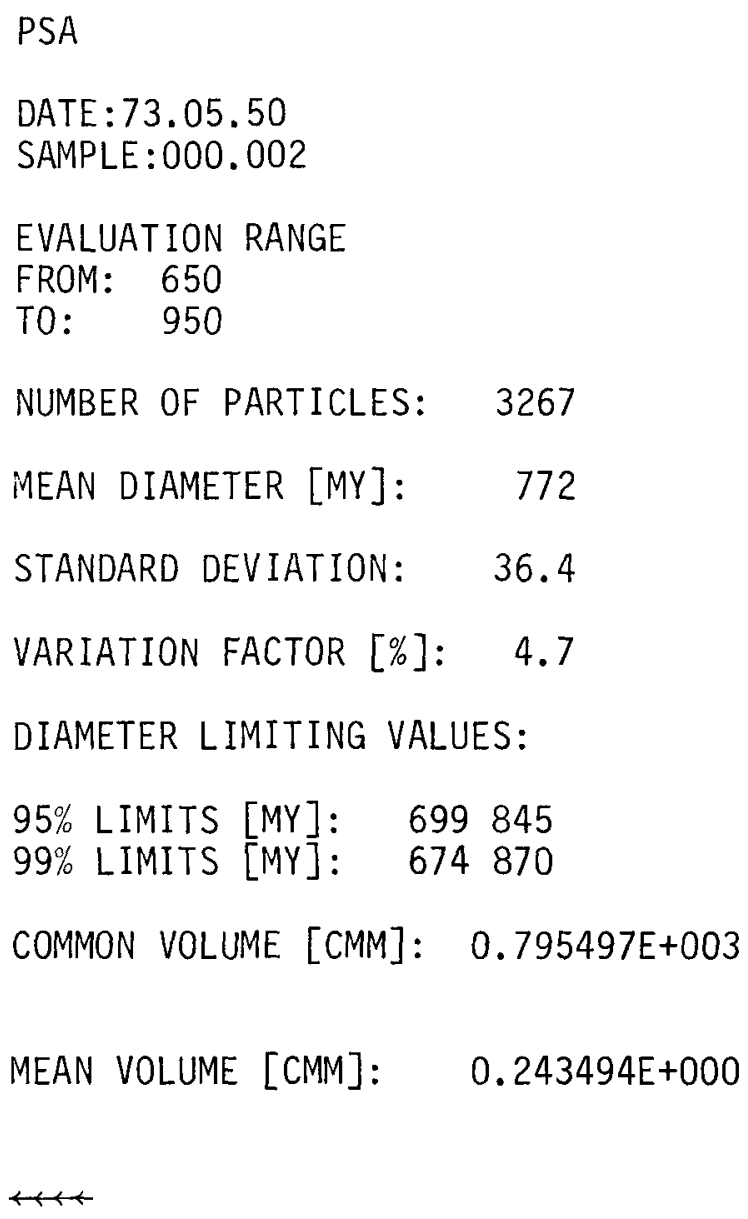

Fig. 7. Dimensions and distribution of coated particles 

PSA

DATE: 73.05 .20

SAMPLE:000.000

EVALUATION RANGE

FROM: 650

TO: $\quad 950$

NUMBER OF PARTICLES: $\quad 3614$

MEAN DIAMETER [MY]: 772

STANDARD DEVIATION: $\quad 36.2$

VARIATION FACTOR $[\%]: 4.7$

DIAMETER LIMITING VALUES:

95\% LIMITS [MY]: 700845

99\% LIMITS [MY]: 675870

COMMON VOLUME [CMM]: $0.881160 E+003$

MEAN VOLUME [CMM]: $0.243818 E+000$

PSA

DATE : 73.05 .20

SAMPLE:000.000

EVALUATION RANGE

FROM: $\quad 350$

TO : 450

NUMBER OF PARTICLES: 1024

MEAN DIAMETER [MY]: 399

STANDARD DEVIATION: 11.8

VARIATION FACTOR $[\%]: \quad 3.0$

DIAMETER LIMITING VALUES:

95\% LIMITS [MY]: 375423

99\% LIMITS [MY]: 367431

COMMON VOLUME [CMM]: $0.341191 \mathrm{E}+002$

MEAN VOLUME [CMM]: $0.333194 \mathrm{E}-001$

$\longleftrightarrow \leftarrow$

Fig. 9. Dimensions and distribution of a mixed sample 


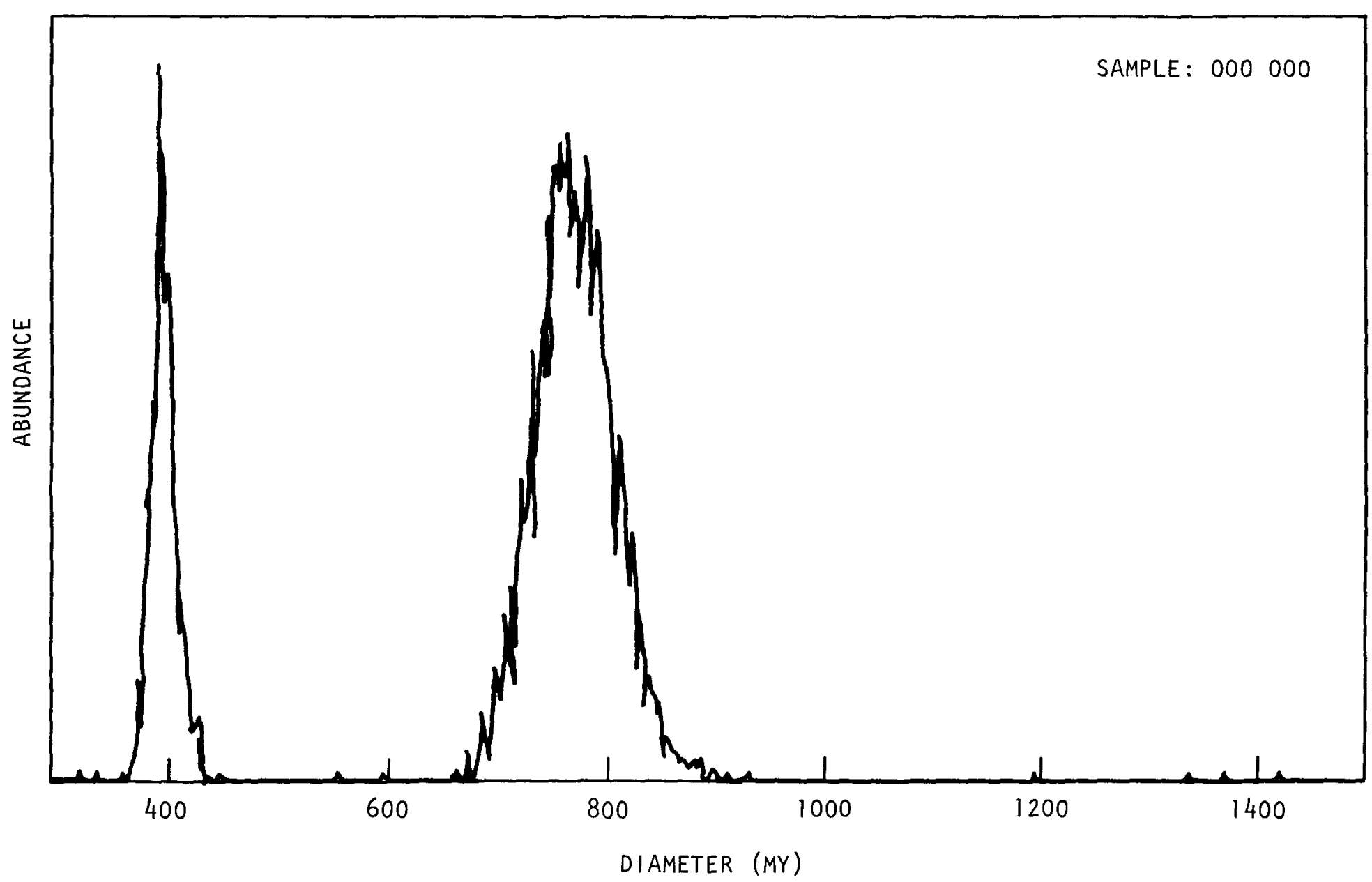

Fig. 10. Size distribution of a mixed sample 
TABLE 1

COMPARISON OF RESULTS FOR DIAMETER, COATING THICKNESS

AND DENSITY MEASURED BY DRAGON AND SGAE

\begin{tabular}{|c|c|c|}
\hline & DRAGON & SGAE-PSA \\
\hline \multicolumn{3}{|l|}{ SiC coated particles without outer PyC } \\
\hline Overall diameter $(\mu \mathrm{m})$ & 1043 & 1043 \\
\hline Particle density $\left(\mathrm{g} / \mathrm{cm}^{3}\right)$ & 5.02 & 5.00 \\
\hline Thickness of SiC 1ayer ( $\mu \mathrm{m})$ & $\begin{array}{l}34 \text { ( } x-\text { ray }) \\
32 \text { (Hg) }\end{array}$ & 31 \\
\hline SiC density $\left(\mathrm{g} / \mathrm{cm}^{3}\right)$ & $\begin{array}{l}3.21 \text { (Flotation) } \\
3.14 \text { (Batch weight) }\end{array}$ & 3.21 \\
\hline \multicolumn{3}{|l|}{ Particles with outer PyC } \\
\hline Overall diameter $(\mu \mathrm{m})$ & 1156 & 1161 \\
\hline Particle density $\left(\mathrm{g} / \mathrm{cm}^{3}\right)$ & 4.14 & 4.11 \\
\hline Thickness of outer PyC layer $(\mu \mathrm{m})$ & $\begin{array}{l}57 \text { (x-ray) } \\
56(\mathrm{Hg})\end{array}$ & 59 \\
\hline PyC density $\left(\mathrm{g} / \mathrm{cm}^{3}\right)$ & $\begin{array}{l}1.77 \text { (Flotation) } \\
1.74 \text { (Batch weight) }\end{array}$ & 1.72 \\
\hline
\end{tabular}




\section{APPENDIX E}

COMPUTER PROGRAMS USED FOR DATA REDUCTION

$\mathrm{E}-1$ 
- 


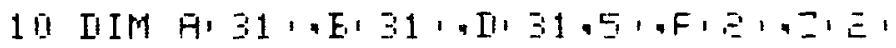

EU OFEN "M" IIFIIT 1

EZ IHFIIT FFOM $1: 1$

$\because \mathrm{FOF} F=1$ TO H $\mathrm{E}$

E4 FDF $L=1$ TO $\Xi$

25 ITHFIIT FFOM $1:$ : L.

ZI IHFUT FFIM 1 : FIL.

30 MAT IHFIIT FFOM 1: $A_{1} \equiv 1$.

$31 \mathrm{~L}=0$

3 FDF $I=1$ TQ $\equiv 1$

$3 E=E+A \cdot I$.

34 HE:TT I

35 FOF $I=1$ TO 31

3EI,I,E = A.I, E* 100

B. HE'T I

$\because E=0$

40 FOF I $=1$ TO $\equiv 1$

$50 I \cdot I \cdot 11=230+211+I$

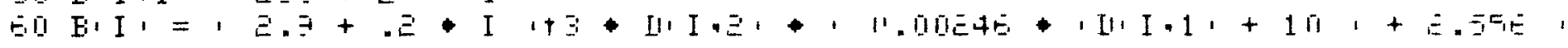

DE $E=E+E \cdot I$,

BO IHE: $\because T$ I

G10 FOF $1=1$ TO $\equiv 1$

105 I1 $1, \equiv 1=F^{\prime} 11+100.05$

10, I $, 1,3+L_{1}=\left[1,1, \vdots, F_{1} L, 100\right.$

11 II HE: IT I

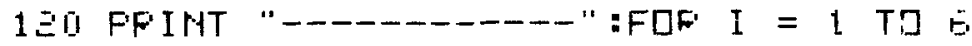

130 FFIHT FOF I $=1$ TO 13

135 FFIHT IHA FOFM "

13 FPINT FOF $\mathrm{I}=1$ TO

1 II: FFINT TAEIE1, "MEIBHTEI"

140 FFINT

150 FFIHT

IIIANETEF MUMEEF FEF CEEHT WEIEHT FEF LEHT

WEISHT FEF IEHT"

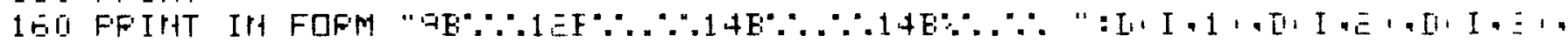
I'I I $:+L \cdot$ :FOF $I=1$ TO $\equiv 1$

1.0 FFINT FOF $I=1$ TO 14

190 HE::T L

13 III FFIHT "

EOTOF $1=1$ TO $\vdots 1$

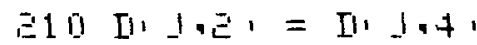

$E 00$ I1 $1.51=[1,1.51$

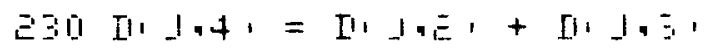

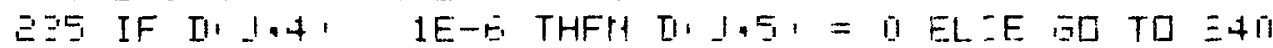

Ė

$2+1]$ I1, $1,51=[1,1,3, \quad$ [1, 1,4,

EST HEI,T I

ED FFIHT FOF $I=1$ TI $1 E$

EES $=$

ED MAT FFIHT IH IMATE : $\because$

$\because \because \because \because{ } \quad$ TDTFL

EDAF:E

ZEI FFINT

" IIIAMETEF

ב"AD FFIITT

HEIGHT:

1, IE IGHT :

IEIEHT :

TDTHL"

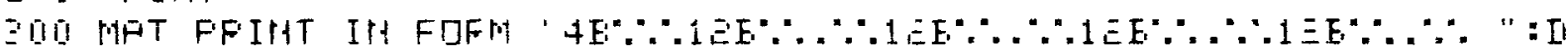

310 FFIHT FDF $I=1$ TQ 1 T

OU HE::T + 


\begin{tabular}{|c|c|}
\hline & HI $\quad=1$ \\
\hline IIAMETEF & WE IGHT \\
\hline 5190 & $1 \Xi$ \\
\hline$\Xi \Xi 10$ & . \\
\hline$\Xi 40$ & 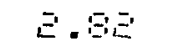 \\
\hline$\exists=1$ & 3.75 \\
\hline 301 & 1.75 \\
\hline 4010 & $\overline{2}=-\bar{i}$ \\
\hline $4=0$ & 5.54 \\
\hline 445 & $E . E$ \\
\hline 450 & 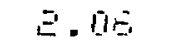 \\
\hline $4 \equiv 0$ & $1.1 \Xi$ \\
\hline 5010 & $1 . \Xi$ \\
\hline $5 \Xi 0$ &.$T E$ \\
\hline 5411 & $.5=$ \\
\hline $5 E 1$ & . \\
\hline $5: 00$ & .010 \\
\hline$E \square$ & .110 \\
\hline$E \Xi \square$ & .010 \\
\hline$\Xi 40$ & .010 \\
\hline EシE & . \\
\hline $5: \because 1$ & $=91$ \\
\hline 7011 & .11 \\
\hline マジ & 1018 \\
\hline 741 & . \\
\hline TEII & .010 \\
\hline 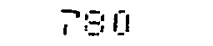 & .11 \\
\hline$=010$ & .00 \\
\hline$\Xi \Xi 0$ & . \\
\hline 9415 & .10 \\
\hline 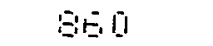 & .011 \\
\hline 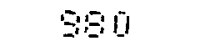 & .01 \\
\hline 9111 & .010 \\
\hline
\end{tabular}

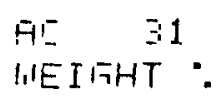

!n

.11

.11

.

.11

- $11=$

.

.

- 51

E.E

4.

ㄷ. 타

ᄀ.

E. 4

$\vec{i} . \overrightarrow{1}$

5. 是

4. 쿠

4.

5.113

$4.11=$

1. 특

.45

E.

- II

- 010

- iit

- II

- III

- 10

- II

- 15
TOTAL
WEIBHT

$.1 E$

1. II

플

4.

1.

‥17

ㅂ.

豆。马

三.

$\Xi .50$

5.014

$5 . \xi \vdots$

5.75

$=40$

․․․

ㅂ.

4.5

4. 311

5.07

4.115

1.

.43

50

- II

. 10

.98

- 110

- 10

.010

- 01

. 010
-DHF-E

TITAL

.01

. 01

.04

-

- IIE

- 115

.14

- 15

- $\Xi$

.71

- 73

.

.73

- $\exists$

1. 11

1. मा

1.

1. 00

1.

1.00

1. 00

1.00

1.00

.00

. 00

.00

- 00

. 010

.00

.00

- 01 
तां $इ$

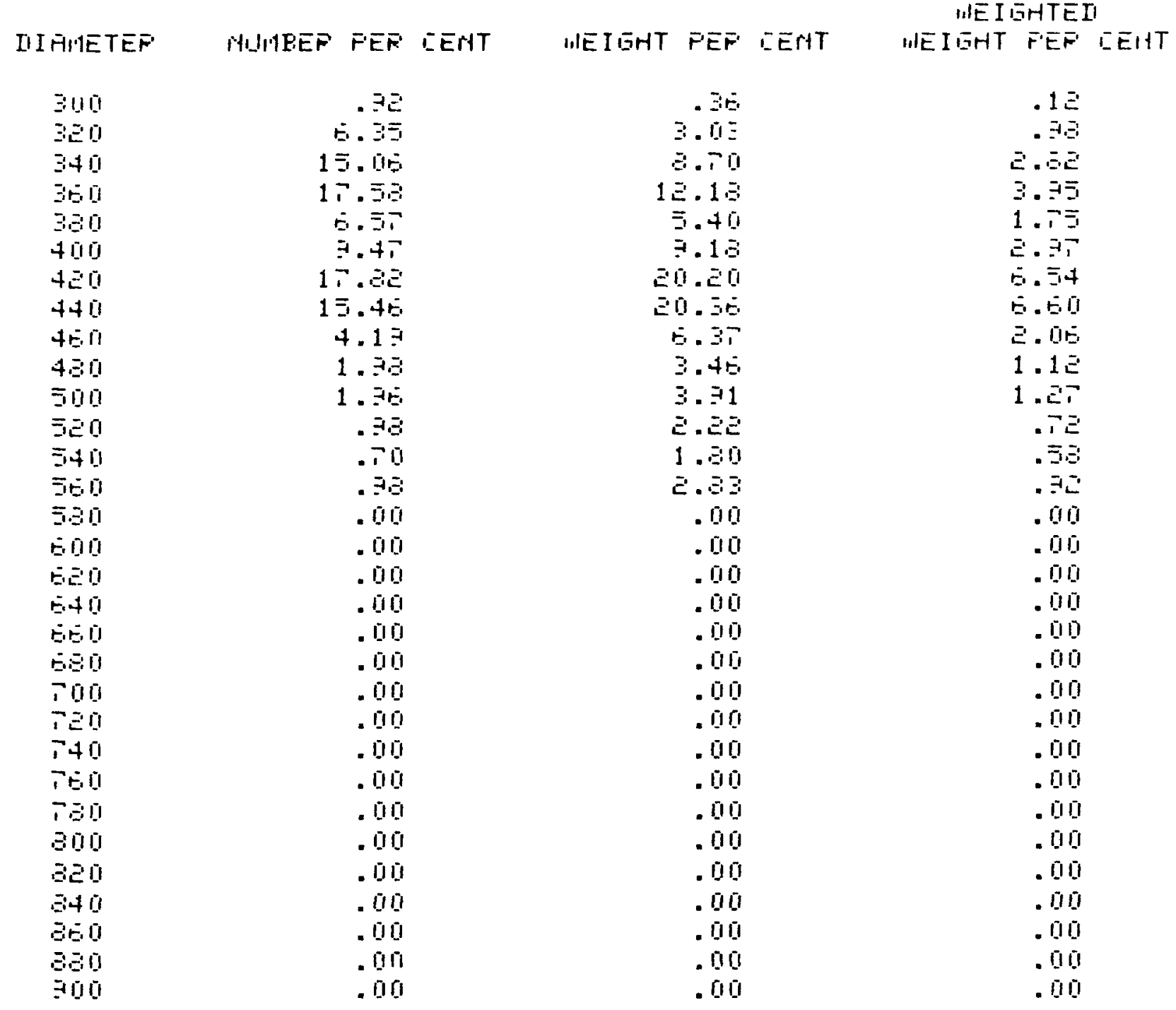


तi: $\quad 31$

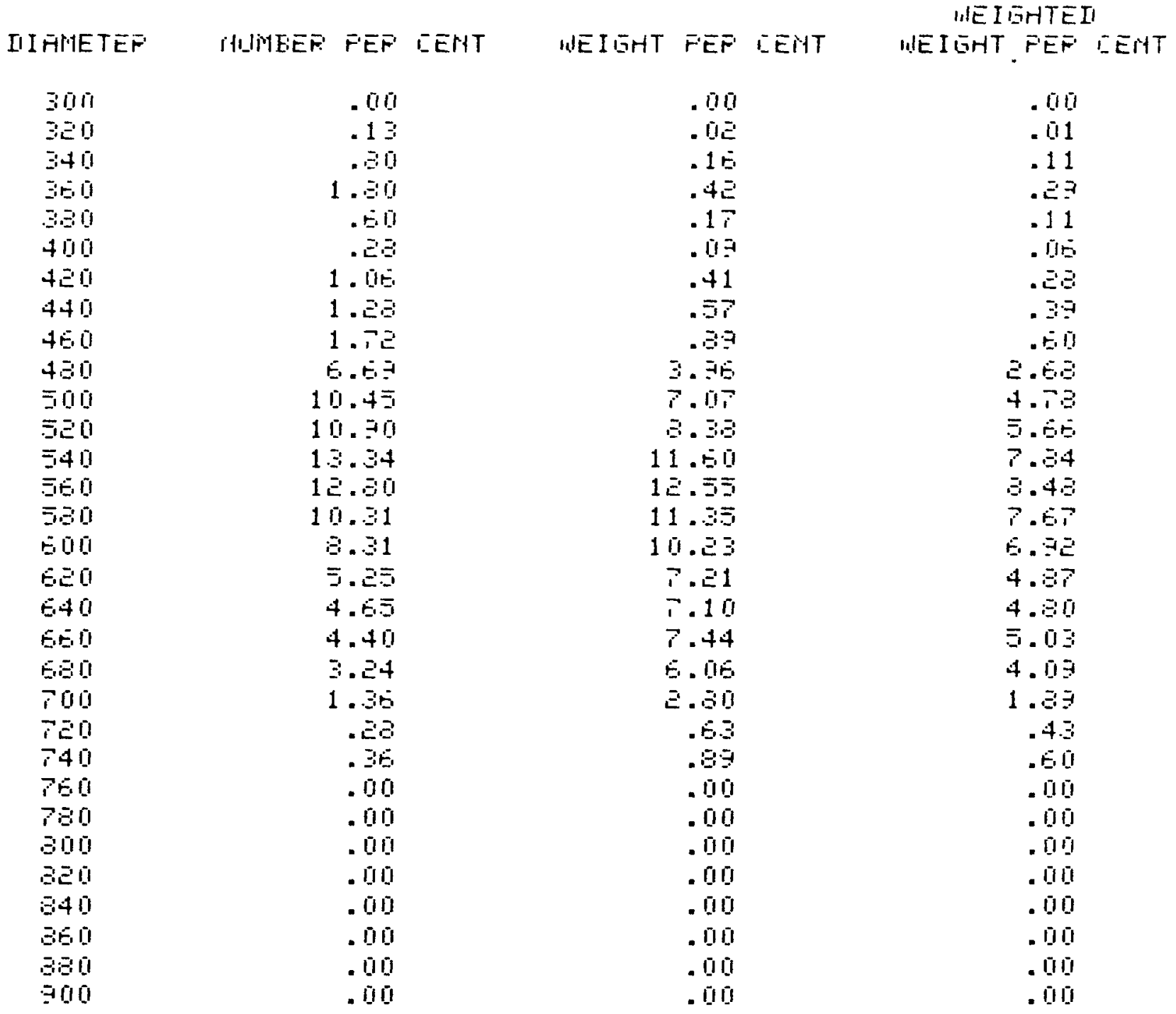


A - Number of particles per size increment

B - Volume percent

C - Summing register

$D(I, 1)$ - Diameter

$D(I, 2)$ - Number percent

$D(I, 3)$ - Weight percent

$D(I, 4)$ - Weighted weight percent or total weight percent

$D(I, 5)$ - Weighted weight percent or separation efficiency

$F(1)$ - Fines weight fraction of feed

$F(2)$ - Coarse weight fraction of feed

$I$ - Counter

$J$ - Counter

K - Counter

L - Counter

M - Data file

$\mathrm{N}$ - Number of runs

S - Output format

Z - Labe1 
• 
APPENDIX F

DRAWINGS FOR MODULAR CLASSIFIER

F-1 



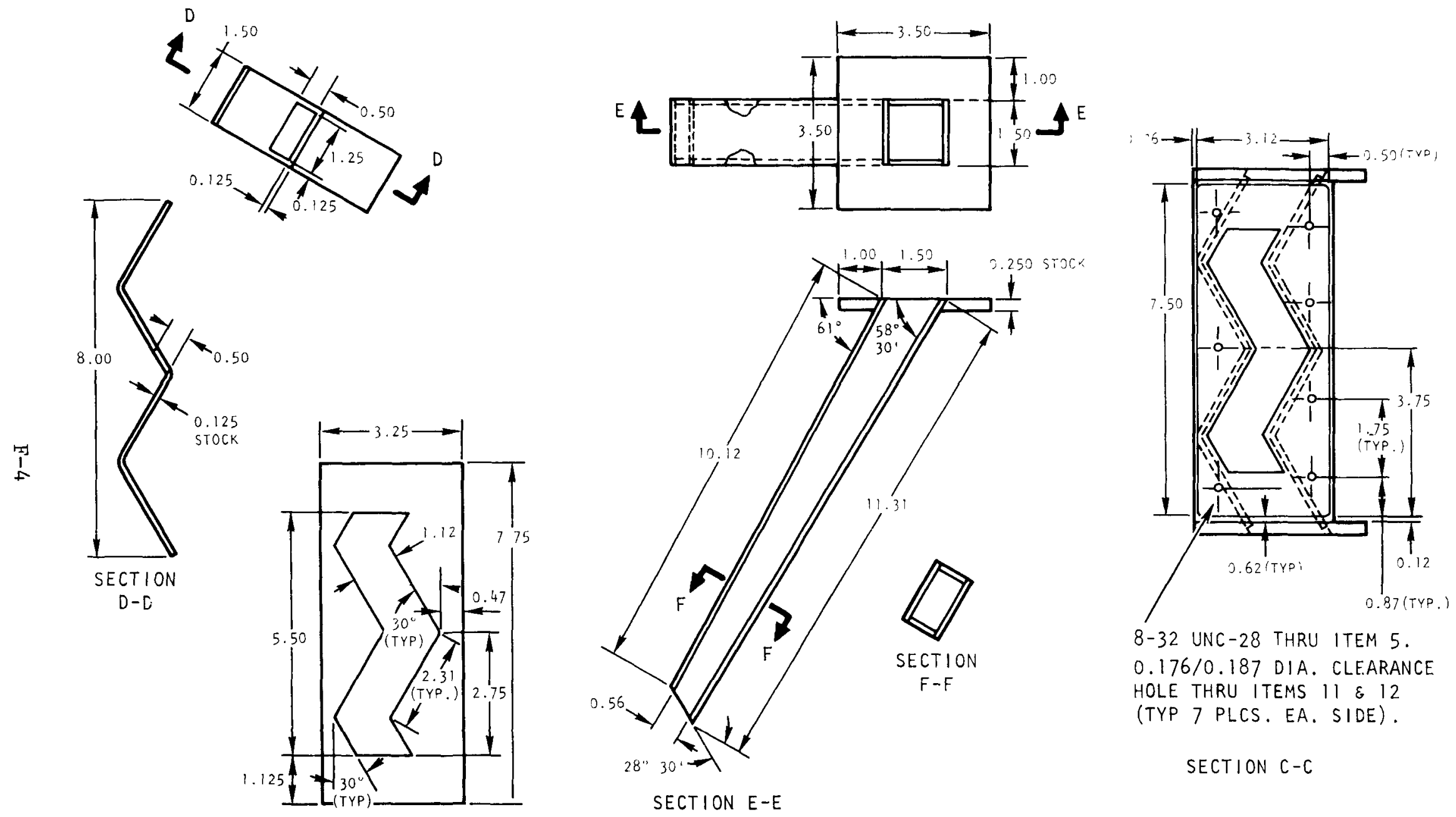

Fig. F-1. Feed section of the pneumatic classifier used for fissile/fertile particle separation (Sheet 2 of 2) 


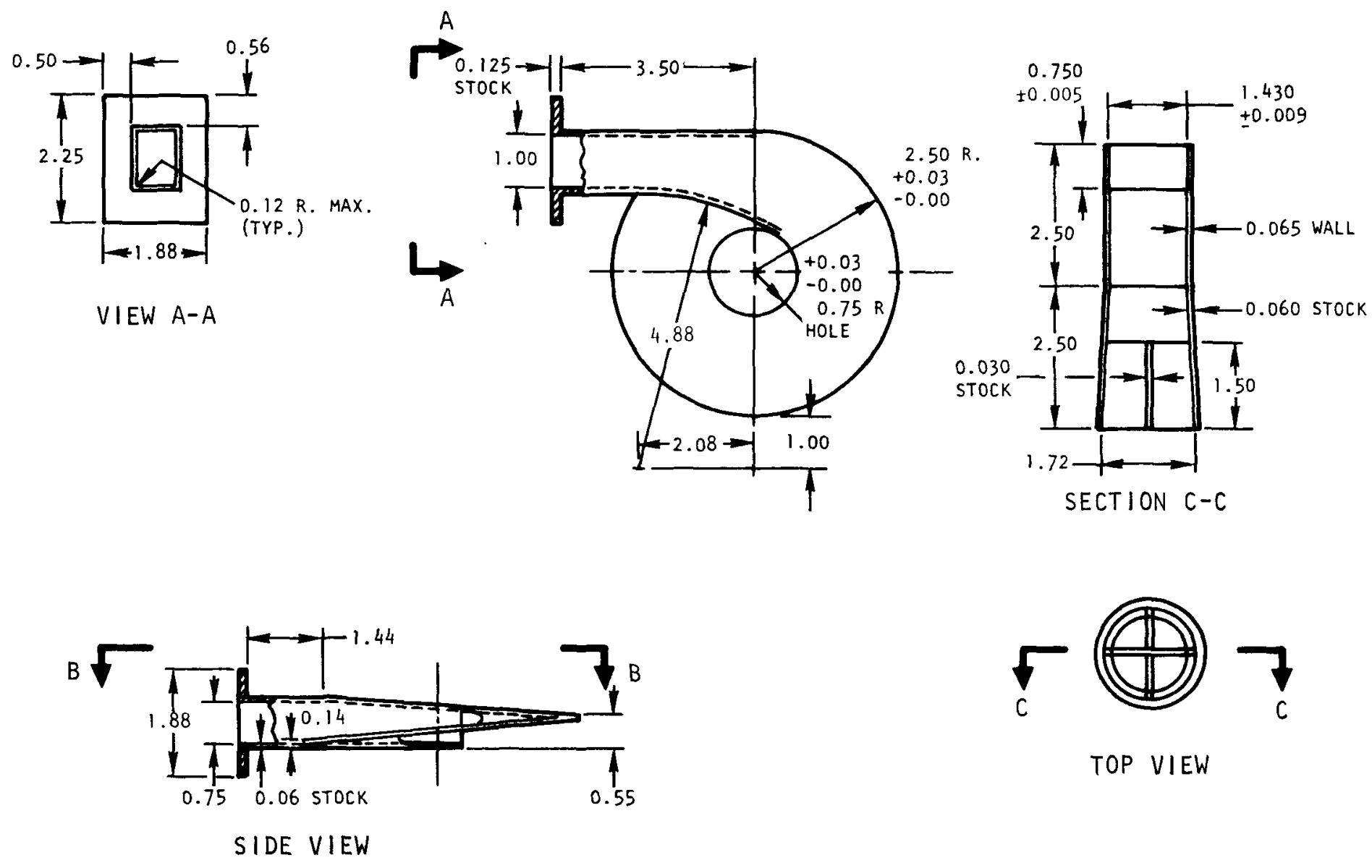

Fig. F-2. Schematic of cyclone for fines particle separator component of pneumatic classifier (Sheet 2 of 3 ) 


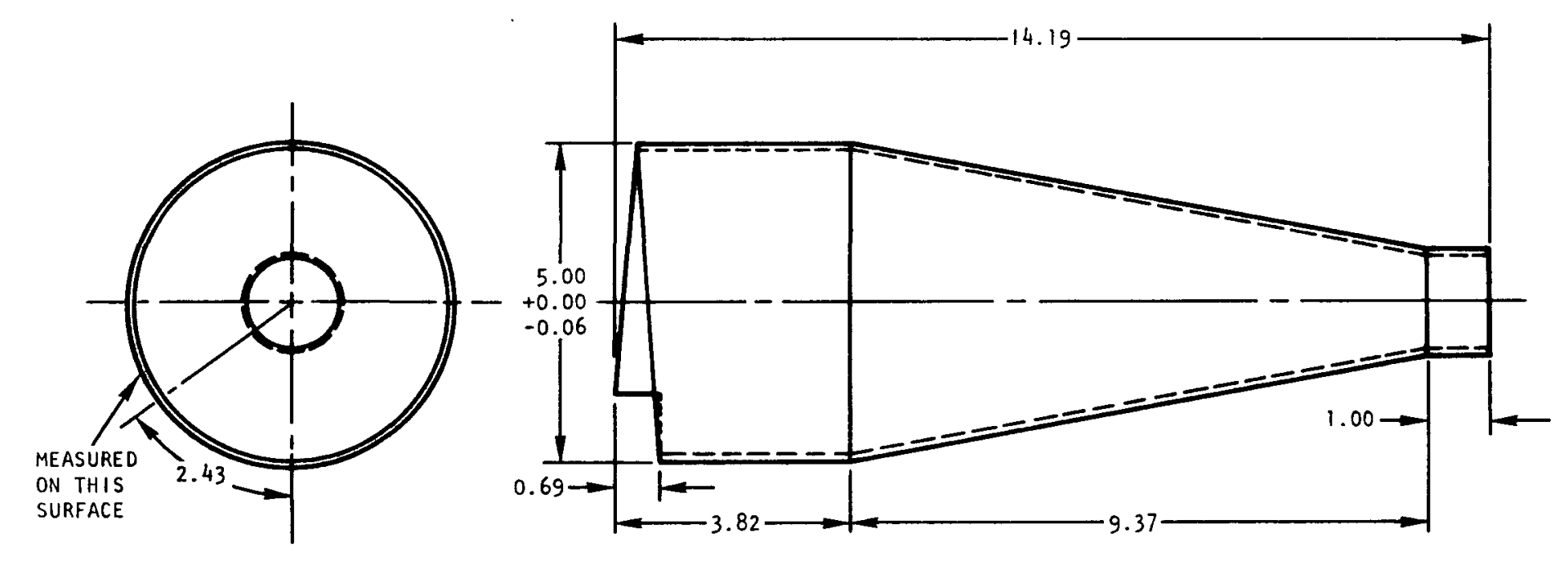

Fig. F-2. Schematic of cyclone for fines particle separator component of pneumatic classifier (Sheet 3 of 3 ) 


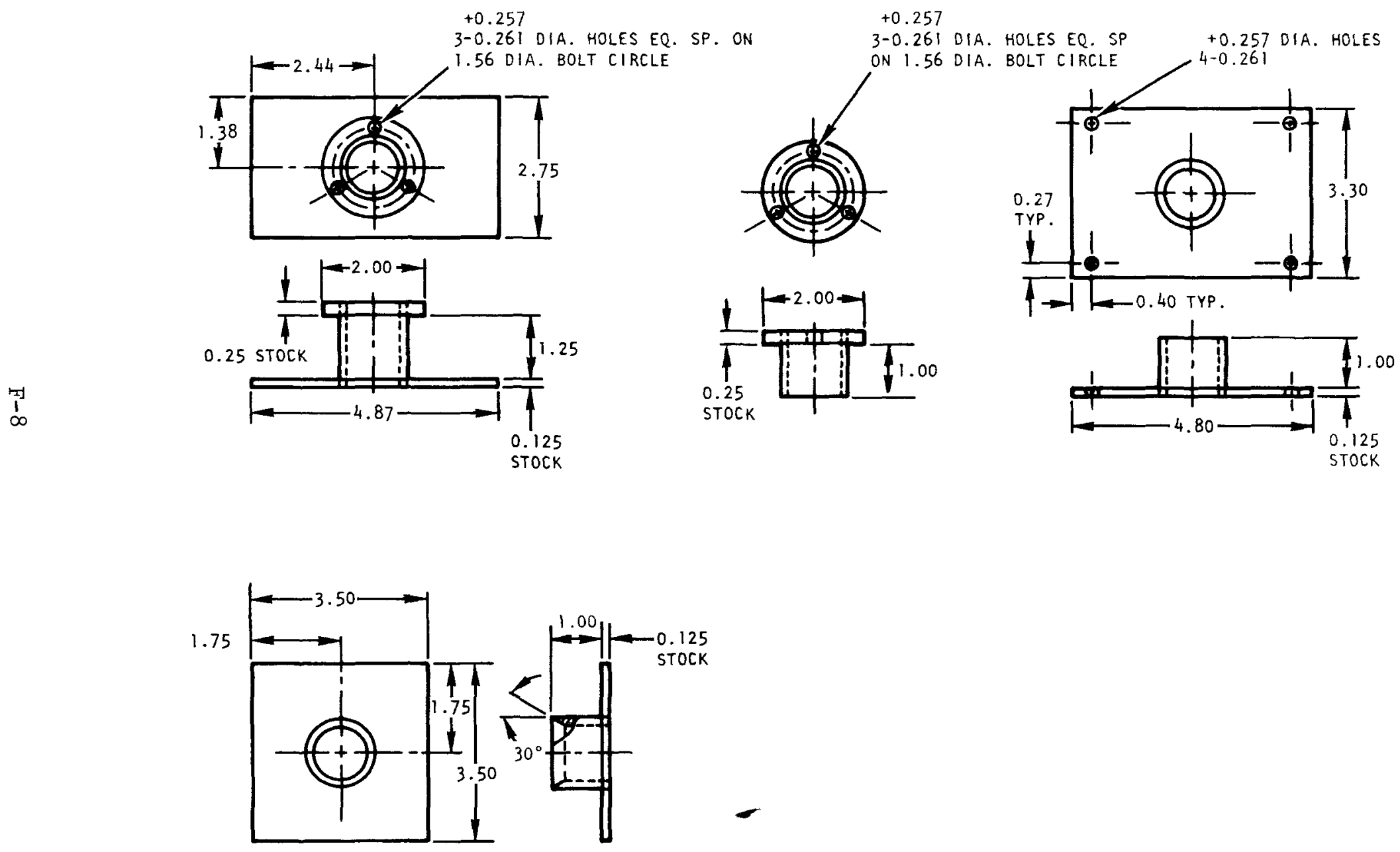

Fig. F-3. Schematic of pneumatic classifier feed adaptors 

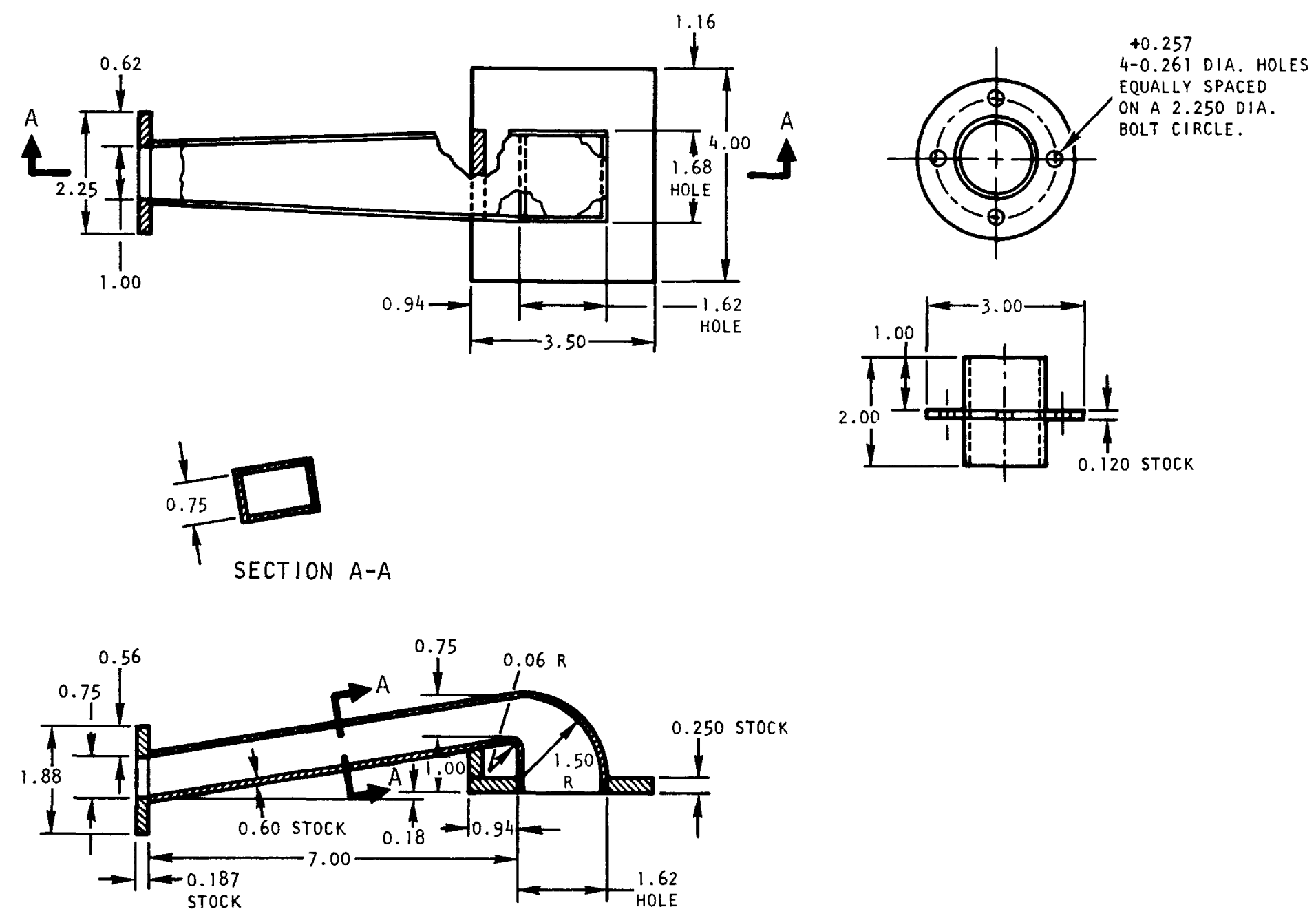

Fig. F-4. Schematic of top take-off and cyclone-to-fines adaptor components of pneumatic classifier 

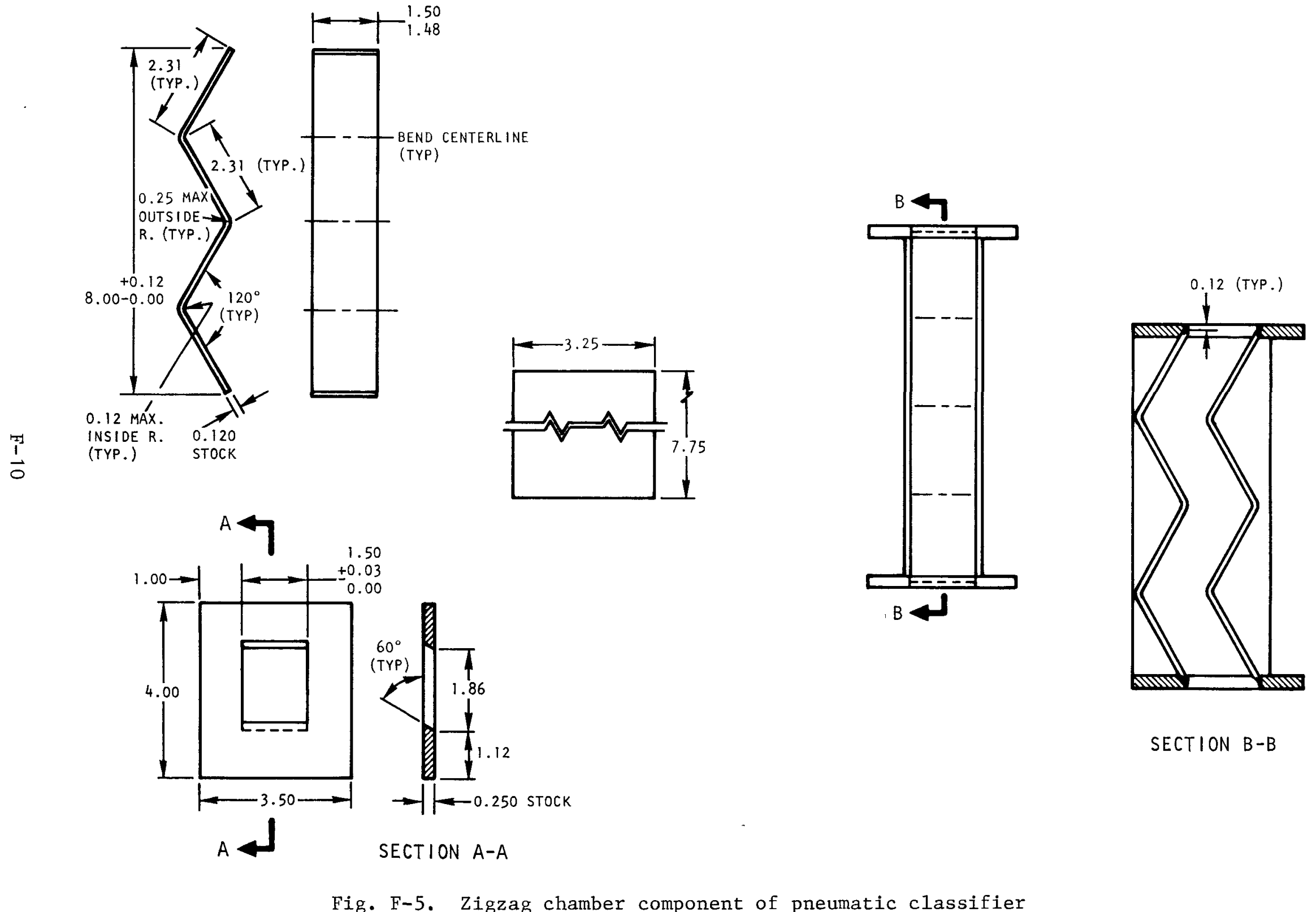

SECTION B-B

ig. F-5. Zigzag chamber component of pneumatic classifier 

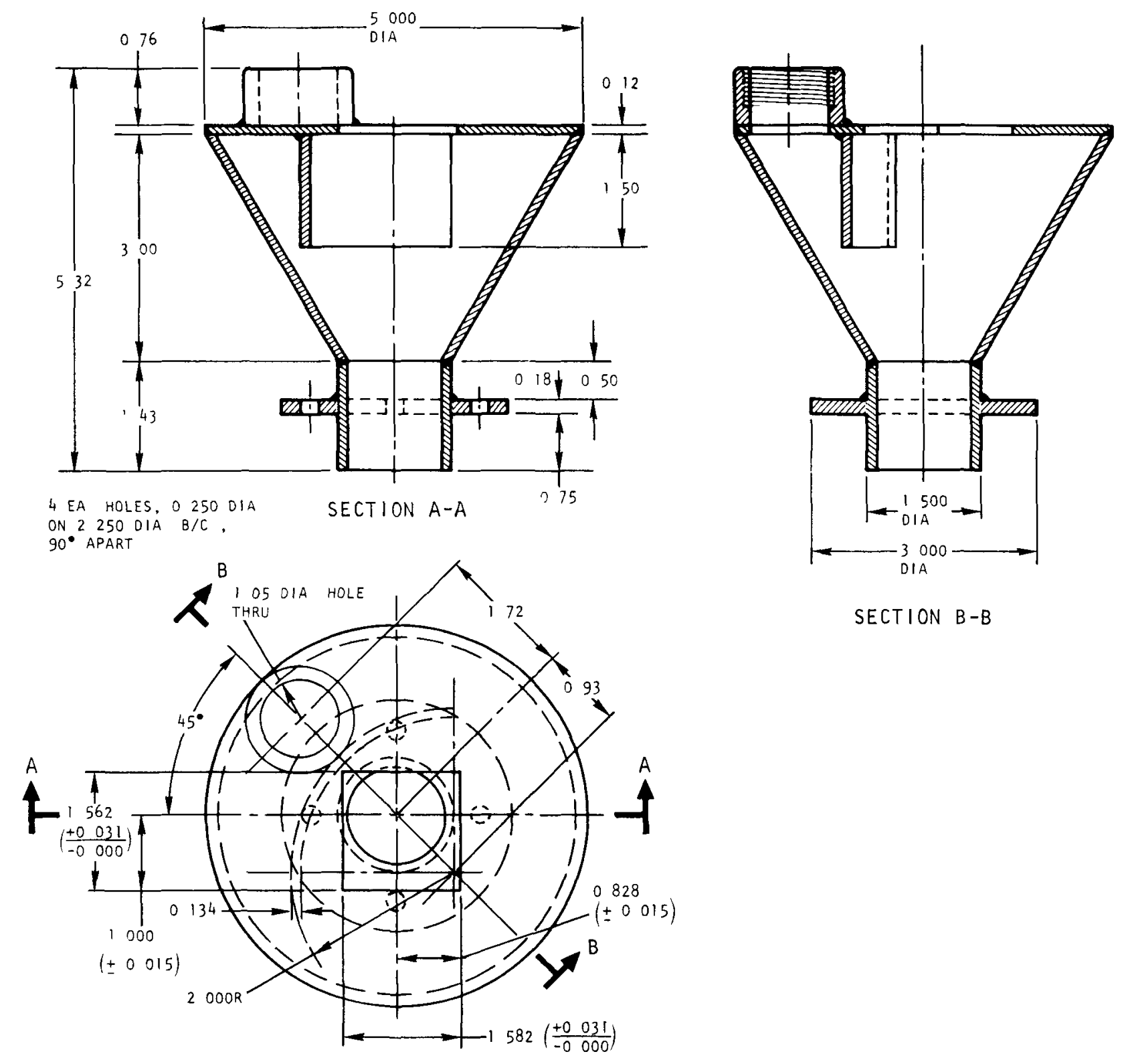

SECTION B-B

Fig. F-6. Coarse particle take-off cone assembly component of pneumatic classifier 
- 
APPENDIX G

ABBREVIATIONS FOR SECTION 3

G-1 
$\bullet$

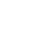

.

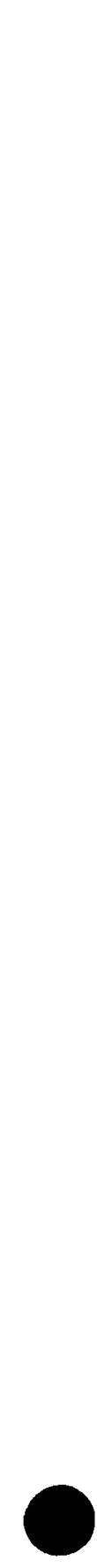

$\bullet$ 


\section{ABBREVIATIONS FOR SECTION 3}

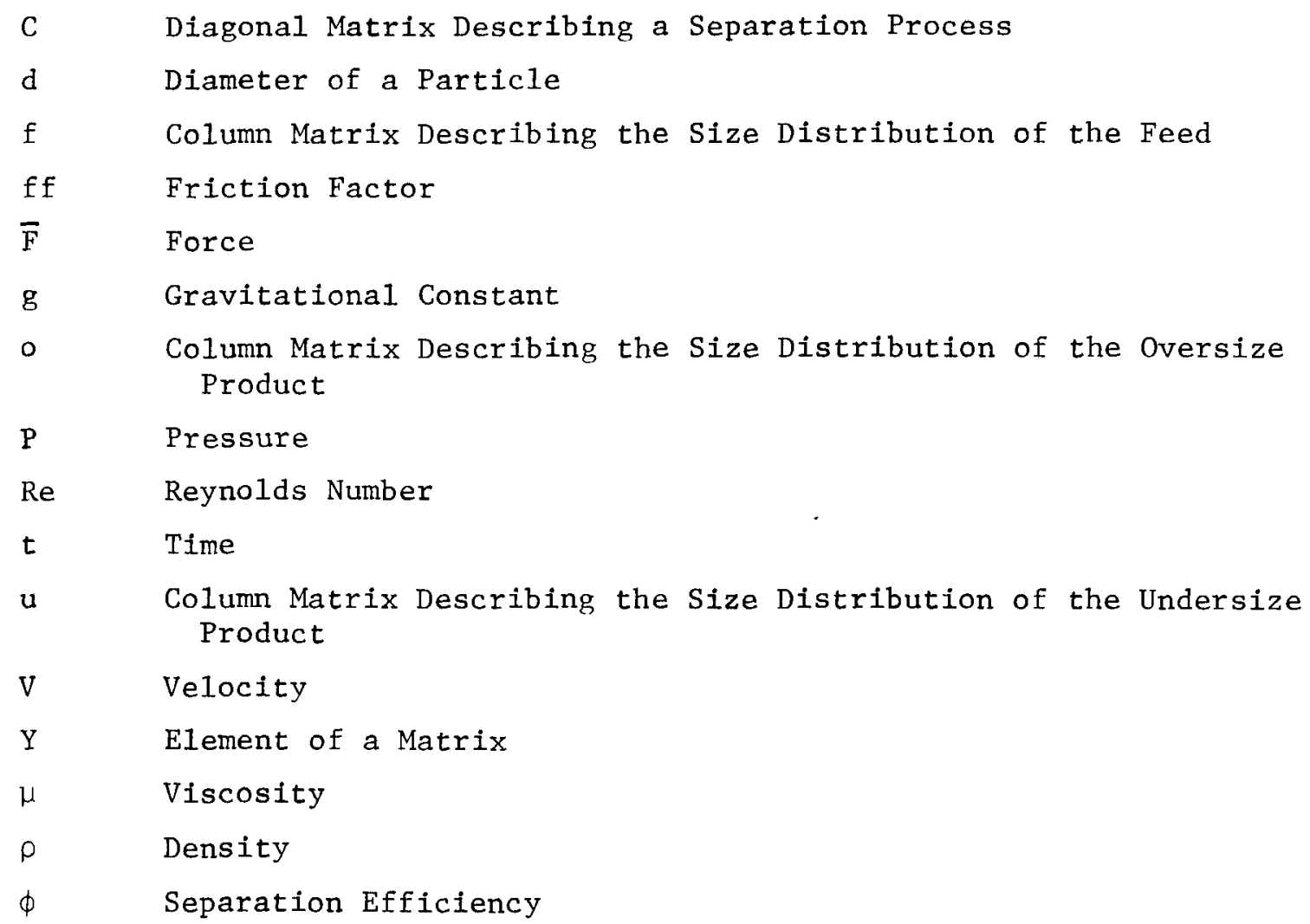

